Development Center

Monitoring Completed Navigation Projects

\title{
Brazos Santiago Inlet, Texas, Shoaling Study
}

David B. King Jr., Mary A. Bryant, Richard Styles,

February 2018

Tahirih C. Lackey, Ernest Smith, and Ryan Visperas

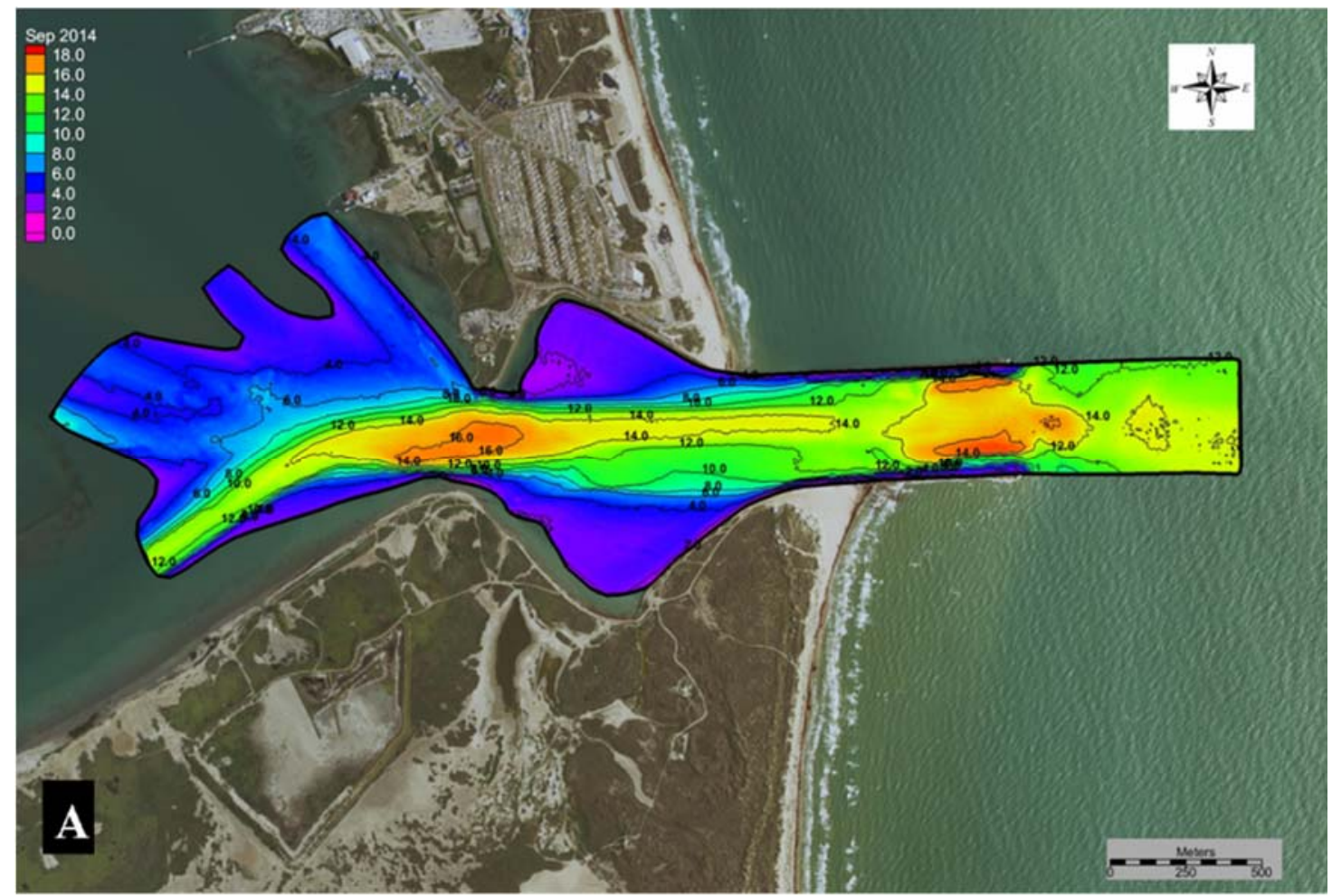


The U.S. Army Engineer Research and Development Center (ERDC) solves the nation's toughest engineering and environmental challenges. ERDC develops innovative solutions in civil and military engineering, geospatial sciences, water resources, and environmental sciences for the Army, the Department of Defense, civilian agencies, and our nation's public good. Find out more at www.erdc.usace.army.mil.

To search for other technical reports published by ERDC, visit the ERDC online library at http://acwc.sdp.sirsi.net/client/default. 


\section{Brazos Santiago Inlet, Texas, Shoaling Study}

David B. King Jr., Mary A. Bryant, Richard Styles, Tahirih C. Lackey, Ernest Smith, and Ryan Visperas

Coastal and Hydraulics Laboratory

U.S. Army Engineer Research and Development Center 3909 Halls Ferry Road

Vicksburg, MS 39180-6199

Final report

Approved for public release; distribution is unlimited.

Prepared for U.S. Army Corps of Engineers

Washington, DC 20314-1000

Under Project Number 454631, "Brazos Santiago Inlet Channel Shoaling Study" 


\section{Abstract}

The Brazos Santiago Inlet (BSI), located at the southern end of Laguna Madre, is a key part of the federal deep-draft Brownsville Ship Channel extending from the Gulf of Mexico to the Port of Brownsville, TX. As part of the Monitoring Completed Navigation Projects program, the focus of this study was to understand the shoaling process in the BSI and to suggest sand management alternatives to reduce inlet maintenance dredging costs. Hydrodynamics and sediment transport were examined for the BSI region to understand the channel shoaling within the jetty entrance. Field data collection and numerical modeling using the Coastal Modeling System were performed to gain insight into the complex circulation, wave action, and sediment deposition patterns. Structural changes to the system as well as dredging modifications are presented as potential alternative solutions to reduce inlet shoaling. Results show the potential benefits of an in-channel sediment trap and alterations to the structure of the jetty. However, benefits to dredging costs are not considered and must be weighed against other issues such as environmental concerns.

DISCLAIMER: The contents of this report are not to be used for advertising, publication, or promotional purposes. Citation of trade names does not constitute an official endorsement or approval of the use of such commercial products. All product names and trademarks cited are the property of their respective owners. The findings of this report are not to be construed as an official Department of the Army position unless so designated by other authorized documents. 


\section{Contents}

Figures and Tables....

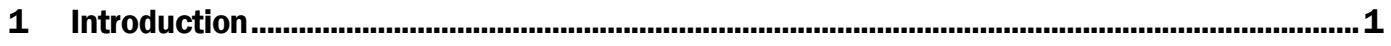

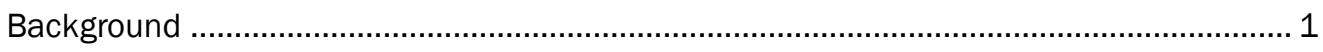

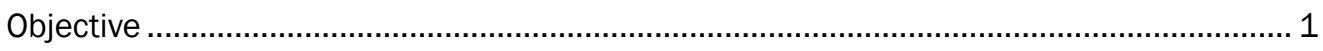

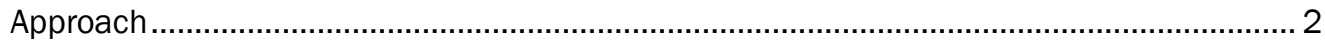

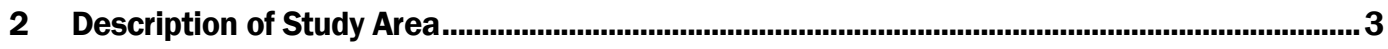

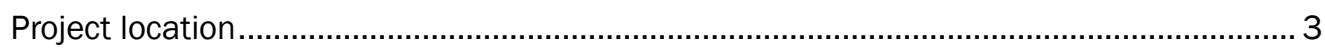

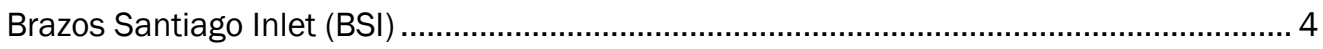

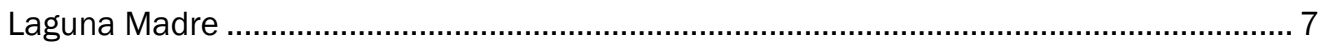

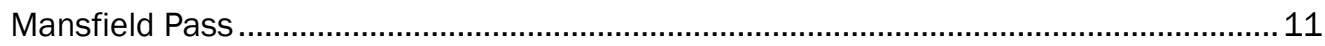

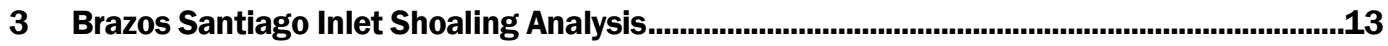

Recent dredging events ....................................................................................... 13

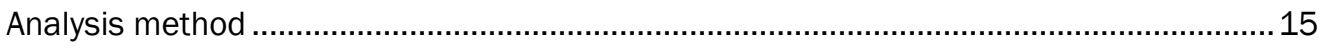

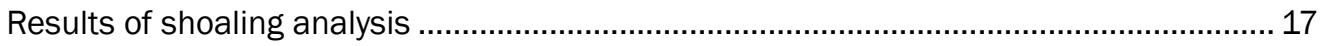

Entrance Channel analysis.................................................................................... 17

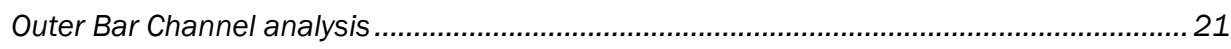

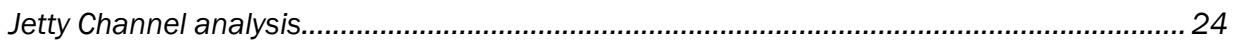

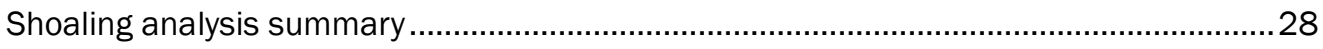

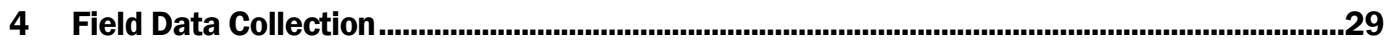

Regional tide, wind, and wave measurements ..............................................................29

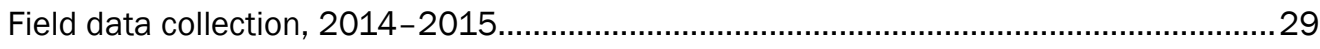

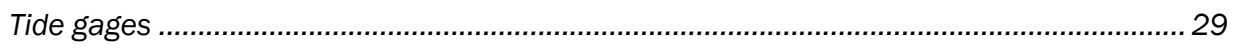

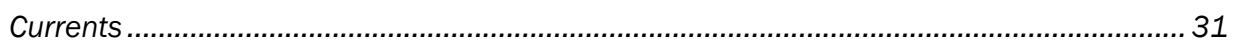

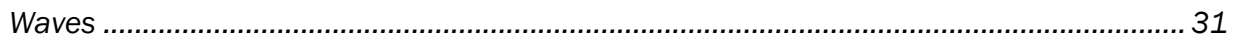

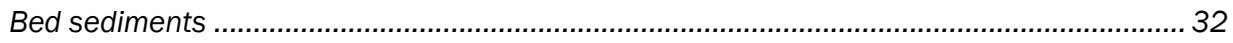

Results

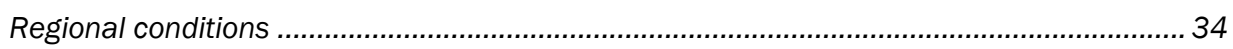

Field Study, 2014-2015 ….................................................................................... 39

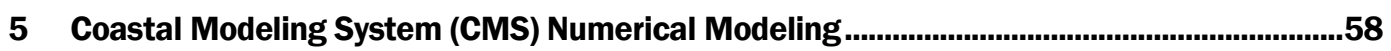

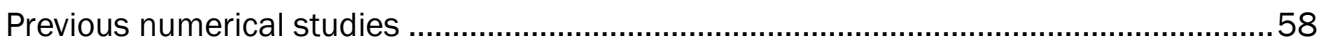

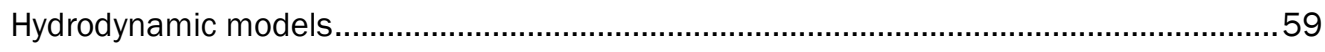

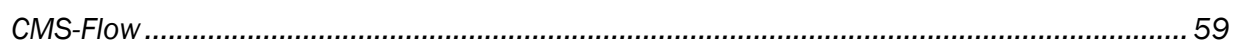




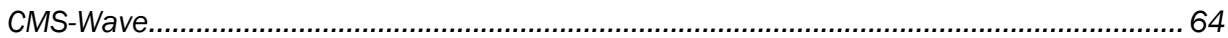

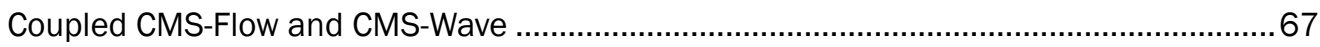

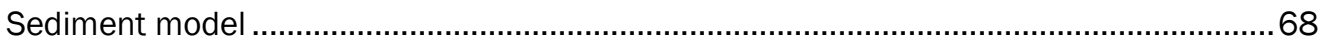

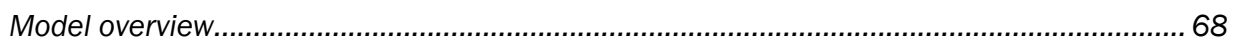

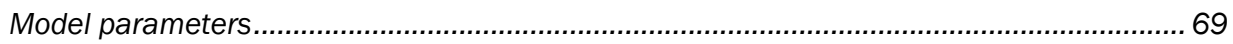

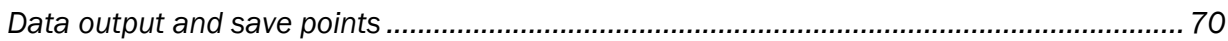

6 Numerical Model Evaluation.................................................................................................

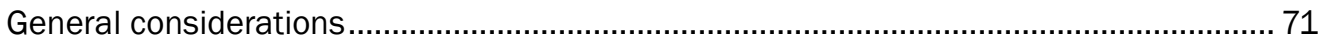

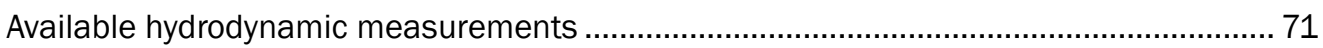

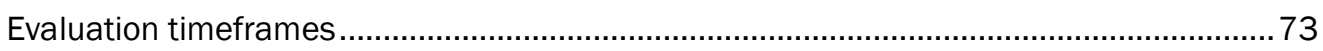

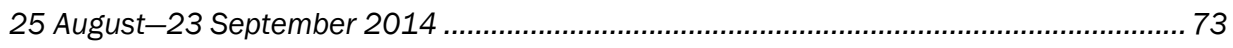

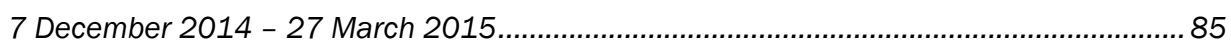

Sediment evaluation of Base Case (present condition) ............................................. 97

Sedimentation patterns of the system ......................................................................... 101

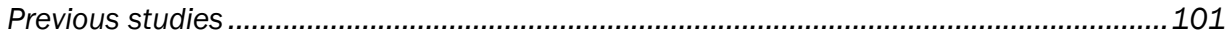

Base Case numerical modeling results ........................................................................ 102

7 Hydrodynamics of the Lower Laguna Madre/Brazos Santiago/Mansfield System ..........107

Shoal location within Brazos Santiago Inlet ............................................................... 107

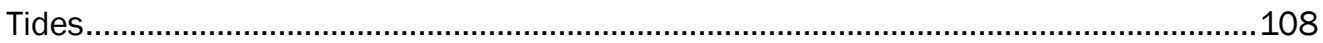

Winds

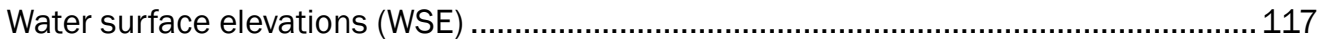

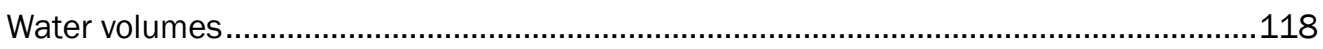

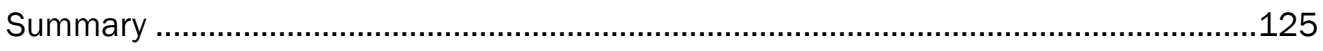

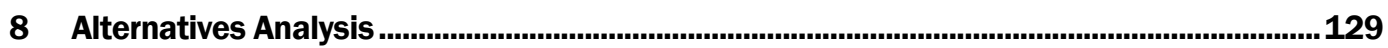

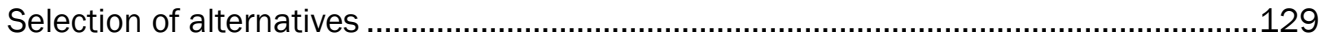

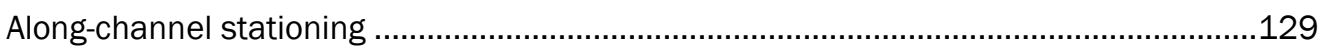

Executive summary assessment of alternatives ........................................................130

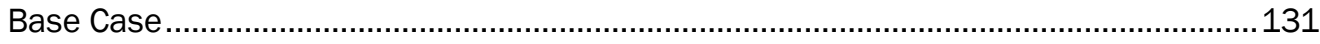

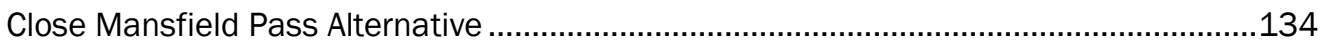

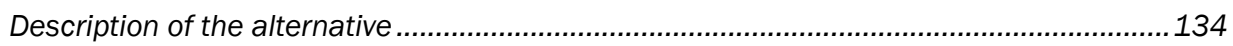

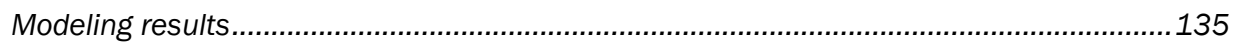

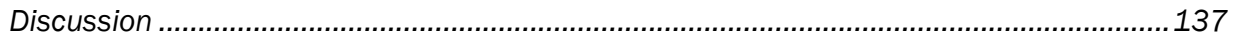

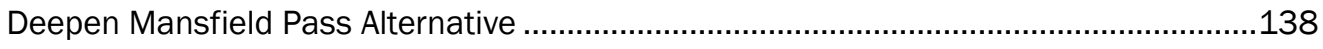

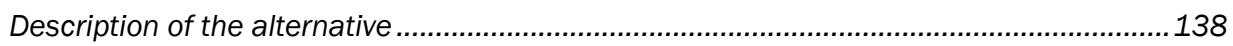

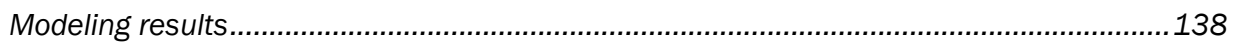

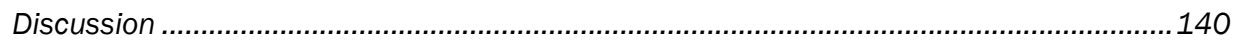

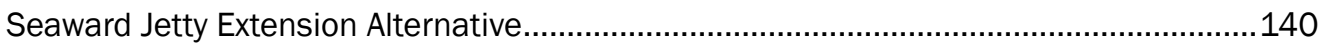

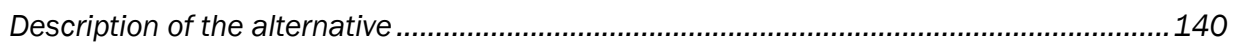

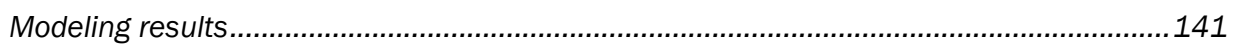

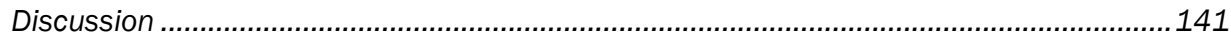

Interior Jetty Straightening Alternative ....................................................................143

Description of the alternative ..................................................................................... 143

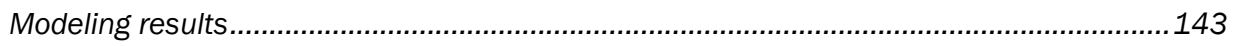

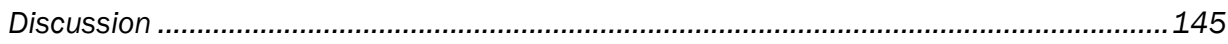




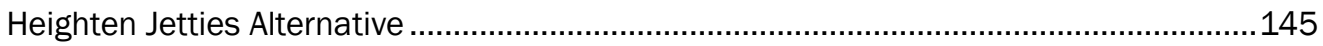

Description of the alternative .................................................................................145

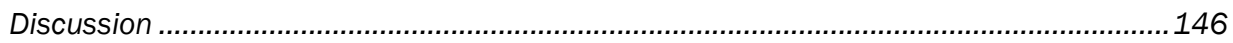

In-Channel Sediment Trap Alternative...................................................................... 147

Description of the alternative ......................................................................................147

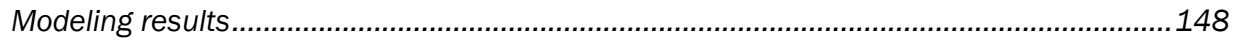

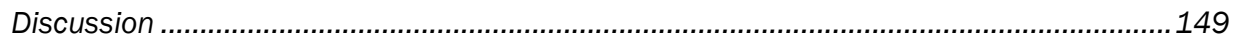

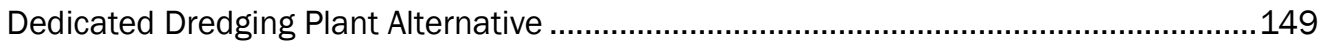

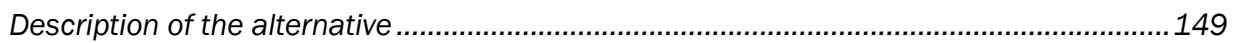

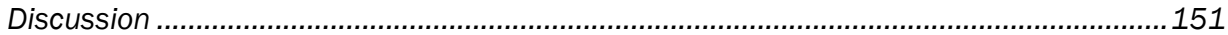

Proposed 15.8 m (52ft) Channel Deepening Project..................................................... 151

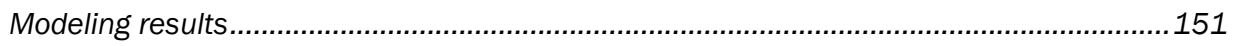

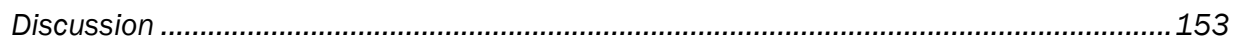

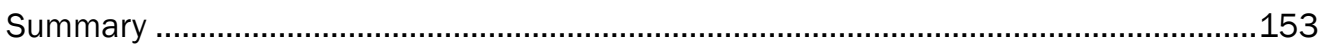

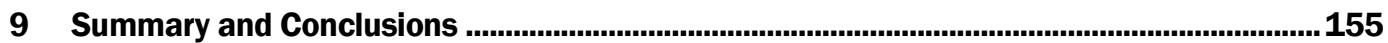

Alternatives for managing the BSI localized shoaling ....................................................156

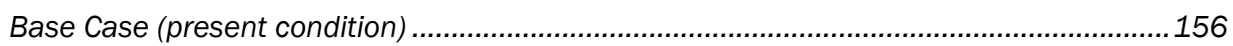

Close Mansfield Pass Alternative ..................................................................................156

Deepen Mansfield Pass Alternative ............................................................................ 156

Seaward Jetty Extension Alternative ...................................................................... 157

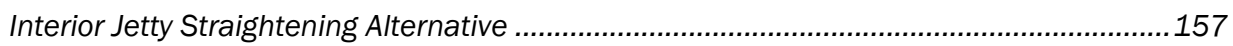

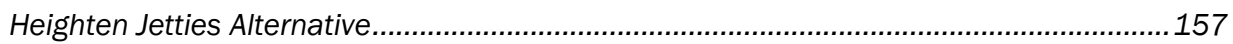

In-Channel Sediment Trap Alternative ................................................................. 158

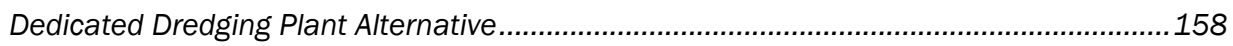

Proposed 15.8 m (52 ft) Channel Deepening Project........................................................159

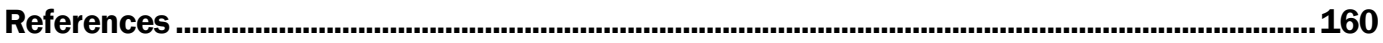

Appendix A: Datums

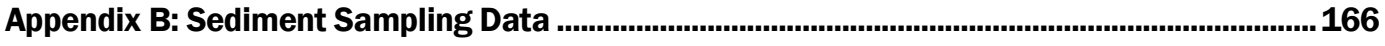

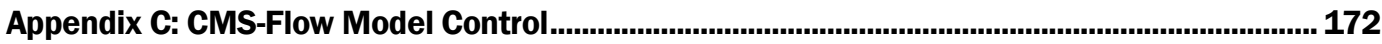

Report Documentation Page 


\section{Figures and Tables}

\section{Figures}

Figure 2-1. Overview of south Texas region (from Google Earth https://www.google.com/earth/).

Figure 2-2. BSI and Brownsville Ship Channel, showing stationing positions. ................................... 5

Figure 2-3. Hopper dredge Newport, dredging Brazos Santiago Inlet, 10 April 2014......................... 6

Figure 2-4. Lower Laguna Madre (from Google Earth https://www.google.com/earth/)......................... 8

Figure 2-5. Main waterways and canals in the Laguna Madre (after Diener [1975]).......................11

Figure 2-6. Mansfield Channel (red line); Gulf Intracoastal Waterway, GIWW (blue line);

Designated dredge deposition areas (tan boxes) (after USACE [2014c]) (from Google

Earth https://www.google.com/earth/)...............................................................................................12

Figure 3-1. Location of Dolphin Cove and location and frequency of dredging events in the Brazos Santiago Inlet Jetty Channel and Outer Bar Channel reaches.

Figure 3-2. Total volume dredged and volume dredged in channel by station in 2014 (upper panel) and bathymetry after dredging in 2014 (lower panel) (from Google Earth https://www.google.com/earth/).

Figure 3-3. Cumulative volume dredged, Brazos Santiago Inlet Entrance Channel, 19702014.

Figure 3-4. Cumulative probability distribution function of Brazos Santiago Inlet Entrance Channel maintenance dredging quantities (normal distribution).

Figure 3-5. Cumulative probability distribution function of Brazos Santiago Inlet Entrance Channel historical dredging interval (non-parametric distribution).

Figure 3-6. Cumulative volume dredged, Brazos Santiago Inlet Outer Bar Channel, 19792014.

Figure 3-7. Cumulative probability distribution function of Outer Bar Channel maintenance dredging quantities (normal distribution).

Figure 3-8. Cumulative probability distribution function of Outer Bar Channel historical dredging interval (non-parametric distribution).

Figure 3-9. Cumulative volume dredged, Brazos Santiago Inlet Jetty Channel, 19792014.

Figure 3-10. Cumulative probability distribution function of Jetty Channel maintenance dredging quantities (normal distribution).

Figure 3-11. Cumulative probability distribution function of Jetty Channel historical dredging interval (non-parametric distribution).

Figure 3-12. Frequency of Brazos Santiago Inlet Jetty Channel dredging.

Figure 4-1. Location of hydrodynamic measurements. TCOON gages are represented by red symbols, and $\mathrm{CHL}$ gages are represented by green symbols. Teardrop symbols are water level gages, and circular symbols are Acoustic Wave and Current (AWAC) profilers (from Google Earth https://www.google.com/earth/).

Figure 4-2. Sediment sample locations (from Google Earth https://www.google.com/earth/)............33

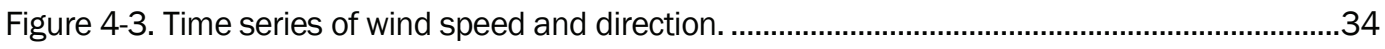

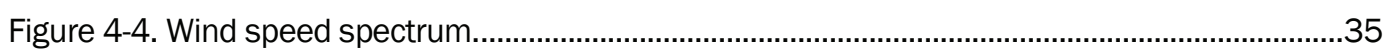

Figure 4-5. Time series of low-pass filtered winds and WSE............................................................36 
Figure 4-6. Low-pass filtered sea surface elevation difference between Rincon and SPI as a function of wind direction.

Figure 4-7. Wave climatology for south Texas coast. Color bar denotes wave height in meters.

Figure 4-8. Wave statistics for the south Texas coast. (A) wave direction, (B) wave height, and $(\mathrm{C})$ average wave period.

Figure 4-9. Wind vectors for south Texas coast.

Figure 4-10. Low-pass filtered wind speed and direction. The axis displaying wind direction is in meteorological coordinates (North $\mathrm{O}^{\circ}$ ) and denotes the direction from which the winds are coming.

Figure 4-11. Time series of WSE and bottom temperature in the BSI Navigation Channel. .............41

Figure 4-12. Time series of water elevation and bottom temperature at the offshore site................41

Figure 4-13. Depth-averaged current time series in the BSI Navigation Channel. .............................42

Figure 4-14. Depth-averaged currents at the offshore station............................................................43

Figure 4-15. Low-pass filtered currents in the BSI. Negative values denote flow towards Laguna Madre.

Figure 4-16. Low-pass filtered currents at the offshore site.

Figure 4-17. Cumulative discharge from the BSI. Note the break in the record precludes a continuous time series of the cumulative flux. Negative values denote flow towards the west.

Figure 4-18. Cumulative discharge per unit width at the offshore AWAC. Positive values denote flow towards the north (alongshore) and east (cross-shore).

Figure 4-19. Time series of wave parameters in the BSI Navigation Channel.

Figure 4-20. Time series of wave parameters at the offshore site.

Figure 4-21. Bottom orbital velocity and excursion amplitude in the BSI Navigation Channel.

Figure 4-22. Bottom orbital velocity and excursion amplitude at the offshore site...........................48

Figure 4-23. Density profiles collected in the inlet throat...............................................................49

Figure 4-24. Plot of particle size spectrum for Brazos MPI-5 ...........................................................49

Figure 4-25. Plot of cumulative size distribution for Brazos MPI-5. .................................................50

Figure 4-26. D50 for lower Laguna Madre including the BSI. Numbers denote sediment size in microns (from Google Earth https://www.google.com/earth/).

Figure 4-27. D50 for lower Laguna Madre. Numbers denote sediment size in microns (from Google Earth https://www.google.com/earth/).

Figure 4-28. D50 for upper Laguna Madre including Mansfield Pass. Numbers denote sediment size in microns (from Google Earth https://www.google.com/earth/).

Figure 4-29. Bathymetry snapshots during the 2014-2015 field deployment. (A) 14 September 2014, (B) 15 March 2015, and (C) 07 July 2015. The dashed line (C) denotes a transect line from which a bathymetry profile is extracted. Water depths are in meters (from Google Earth https://www.google.com/earth/).

Figure 4-30. Bed change in meters. Positive values denote deposition. Negative values denote erosion. (A) September 2014 to July 2015, (B) September 2014 to March 2015, (C) March 2015 to July 2015 (from Google Earth https://www.google.com/earth/).

Figure 4-31. Depth profile along the BSI Navigation Channel. The transect follows the centerline curve depicted in Figure 4-29, C. Depths are referenced to NAVD88. 
Figure 5-1. Telescoping CMS-Flow grid (from Google Earth https://www.google.com/earth/). .............60

Figure 5-2. Resolutions of telescoping CMS-Flow grid (from Google Earth https://www.google.com/earth/).

Figure 5-3. Multi-beam bathymetry survey collected in September 2014 (from Google

Earth https://www.google.com/earth/)...

Figure 5-4. CMS-Flow bathymetry (left) with verified incorporation of multi-beam survey data into CMS (right) (from Google Earth https://www.google.com/earth/). 62

Figure 5-5. CMS-Flow Manning's n (from Google Earth https://www.google.com/earth/) 63

Figure 5-6. Location of CMS-Wave grid with respect to CMS-Flow domain (from Google Earth https://www.google.com/earth/)..

Figure 5-7. Non-uniform CMS-Wave grid and bathymetry (from Google Earth https://www.google.com/earth/). .66

Figure 5-8. CMS-Flow and CMS-Wave inline coupling process. 67

Figure 5-9. Specified non-erodible hard bottom dataset indicated by red cells. .70

Figure 6-1. Location of measurements for model evaluation. TCOON gages are represented by red symbols, NOAA gages are represented by blue symbols, and CHL gages are represented by green symbols. Teardrop symbols are water level gages, and circular symbols are AWACs (from Google Earth https://www.google.com/earth/). .72

Figure 6-2. Water level comparison at Rincon for 25 August - 23 September 2014 ........................73

Figure 6-3. Water level comparison at TIDE2 for 25 August - 23 September 2014........................... 74

Figure 6-4. Water level comparison at Port Mansfield for 25 August - 23 September 2014.

Figure 6-5. Water level comparison at TIDE1 for 25 August - 23 September 2014.........................75

Figure 6-6. Water level comparison at TIDE3 for 25 August - 23 September 2014..........................75

Figure 6-7. Water level comparison at Port Isabel for 25 August - 23 September 2014...................76

Figure 6-8. Water level comparison at TIDE4 for 25 August - 23 September. ..................................76

Figure 6-9. Water level comparison at S. Padre Island for 25 August - 23 September 2014.

Figure 6-10. East-west (top) and north-south (bottom) velocity comparisons at oAWAC for 25 August - 23 September 2014.

Figure 6-11. East-west velocity comparisons at iAWAC for 25 August - 23 September 2014.

Figure 6-12. North-south velocity comparisons at iAWAC for 25 August - 23 September 2014.

Figure 6-13. Velocity excursion at iAWAC for 25 August - 23 September 2014.

Figure 6-14. Wave comparisons at oAWAC from 25 August - 23 September 2014..........................83

Figure 6-15. Wave comparisons at iAWAC from 25 August - 23 September 2014.

Figure 6-16. Best track positions for Tropical Storm Dolly, 1-3 September 2014 (after Beven [2015]).

Figure 6-17. Water level comparison at Rincon for 7 December 2014 - 27 March 2015. .86

Figure 6-18. Water level comparison at TIDE2 for 7 December 2014 - 27 March 2015.

Figure 6-19. Water level comparison at Port Mansfield for 7 December 2014 - 27 March 2015.

Figure 6-20. Water level comparison at TIDE1 for 7 December 2014 - 27 March 2015. 
Figure 6-21. Water level comparison at TIDE3 for 7 December 2014 - 27 March 2015................88

Figure 6-22. Water level comparison at Port Isabel for7 December 2014 - 27 March 2015..............88

Figure 6-23. Water level comparison at TIDE4 for 7 December 2014 - 27 March 2015.................89

Figure 6-24. Water level comparison at S. Padre Island for 7 December 2014 - 27 March 2015.

Figure 6-25. East-west velocity comparisons at oAWAC for 7 December 2014 - 27 March 2015.

Figure 6-26. North-south velocity comparisons at oAWAC for 7 December $2014-27$ March 2015.

Figure 6-27. East-west velocity comparisons at iAWAC for 7 December 2014 - 27 March 2015.

Figure 6-28. North-south velocity comparisons at iAWAC for 7 December 2014 - 27

March 2015.

Figure 6-29. Velocity excursion at iAWAC for 7 December 2014 - 27 March 2015..........................95

Figure 6-30. Wave comparisons at oAWAC from 7 December 2014 - 27 March 2015...................96

Figure 6-31. Wave comparisons at iAWAC from 7 December 2014 - 27 March 2015.......................97

Figure 6-32. Predicted and surveyed bathymetry for September 2014 (yellow), March 2015 (blue), and July 2015 (green).

Figure 6-33. Current magnitude extracted from location (435561.3, 5044970.0) between the tips of the jetties.

Figure 6-34. Measured (top) and modeled (center and bottom) bed change. 100

Figure 6-35. Simplified pattern of net longshore sediment transport along the Texas coast (from McGowen et al. [1977]; after Watson [1971]) ..................................................................... 101

Figure 6-36. HDR (2009) conceptual sediment budget, 1980 - 2008. ........................................ 102

Figure 6-37. Rose diagram selected locations. ................................................................................ 103

Figure 6-38. Sediment transport rose diagrams. ........................................................................... 104

Figure 6-39. Transect locations for sediment transport calculations. .............................................. 105

Figure 6-40. Cumulative sediment transport encompassing the BSI. Positive/negative values denote total sediment volume flux surplus/deficit. The curves represent the total sediment flux expressed in terms of cumulative volume normal to the transect lines integrated through time.

Figure 7-1. Inlet flow velocities at different along-channel locations in Brazos Santiago Inlet.

Figure 7-2. Tide stations in Lower Laguna Madre used in this present study (from Google Earth https://www.google.com/earth/). 109

Figure 7-3. Measured hourly WSEs for October 2014 at Port Isabel............................................. 110

Figure 7-4. Low-pass filtered tide data at Port Isabel. ....................................................................... 111

Figure 7-5. October 2014 WSE data for tide gages near Brazos Santiago Inlet. ............................ 112

Figure 7-6. WSE data for October 2014 from gages at the north end of Lower Laguna Madre.

Figure 7-7. Average wind speeds in the United States (from NREL, U.S. Department of Energy https://windexchange.energy.gov/maps-data?height=80m).

Figure 7-8. Monthly wind roses at Realitos Peninsula for model time period. 
Figure 7-9. Yearly wind rose for Realitos Peninsula with Lower Laguna Madre for alignment comparison

Figure 7-10. October 2014 WSE at south, mid, and north ends of Lower Laguna Madre, plus wind direction (from the Realitos Peninsula gage).

Figure 7-11. Numerical model data showing the cumulative volume flow (in cubic kilometers) through Brazos Santiago Inlet over the model year. Positive flows are seaward (ebb) flows; negative flows are landward (flood) flows.

Figure 7-12. Numerical model data showing the cumulative volume flow through both Brazos Santiago Inlet and Mansfield Pass over the model year. Positive flows are net seaward (ebb) flows; negative flows are net landward (flood) flows.

Figure 7-13. Monthly gross and net flow volumes through Brazos Santiago Inlet over the model year.

Figure 7-14. Monthly gross and net along-channel flow volumes through Laguna Madre at Realitos Peninsula over the model year.

Figure 7-15. Monthly gross and net flow volumes through Mansfield Pass over the model year.

Figure 7-16. Yearly velocity time series through Mansfield Pass.

Figure 7-17. Monthly gross and net flow volumes through Mansfield Pass over the model year for the scenario in which the model winds have been turned off.

Figure 7-18. Schematic of seasonal circulation patterns in Lower Laguna Madre (from Google Earth https://www.google.com/earth/).

Figure 8-1. CESWG stationing system for Brazos Santiago Inlet and the Brownsville Ship Channel.

Figure 8-2. Monthly growth of the flood shoal over the model year (September 2014 -

September 2015) for the Base Case.

Figure 8-3. Base Case cumulative channel shoaling volume through the model year. Inset shows the location of the shoaling volume calculation box.

Figure 8-4. Change in channel depth for the Close Mansfield Alternative compared to the Base Case.

Figure 8-5. Differences in the model-predicted shoaling volume through time for the Close Mansfield Alternative compared to the Base Case.

Figure 8-6. Change in channel depth for the Deepen Mansfield Alternative compared with the Base Case.

Figure 8-7. Differences in the model-predicted shoaling volume through time for the Dredge Mansfield Alternative compared to the Base Case.

Figure 8-8. Brazos Santiago Inlet showing the Seaward Jetty Extension Alternative in red (from Google Earth https://www.google.com/earth/).

Figure 8-9. Change in channel depth for the Seaward Jetty Extension Alternative compared with the Base Case.

Figure 8-10. Differences in the model-predicted shoaling volume through time for the Seaward Jetty Extension Alternative compared to the Base Case.

Figure 8-11. Brazos Santiago Inlet showing the Interior Jetty Straightening Alternative in red (from Google Earth https://www.google.com/earth/).

Figure 8-12. Change in channel depth for the Interior Jetty Straightening Alternative compared with the Base Case. 
Figure 8-13. Differences in the model-predicted shoaling volume through time for the Interior Jetty Straightening Alternative compared to the Base Case.

Figure 8-14. Brazos Santiago Inlet south (left panel) and north (right panel) jetties at dune line showing sand level near the crests of the jetties.

Figure 8-15. Brazos Santiago Inlet showing likely locations (in red) to increase the jetty height for the Heighten Jetty Alternative (from Google Earth https://www.google.com/earth/)......... 146

Figure 8-16. Location (in red) of the deepened portion of the channel for the In-Channel Sediment Trap Alternative (from Google Earth https://www.google.com/earth/)

Figure 8-17. Change in channel depth for the In-Channel Sediment Trap Alternative compared with the Base Case.

Figure 8-18. Schematic location of the dredging location for a dedicated pump plant and associated discharge pipe (from Google Earth https://www.google.com/earth/).

Figure 8-19. Change in channel depth for the Proposed $15.8 \mathrm{~m}$ (52 ft) Channel Deepening Project compared with the Base Case.

Figure 8-20. Differences in the model-predicted shoaling volume through time for the Proposed $15.8 \mathrm{~m}$ (52 ft) Channel Deepening Project compared to the Base Case.

Figure 8-21. Minimum controlling depths over the Brazos Santiago Inlet flood shoal for the six modeled alternatives.

Figure 8-22. Relative accumulation volume for each of the alternatives.

\section{Tables}

Table 2-1. History of improvements to Brazos Santiago Inlet.

Table 2-2. Lower Laguna Madre table of dimensions. Source A is from Diener (1975);

Source B is from Tunnell and Judd (2002). 9

Table 3-1. Maintenance dredging history for the Brazos Santiago Inlet (BSI), Jetty Channel, Outer Bar Channel, and Entrance Channel. ..................................................................................18

Table 3-2. Brazos Santiago Inlet Entrance Channel statistical measures. .........................................19

Table 3-3. Brazos Santiago Inlet Outer Bar Channel statistical measures. ........................................21

Table 3-4. Brazos Santiago Inlet Jetty Channel statistical measures. ..............................................24

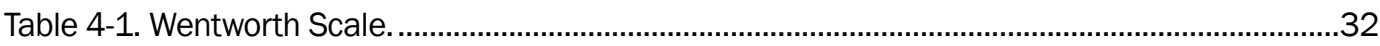

Table 7-1. Comparative wind speeds from south to north in Laguna Madre. ................................. 115

Table 8-1. Location of key along-channel features........................................................................... 130

Table 8-2. Brief overview of alternatives. ....................................................................................... 132

Table A-1. Vertical datum relationships at the Bob Hall Pier, Corpus Christi, TX, NOAA Tide

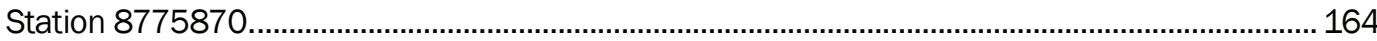

Table B-1. Laguna Madre 2014: Brazos bed sample locations...................................................... 166

Table B-2. Laguna Madre 2014: Brazos bed samples, including grain size distribution, sediment classification, and statistical deviations for all samples listed in Table B-1. 168 


\section{Preface}

This study was conducted for Headquarters, U.S. Army Corps of Engineers (HQUSACE), under Project Number 454631, "Brazos Santiago Inlet Channel Shoaling Study," as part of the USACE Monitoring Completed Navigation Projects (MCNP) Program.

This study was executed by the Coastal Processes Branch (HFC) of the Flood and Storm Protection Division (CEERD-HF), and the Coastal Engineering Branch (HNC) of the Navigation Division (CEERD-HN), U.S. Army Engineer Research and Development Center, Coastal and Hydraulics Laboratory (ERDC-CHL). Field data and analyses were performed by the Field Data Collection and Analysis Branch (HNF) of the Navigation Division. At the time of publication of this report, Ms. Ashley Frey (CEERD-HFC) and Mr. Thad Pratt (CEERD-HNF) were Branch Chiefs, and Mr. Gregory W. Dreaper (CEERD-HNC) was Acting Branch Chief. Dr. Cary A. Talbot (CEERD-HF) was Division Chief, and Mr. Charles E. Wiggins (CEERD-HN) was Acting Division Chief. Mr. Jeffrey A. McKee, Chief, Headquarters, USACE Navigation Branch, was the Navigation Business Line Manager. Mr. W. Jeff Lillycrop, CHL, was the ERDC Technical Director for Civil Works and Navigation Research, Development, and Technology Transfer (RD\&T) portfolio. Dr. Lyndell Z. Hales was the MCNP Program Manager.

At the time of publication of this report, the Acting Deputy Director of ERDC-CHL was Dr. Jacqueline S. Pettway, and the Acting Director was Mr. Jeffrey R. Eckstein.

COL Bryan S. Green was the Commander of ERDC, and Dr. David W. Pittman was the Director of ERDC. 


\section{Acknowledgements}

This study was nominated for inclusion in the U.S. Army Corps of Engineers (USACE) Monitoring Completed Navigation Projects (MCNP) Program by Mr. Joseph Hrametz, Chief, Operations Division, USACE Galveston District (SWG). Appreciation is extended to Mr. Robert Thomas, Chief, Engineering and Construction Division; Mr. Seth Jones, and Ms. Kimberly Townsend (SWG) for assistance in coordinating the various elements of the field data collection efforts and for performing the extensive historical background literature review.

The authors also extend appreciation to SWG for in-kind contributions during the conduct of this study. Funding provided by the MCMP Program is acknowledged with appreciation. The USACE Coastal Inlets Research Program (CIRP) is extended appreciation for developing the Coastal Modeling System (CMS) used in this study. Support of the U.S. Army Engineer Research and Development Center (ERDC), Coastal and Hydraulics Laboratory (CHL), Field Data Collection and Analysis Branch (HNF), is acknowledged for extensive instrumentation deployment and data processing support. 


\section{Unit Conversion Factors}

\begin{tabular}{|c|c|c|}
\hline Multiply & By & To Obtain \\
\hline acres & $4,046.873$ & square meters \\
\hline acre-feet & $1,233.5$ & cubic meters \\
\hline cubic feet & 0.02831685 & cubic meters \\
\hline cubic inches & 1.6387064 E-05 & cubic meters \\
\hline cubic yards & 0.7645549 & cubic meters \\
\hline fathoms & 1.8288 & meters \\
\hline feet & 0.3048 & meters \\
\hline Inches & 0.0254 & meters \\
\hline inch-pounds (force) & 0.1129848 & newton meters \\
\hline knots & 0.5144444 & meters per second \\
\hline microinches & 0.0254 & micrometers \\
\hline microns & $1.0 \mathrm{E}-06$ & meters \\
\hline miles (nautical) & 1,852 & meters \\
\hline miles (U.S. statute) & $1,609.347$ & meters \\
\hline miles per hour & 0.44704 & meters per second \\
\hline mils & 0.0254 & millimeters \\
\hline square feet & 0.09290304 & square meters \\
\hline square inches & 6.4516 E-04 & square meters \\
\hline square miles & $2.589998 \mathrm{E}+06$ & square meters \\
\hline square yards & 0.8361274 & square meters \\
\hline yards & 0.9144 & meters \\
\hline
\end{tabular}




\section{Introduction}

\section{Background}

The Brazos Santiago Inlet (BSI), at the southern end of Laguna Madre on the south Texas coast, is the entranceway leading from the Gulf of Mexico to the Brownsville Ship Channel and the Port of Brownsville, TX. The inlet portion of this federal navigation project has been dredged to its presently authorized depth of 12.8 meters $(\mathrm{m})$ (42 feet [ft)]), plus $0.6 \mathrm{~m}$ ( $2 \mathrm{ft}$ ) of overdraft starting in 1992, and the Galveston District of the U.S. Army Corps of Engineers (CESWG) has developed plans pursuant to an increased authorized channel depth of $15.8 \mathrm{~m}(52 \mathrm{ft})+0.6 \mathrm{~m}$ (2 ft) overdraft (USACE 2014b). The BSI presently experiences rapid shoaling that has led to draft

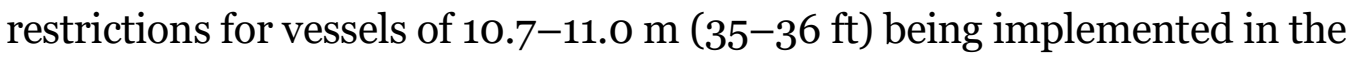
inlet as soon as 9-12 months post dredging. The CESWG has requested assistance from the U.S. Army Engineer Research and Development Center, Coastal and Hydraulics Laboratory (ERDC-CHL), in understanding and addressing this issue (Hrametz 2013).

\section{Objective}

The objective of this study has been for ERDC-CHL to work with and convey to CESWG a better understanding of the hydrodynamics and sediment dynamics of the BSI, Texas, to develop strategies to reduce dredging and other management costs at the federally authorized inlet. This study is not intended to produce final, construction-ready designs for implementation by CESWG but rather to suggest promising avenues that appear to be worthy of further study and refinement to meet this goal.

In developing these alternatives, it is understood that the BSI is part of a larger complex system and that there would be environmental, economic, and sociological impacts for any of these alterations. While not a key component of this study, some of these factors have been considered in the evaluation of the alternatives and discussed in this report. For example, the town of South Padre Island has a clear need for the sediment dredged from the inlet to be used for re-nourishment of its beaches. As another example, this study has concluded that closing Mansfield Pass would be expected to create a small beneficial reduction in the shoaling rate at the BSI. However, it is also clear that closing the Mansfield Pass would have substantial 
negative ecological impacts on Laguna Madre, and thus this alternative was not recommended for further study.

\section{Approach}

The approach used in this study was to analyze field data collected by ERDC-CHL plus additional data from other sources, along with numerical modeling and technical analysis, to first better understand the hydrodynamics and sediment dynamics of the BSI and the coupled waterway system and then to evaluate and recommend design alternatives to CESWG that have the potential to reduce costs associated with the dredging of the BSI.

As discussed in Chapter 3, the dredging record history, with data mostly supplied by CESWG, was used to evaluate the shoaling issues at the BSI. The field data collection program conducted for this study is described in Chapter 4. These data along with other data were required in the setup and calibration of the numerical model (Chapters 5 and 6). The field data and the numerical model results were used to better understand the behavior of the system (Chapter 7). Then, after a series of alternatives was formulated, information from all aspects of the study was used to evaluate the alternatives (Chapter 8). The results are summarized in Chapter 9. 


\section{Description of Study Area}

\section{Project location}

The BSI $\left(26.066^{\circ} \mathrm{N}, 97.153^{\circ} \mathrm{W}\right)$ is located on the south coast of Texas approximately 12.0 kilometers [km] (7.5 miles) north of the mouth of the Rio Grande River, the U.S. border with Mexico (Figure 2-1). The Gulf of Mexico is to the east of the inlet. Laguna Madre stretches $190 \mathrm{~km}$ (120 miles) to the north to the town of Corpus Christi and Corpus Christi Bay. The lagoon is divided into Upper Laguna Madre and Lower Laguna Madre by an area of shallow/dry flats called the Land Cut, which is 89 to $120 \mathrm{~km}$ ( 55 to 75 miles) north of the BSI.

Laguna Madre is separated from the Gulf of Mexico by Padre Island, one of the longest barrier islands in the world. Most of the island is undeveloped, being owned by the National Park Service as the Padre Island National Seashore. Mansfield Pass, a small manmade inlet within the National Seashore, bisects the island $56 \mathrm{~km}$ (35 miles) north of the BSI. Mansfield Channel runs from the inlet entrance at the Gulf of Mexico on the east to the town of Port Mansfield on the inland (west) side of Laguna Madre. The town of South Padre Island occupies the southern $10.5 \mathrm{~km}$ (6.5 miles) of the barrier island. This section of beach is one of the most heavily developed shorelines on the Texas coast.

Inland from the town of South Padre Island is the town of Port Isabel, on the western side of the south end of Laguna Madre. The Brownsville Ship Channel, a $27 \mathrm{~km}$ (17 mile) long blind channel, runs southwest from the BSI and the south end of Laguna Madre to the Port of Brownsville at the eastern edge of the city of Brownsville. Along the coast between the BSI and the Rio Grande River is an undeveloped area known as Brazos Island. In the past, a shallow intermittent inlet known as Boca Chica Pass was open approximately $8 \mathrm{~km}$ ( 5 miles) south of the BSI, connecting the Gulf of Mexico with the south end of Laguna Madre through an area known as South Bay, that is today mostly dry flats. Aside from temporary hurricane washovers, this inlet has been closed for many years; thus, Brazos Island is attached to the mainland (USACE 1992). 
Figure 2-1. Overview of south Texas region (from Google Earth https://www.google.com/earth/).

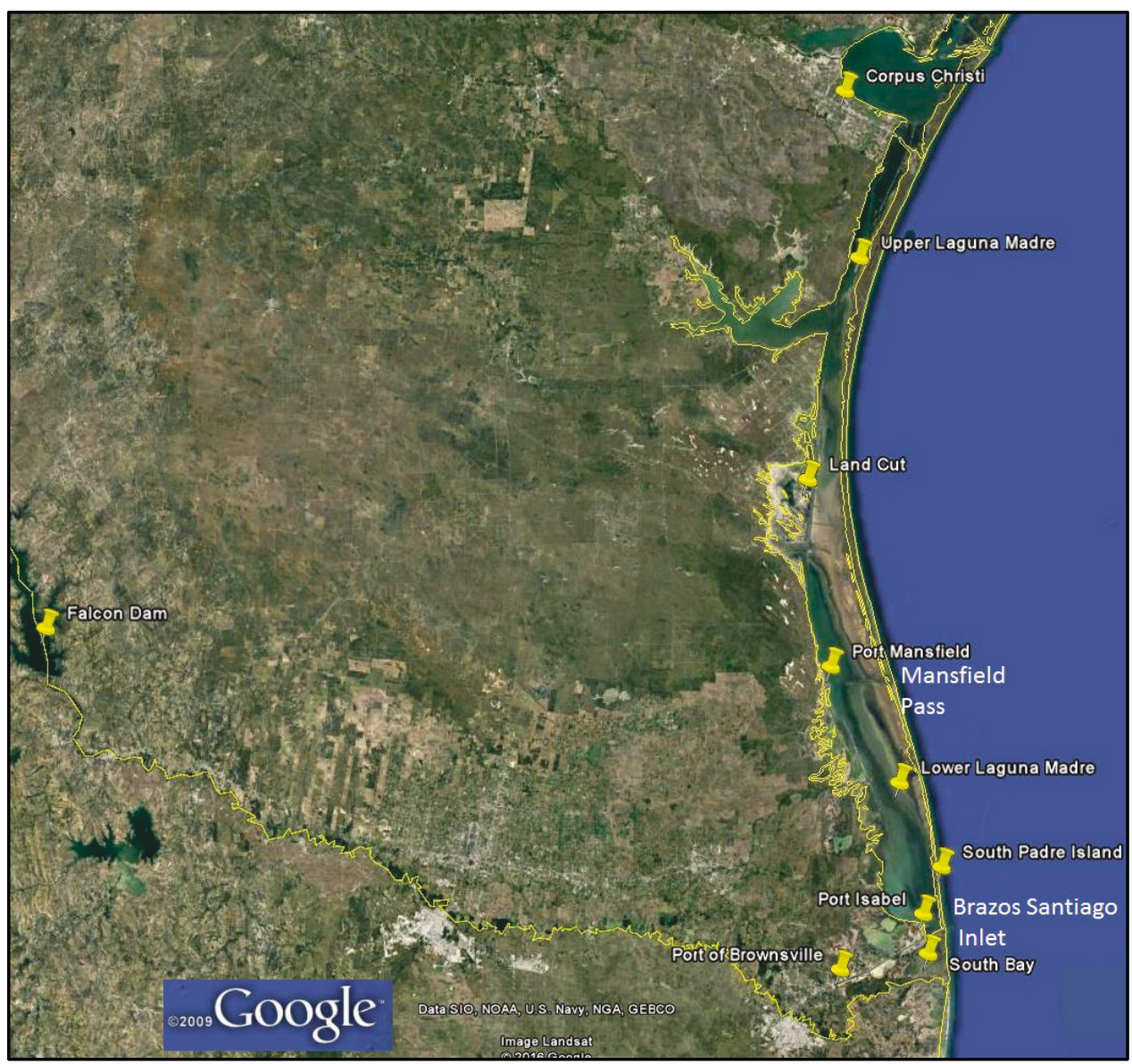

\section{Brazos Santiago Inlet (BSI)}

The BSI (Figure 2-2) is a natural inlet between Padre Island and Brazos Island that connects the southern end of Laguna Madre to the Gulf of Mexico. Brazos Island Harbor and Brazos Santiago Pass are other names commonly applied to this inlet. The inlet forms part of the Brownsville Ship Channel, a federal navigation channel between the Gulf and the Port of Brownsville. The inlet is $1,830 \mathrm{~m}(6,000 \mathrm{ft})$ long from the seaward tips of the two jetties in the Gulf to the point where the inlet joins the southern end of Lower Laguna Madre (Station O+Ooo in Figure 2-2). The channel is

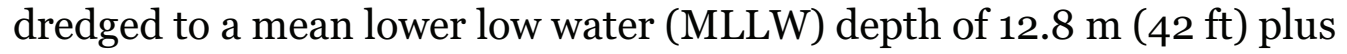

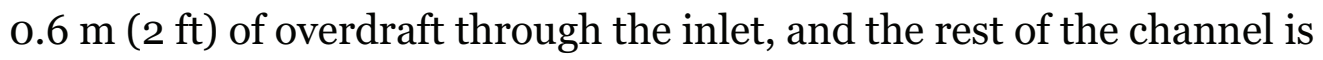

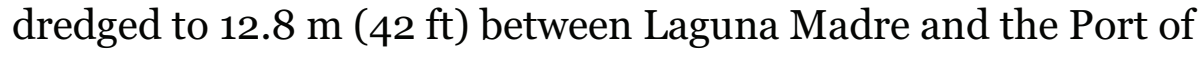
Brownsville. Through the inlet, the channel bottom width is $91.5 \mathrm{~m}$ (300 ft), with side slopes of 1:6. 
Figure 2-2. BSI and Brownsville Ship Channel, showing stationing positions.

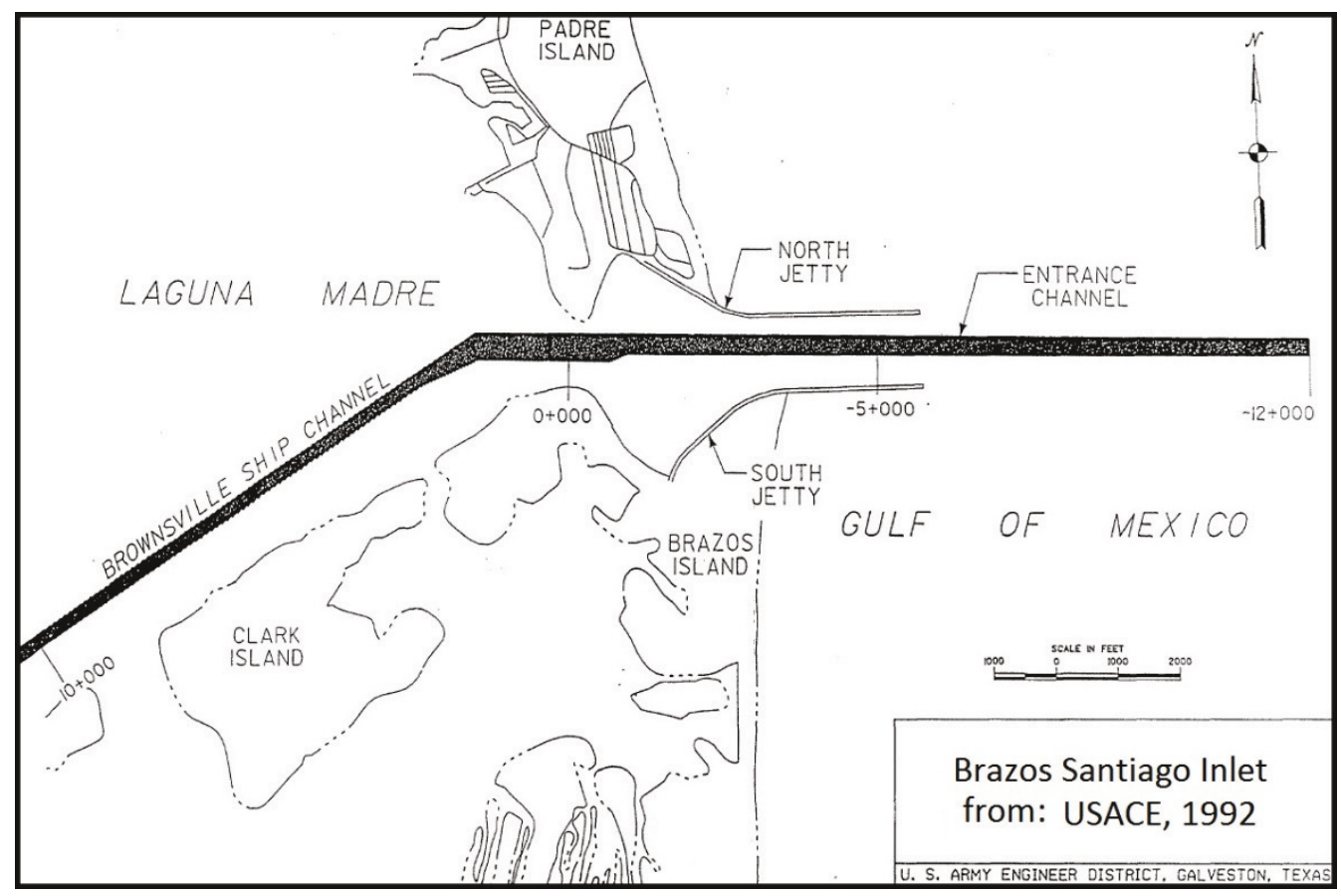

Within the inlet, the high point (controlling depth) of the shoaling occurs in the vicinity of station -2+OOO (Figure 2-2), where the inlet first starts to widen. At this location, sediment that is carried in on the flood tide is deposited as the flow velocity starts to decrease. Dredging of the channel through the inlet occurs every 1 to 2 years and is performed by hopper dredges (Figure 2-3). Material dredged from the channel is placed either in feeder berms or directly onto the beaches of South Padre Island, adjacent to the north side of the inlet (USACE 2014b).

Prior to navigation improvements, the inlet had a narrow, shifting channel with a controlling depth over the bar of between 2.0 and $3.4 \mathrm{~m} \mathrm{(6.5}$ and $11 \mathrm{ft}$ ) at mean low tide (MLT) (USACE 1992). Since the late 1800s, there has been a series of modifications to the inlet to improve navigation, as listed in Table 2-1. The information in this table has been obtained from USACE (1977, 1992, 1993a, 2014b) and from Sargent and Bottin (1989). 
Figure 2-3. Hopper dredge Newport, dredging Brazos Santiago Inlet, 10 April 2014.

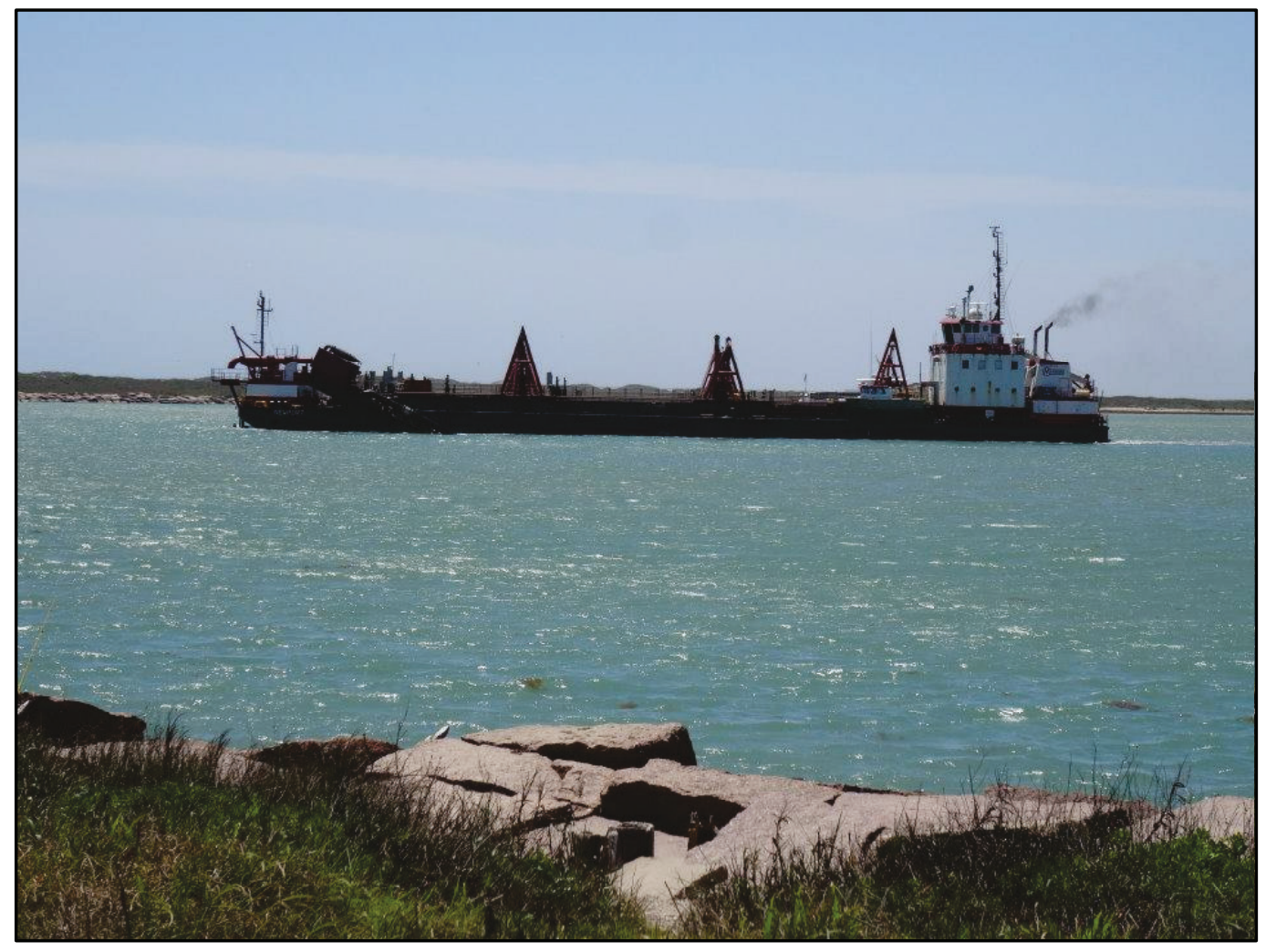

Table 2-1. History of improvements to Brazos Santiago Inlet.

\begin{tabular}{|c|c|}
\hline Date & Event \\
\hline 1523 & $\begin{array}{l}\text { On Saint James Day (July 25), Captain Francisco Garay named the inlet at } \\
\text { the south end of Padre Island as the "Brazos de San lago" (Arms of Saint } \\
\text { James). }\end{array}$ \\
\hline 1878 & $\begin{array}{l}\text { First federal improvement of the pass involved with the removal of a } \\
\text { shipwreck from the channel. }\end{array}$ \\
\hline 1880-1881 & $\begin{array}{l}\text { The Rivers and Harbors Acts (RHAs) of } 1880 \text { and } 1881 \text { provided for } \\
\text { deepening of the natural channel through the BSI to } 10 \mathrm{ft} \text {, widening the } \\
\text { channel through the pass to } 70 \mathrm{ft} \text {, and the construction of two parallel } \\
\text { jetties at the pass. }\end{array}$ \\
\hline 1882 & $\begin{array}{l}\text { Construction was begun on the South Jetty, which consisted of brush } \\
\text { mattresses weighted down with clay bricks. }\end{array}$ \\
\hline 1884 & Construction halted because of lack of funds. \\
\hline 1887 & Unfinished jetty destroyed by storms. \\
\hline 1919 & $\begin{array}{l}\text { The RHA of } 1919 \text { provided authorization to deepen the channel to } 18 \mathrm{ft} \text { with } \\
\text { a } 400 \mathrm{ft} \text { width through the pass. Under this authorization, two short stone } \\
\text { jetties were constructed, and some channel dredging was performed. }\end{array}$ \\
\hline
\end{tabular}




\begin{tabular}{|c|c|}
\hline Date & Event \\
\hline 1927 & $\begin{array}{l}\text { Completion of experimental project to dredge channel } 18 \text { by } 400 \mathrm{ft} \text { through } \\
\text { pass and a } 16 \mathrm{ft} \text { by } 100 \mathrm{ft} \text { channel from pass to turning basin at Port Isabel. } \\
\text { Project included two short stone dikes extending into Gulf (north side } 1 \text { @ } \\
700 \mathrm{ft} \text {; south side } 1 @ 400 \mathrm{ft} \text { ). Experimental project discontinued in } 1928 \\
\text { because of rapid reshoaling. }\end{array}$ \\
\hline 1930 & The RHA of 1930 authorized inlet improvements. \\
\hline 1935 & $\begin{array}{l}\text { Completion of the BSI North Jetty to } 5,600 \mathrm{ft} \text { long, South Jetty to } 3,600 \mathrm{ft} \\
\text { long, and construction of rock groins to protect inner end of jetties. Passes } \\
\text { were constructed in conjunction with the construction of a navigation } \\
\text { channel to Port Isabel. }\end{array}$ \\
\hline $1936-1967$ & $\begin{array}{l}\text { Brownsville Ship Channel constructed. Channel dredged to } 25 \mathrm{ft} \text { deep by } \\
300 \mathrm{ft} \text { wide through the inlet and } 25 \mathrm{ft} \text { deep by } 100 \mathrm{ft} \text { wide from Laguna } \\
\text { Madre to the Port of Brownsville. }\end{array}$ \\
\hline 1940 & $\begin{array}{l}\text { Channel deepened to } 31 \mathrm{ft} \text { through the inlet and to } 28 \mathrm{ft} \text { through the interior } \\
\text { channel to Brownsville. }\end{array}$ \\
\hline 1945 & $\begin{array}{l}\text { RHA of } 1945 \text { authorized channel improvements. Channel depth authorized } \\
\text { to } 32 \mathrm{ft} \text {. }\end{array}$ \\
\hline 1947 & $\begin{array}{l}\text { Completion of channel deepening through the inlet to } 35 \mathrm{ft} \text { deep and farther } \\
\text { inland to Brownsville and in the turning basins to } 32 \mathrm{ft} \text { deep. }\end{array}$ \\
\hline 1957 & Completion of channel widening through the inlet to $300 \mathrm{ft}$. \\
\hline 1960 & $\begin{array}{l}\text { RHA of } 1960 \text { authorized channel improvements. Completion of channel } \\
\text { dredging through the inlet to } 38 \mathrm{ft} \text { and through all other channels and } \\
\text { basins to } 36 \mathrm{ft} \text { deep. }\end{array}$ \\
\hline 1961 & Construction of erosion protection of North Jetty. \\
\hline 1966 & Completion of major rehabilitation of North and South Jetties. \\
\hline 1978 & Extended shore protection of North Jetty resulting in total length of $6,770 \mathrm{ft}$. \\
\hline 1986 & $\begin{array}{l}\text { Water Resources Development Act of } 1986 \text { authorized channel } \\
\text { improvements. }\end{array}$ \\
\hline 1992 & $\begin{array}{l}\text { Completion of channel dredging to its present configuration of } 44 \mathrm{ft} \text { through } \\
\text { the inlet and } 42 \mathrm{ft} \text { through the interior channel to Brownsville Harbor. }\end{array}$ \\
\hline 1993 & $\begin{array}{l}\text { Dredge material was first used to create a feeder berm for beach } \\
\text { nourishment for the town of South Padre Island. }\end{array}$ \\
\hline
\end{tabular}

\section{Laguna Madre}

Laguna Madre is a long, narrow, shallow, hypersaline lagoon in south Texas, running from Corpus Christi Bay in the north to the BSI in the south (Figure 2-1). The lagoon has been isolated into two parts, the Upper Laguna Madre and the Lower Laguna Madre, by an approximately $19 \mathrm{~km}$ (12-mile) long stretch of wind-blown sand, which is most commonly referred to as the Land Cut (Figure 2-4). Prior to the Gulf Intracoastal Waterway being dredged through this area, water exchange between the 
two portions of the lagoon was limited to times when wind-driven flooding occurred over the flat plane area. (See Miller [1975], Watson [1979], and Morton and Holmes [2009] for detailed discussions of this feature.)

Figure 2-4. Lower Laguna Madre (from Google Earth https://www.google.com/earth/).

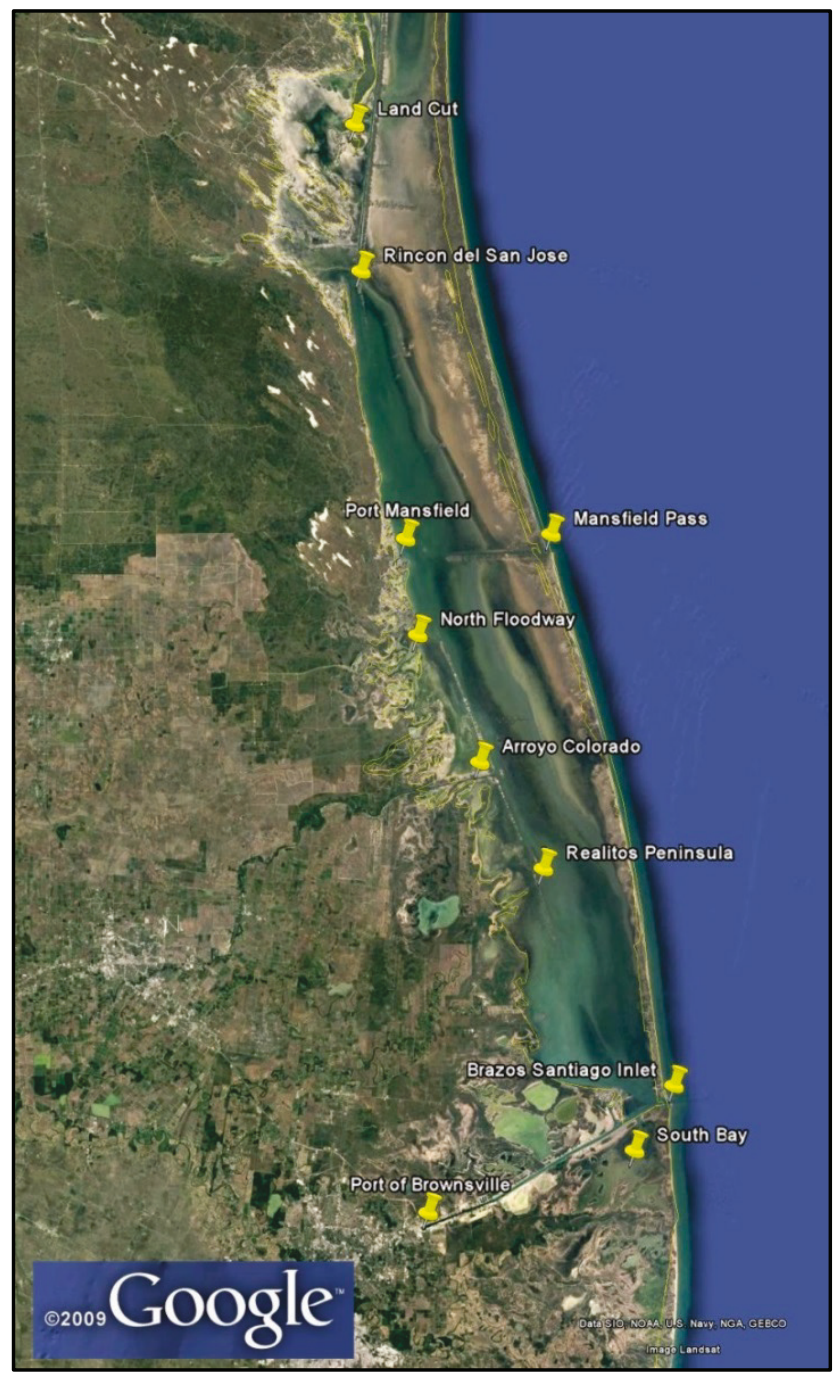

Lower Laguna Madre generally refers to the portion of the lagoon between Rincon del San Jose in the north and the BSI and South Bay in the south (Figure 2-4). Table 2-2 provides information on the dimensions of the Lower Laguna Madre.

This region of south Texas has a subtropical, semiarid climate, characterized by short, mild winters and long, hot summers. The average annual temperature is approximately $23^{\circ}$ Celsius ( $74^{\circ}$ Fahrenheit), although daily temperatures of $38^{\circ}$ Celsius $\left(100^{\circ}\right.$ Fahrenheit) are not 
uncommon in the western regions during the summer (Keislich 1977). The lagoon is classified as hypersaline because in most years, evaporation rates exceed all surface inflow plus precipitation over the lagoon surface. The relatively high temperatures and low humidity lead to high evaporation rates while the dry climate leads to little freshwater input.

Table 2-2. Lower Laguna Madre table of dimensions. Source A is from Diener (1975); Source B is from Tunnell and Judd (2002).

\begin{tabular}{|l|l|l|l|}
\hline & Feet & Meters & Source \\
\hline Max depth at MLW & 26.0 & 7.9 & A \\
\hline Avg depth at MLW & 4.7 & 1.4 & A \\
\hline & & & \\
\hline & Miles & Kilometers & \\
\hline Length & 47.2 & 76.0 & B \\
\hline Min width across water & 3.7 & 6.0 & B \\
\hline Min width: water + tidal flats & 6.8 & 11.0 & B \\
\hline Avg width across water & 5.0 & 8.0 & B \\
\hline Avg width: water + tidal flats & 8.7 & 14.0 & B \\
\hline Max width across water & 7.5 & 12.0 & B \\
\hline & & & \\
\hline & Feet 2 & Meters & \\
\hline MLW surface area & $9,364,000,000$ & $709,000,000$ & A \\
\hline MHW surface & $17,628,000,000$ & $1,334,000,000$ & A \\
\hline & & & \\
\hline MLW volume & $35,861,000,000$ & $1,015,000,000$ & A \\
\hline MHW volume & $81,872,000,000$ & $2,318,000,000$ & A \\
\hline
\end{tabular}

No significant streams flow into the Lower Laguna Madre. The main surface flow discharge points are two drainage canals, the Arroyo Colorado and North Floodway, whose outlets into the lagoon are shown in Figure 2-4. These two canals can be used to divert water from the Rio Grande River upstream of Brownsville and adjacent Matamoros to protect those cities from flooding when the Rio Grande flow exceeds capacity. However, this is an unusual event since the construction of Falcon Dam (1950-1953) on the Rio Grande between Laredo and Brownsville; plus, the construction of other dams on local Rio Grande tributaries has limited flooding events. 
The most recent Rio Grande discharge into these canals was between 8 July and 16 August 2010 (IBWC 2010) when Hurricane Alex and Tropical Depression \# 2 passed through the area releasing large amounts of rainfall locally. Lower Laguna Madre salinity levels in the vicinity of the drainage channels were reported to have dropped to zero (Tompkins 2010). However, under normal conditions, these two canals carry very modest but variable volumes of agricultural runoff and local storm water drainage.

Analyzing data from the 36-year period of 1941 through 1976, Texas Department of Water Resources (TDWR 1983) calculated that the average evaporation rate for Lower Laguna Madre was 39\% higher than the average total freshwater inflow rate. Continuing the study over the 34-year period from 1977 through 2010, Schoenbaechler and Guthrie (2011) present data that show the average Lower Laguna Madre evaporation rates exceeded average total inflow plus precipitation rates by $31 \%$. Both studies indicate that the main contributor to the year-to-year variability in this ratio is the variable inflow rate. For example, if the year 2010 is removed from the second study (the year of the Rio Grande diversions discussed above), the average rate that evaporation exceeds average total inflow jumps to $40 \%$.

One of the largest man-made changes to the lagoon has been the dredging of the Gulf Intracoastal Waterway (GIWW) along its length. The waterway was first considered when The Rivers and Harbors Act (RHA) of 1873 appropriated funds to survey an intracoastal waterway route between Donaldsonville in Louisiana and the Rio Grande River in Texas. Following the initial survey, which was completed in August of 1874, sections of the GIWW in Louisiana and Texas were completed in a piecemeal fashion and then slowly joined together into a continuous canal as more sections were completed. The last segment to be constructed was the westernmost, through Laguna Madre. In the 4 years following World War II, The GIWW was extended from Corpus Christi to Port Isabel, where it connected with the Brownsville Ship Channel. With the completion of this segment, a continuous inland waterway having a MLLW of $3.0 \mathrm{~m}$ (10 ft) depth, ran from Carrabelle, FL, to Brownsville, TX (Alperin 1983). Figure 2-5 shows the route of the GIWW through Laguna Madre, along with the other major canals in the region. 
Figure 2-5. Main waterways and canals in the Laguna Madre (after Diener [1975]).

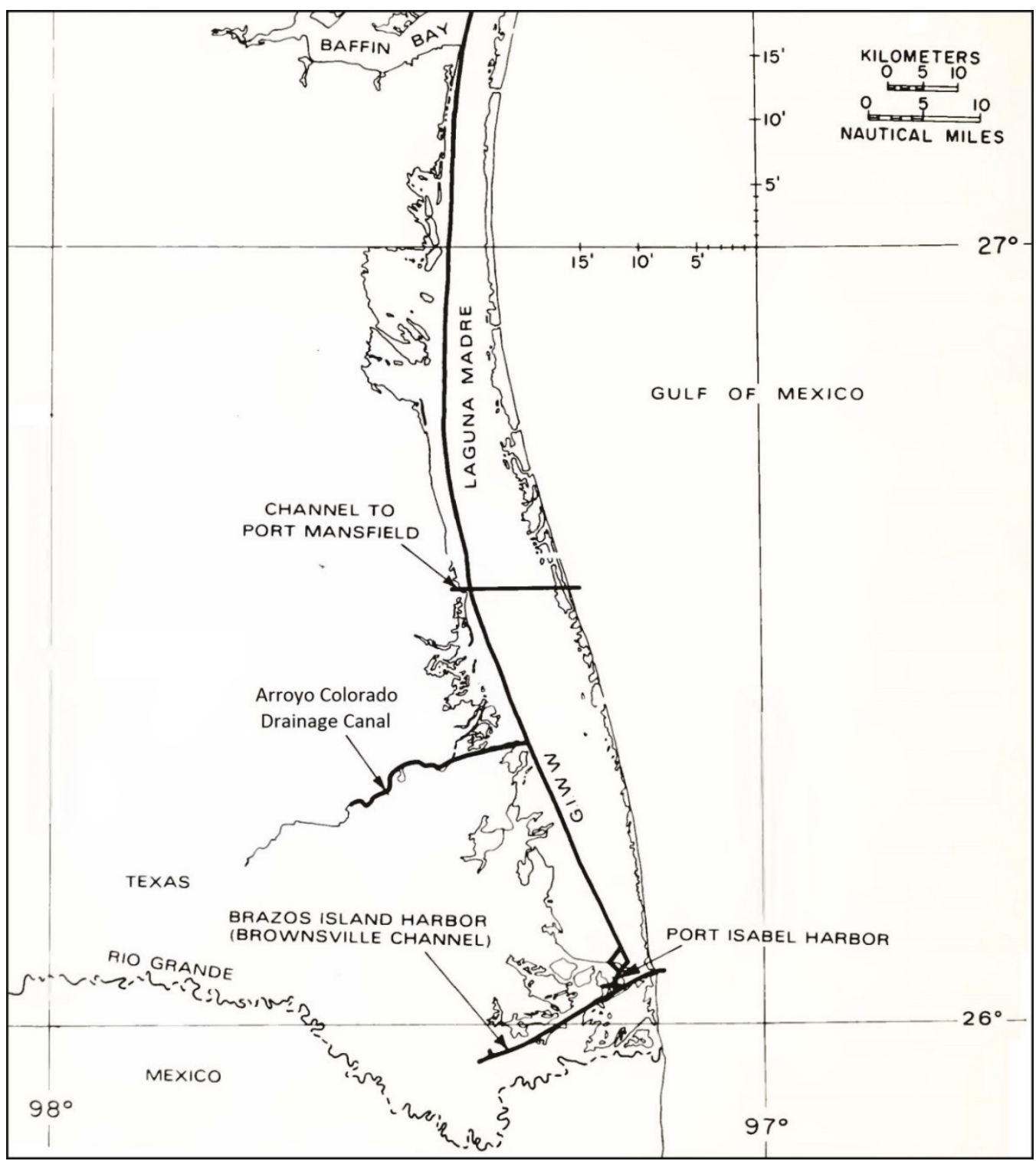

\section{Mansfield Pass}

Mansfield Pass is a man-made, shallow-draft, jettied inlet (Figure 2-6). It is part of the Mansfield Channel, which runs for $20.8 \mathrm{~km}$ (12.9 miles) between the Gulf of Mexico and the town of Port Mansfield on the landward side of Laguna Madre. Until recently, the channel was maintained at a $4.3 \mathrm{~m}$ (14 ft) depth with a $38 \mathrm{~m}$ (125 ft) channel bottom width. However, in 2011, the U.S. Army Corps of Engineers (USACE) discontinued maintenance of the channel after Port Mansfield was redesignated as a recreational rather than a commercial port (PAAC 2015). Currently, shoaling has reduced the channel depths generally to 2.4 to $3.7 \mathrm{~m}(8$ to $12 \mathrm{ft})$. 
Figure 2-6. Mansfield Channel (red line); Gulf Intracoastal Waterway, GIWW (blue line); Designated dredge deposition areas (tan boxes) (after USACE [2014c]) (from Google Earth https://www.google.com/earth/).

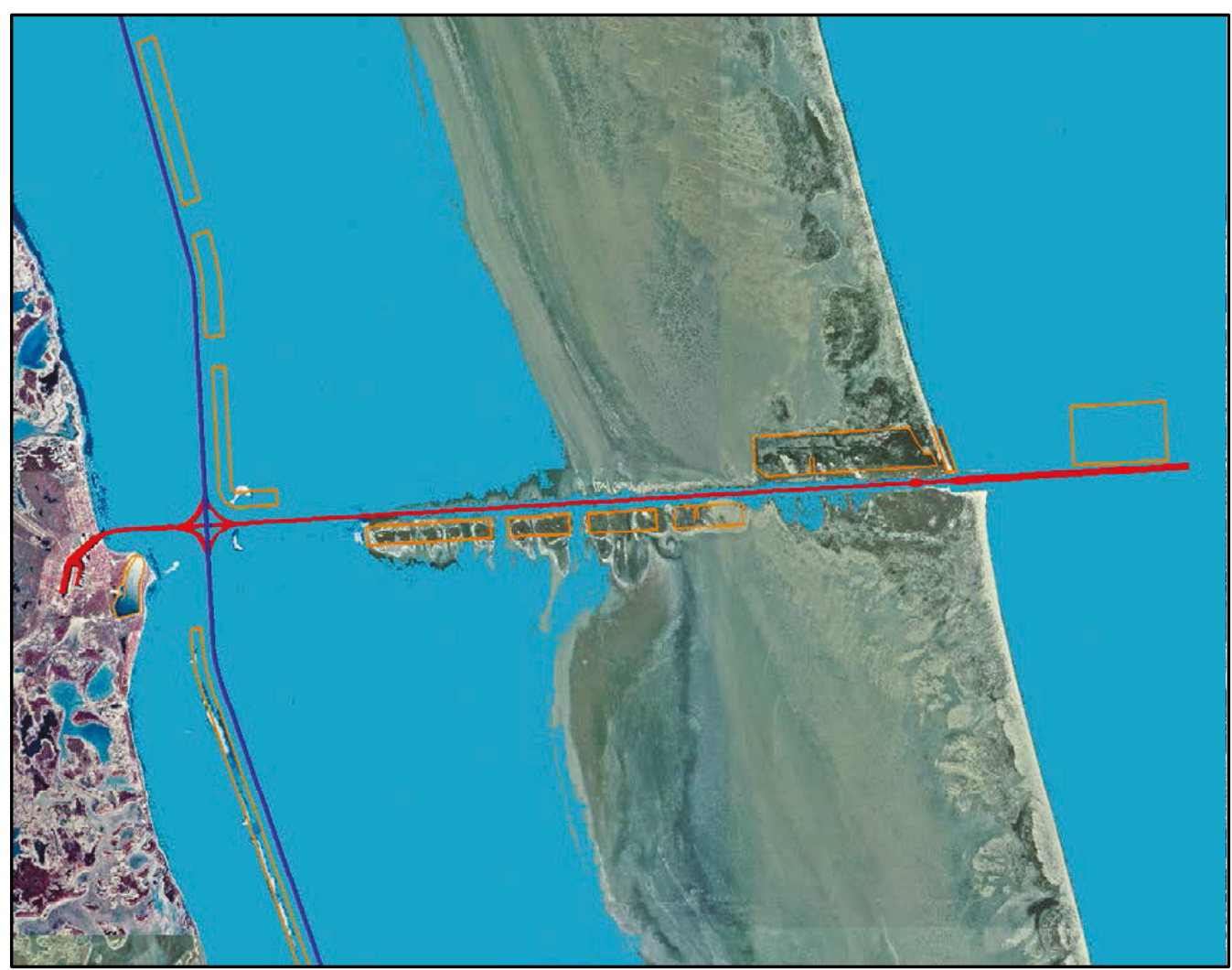

In 1950, the town of Port Mansfield was first established and named for U.S. Congressman Joseph J. Mansfield from Texas, who introduced congressional legislation to extend the GIWW from Corpus Christi to Port Isabel. In September 1957, the Willacy County Navigation District completed dredging of a channel from Port Mansfield through the lagoon (3.0 $\mathrm{m}[10 \mathrm{ft}]$ depth) and barrier island $(4.9 \mathrm{~m}[16 \mathrm{ft}]$ depth) to the Gulf of Mexico. However, within 2 months an intense storm caused landward flanking and extensive subsidence to both tetrapod jetties at the entrance to the Gulf. Deterioration of the inlet continued until its closure within a few years. In 1959, the inlet was authorized as a federal navigation channel. By May of 1962, the channel had been re-dredged and re-opened with new rubble mount jetties replacing the original structures (Hansen 1960; Kieslich 1977). 


\section{Brazos Santiago Inlet Shoaling Analysis}

This chapter describes recent dredging events and the shoaling analysis methods applied to the BSI. The method used was adapted from the Navy Shoaling Analysis Tool (NSAT) ${ }^{12}$ developed by the USACE for U.S. Navy Fleet Concentration Areas to forecast dredging requirements at Navy ports over a 5-year budget cycle. Although the purpose of NSAT is to determine future dredging, some of the analysis methods of the tool can be applied to examine historical dredging frequency and volumes dredged. The analysis was performed to determine the historical dredging frequency and volume dredged compared to recent events.

\section{Recent dredging events}

The Entrance Channel is comprised of two reaches: (1) the Jetty Channel reach, a 1,830 $\mathrm{m}(6,000 \mathrm{ft})$ long reach protected by dual jetties and (2) the Outer Bar Channel reach that extends gulfward of the jetties an additional 2,135 m (7,000 ft) (Figure 3-1). Harbor pilots have frequently reported increased shoaling within the BSI Jetty Channel. The shoaling, documented by channel surveys, has resulted in implementation of 10.7 to $11.0 \mathrm{~m}$ ( 35 to $36 \mathrm{ft}$ ) draft restrictions 9 to 12 months after maintenance dredging. The increased frequency of channel shoaling has posed a challenge for the USACE in maintaining the presently authorized depth of $12.8+0.6 \mathrm{~m}(42+2 \mathrm{ft})$ MLLW, resulting in vessels being sent to other ports including Mexico for either lightering or completely offloading cargo. Based on a recent economic impact study, the effect of not maintaining the

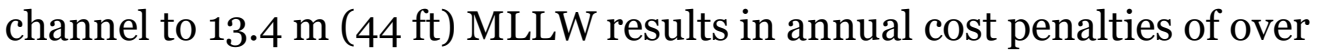
$\$ 5.7$ million per year for a $11.6 \mathrm{~m}(38 \mathrm{ft})$ draft restriction and could escalate to over $\$ 19.4$ million per year for a $10.7 \mathrm{~m}$ (35 ft) draft restriction (Hrametz 2013). The Port of Brownsville is ranked low in yearly tonnage and consequently is not a high priority for maintenance dredging funding. However, any impacts to inbound vessels ensure a major negative economic impact to the entire region of south Texas.

From 2002 to present, regular maintenance for portions of the channel was deferred or reduced because of funding limitations. This has resulted

\footnotetext{
1 Dunkin, L. M., R. C. Thomas, and J. Ratcliff. In preparation. U.S. Navy FCA Shoaling Study: Navigation Shoaling Analysis Tool. Vicksburg, MS: U.S. Army Engineer Research and Development Center.

2 Thomas, R. C., and L. M. Dunkin. In preparation. U.S. Navy FCA Shoaling Study: Demonstration Project; Mayport, FL. Vicksburg, MS: U.S. Army Engineer Research and Development Center.
} 
in interim nonscheduled emergency dredging to partially alleviate the shoaling (HDR 2009). The lower portion of Figure 3-1 shows dredging locations in the Entrance Channel since 1995 based on CESWG dredge records. This figure indicates more frequent dredging in later years, with no dredging performed in the Outer Bar Channel since 2002. Shoaling within the BSI Jetty Channel reported by harbor pilots in recent years and documented by channel surveys is particularly significant in the vicinity of Dolphin Cove (Figure 3-1).

Figure 3-1. Location of Dolphin Cove and location and frequency of dredging events in the Brazos Santiago Inlet Jetty Channel and Outer Bar Channel reaches.

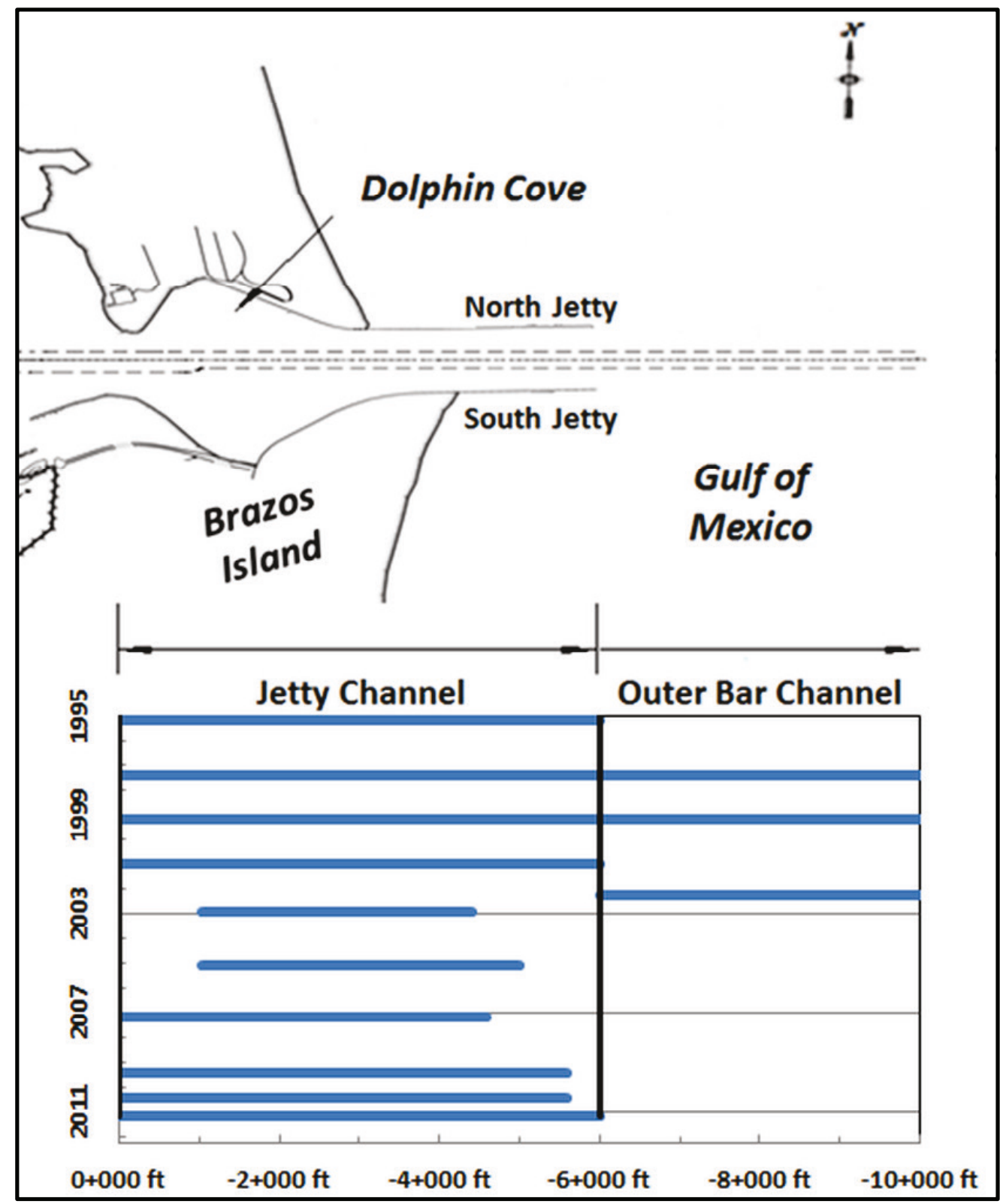


Emergency dredging was performed in the Jetty Channel due to shallow navigable draft during the spring of 2014. Volume dredged by station and the bathymetry from the post-dredge survey are shown in Figure 3-2. The red line signifies volume dredged from only the channel, and the blue line represents total volume dredged (channel, over-depth, and side slopes). Most of the dredged volume occurs between Station $-1+000$ and $-4+000$ with the peak volume coming from the Dolphin Cove region near Station $-2+200$.

Figure 3-2. Total volume dredged and volume dredged in channel by station in 2014 (upper panel) and bathymetry after dredging in 2014 (lower panel) (from Google Earth https://www.google.com/earth/).

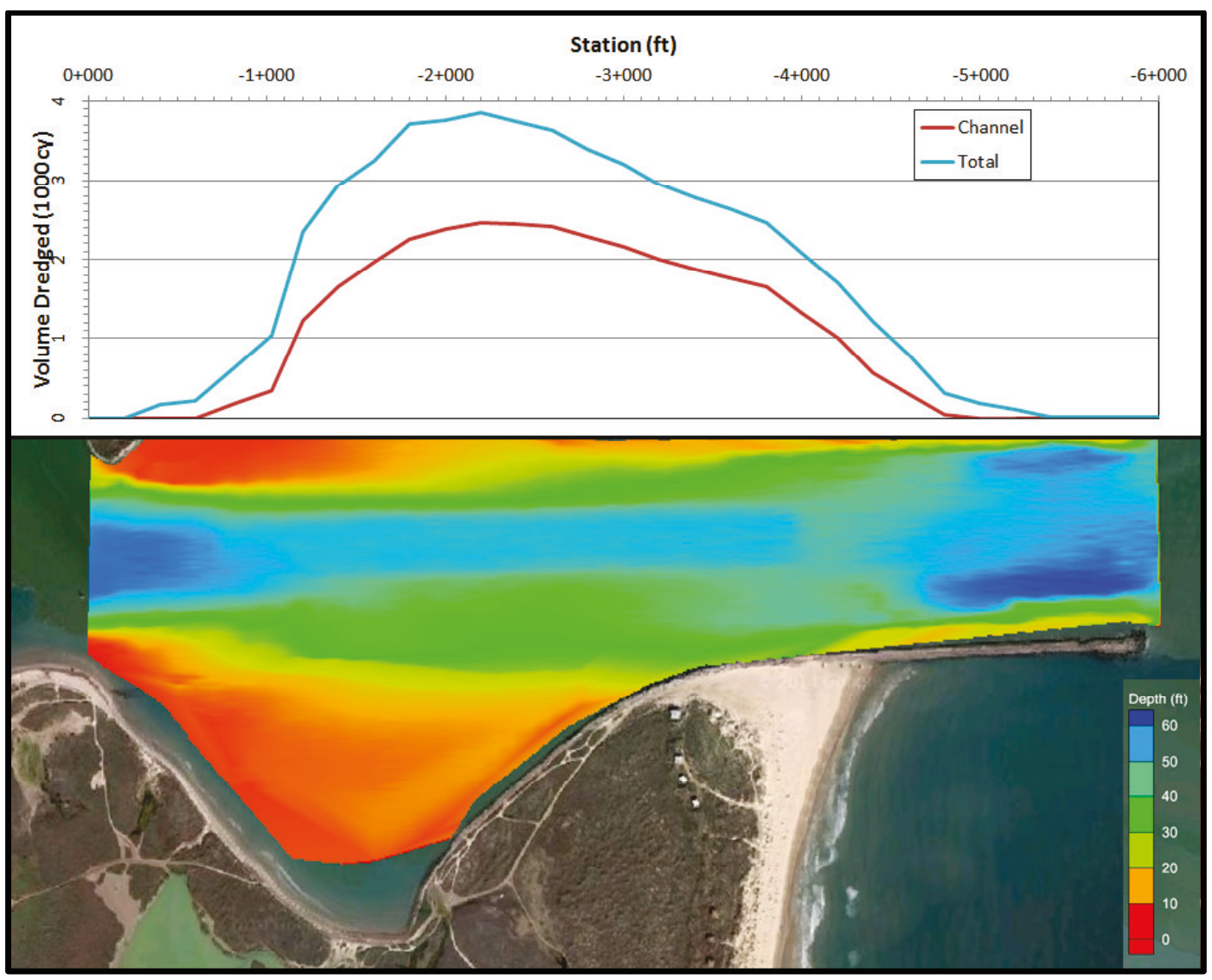

\section{Analysis method}

The NSAT is designed to utilize two sets of data to forecast dredging requirements: (1) historical dredging records and (2) available survey data. Both sets of data are analyzed by respective MATLAB scripts for the purpose of budget planning. However, only historical dredging trends were examined in the present study. The BSI dredging records, which include dredging location information, were sufficient for historical analysis. 
The primary input data for historical dredging record analysis are (1) the date dredging was completed and (2) the quantity dredged during each dredging event. The analysis can also account for increased shoaling after channel deepening by adjusting post-deepening dredge events by the increased rate. The increased shoaling rate can be determined either by numerical model simulations or by comparing records before and after the deepening. If the shoaling increase is not known, no adjustment is made to the quantities.

The analysis tool estimates the parameters of a linear least squares model. Two assumptions of the input parameters are required for analysis:

(1) means of the random errors in the observations are zero, and there are neither biases nor systematic errors in the data sets, and (2) random errors have a constant standard deviation, and the forcing factors that influence shoaling remain the same. Dredging events that could bias the results (e.g., new work, extreme events) were omitted from analysis.

A traditional method to estimate future dredging needs by fitting a line to a record of previous dredged quantities was applied in the present study. Applying a goodness of fit to the data provides insight into the accuracy of the shoaling estimates ${ }^{1}$. Previous applications of the NSAT to dredging records indicated that a linear regression model statistically represented historic dredging and would be appropriate for predicting future dredging needs. Using linear regression, the model is

$$
D_{\text {cumulative }}=r_{a} t+b
$$

where $D_{\text {cumulative }}$ is the cumulative volume of dredged material calculated for all quantities selected for analysis, $r_{a}$ is the annual rate of dredging in cubic yards per year, $t$ is time in years, and $b$ is the $y$-intercept. The $y$ intercept has no comparative meaning because the regression model for all data is based on serial dates and the model is based on time in years; therefore, the intercept value is not reported.

The coefficient of determination $\left(R^{2}\right)$ gives a measure of how well a model is expected to predict future outcomes, where $R^{2}=1$ is a perfect fit. In estimating shoaling, $R^{2}$ is representative of how well dredging rates are estimated with a linear model based solely on time. In addition, the $p$-value determines if relationships are statistically significant within some significance level. Previous NSAT applications have set the significance

1 Thomas, R. C., and L. M. Dunkin. In preparation. U.S. Navy FCA Shoaling Study: Demonstration Project; Mayport, FL. Vicksburg, MS: U.S. Army Engineer Research and Development Center. 
level at 0.05 (the 95\% confidence level). That level was used in this present Monitoring Completed Navigation Projects study. Therefore, a $p$-value less than 0.05 suggests the relationship is statistically significant. In the NSAT, the dredge interval or period between dredging events is calculated as the median of the dredging intervals if the $p$-value is less than 0.05 .

Otherwise, the dredge interval is calculated from the average of the dredging intervals ${ }^{1}$.

\section{Results of shoaling analysis}

Dredging volume rates and nominal dredging frequency were determined with individual dredging events compared to the historical values. Dredging history records of the Entrance Channel were obtained for the analysis from CESWG through the Dredging Histories Database from 1970 to 2014. Dredge records prior to 1979 did not specify the reach within the Entrance Channel that was dredged, only the combined volumes of the Jetty Channel and Outer Bar Channel. Therefore, analyses were performed for the entire Entrance Channel from 1970 to 2014 and for the Jetty Channel and the Outer Bar Channel from 1979 to 2014. The dates and dredged volumes from the Jetty Channel, Outer Bar Channel, and Entrance Channel are listed in Table 3-1. Dredging in the Entrance Channel also was performed in late 2015, but quantities were not available at the time of this writing.

The Entrance Channel (Jetty Channel and Outer Bar Channel) was deepened from $11.6 \mathrm{~m}$ (38 ft) MLT to $13.4 \mathrm{~m}$ (44 ft) MLT in 1992. Deepening of channels can increase shoaling in the channel, and an adjustment in the analysis can be incorporated to account for additional shoaling. However, an analysis of the deepening of the channel was not performed, and no adjustment to the calculated shoaling rate was made.

\section{Entrance Channel analysis}

Maintenance dredging was performed on 28 occasions in the BSI Entrance Channel between 1970 and 2014, totaling 10.4 million cubic meters $\left(\mathrm{m}^{3}\right)$ (13.6 million cubic yards [yd3]). The average, standard deviation, minimum, and maximum dredged volume were calculated per dredging event, per dredging interval, and per year from the historical dredging records and are listed in Table 3-2.

\footnotetext{
1 Dunkin, L. M., R. C. Thomas, and J. Ratcliff. In preparation. U.S. Navy FCA Shoaling Study: Navigation Shoaling Analysis Tool. Vicksburg, MS: U.S. Army Engineer Research and Development Center.
} 
Table 3-1. Maintenance dredging history for the Brazos Santiago Inlet (BSI), Jetty Channel, Outer Bar Channel, and Entrance Channel.

\begin{tabular}{|c|c|c|c|}
\hline \multirow[b]{2}{*}{ Completed Date } & \multicolumn{3}{|c|}{ Quantity Dredged $\left(y d^{3}\right)$} \\
\hline & Jetty Channel & $\begin{array}{l}\text { Outer Bar } \\
\text { Channel }\end{array}$ & $\begin{array}{c}\text { Entrance } \\
\text { Channel* }\end{array}$ \\
\hline 30 August, 1970 & - & - & 341.593 \\
\hline 19 September, 1971 & - & - & 394,387 \\
\hline 30 June, 1972 & - & - & 346,000 \\
\hline 16 July, 1973 & - & - & 183,340 \\
\hline 31 August, 1974 & - & - & 160,361 \\
\hline 9 April, 1975 & - & - & 303,438 \\
\hline 30 June, 1976 & - & - & 156,366 \\
\hline 19 April, 1977 & - & - & 360,061 \\
\hline 13 March, 1978 & - & - & 761,523 \\
\hline 8 December, 1979 & 423,500 & 352,917 & 776,417 \\
\hline 10 January, 1982 & - & $1,016,000$ & $1,016,000$ \\
\hline 8 September, 1983 & 539,213 & 283,519 & 822,732 \\
\hline 14 May, 1986 & 437,889 & - & 437,889 \\
\hline 16 January, 1989 & 504,248 & 227,297 & 731,545 \\
\hline 21 April, 19911 & 288,466 & 288,466 & 576,932 \\
\hline 14 April, 1992 & 313,699 & 209,072 & 522,771 \\
\hline 26 February, 1995 & 755,307 & 332,000 & $1,087,307$ \\
\hline 14 June, 1997 & 489,211 & 397,121 & 886,332 \\
\hline 2 March, 1999 & 494,766 & 196,571 & 691,337 \\
\hline 2 January, 2001 & 314,474 & - & 314,474 \\
\hline 3 December, 2002 & 306,402 & 328,958 & 635,360 \\
\hline 1 February, 2005 & 277,997 & - & 277,997 \\
\hline 15 March, 2007 & 391,593 & - & 391,593 \\
\hline 19 May, 2009 & 197,512 & - & 197,512 \\
\hline 8 June, 2010 & 205,741 & - & 205,741 \\
\hline 18 March, 2011 & 345,077 & - & 345,077 \\
\hline 9 December, 2012 & 347,000 & - & 347,000 \\
\hline 29 May, 2014 & 304,629 & - & 304,629 \\
\hline
\end{tabular}

*Dredge locations were identified over the entire Entrance Channel, and it was assumed that volumes were split evenly between Jetty Channel and Outer Bar Channel. 
Table 3-2. Brazos Santiago Inlet Entrance Channel statistical measures.

\begin{tabular}{|l|c|c|c|c|}
\hline & Average & Standard Deviation & Minimum & Maximum \\
\hline Dredged volume per event $\left(\mathrm{yd}^{3}\right)$ & 484,847 & 267,556 & 156,366 & $1,087,307$ \\
\hline Interval between dredge events (year) & 1.62 & 0.66 & 0.61 & 2.87 \\
\hline Annual dredged volume $\left(\mathrm{yd}^{3}\right)$ & 327,085 & 173,910 & 90,568 & 847,427 \\
\hline
\end{tabular}

The cumulative volume dredged from the BSI Entrance Channel from 1970 to 2014 is shown in Figure 3-3. The $R^{2}$ value from linear regression is 0.99 , and the $p$-value is 0.010 , which is good correlation for cumulative dredging in the Entrance Channel. The estimated $r_{a}$ from linear regression is shown by the solid line in Figure 3-3 and represents 241,130 m3/year $(315,200 \mathrm{yd} 3 /$ year $)$. The median of dredge intervals is used to determine the nominal dredge interval because the $p$-value is less than 0.05; therefore, the nominal dredge interval is 1.72 years. Applying $r_{a}$ over the nominal dredge interval, an expected volume per dredging event is approximately 414,630 $\mathrm{m}^{3}(542,000 \mathrm{yd} 3)$.

The Entrance Channel was deepened in 1992, and Figure 3-3 indicates an increase in dredge volume between 1991 and 1992. However, subsequent dredging events follow the annual dredging rate, and deepening of the channel does not appear to have had a significant influence on the shoaling rate.

Figure 3-3. Cumulative volume dredged, Brazos Santiago Inlet Entrance Channel, 1970-2014.

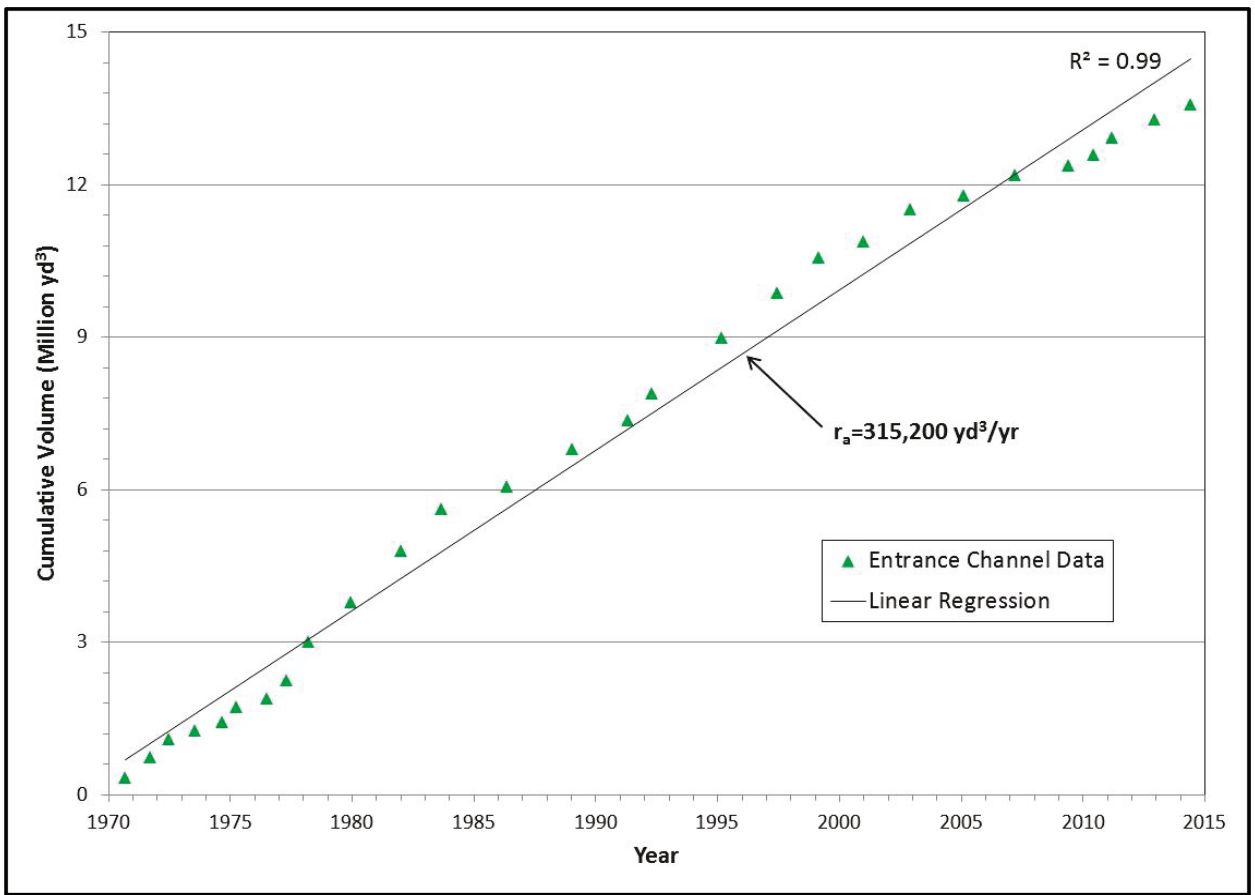


In the NSAT, risk is defined as quantification of the amount that dredging volume has historically varied. An empirical cumulative probability distribution function fit to the recorded maintenance dredging records by a normal distribution is shown in Figure 3-4. The cumulative probability distribution function covers the range of dredged quantities and indicates the probability that a given dredged quantity will be equal to or less than that quantity. For example, a 50\% probability exists that a single dredging event will be $372,550 \mathrm{~m}^{3}(487,000 \mathrm{yd} 3)$ or less. The expected dredging event of $414,630 \mathrm{~m}^{3}\left(542,000 \mathrm{yd}^{3}\right)$ is approximately $58 \%$.

Figure 3-4. Cumulative probability distribution function of Brazos Santiago Inlet Entrance Channel maintenance dredging quantities (normal distribution).

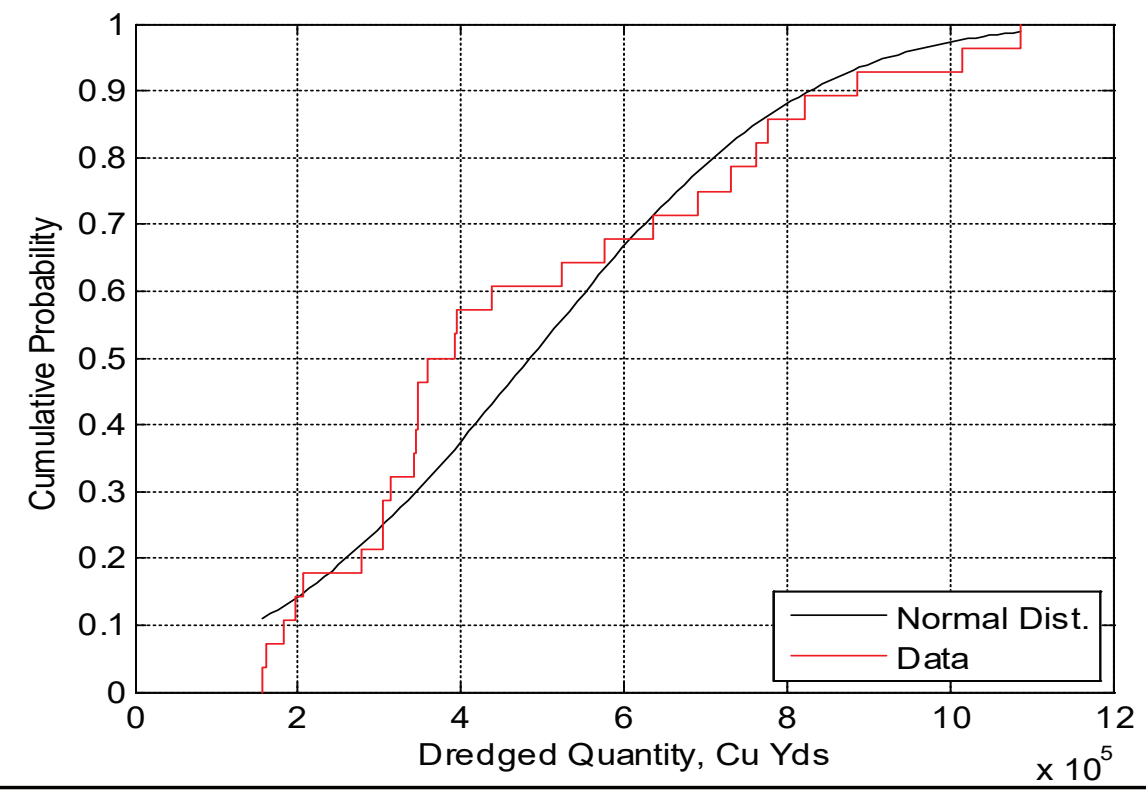

Figure 3-5 shows the Entrance Channel dredging interval plotted as a cumulative probability distribution function, which gives the likelihood of any given interval occurring. The interval is a function of shoaling rate (i.e., dredging must occur before the channel becomes impassable) but also is heavily dependent on funding, contracting requirements, and environmental windows ${ }^{1}$. The data are fit to a nonparametric distribution. Figure 3-5 indicates a probability of $55 \%$ that maintenance dredging will be required within the nominal interval of 1.72 years. There is approximately a $24 \%$ probability that maintenance dredging would be required in 1 year or less.

\footnotetext{
1 Thomas, R. C., and L. M. Dunkin. In preparation. U.S. Navy FCA Shoaling Study: Demonstration Project; Mayport, FL. Vicksburg, MS: U.S. Army Engineer Research and Development Center.
} 
Figure 3-5. Cumulative probability distribution function of Brazos Santiago Inlet Entrance Channel historical dredging interval (non-parametric distribution).

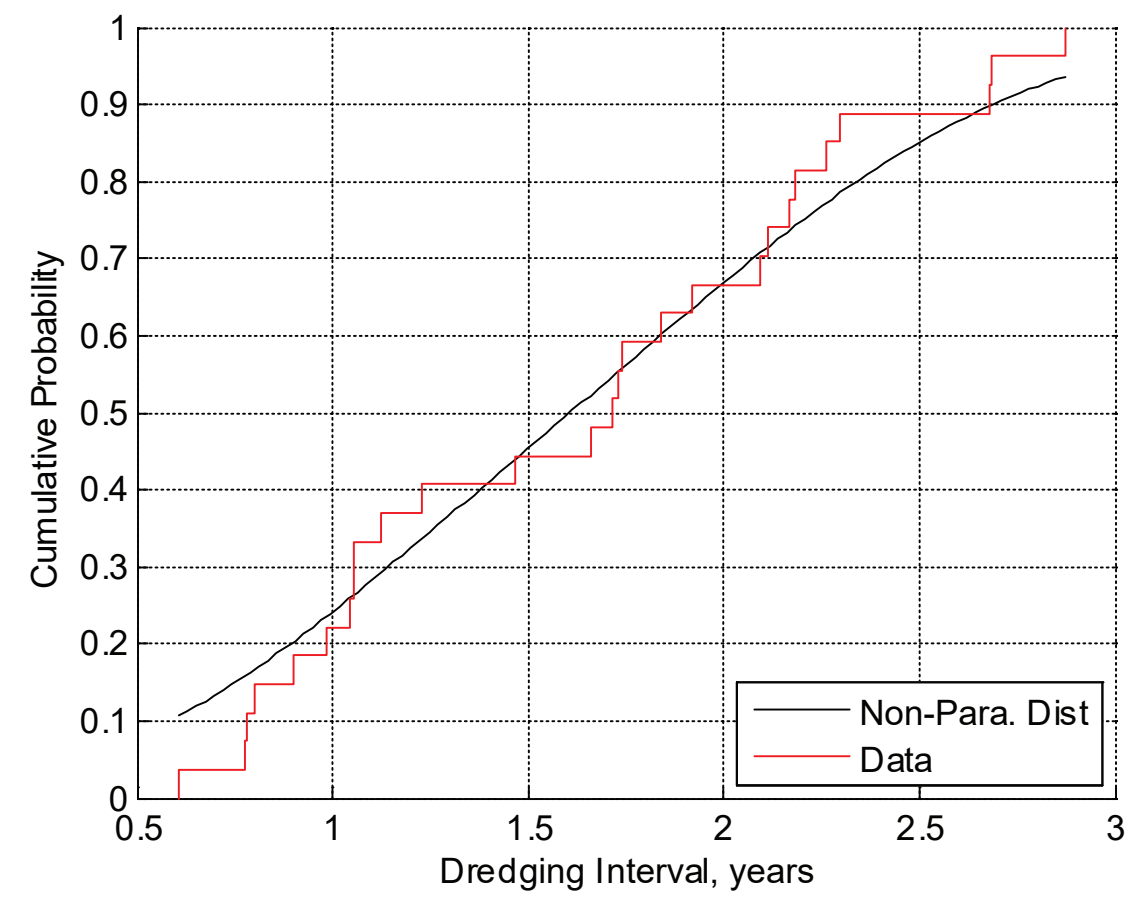

\section{Outer Bar Channel analysis}

The Outer Bar Channel was dredged less frequently than the Jetty Channel with 10 maintenance dredging events performed between 1979 and 2002 (Table 3-1). The total maintenance dredged volume from the Outer Bar Channel over this time period was 2.75 million $\mathrm{m}^{3}$ (3.60 million yd3). The average, standard deviation, minimum, and maximum dredged volume were calculated per dredging event, per dredging interval, and per year from the historical dredging records and are listed in Table 3-3.

Table 3-3. Brazos Santiago Inlet Outer Bar Channel statistical measures.

\begin{tabular}{|l|c|c|c|c|}
\hline & Average & Standard Deviation & Minimum & Maximum \\
\hline Dredged volume per event $\left(\mathrm{yd}^{3}\right)$ & 363,192 & 238,392 & 196,571 & $1,016,000$ \\
\hline Interval between dredge events (year) & 2.48 & 1.25 & 0.98 & 5.36 \\
\hline Annual dredged volume $\left(\mathrm{yd}^{3}\right)$ & 172,170 & 127,094 & 42,393 & 485,393 \\
\hline
\end{tabular}

Figure 3-6 shows the cumulative volume dredged from the Outer Bar Channel from 1979 to 2002. The $R^{2}$ value of 0.95 from linear regression shows good correlation for cumulative dredging, and the relationship is expected to predict future outcomes well. The solid line represents an $r_{a}$ of 
$97,920 \mathrm{~m}^{3} /$ year (128,000 yd3/year). However, the $p$-value is 0.806 , which is well above the significance level of 0.05. By definition, the relationship is not statistically significant (i.e., there is an $80.6 \%$ probability that the linear relationship in Figure 3-6 is not reliable). The high $p$-value is related to the relatively small sample size of 10 dredging events. In addition, the standard deviation is high for both dredged volume and dredging interval. Although the relationship is not statistically significant, a trend is present, particularly after 1990 (Figure 3-6). The average of dredge intervals is used to determine the nominal dredge interval because the confidence level was not met; therefore, the nominal dredge interval is 2.48 years. An expected volume per dredging event is approximately $242,810 \mathrm{~m}^{3}$ (317,400 yd 3 ) by applying $r_{a}$ over the nominal dredge interval. Despite having a nominal dredge interval of 2.48 years, the Outer Bar Channel did not require dredging from 2002 to 2015. The shoaling rate in the Outer Bar Channel does not appear to be influenced by deepening of the channel in 1992 (Figure 3-6).

Figure 3-6. Cumulative volume dredged, Brazos Santiago Inlet Outer Bar Channel, 1979-2014.

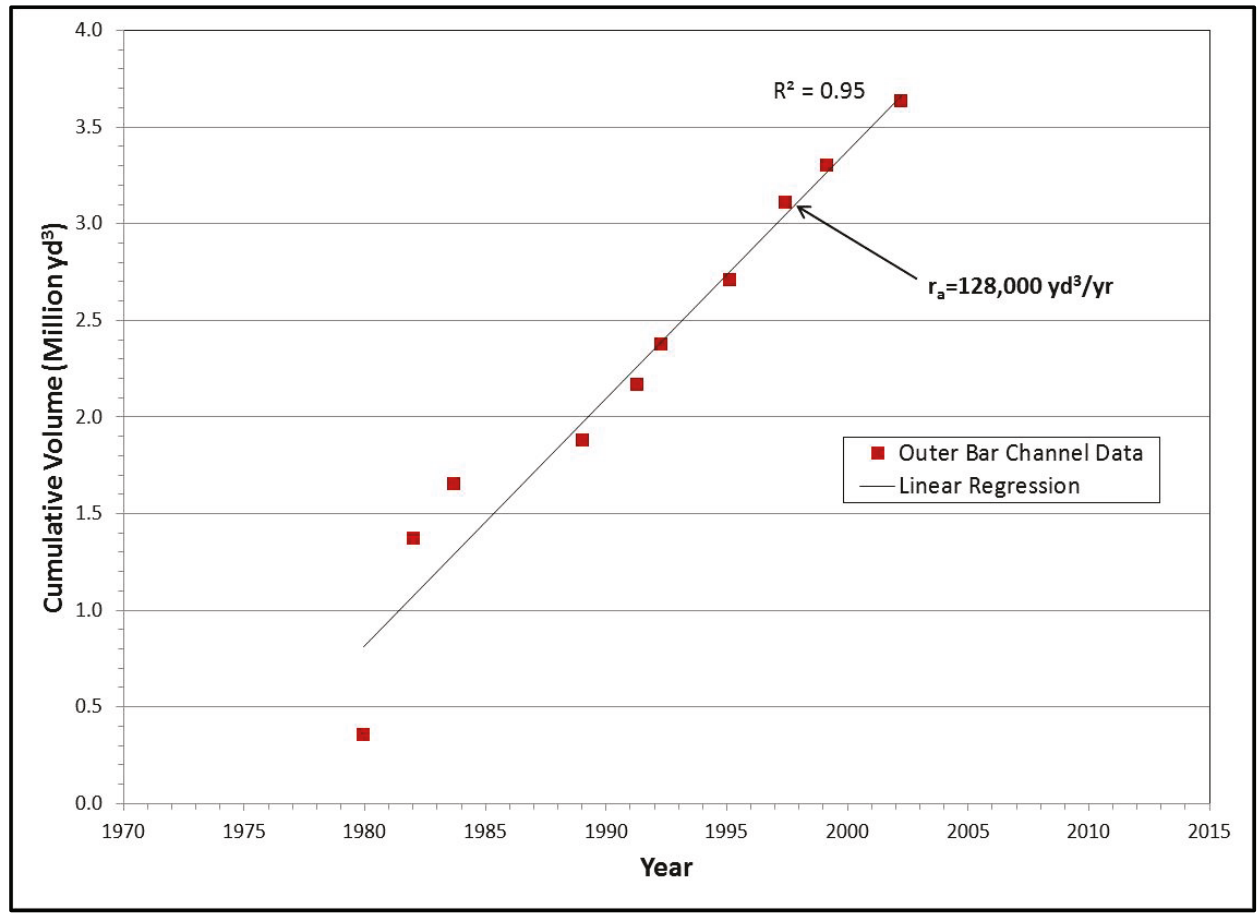

Although there are limited dredging events, an empirical probability distribution function covering the dredged quantities range was plotted and fit to the recorded maintenance dredging records by a normal distribution (Figure 3-7). The figure indicates that if a $50 \%$ probability 
exists, a single dredging event of up to $274,630 \mathrm{~m}^{3}(359,000 \mathrm{yd} 3)$ would occur. The expected dredging event of $242,810 \mathrm{~m}^{3}\left(317,400 \mathrm{yd}^{3}\right)$ is approximately $45 \%$; it is more likely that a dredging event will exceed the expected dredging event in the Outer Bar Channel.

Figure 3-7. Cumulative probability distribution function of Outer Bar Channel maintenance dredging quantities (normal distribution).

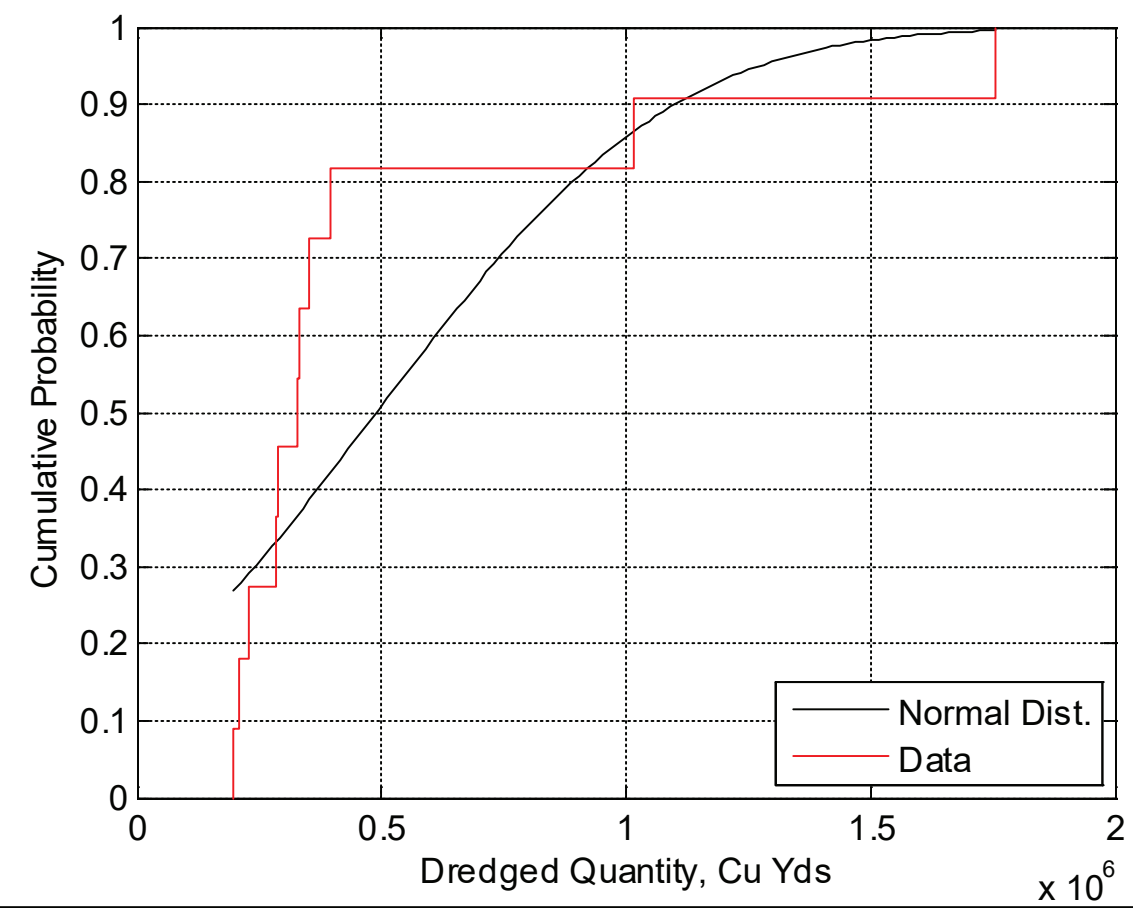

Figure 3-8 shows the dredging interval plotted as a cumulative probability distribution function, fit to a nonparametric distribution. Figure 3-8 indicates a probability of $59 \%$ that maintenance dredging will be required within the nominal interval of 2.48 years. There is approximately a $9 \%$ probability that maintenance dredging will be required in 1 year or less.

The statistical analysis was not strong for the Outer Bar Channel; however, only 10 events were available for analysis, and no dredging was performed in the channel between 2003 and 2014. This indicates the Outer Bar Channel remained navigable over the time period. 
Figure 3-8. Cumulative probability distribution function of Outer Bar Channel historical dredging interval (non-parametric distribution).

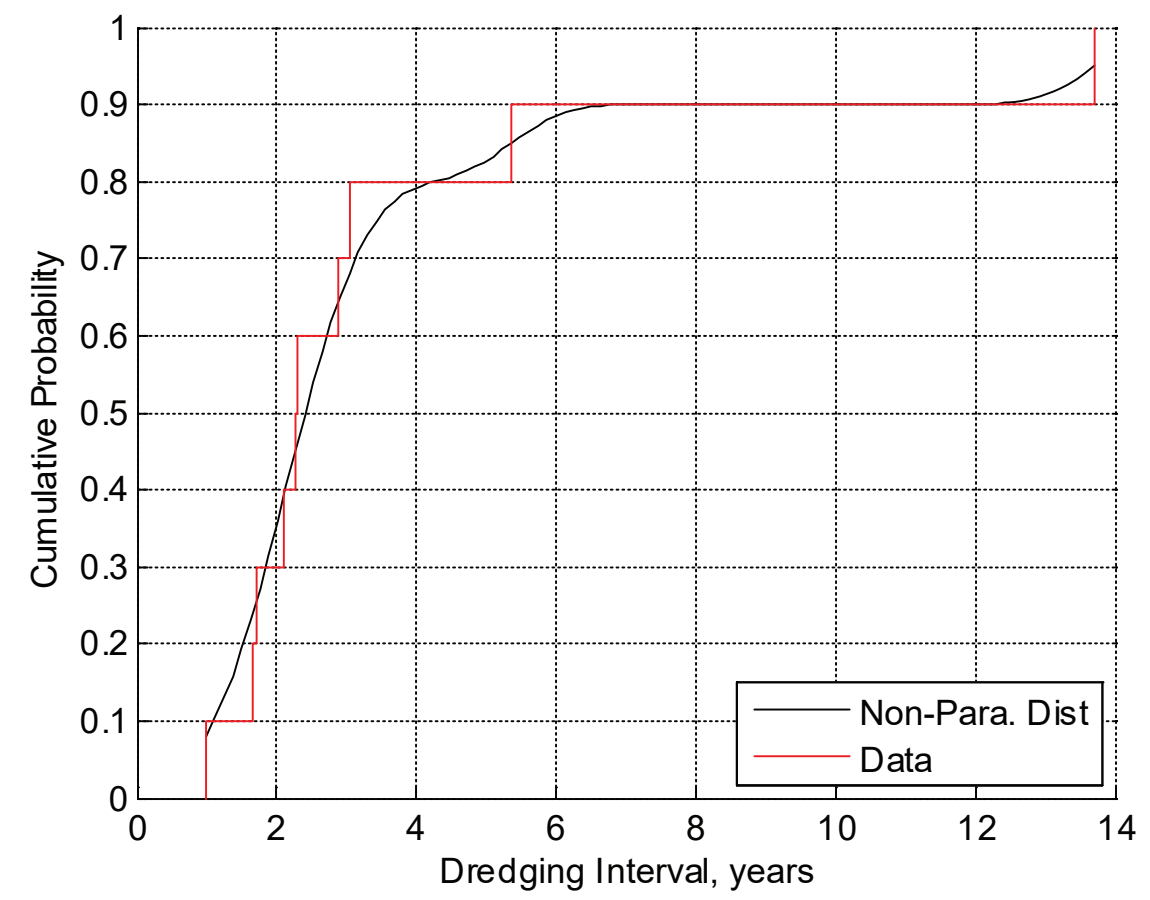

\section{Jetty Channel analysis}

Eighteen maintenance dredging events in the BSI Jetty Channel between 1979 and 2014 were provided for input into the analysis (Table $3-1$ ). The total maintenance dredged volume from the Jetty Channel over this time period was 5.3 million $\mathrm{m}^{3}$ (6.9 million $\mathrm{yd}^{3}$ ). The average, standard deviation, minimum, and maximum dredged volume were calculated per dredging event, per dredging interval, and per year from the historical dredging records, and are listed in Table 3-4.

Table 3-4. Brazos Santiago Inlet Jetty Channel statistical measures.

\begin{tabular}{|l|c|c|c|c|}
\hline & Average & Standard Deviation & Minimum & Maximum \\
\hline Dredged volume per event $\left(\mathrm{yd}^{3}\right)$ & 385,374 & 136,370 & 197,512 & 755,307 \\
\hline Interval between dredge events (year) & 2.03 & 0.74 & 0.78 & 3.75 \\
\hline Annual dredged volume $\left(\mathrm{yd}^{3}\right)$ & 205,210 & 84,965 & 90,568 & 445,064 \\
\hline
\end{tabular}

The cumulative volume dredged from the BSI Jetty Channel from 1979 to 2014 is shown in Figure $3-9$. The $R^{2}$ value from linear regression is 0.99 , and the $p$-value is 0.012 . This indicates good correlation for cumulative dredging in the Jetty Channel. The estimated $r_{a}$-value from linear 
regression is shown by the solid line in Figure 3-9 and represents $147,340 \mathrm{~m}^{3} /$ year $(192,600 \mathrm{yd} 3 /$ year). The median of dredge intervals is used to determine the nominal dredge interval because the $p$-value is less than 0.05; therefore, the nominal dredge interval is 2.12 years. Applying $r_{a}$ over the nominal dredge interval, an expected volume per dredging event is approximately $312,350 \mathrm{~m}^{3}\left(408,300 \mathrm{yd}^{3}\right)$.

Figure 3-9. Cumulative volume dredged, Brazos Santiago Inlet Jetty Channel, 1979-2014.

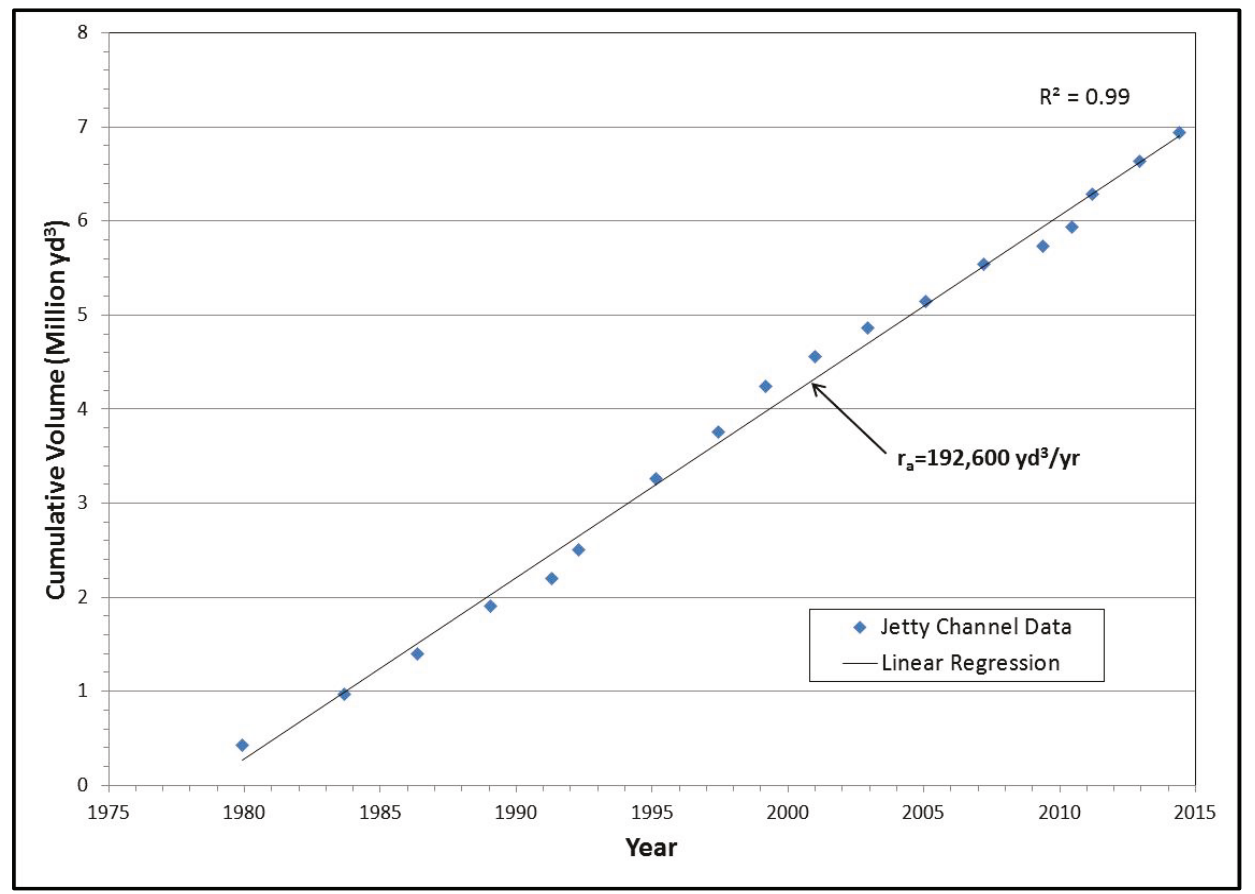

Deepening of the Jetty Channel in 1992 does not appear to have had a significant influence on the shoaling rate, based on $r_{a}$ in Figure 3-9. However, the dredge events prior to deepening (1979 to 1992) indicate a lower shoaling rate than the annual dredging rate. Dredging volumes for the Jetty Channel were available for only six events before channel deepening. It is not known if the trend is representative of the historical pre-deepening dredging rate or because of fluctuations in the historical rate due to other events. Therefore, no adjustment was made to the shoaling rate due to the 1995 channel deepening.

Figure 3-10 shows an empirical cumulative probability distribution function that covers the range of dredged quantities fit to the recorded maintenance dredging records by a normal distribution. The figure indicates a $50 \%$ probability exists that a single dredging event will be $298,350 \mathrm{~m}^{3}$ (390,000 yd3) or less. The expected dredging event of 312,120 $\mathrm{m}^{3}(408,000 \mathrm{yd} 3)$ is approximately $56 \%$. 
Figure 3-10. Cumulative probability distribution function of Jetty Channel maintenance dredging quantities (normal distribution).

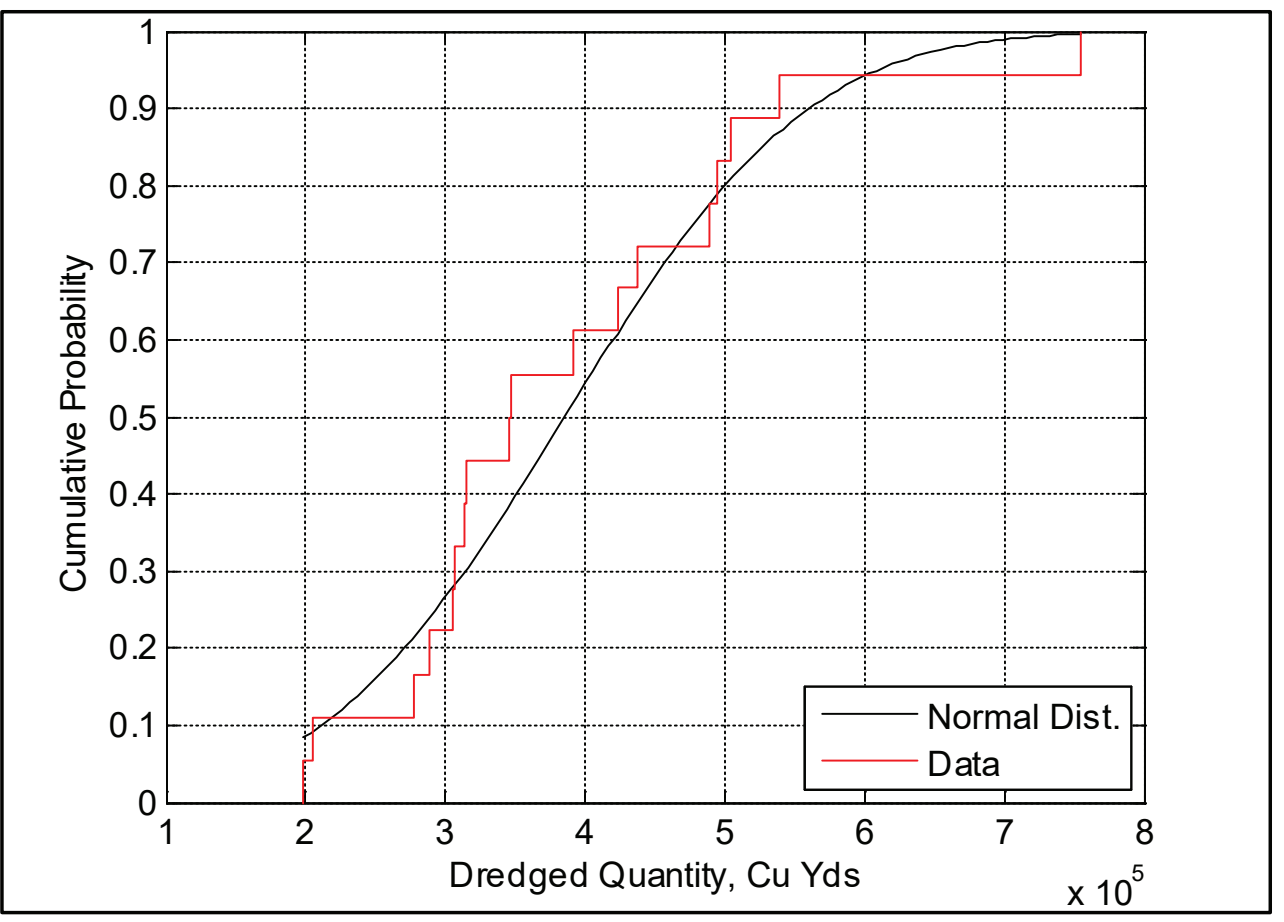

The dredging interval plotted as a cumulative probability distribution function, fit to a nonparametric distribution is shown in Figure 3-11. The figure indicates a probability of $55 \%$ that maintenance dredging will be required within the nominal interval of 2.12 years. There is approximately a $10 \%$ probability that maintenance dredging will be required in 1 year or less.

The analysis indicates the annual shoaling rate between 1979 and 2014 follows a linear trend (Figure 3-9). However, Table 3-1 indicates the volume dredged has been less than the expected dredging event volume of $312,120 \mathrm{~m}^{3}$ (408,000 $\mathrm{yd}^{3}$ ) since 1999 (i.e., the need to dredge the Jetty Channel occurs more frequently than expected). This also is reflected by Figure 3-9 that shows more frequent dredging in recent years. Figure 3-12 presents dredging intervals in years from 1995 to 2014. The nominal dredging interval from the analysis is shown as the horizontal solid line. Points that fall below the nominal interval indicate more frequent dredging. Seven of the last ten dredging events have occurred more frequently than the nominal interval. The four dredging events since 2009 have all been more frequent than the nominal interval. 
Figure 3-11. Cumulative probability distribution function of Jetty Channel historical dredging interval (non-parametric distribution).

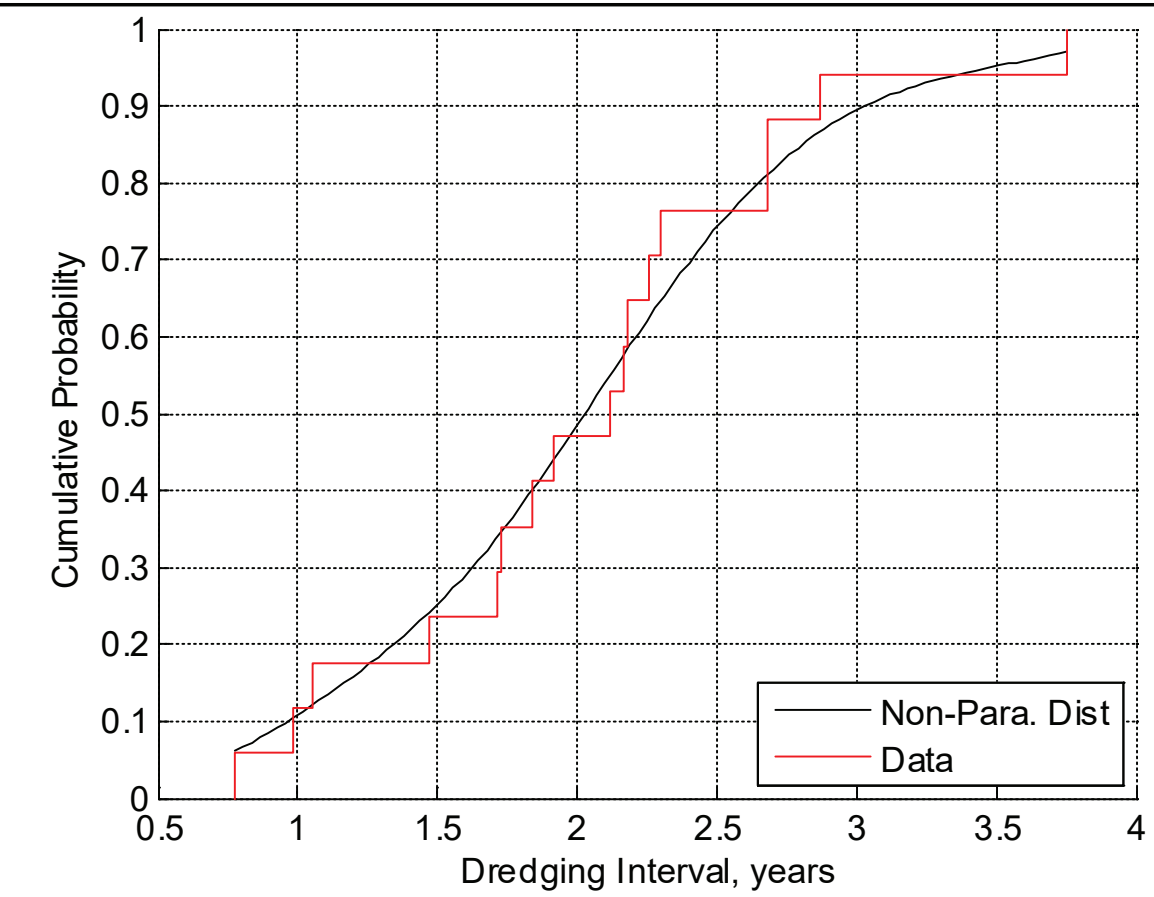

Figure 3-12. Frequency of Brazos Santiago Inlet Jetty Channel dredging.

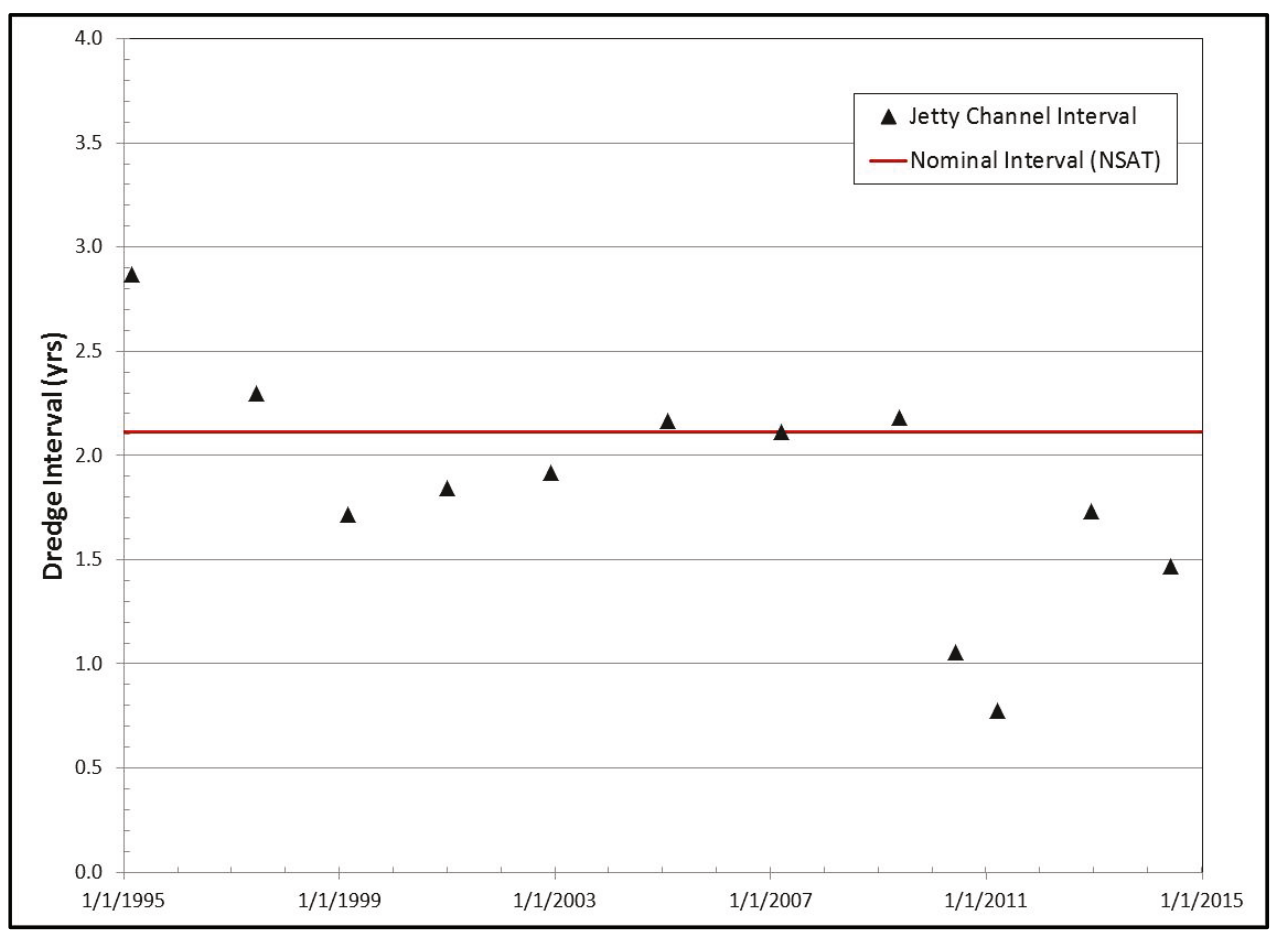




\section{Shoaling analysis summary}

The analysis indicates that a linear dredging rate of $147,340 \mathrm{~m}^{3}$ $(192,600 \mathrm{yd} 3)$ in the Jetty Channel corresponds with the historical data and also agrees with findings of HDR (2009) from an evaluation of shoaling in the BSI. This implies that the frequent need to dredge is related to relatively small areas of localized channel shoaling that reduce the navigable depth at these locations and is not necessarily based on the total volume of material infilling the Jetty Channel. The emergency dredging operation that was conducted in 2014 indicates that localized channel shoaling is centered on -2+200 (Figure 3-2). Localized dredging could be an important factor in understanding historical trends, especially if the sediment volume and deposition areas migrate over time.

HDR (2009) suggested several possible alternatives to reduce the problematic shoaling in the BSI, including (1) dredging the Outer Bar Channel during dredging of the Jetty Channel, (2) lengthening one or both jetties to reduce the ability of sediment to enter the channel by longshore transport, (3) artificial sand bypassing, or (4) narrowing the channel at Dolphin Cove to increase current speed, although HDR (2009) states this approach alone may lead to shoaling elsewhere in the channel. 


\section{Field Data Collection}

\section{Regional tide, wind, and wave measurements}

Measurements of wind, water level, and waves were obtained from National Oceanic and Atmospheric Administration (NOAA) and Texas Coastal Ocean Observation Network (TCOON) stations within and offshore of Laguna Madre (Figure 4-1). Wind and water level data were collected from the following Laguna Madre TCOON stations: South Padre Island Coast Guard Station (26.0726 ${ }^{\circ} \mathrm{N}, 97.1674^{\circ} \mathrm{W}$; TCOONo51), Realitos Peninsula (26.0683 ${ }^{\circ} \mathrm{N}, 97.1667^{\circ} \mathrm{W}$; TCOON181), Port Mansfield $\left(26.565^{\circ} \mathrm{N}, 97.430^{\circ} \mathrm{W}\right.$; TCOONo17), and Rincon del San Jose $\left(26.8015^{\circ} \mathrm{N}\right.$, $97.4706^{\circ} \mathrm{W}$; TCOONoO3). Water levels were referenced to NAVD88. In addition to hourly water level, the Realitos station recorded wind speed and direction. Data were downloaded from the NOAA online server for the period spanning January 2010 through August 2014. The website does not provide data for download beyond August 2014.

Wave data were collected from NOAA buoy $42020\left(26.968^{\circ} \mathrm{N}, 96.694^{\circ} \mathrm{W}\right)$ located approximately $108 \mathrm{~km}$ (67 miles) northeast of the BSI entrance in $80 \mathrm{~m}$ (26o ft) water depth, as this was the only continually operating buoy along the south Texas coast. The output includes significant wave height, average period and average wave direction in 10-minute ( $\mathrm{min}$ ) intervals. The data underwent quality assurance/quality control prior to posting on the server, and the system labels suspect data with a value of 999. All suspect data were removed from the record prior to analysis.

\section{Field data collection, 2014-2015}

Wave, tide, and current sensors were deployed between August 2014 and September 2015 in Laguna Madre and offshore of the BSI as part of an intensive field monitoring campaign to characterize the local hydrodynamic regime and to provide validation data for CMS.

\section{Tide gages}

Tide gages were deployed at four locations within Laguna Madre (Figure 4-1). Three were deployed in the northern section of the lagoon including the entrance channel at Mansfield Pass. Their locations are the following: Mansfield Pass $\left(26.5642^{\circ} \mathrm{N}, 97.2768^{\circ} \mathrm{W}\right.$; TIDE1), North of Mansfield Pass (26.6757 $\mathrm{N}, 97.4383^{\circ} \mathrm{W}$; TIDE2), and South of Mansfield 
Pass $\left(26.4146^{\circ} \mathrm{N}, 97.3488^{\circ} \mathrm{W}\right.$; TIDE3). The fourth, Brownsville $\left(25.9549^{\circ} \mathrm{N}, 97.3949^{\circ} \mathrm{W}\right.$; TIDE4) was deployed at the terminus of the Brownsville Ship Channel. The gages recorded water level at $6 \mathrm{~min}$ intervals and were georeferenced to the Port Isabel and Packery Channel shore-based benchmarks. All water levels were referenced to NAVD88 and corrected for barometric pressure.

Figure 4-1. Location of hydrodynamic measurements. TCOON gages are represented by red symbols, and $\mathrm{CHL}$ gages are represented by green symbols. Teardrop symbols are water level gages, and circular symbols are Acoustic Wave and Current (AWAC) profilers (from Google Earth https://www.google.com/earth/).

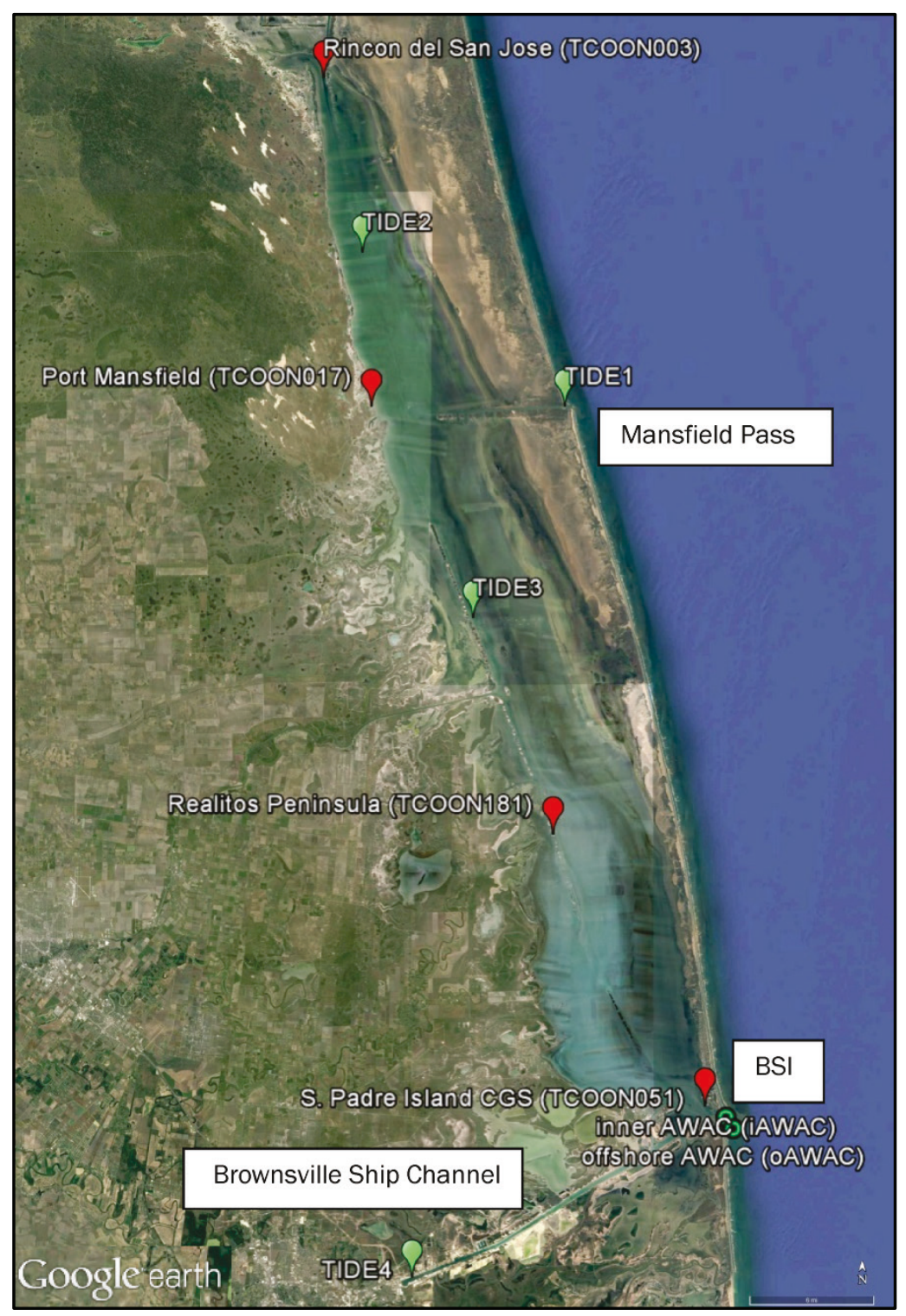




\section{Currents}

Bottom mounted Acoustic Wave and Current (AWAC) profiles were deployed at the BSI between the jetties (inner AWAC [iAWAC]) and offshore of the south jetty (offshore AWAC [oAWAC]) (Figure 4-1). The AWACs measured current profiles in $1 \mathrm{~m}$ (3.28 ft) bins for a 2 min burst every $10 \mathrm{~min}$. The average water depth measured by the AWACs was $13 \mathrm{~m}$ $(42.6 \mathrm{ft})$ in the inlet and $7 \mathrm{~m}(23.0 \mathrm{ft})$ offshore. Depth averaged currents for each velocity component were computed as

$$
U_{i}=\frac{1}{h} \int_{0}^{h} u_{i} d z
$$

where $u_{i}$ is the velocity, $h$ is the water depth, $z$ is the vertical coordinate, and $i$ denotes a velocity component (e.g., east, north, along-shore, alongchannel).

The AWAC has a fourth vertical beam to measure wave height and uses the phasing between the other three slanted beams to compute wave direction. The manufacturer's processing software calculates wave height, period, and direction every hour. Descriptions of the processing algorithms for the wave parameters are provided by Nortek and can be accessed from their website $^{1}$. Significant wave height $\left(H_{m o}\right)$, average wave period $(T)$, and average wave direction $\left(\phi_{w}\right)$ are reported in this technical report.

\section{Waves}

The wave information is used to compute the bottom orbital velocity and excursion amplitude. From linear wave theory, the maximum bottom orbital velocity $\left(U_{b}\right)$ is written as

$$
U_{b}=\frac{H_{m 0} \omega}{2 \sinh (k h)}
$$

where $\omega(=2 \pi / T)$ is the radian frequency and $k$ is the wavenumber (e.g., Dean and Dalyrmple [1991]). The wavenumber is computed from the dispersion relationship for linear waves

\footnotetext{
${ }^{1}$ www.nortek-as.com/lib/brochures/datasheet-awac
} 


$$
\omega^{2}=g k \tanh (k h)
$$

where $g$ is the acceleration due to gravity. The wave bottom excursion amplitude $\left(A_{b}\right)$ is defined as

$$
A_{b}=U_{b} / \omega
$$

Because waves are responsible for sediment mobilization, $U_{b}$ and $A_{b}$ are appropriate metrics to characterize the relative sediment transport potential.

Local winds were acquired from NOAA monitoring station (PT1T2) located at Port Isabel, TX (26.061N 97.215W). The output includes wind speed and direction recorded every $10 \mathrm{~min}$.

\section{Bed sediments}

The samples from Laguna Madre, the BSI, and South Beach were analyzed and reported in the same manner. Analysis is broken down by size as described by the Wentworth Scale shown in Table 4-1 for grain size classification. Additionally the D10, D16, D50, D84, and D90 grain sizes were determined for each sample.

Table 4-1. Wentworth Scale.

\begin{tabular}{|l|l|l|}
\hline Size in Microns & Classification & Abbreviation \\
\hline Between 1 and 4 & Clay & clay \\
\hline Between 4 and 62 & Silt & silt \\
\hline Between 62 and 125 & Very Fine Sand & vf_sand \\
\hline Between 125 and 250 & Fine Sand & f_sand \\
\hline Between 250 and 500 & Medium Sand & md_sand \\
\hline Between 500 and 1,000 & Coarse Sand & C_sand \\
\hline Between 1,000 and 2,000 & Very Coarse Sand & vc_sand \\
\hline Between 2,000 and 4,000 & Gravel & gravel \\
\hline Between 4,000 and 64,000 & Pebble & pebble \\
\hline
\end{tabular}

Particle size spectra are particularly useful in indicating bimodal size populations or changes in size distributions between samples. The particle size spectrum indicates the spectral density versus particle diameter. Spectral density is the fraction of sediment mass, volume, count, or surface 
area divided by the bin width in $\log$ space or $S_{i}=\frac{f_{i}}{\Delta \log _{10}(D)}$, where $S$ is the spectral density, $f$ is the fraction of sediment within the $i^{\text {th }}$ bin, and $D$ is the sediment diameter. Presented in this manner, the sediment size spectrum integrates to one when the sediment diameter is plotted with logarithmic scaling.

A total of 58 bed samples were taken within the study area (Figure 4-2). The samples were acquired using a mechanical sediment sampler that was deployed via electric wench and dragged along the bottom. The recovered samples represent the surface layer (upper 5 to 10 centimeters) (upper 2 to 4 inches [in.]) of the bed. Each sample was analyzed for grain size distribution, classification (e.g., silt, clay, medium sand) and size class. Sample location and classification data are listed in Appendix B.

Figure 4-2. Sediment sample locations (from Google Earth https://www.google.com/earth/).

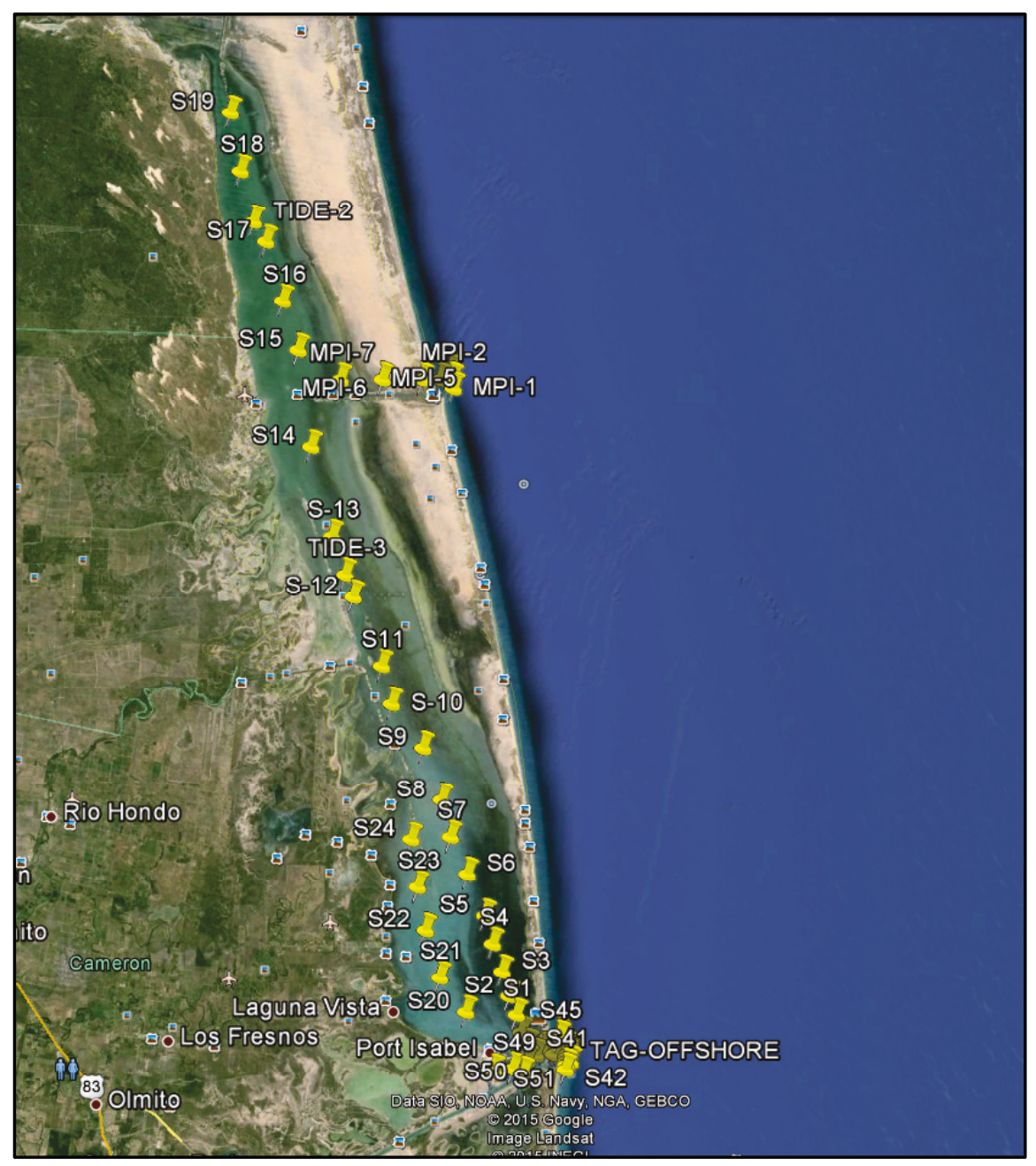




\section{Results}

Results focus on the regional conditions within Laguna Madre and measurements collected between August 2014 and August 2015 during an intensive monitoring effort to quantify the hydrodynamics of the BSI Navigation Channel and Laguna Madre. The regional conditions are discussed first to place the field data collection effort in the context of the broader south Texas coast climatology.

\section{Regional conditions}

Winds. Wind speed and direction derived from the Realitos TCOON station located in Laguna Madre are depicted in Figure 4-3. Time series includes hourly data and 2-day low-pass filter to elucidate the synoptic band and seasonal trends. Wind speed variability is associated with local frontal passages and other meteorological forcing. Wind speed is high in this area as the low-pass magnitude is generally greater than $5 \mathrm{~m} /$ second (s) $(16.4 \mathrm{ft} / \mathrm{s})$. The South Texas coast is known for strong southeasterly winds, particularly in the summer, due to Gulf air originating offshore. Wind direction is out of the southeast for most of the spring/summer then switches to easterly and in some years northerly directions during the late fall and winter.

Figure 4-3. Time series of wind speed and direction.
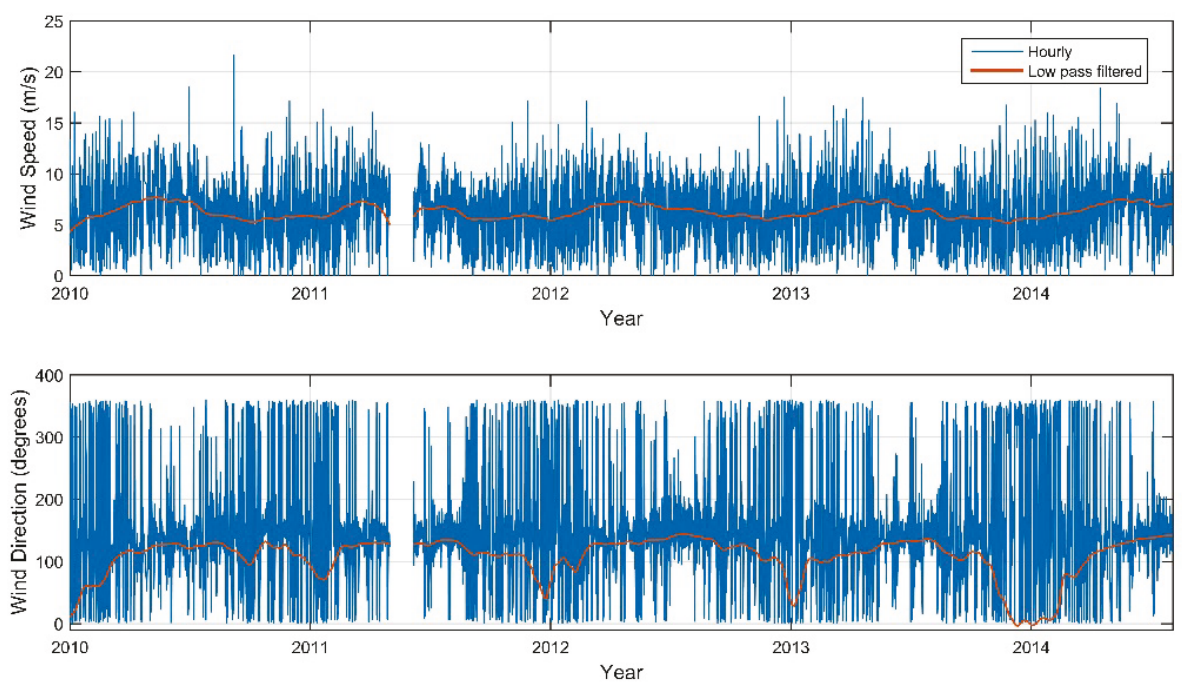
The wind speed spectrum shows peaks at the diurnal and semi-diurnal band, which represents sea breeze and the first higher harmonic (Figure 4-4).

Figure 4-4. Wind speed spectrum.

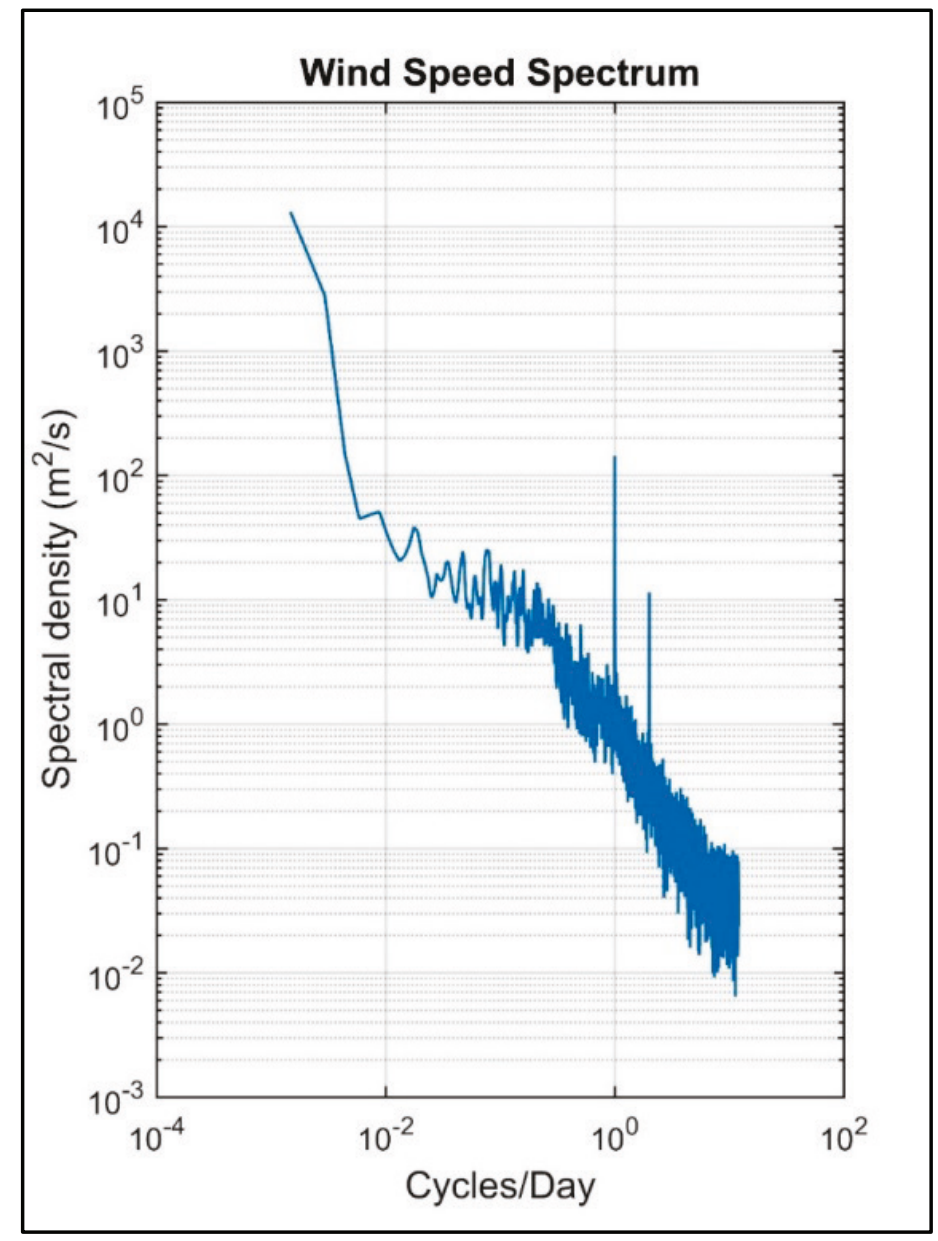

Sea level. Low-pass filtered water surface elevation (WSE) derived from TCOON locations in Laguna Madre reveal a seasonal cycle with higher than average elevations between late spring and fall and lower than average in the winter (Figure 4-5). The cycle is a result of seasonal wind forcing, which switches from persistent southeasterly winds in the spring/summer to weaker and variable winds in the winter. During spring/summer, southeasterlies cause setup along the coast and in the bay, increasing overall water elevations. The lagoon axis is oriented north/northeast, so southeasterly winds push water to the north causing the sea surface to slope upward in the long, shallow bay towards Rincon. Beginning in the latter half of the year and continuing into winter, sea level relaxes at all stations in the absence of strong southerly winds and 
generally weaker forcing. Winds rotate and become easterly or northeasterly. Sea surface slope in the bay reverses in response to the change in wind direction causing elevations to be higher at South Padre Island (SPI).

Figure 4-5. Time series of low-pass filtered winds and WSE.

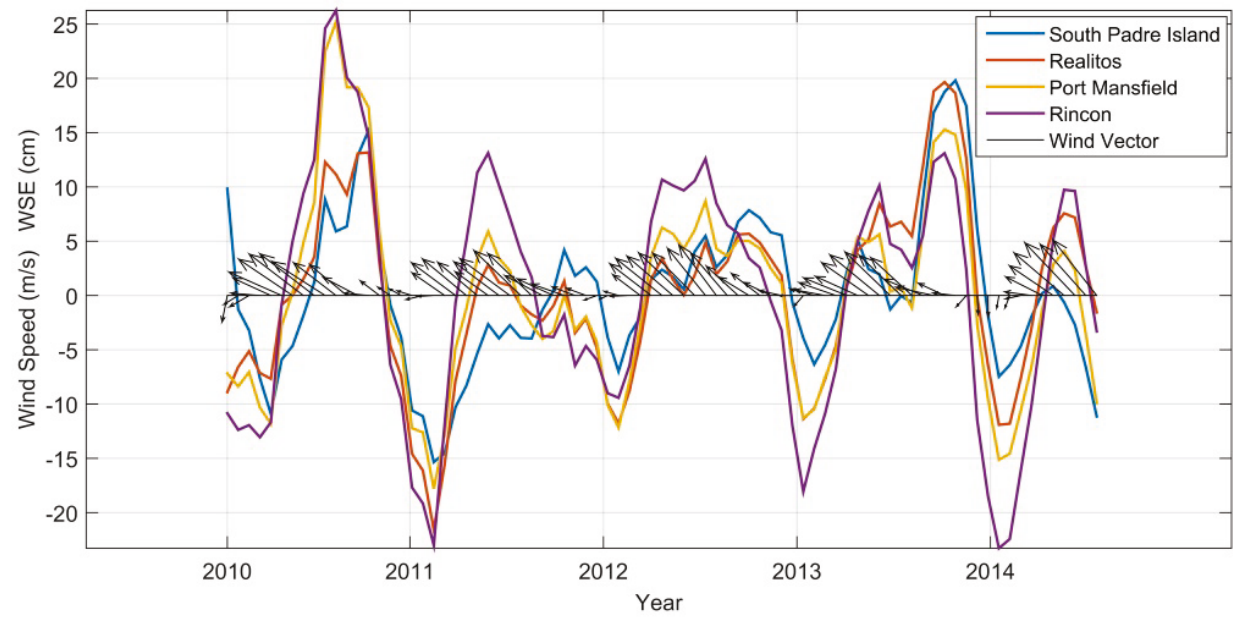

To further elucidate the relationship between wind direction and sea surface slope in the bay, Figure 4-6 depicts the difference in WSE between Rincon and SPI as a function of wind direction. A positive elevation difference indicates that water levels at Rincon are higher than SPI. For wind directions less than $90^{\circ}$ (out of the east or northeast), SPI is higher than Rincon indicating setup in lower Laguna Madre. As the wind rotates to produce southeasterly winds, setup in the bay is reversed with higher elevations at Rincon.

Waves. Wave measurements are derived from NOAA buoy 42020 located $108 \mathrm{~km}$ (67 miles) northeast of the BSI entrance. The record contains 10+ years of hourly wave directional data to compute climatology for the south Texas coast. Waves are primarily out of the southeast in agreement with climatological wind patterns for this area (Figure 4-7). These waves generally have heights between 0.5 and $3 \mathrm{~m}$ (1.6 and $10 \mathrm{ft}$ ). While much fewer in numbers, the percentage of the highest waves tends to be more uniform over each directional bin. Therefore, the area experiences a wave climate consisting of primarily 0.5 to $3.0 \mathrm{~m}$ ( 1.6 to $10 \mathrm{ft}$ ) waves out of the southeast but the highest waves $(\sim>6 \mathrm{~m}[20 \mathrm{ft}])$ are distributed across all offshore angles. Given the approximate north-south orientation of the south Texas coastline, the net wave-driven longshore transport is towards the north. 
Figure 4-6. Low-pass filtered sea surface elevation difference between Rincon and SPI as a function of wind direction.

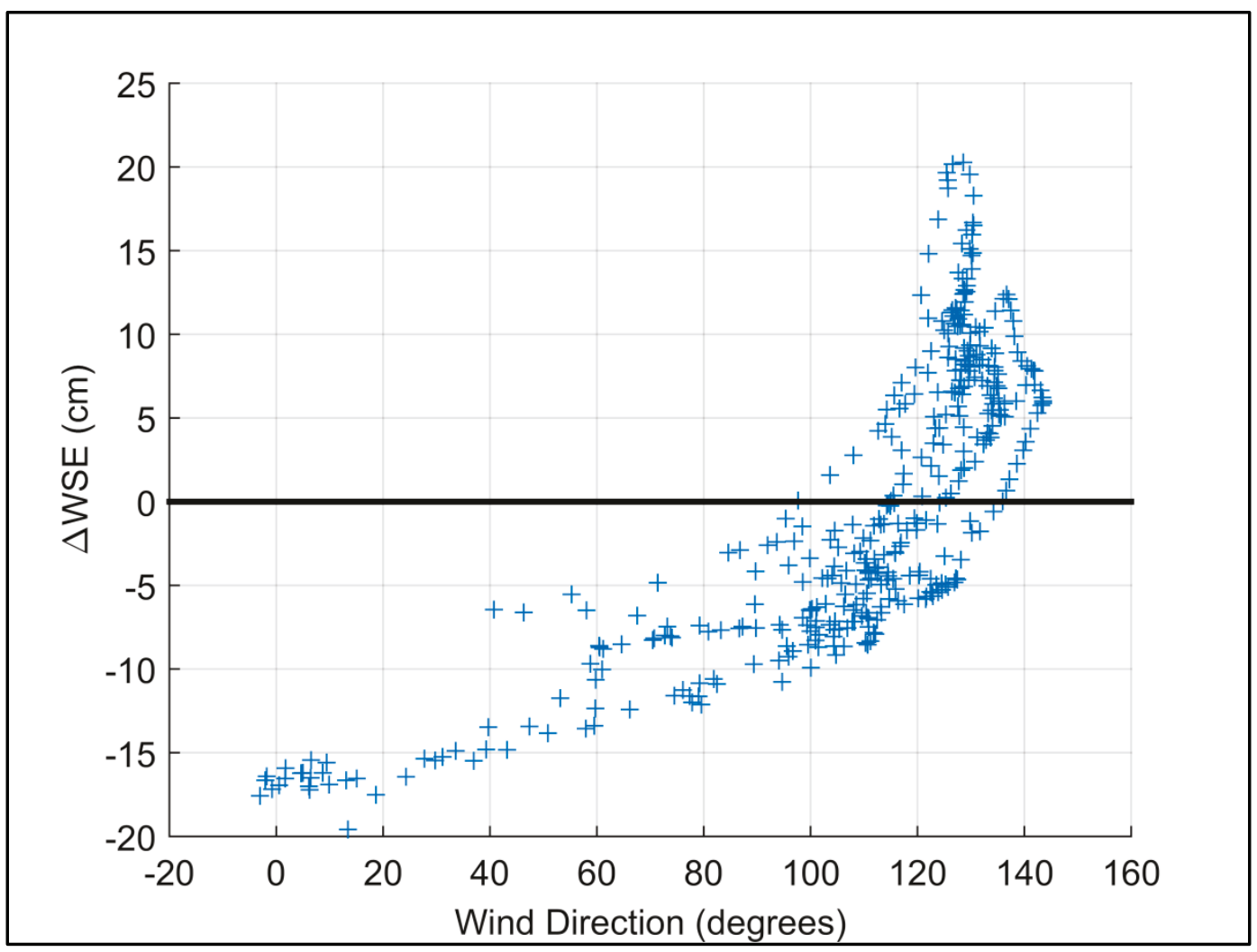

Figure 4-7. Wave climatology for south Texas coast. Color bar denotes wave height in meters.

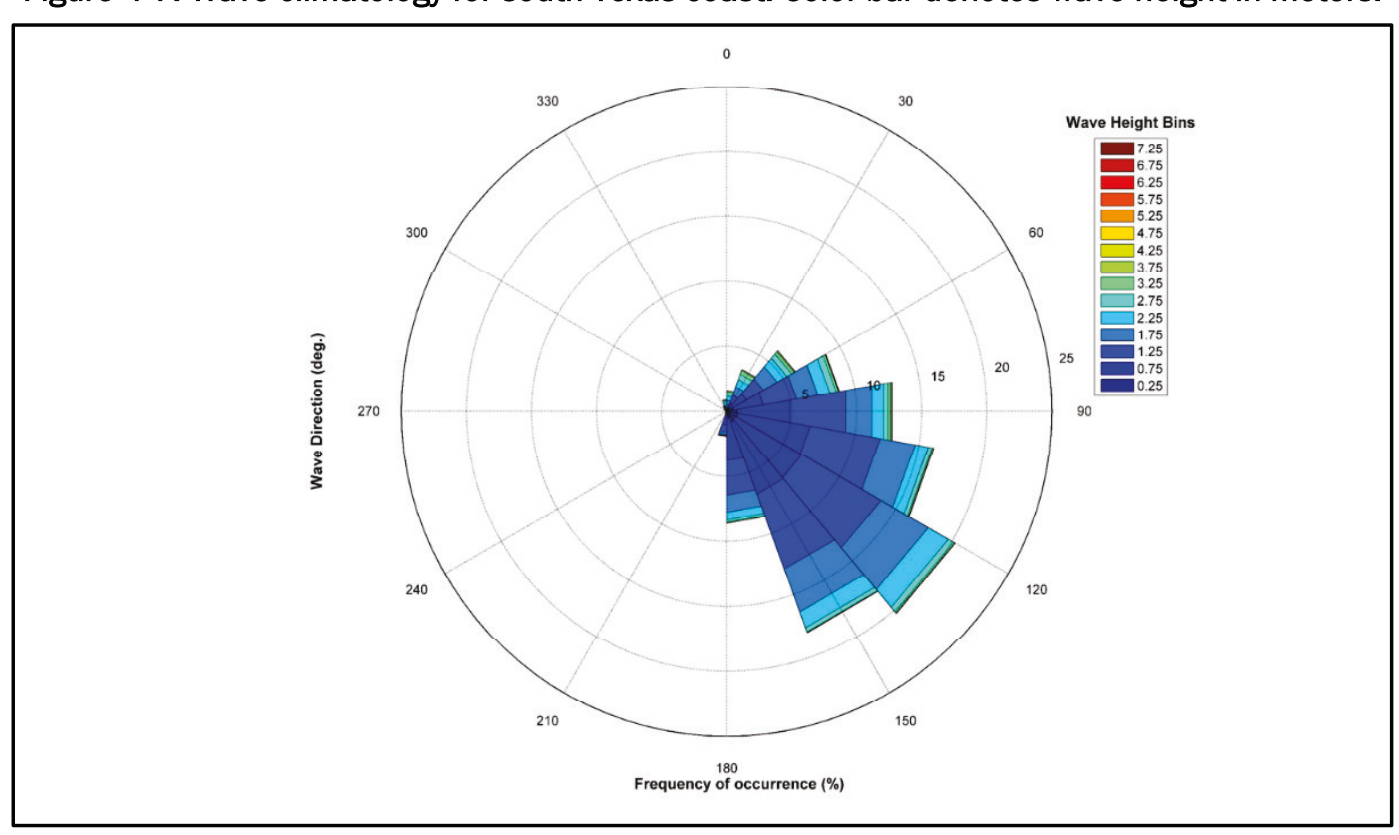


The wave directional distribution peaks at $135^{\circ}$ in agreement with the wave climatology (Figure 4-8). Wave height shows less than $1 \%$ exceedance for waves greater than $3.5 \mathrm{~m}(11.5 \mathrm{ft})$ and for directions greater than $210^{\circ}$. This is consistent with waves arriving from offshore and is in agreement with the polar plot signifying the majority of waves arrive from the southwest. The wave height distribution indicates $90 \%$ of waves are less than $2.5 \mathrm{~m}(8.2 \mathrm{ft})$ with the highest percentage between 0.75 and $1.5 \mathrm{~m}$ $(2.5$ and $4.9 \mathrm{ft})$. Ninety percent of average wave periods are less than $7 \mathrm{~s}$ with a peak at $5 \mathrm{~s}$.

Figure 4-8. Wave statistics for the south Texas coast. (A) wave direction, (B) wave height, and (C) average wave period.

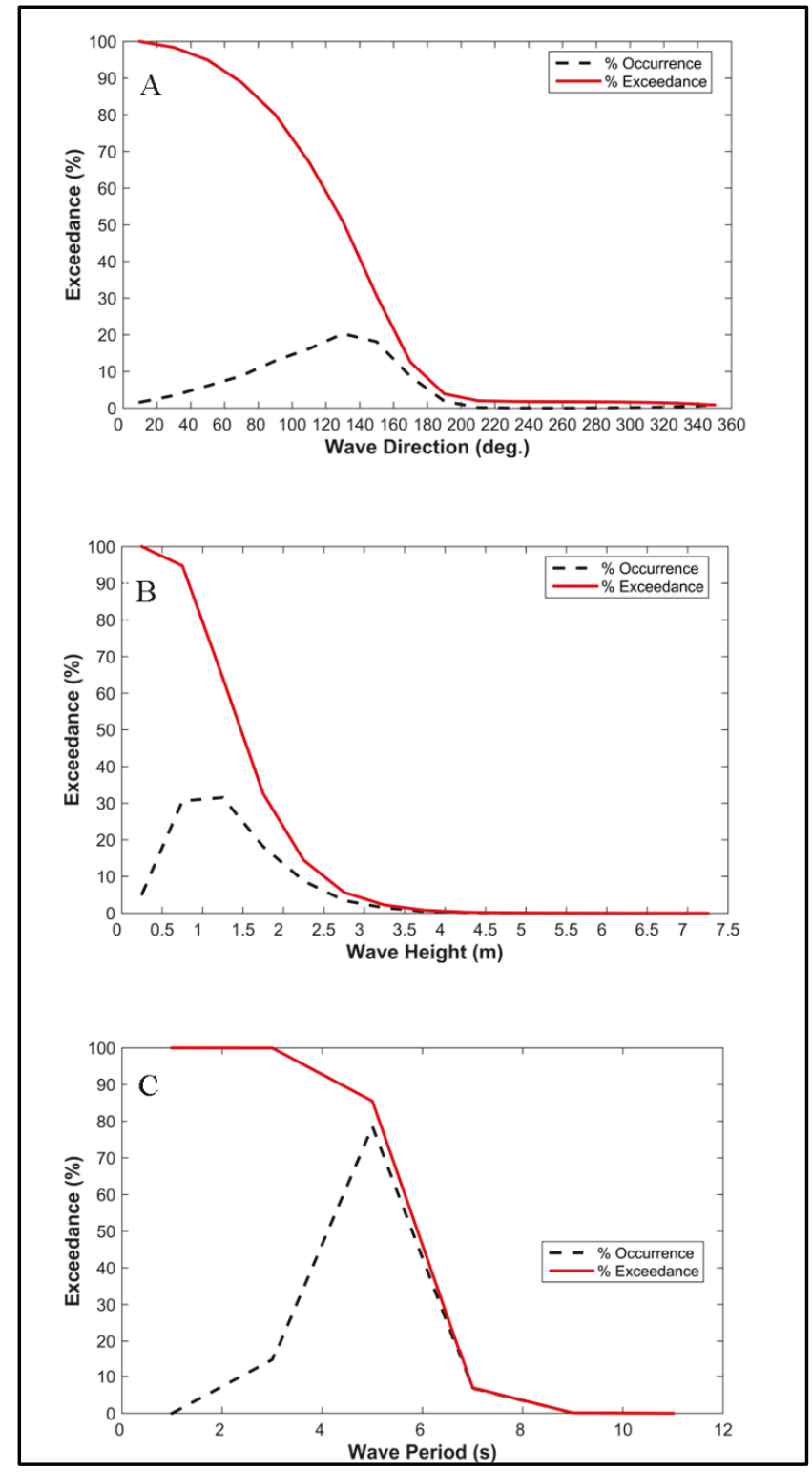




\section{Field Study, 2014-2015}

Winds. Local winds are predominantly out of the southeast with a secondary component out of the north (Figure 4-9). The north-south orientation of the south Texas coast means the predominant winds form an acute angle with a mean of approximately $30^{\circ}$ to the coast. This alignment favors wind-driven alongshore currents and associated setup and setdown along the coast via Ekman transport. The winds are also directed along the main axis of Laguna Madre and likely influence water surface slope and transport within the bay.

Figure 4-9. Wind vectors for south Texas coast.

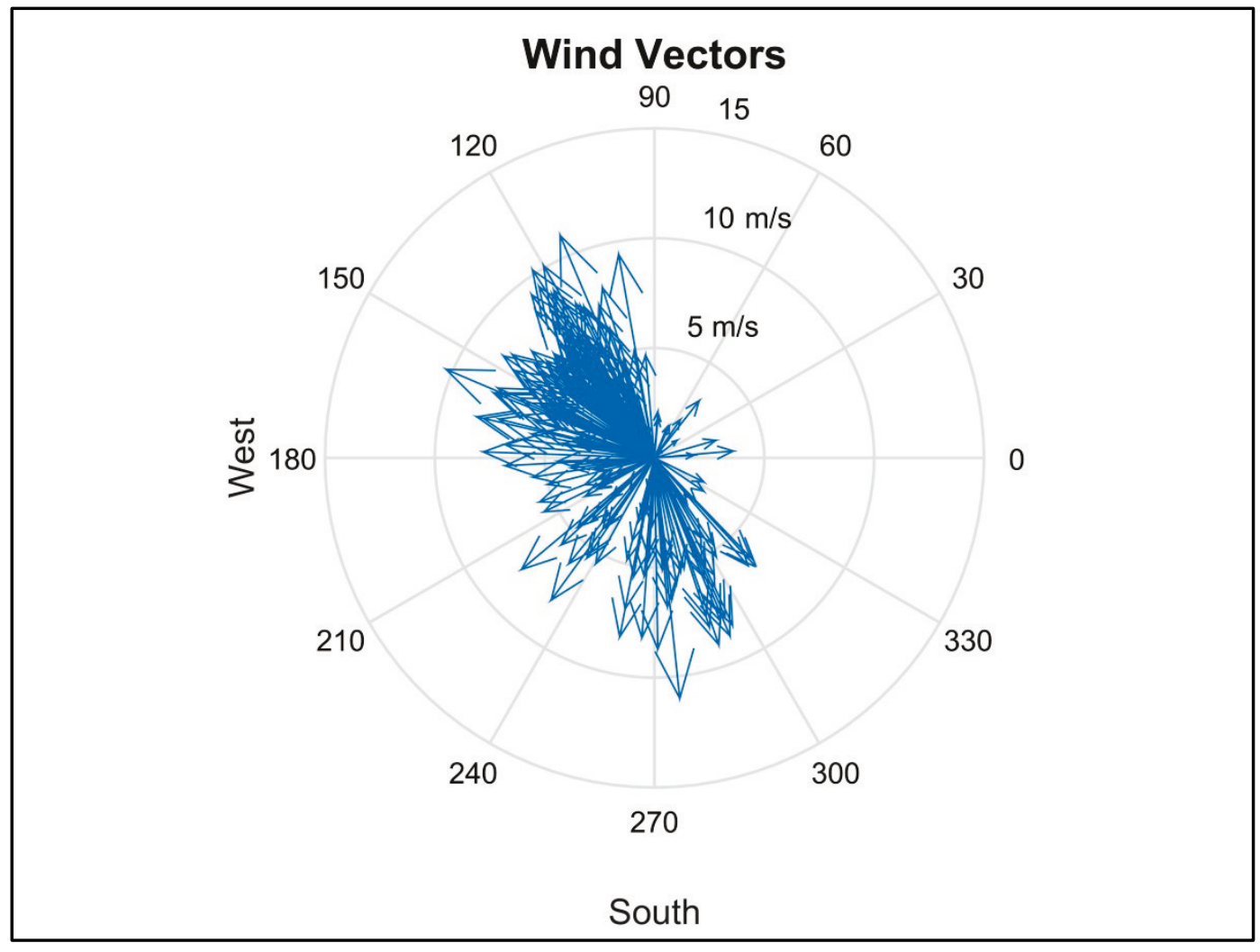

Low-pass filtered wind speed and direction show a pattern consistent with the long-term wind climatology (Figure 4-10). Between August 2014 and January 2015, wind speed decreases and winds shift from the southeast to the north. During the winter, the winds remain weak and are primarily from the north/northeast. In March 2015, wind speeds start to increase and rotate towards the southeast. The southeast winds persist through September 2015 and show higher speeds of over $4 \mathrm{~m} / \mathrm{s}(13 \mathrm{ft} / \mathrm{s})$. 
Figure 4-10. Low-pass filtered wind speed and direction. The axis displaying wind direction is in meteorological coordinates (North $\mathrm{N}^{\circ}$ ) and denotes the direction from which the winds are coming.

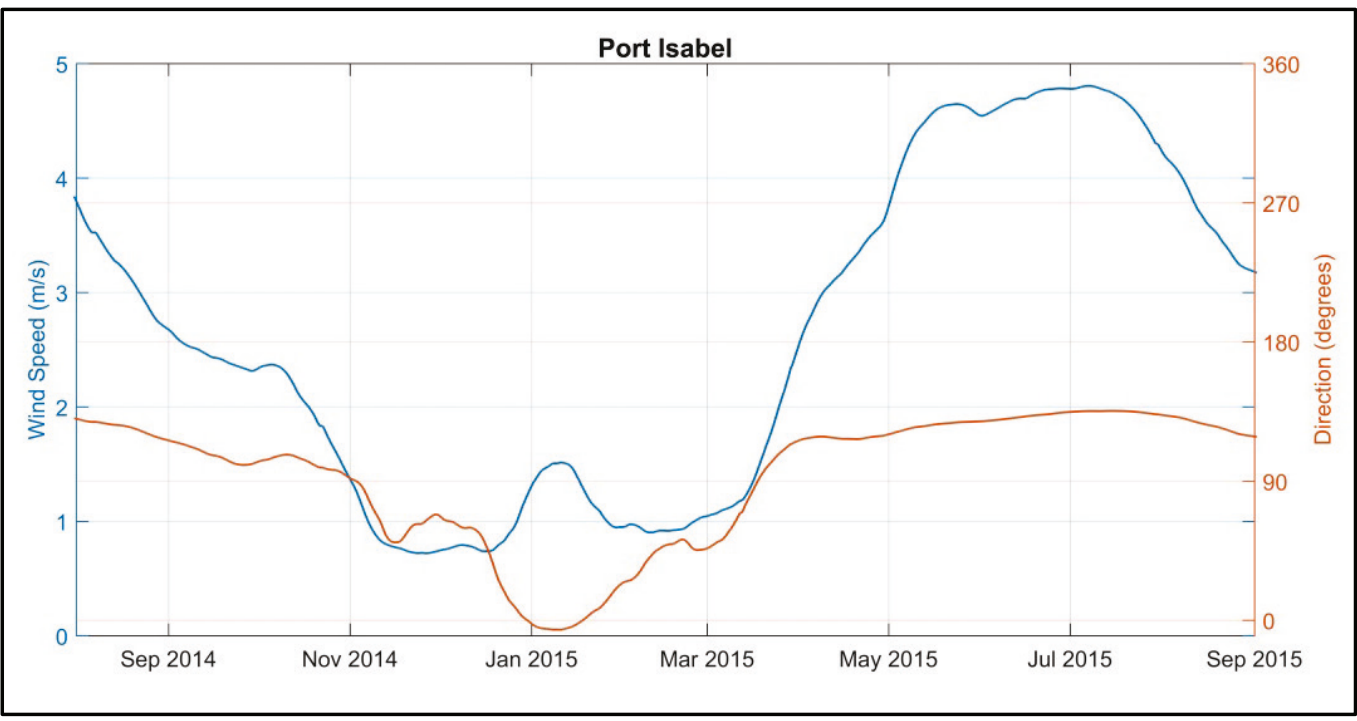

Water surface elevation (WSE) and temperature. WSE within the BSI has a strong diurnal signal that is modulated by the spring/neap cycle and low-frequency variability associated with shelf dynamics in this winddominated system (Figure 4-11). The data gap between September and December is due to instrument failure caused by a loose cable that was discovered when the AWAC was recovered in December. Bottom water temperatures follow a seasonal trend with heating in the summer and cooling in the winter. Tidal period fluctuations in temperature during July and August show warm lagoonal water existing during ebb and replaced with cooler shelf waters during flood. The exchange mechanism persists for several months and modulates with the spring/neap cycle.

WSE at the offshore station shows a similar tidal signal, but the extremes are slightly greater (Figure 4-12). The data gap between September and December is due to instrument burial, as reported by the dive team when they tried to recover the AWAC in December. During the summer months, bottom temperatures offshore show the same general trend as in the inlet but with less pronounced tidal variation. Note that the time series for the offshore station ends in July whereas the inshore station extends into September. The shorter duration is due to a second burial of the offshore sensor in the shallow energetic nearshore region. 
Figure 4-11. Time series of WSE and bottom temperature in the BSI Navigation Channel.

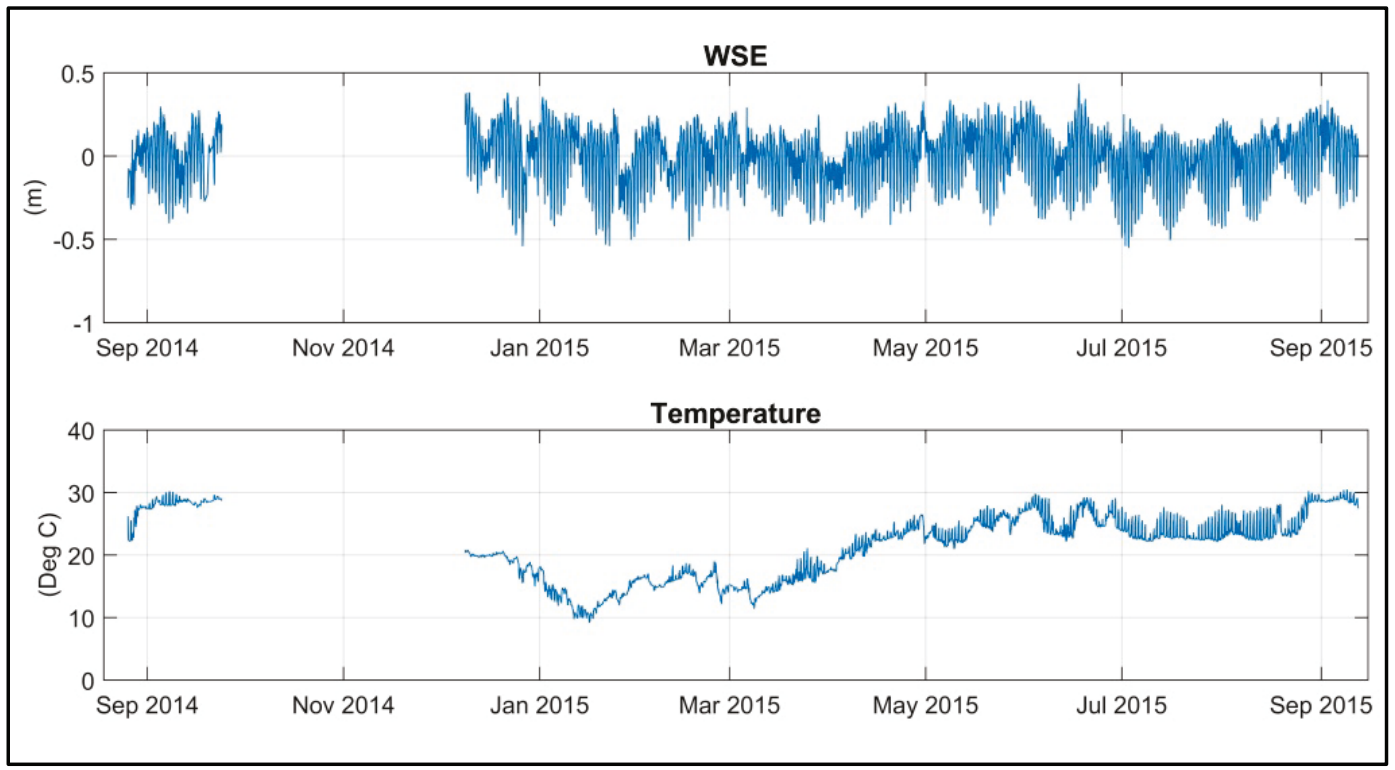

Figure 4-12. Time series of water elevation and bottom temperature at the offshore site.

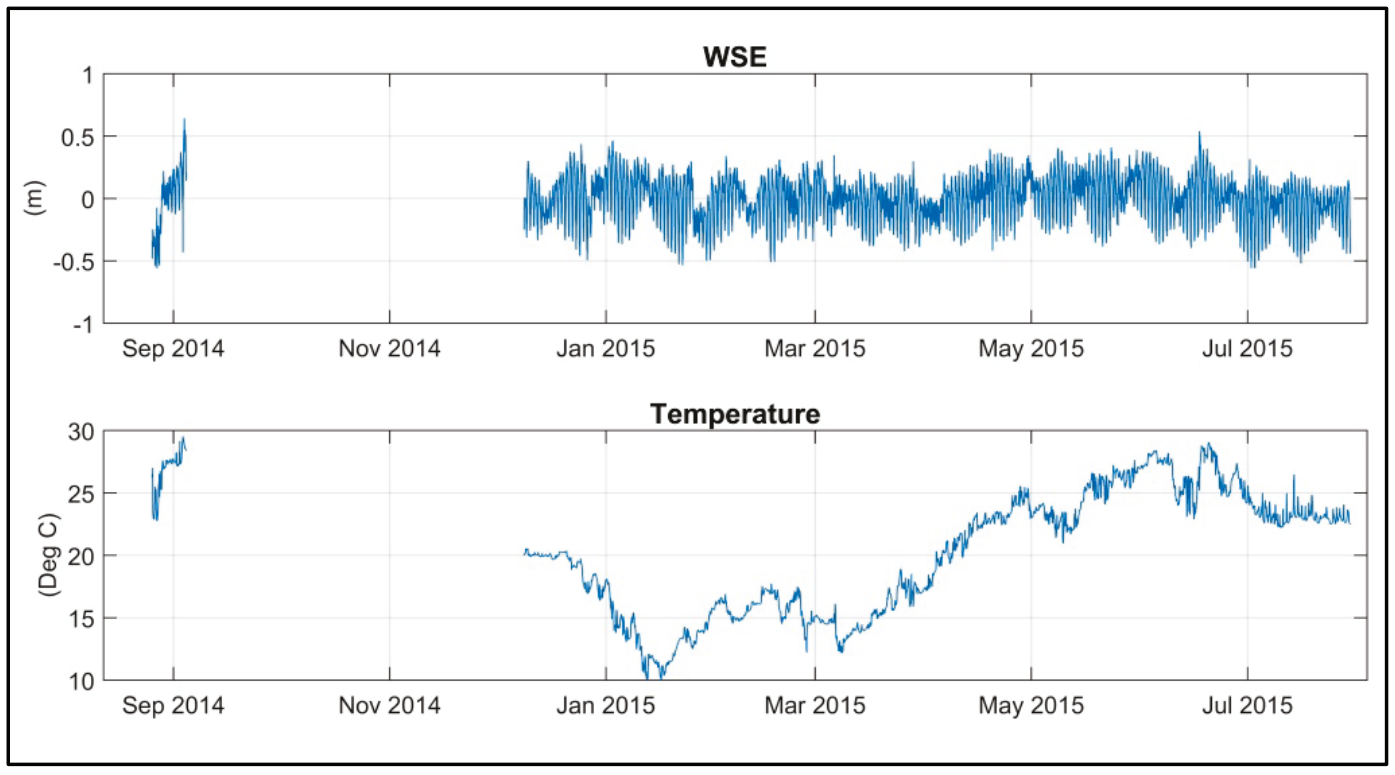

Currents. Time series of the depth-averaged current in the inlet throat reveals oscillations at tidal frequencies oriented in the along-channel direction (Figure 4-13). The absence of data between September and December is due to a sensor malfunction as previously noted. The signal is strongly influenced by the tide, including amplitude variations corresponding to the spring/neap cycle with a spring amplitude of approximately $1 \mathrm{~m} / \mathrm{s}(3.3 \mathrm{ft} / \mathrm{s})$. The cross-channel flow is much weaker consistent with flow in a confined channel and is also modulated by the tide. 
Depth-averaged currents at the offshore station show a tidal component but with greater low-frequency variability (Figure 4-14). As previously noted, the record is disrupted in early September due to instrument burial after a storm. After the instrument is replaced in December, the record continues until July at which time the instrument is again buried before being recovered in September. The amplitude of the tidally influenced alongshore current is weaker than in the inlet throat, and there is more low-frequency variability. The cross-shore component is generally weaker than the alongshore component and shows similar low-frequency variability at sub-tidal scales consistent with a combination of tidal and wind driven forcing.

Figure 4-13. Depth-averaged current time series in the BSI Navigation Channel.

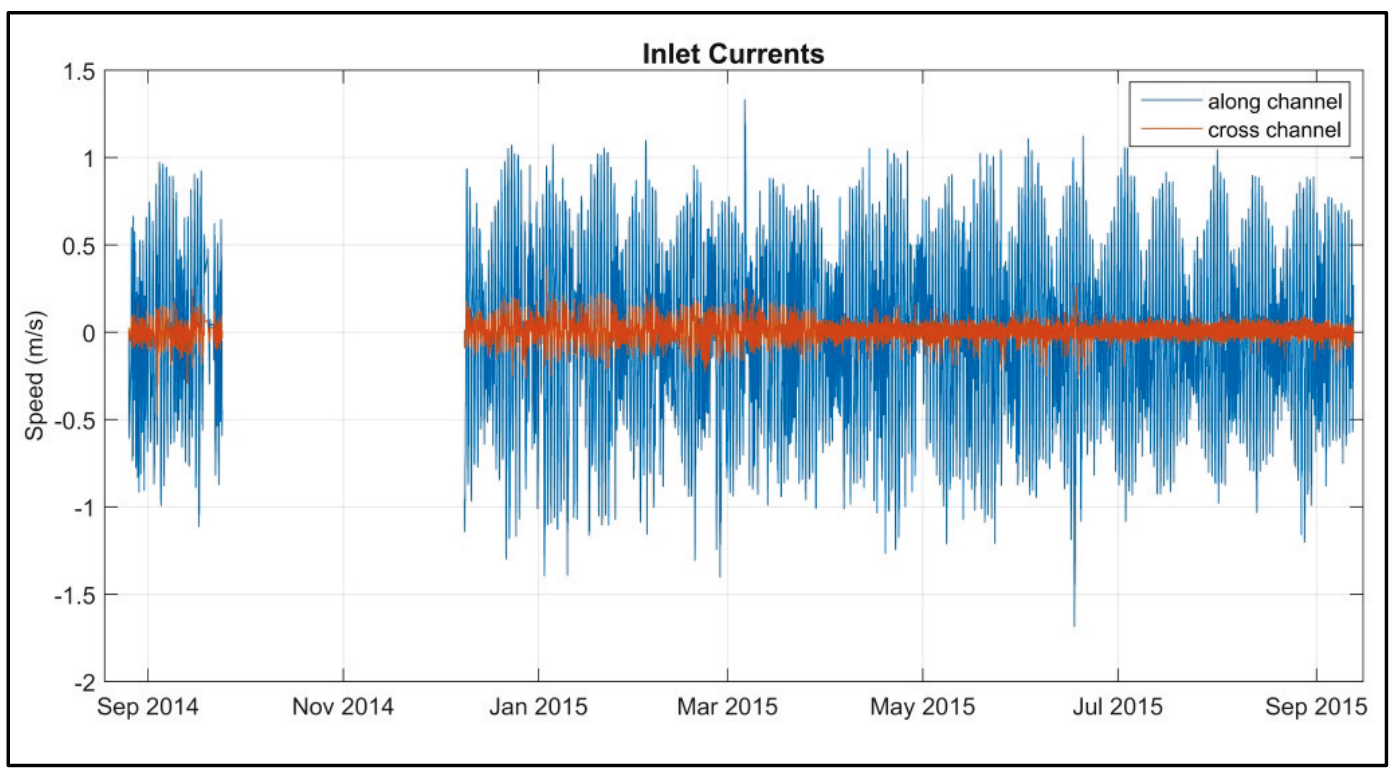

The current profile data are low-pass filtered to reveal the sub-tidal vertical variability (Figure 4-15). For the majority of the record bottom currents show a persistent, yet weak, inflow that increases during spring and summer coincident with strong southeasterly winds. The surface residual currents show outflow in the winter switching to a weak inflow during the spring and summer. The majority of the year shows inflow near the bed, which is consistent with bayward directed transport. 
Figure 4-14. Depth-averaged currents at the offshore station.

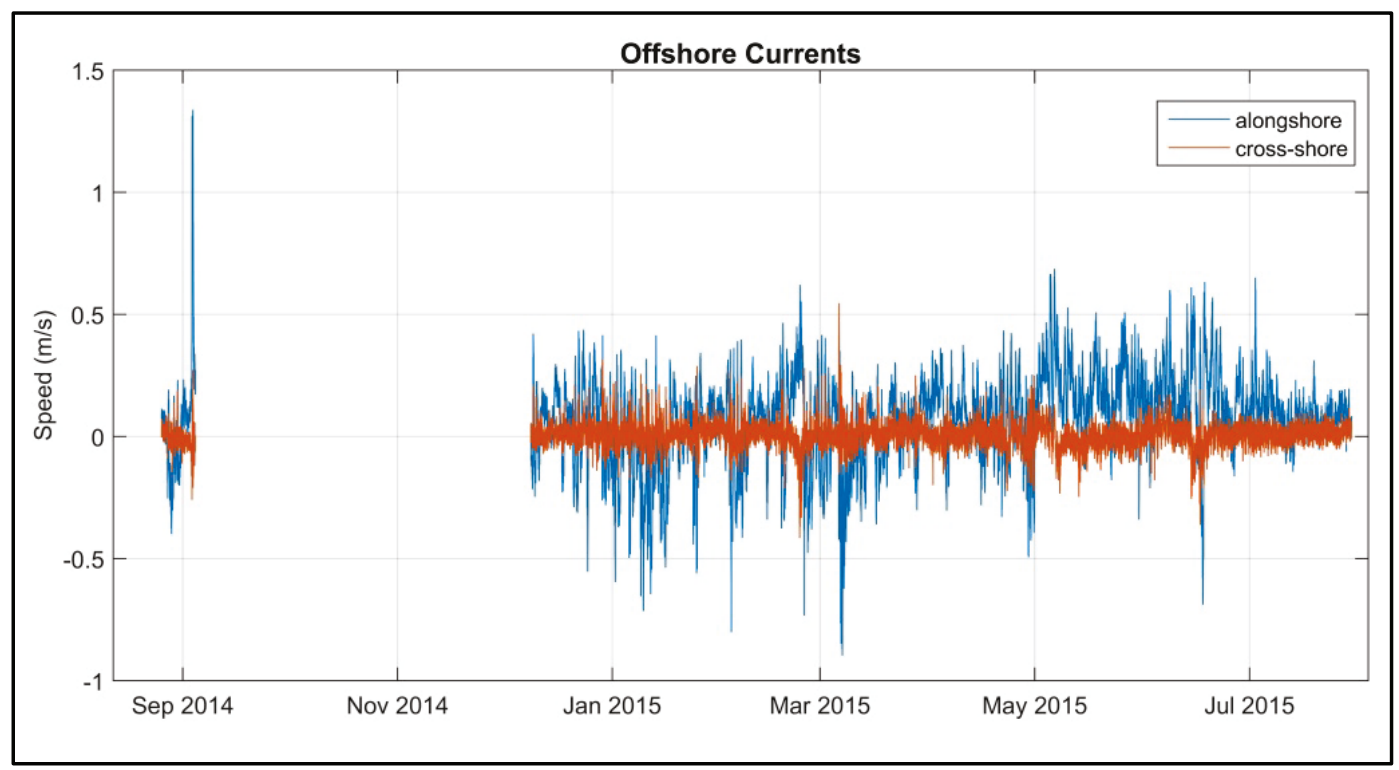

Figure 4-15. Low-pass filtered currents in the BSI. Negative values denote flow towards Laguna Madre.

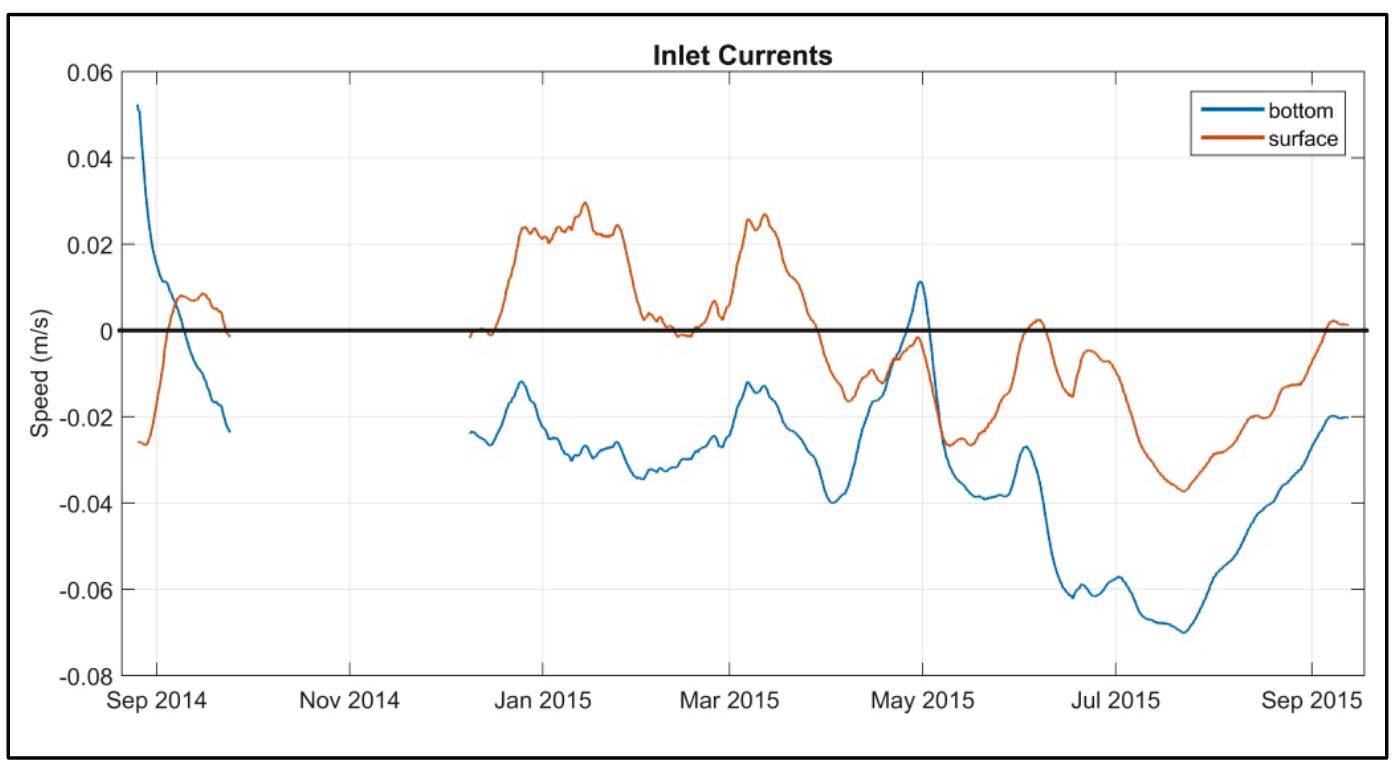

The alongshore transport is more uniform except during spring/summer when it is more vertically sheared (Figure 4-16). The net flow is towards the north and strongest during the summer concurrent with strong southeasterly winds. In the winter, intermittent flow reversals lead to southerly directed transport. 
Figure 4-16. Low-pass filtered currents at the offshore site.

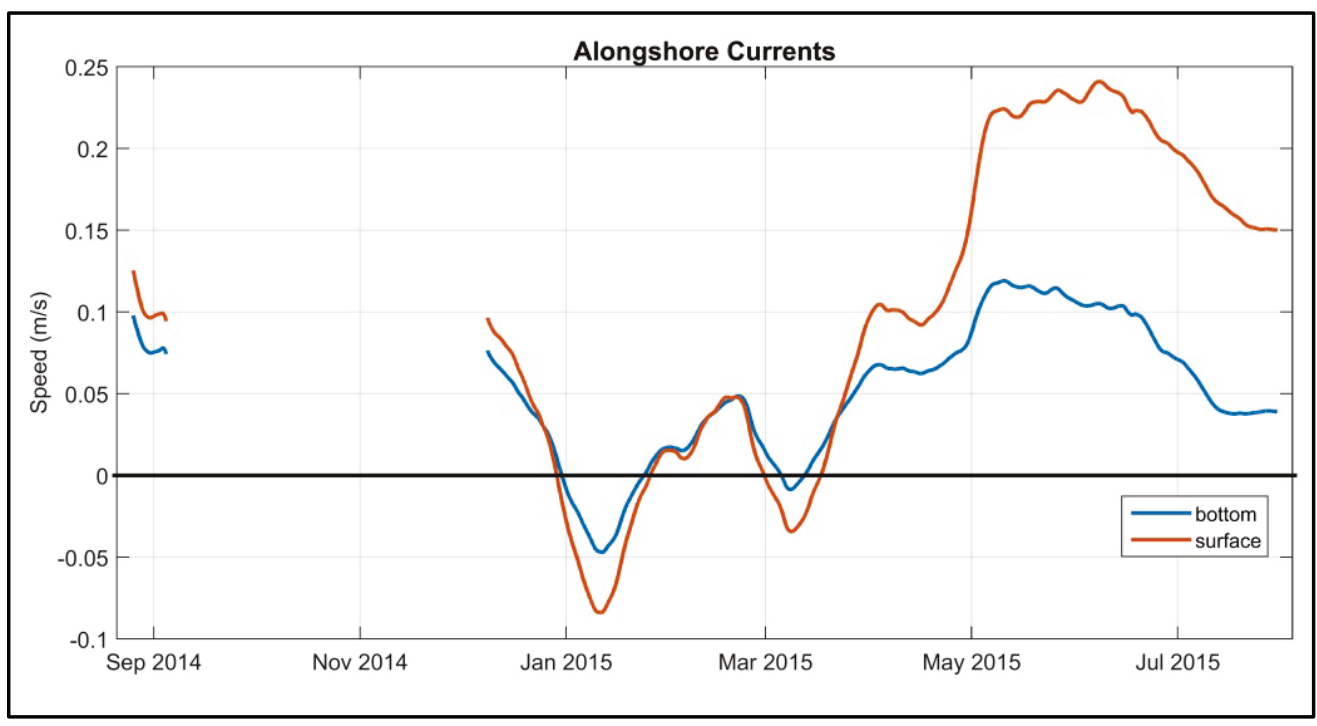

Inlet discharge is computed by integrating the current bins over depth and multiplying the result by the average width of the inlet (350 $\mathrm{m}[1,150 \mathrm{ft}])$ at the deployment location of the AWAC. The transport is directed towards the bay and increases between April and September (Figure 4-17).

Figure 4-17. Cumulative discharge from the BSI. Note the break in the record precludes a continuous time series of the cumulative flux. Negative values denote flow towards the west.

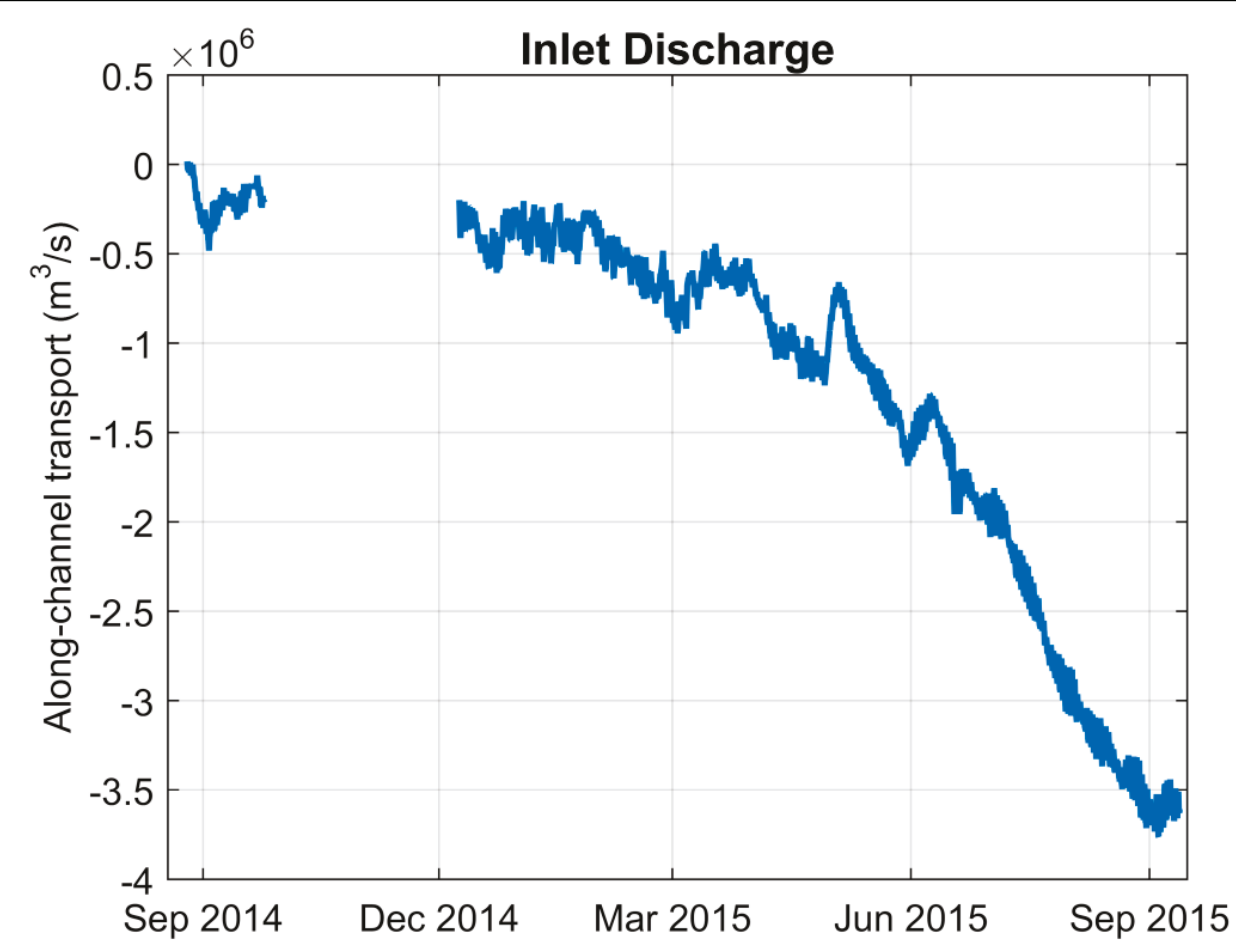


At the offshore location, the current bins are integrated over depth to give the discharge per unit width (Figure 4-18). Because the flow is not confined to a channel, both the alongshore and cross-shore flux are presented. The net transport is offshore and towards the north. The slight offshore rotation is likely due to current veering induced by the presence of the south jetty, which forces the flow eastward to pass beyond the tip of the jetty. The results indicate that between April and September, the next flux is towards the north and is associated with greater inflow at the BSI.

Figure 4-18. Cumulative discharge per unit width at the offshore AWAC. Positive values denote flow towards the north (alongshore) and east (cross-shore).

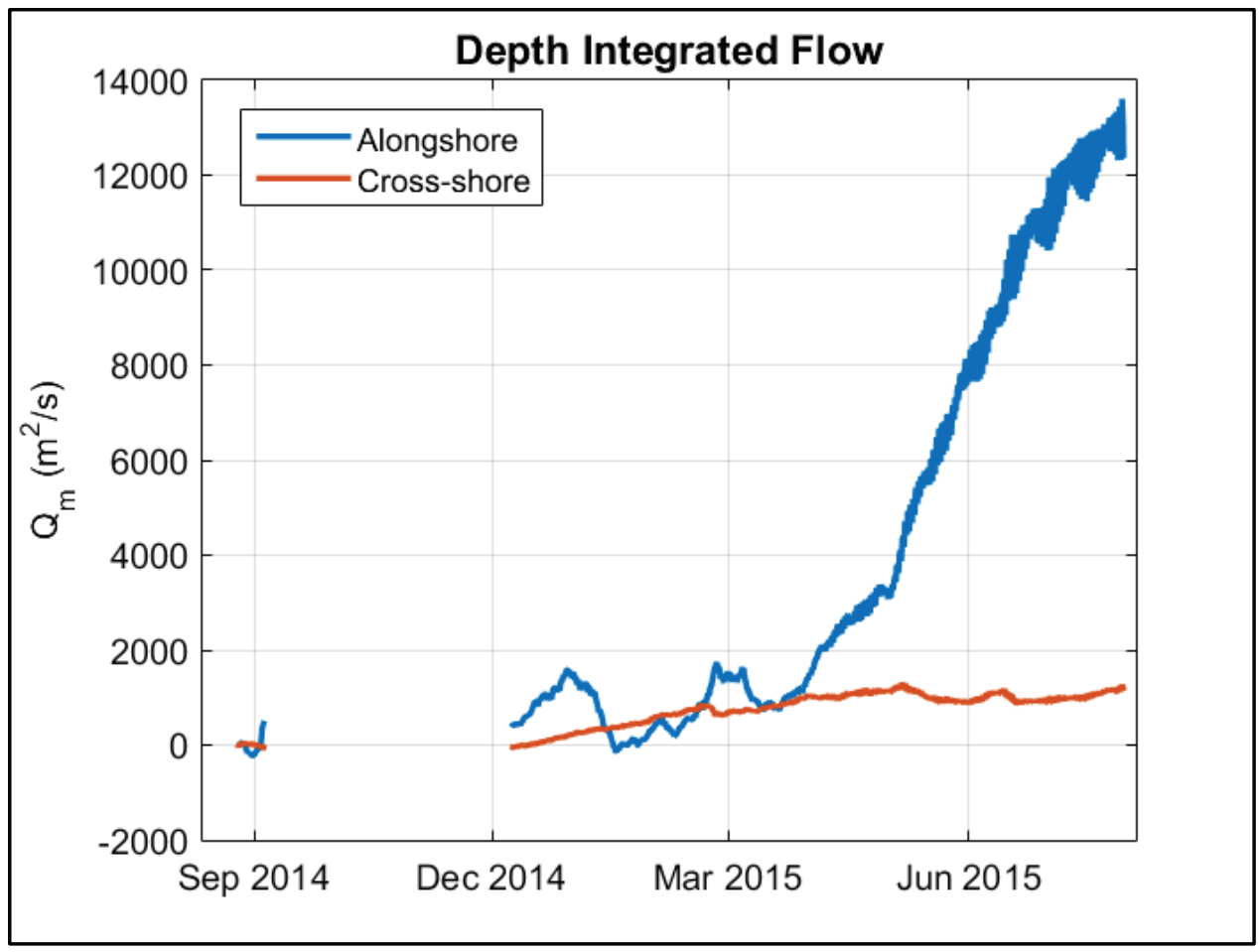

Waves. Wave height in the BSI Navigation Channel is variable during the study period with the highest waves occurring in winter (Figure 4-19). The wave period time series indicates the majority are wind waves, given the period is less than $8 \mathrm{~s}$. The directional distribution is narrowly banded with a peak at $85^{\circ}$. This is consistent with offshore waves entering the inlet between the jetties, which serves as a wave guide prohibiting propagation at steeper angles. The sporadic departure from the average direction is associated with wave heights less than $0.5 \mathrm{~m}(1.6 \mathrm{ft})$ and periods less than $3 \mathrm{~s}$, indicating that the smaller shorter waves may be difficult to resolve with the AWAC due to aliasing caused by beam separation at the surface. In other words, the lateral separation between the slant beams, which are used 
to determine direction through phase differentials, are between 11 and $13 \mathrm{~m}$ (36.1 and $42.6 \mathrm{ft}$ ) at the surface (depending on water depth), while waves

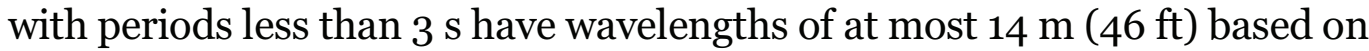
the dispersion relationship. Therefore, the AWAC cannot resolve the phase difference of a single wave when the beam separation at the surface is greater than the wavelength. This is compounded by the small surface displacement, which reduces the signal-to-noise ratio making accurate wave direction estimates more difficult. As such, the accuracy of the large deviations from the average wave direction are suspect.

Figure 4-19. Time series of wave parameters in the BSI Navigation Channel.

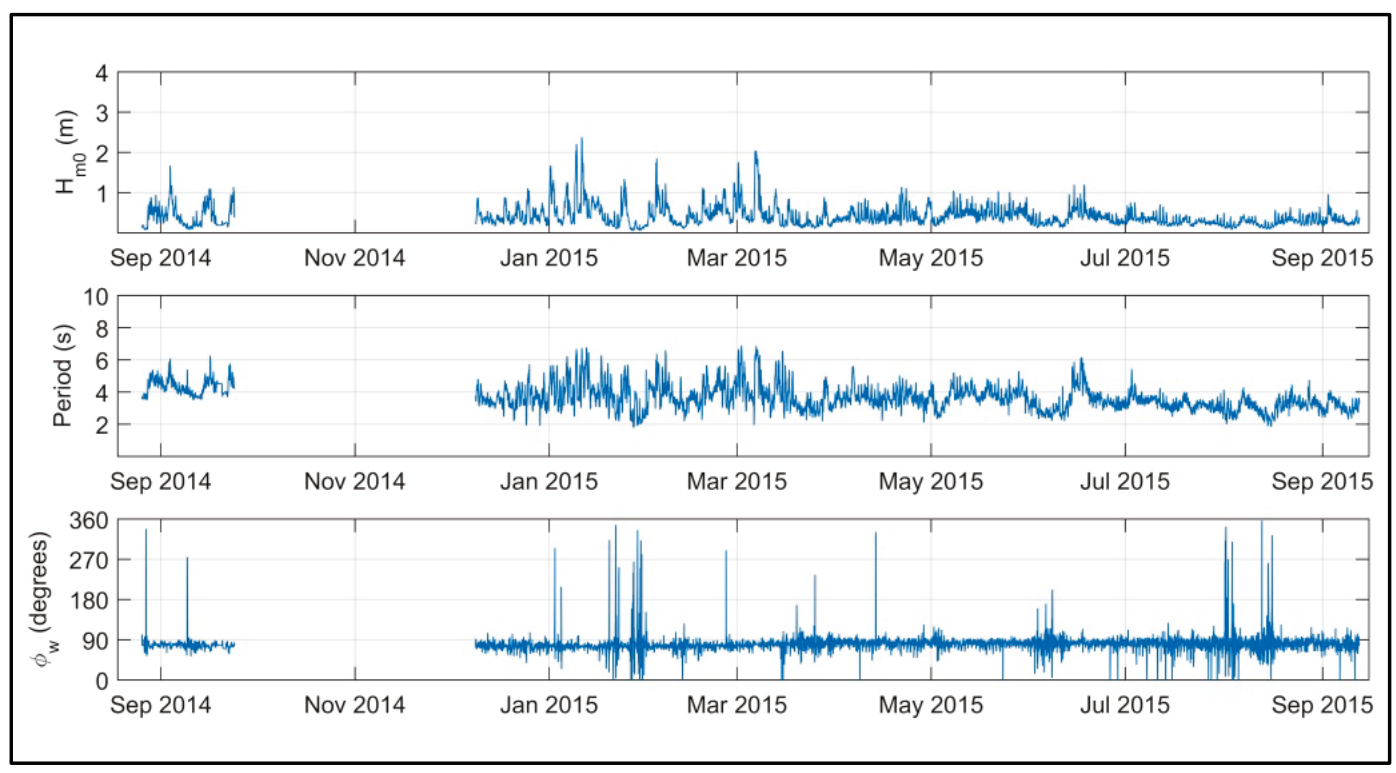

Wave conditions at the offshore site likewise indicate periods in the windgenerated band and a greater frequency of higher waves in winter (Figure 4-20). Wave direction is more variable in the winter, but by April, it is narrowly banded at approximately $90^{\circ}$ (from the east). The winter months show intermittent periods of waves approaching from the north and northeast, which is consistent with the predominant wind direction during the winter storm season.

Estimates of the bottom wave orbital velocity $\left(U_{b}\right)$ and bottom excursion amplitude $\left(A_{b}\right)$ in the BSI Navigation Channel show similar temporal patterns as the waves with higher values in the winter (Figure 4-21). The bottom orbital velocity is a measure of wave-driven sediment resuspension potential, and the excursion amplitude is a measure of wave boundary layer thickness. 
Figure 4-20. Time series of wave parameters at the offshore site.

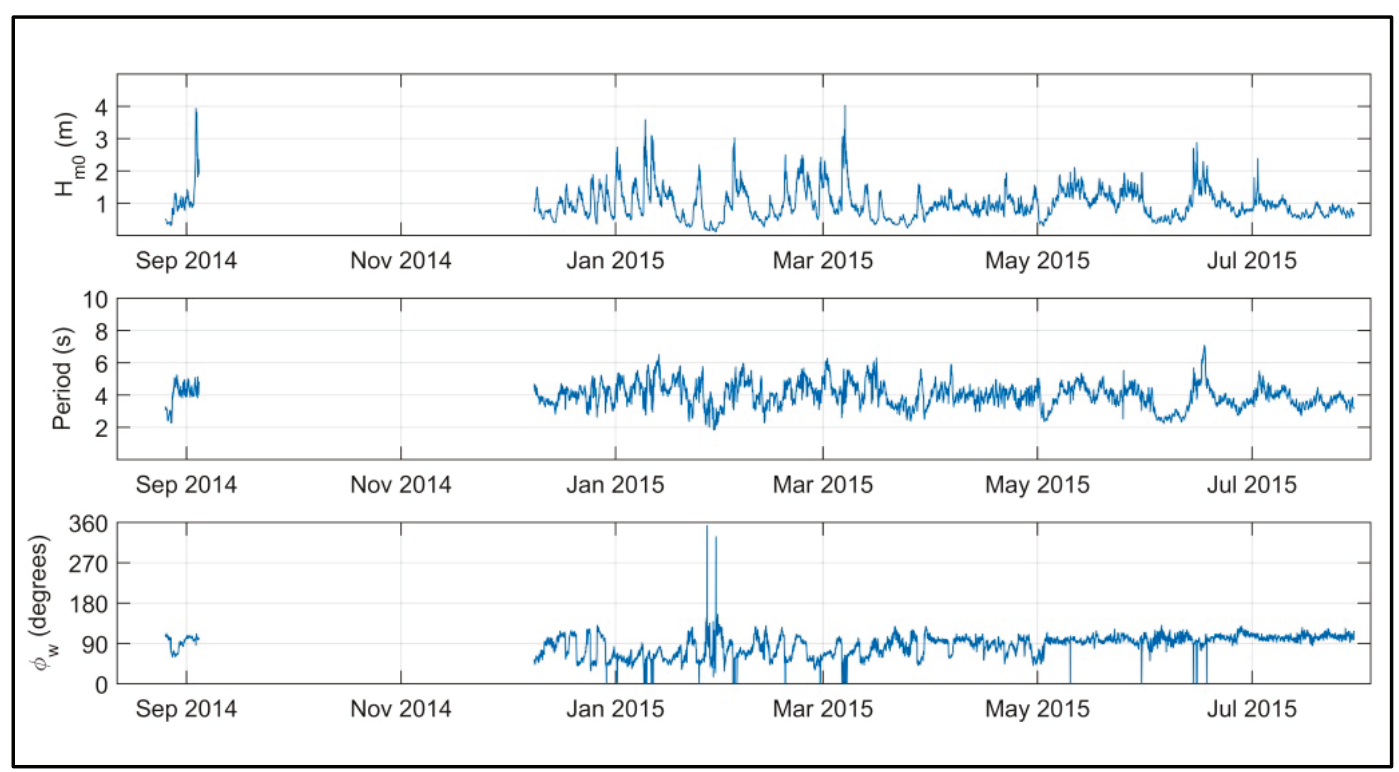

Figure 4-21. Bottom orbital velocity and excursion amplitude in the BSI Navigation Channel.

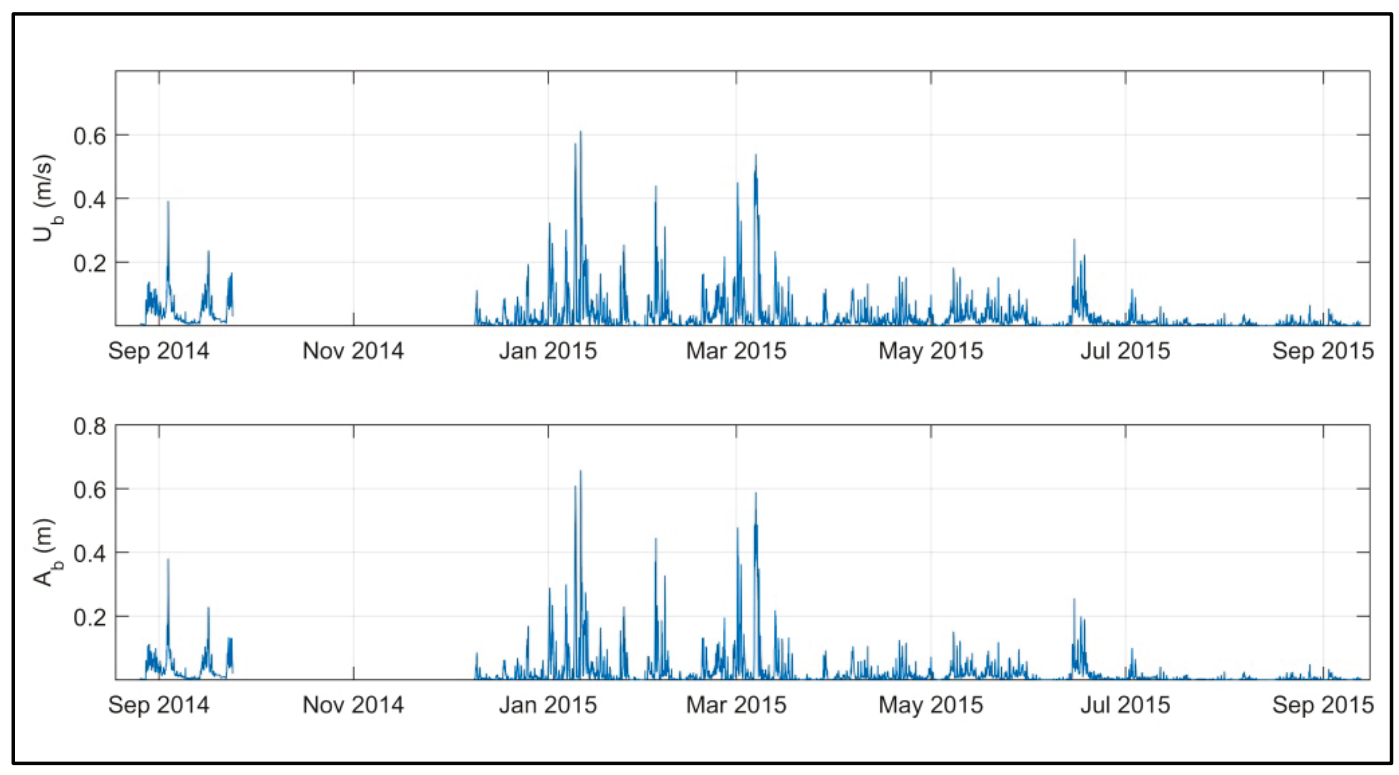

Orbital velocity and excursion amplitude are higher at the offshore site indicating greater potential for sediment resuspension and transport (Figure 4-22). Orbital velocity is largest in September 2014 just prior to the data cutoff, which is consistent with instrument burial coincident with greater sediment transport potential during a period of heightened wave activity. 
Figure 4-22. Bottom orbital velocity and excursion amplitude at the offshore site.

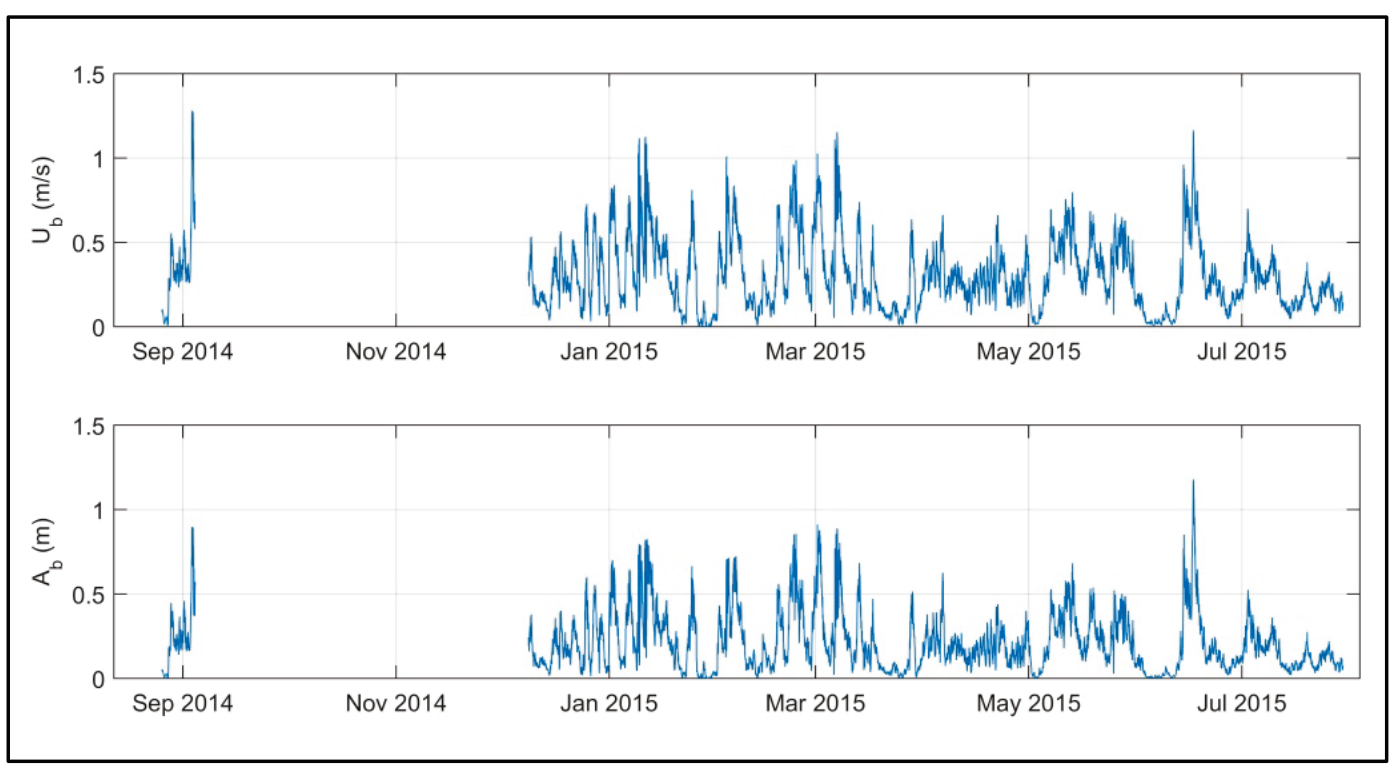

Density. Conductivity, temperature, and depth profile measurements collected on 14 September 2014 over an ebb cycle indicate a vertically wellmixed water column (Figure 4-23). The results establish the absence of density stratification during this time period such that baroclinicity and three-dimensional effects are not critical factors in describing the hydrodynamics. The primary distributary in south Laguna Madre is the Arroyo Colorado River, which serves as a floodway and conduit for wastewater discharge. It is likely that periods of freshwater discharge can intermittently stratify the water column, but these would be a rare occurrence given the arid climate. As such, baroclinic effects are neglected, and a two-dimensional (2D) hydrostatic model is adequate to examine the hydrodynamics.

Bottom sediments. Figure 4-24 shows an example particle size spectrum plot. The sediment consists primarily of fine sand with a D50 of 0.215 millimeters [mm] (215 microns) (0.0085 in.). This sample is from the navigation channel at Mansfield Pass, where a sand bed is expected considering the higher tidal flows. 
Figure 4-23. Density profiles collected in the inlet throat.

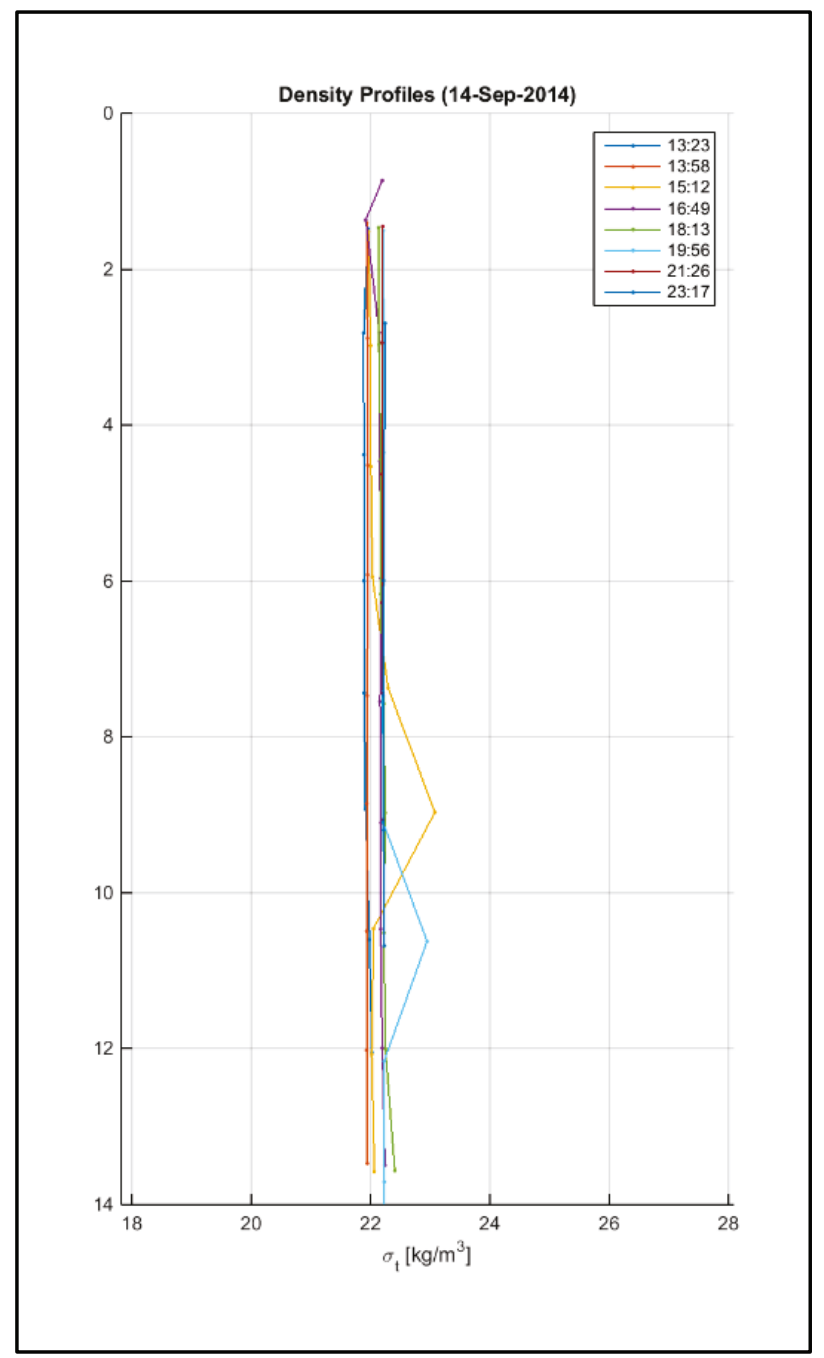

Figure 4-24. Plot of particle size spectrum for Brazos MPI-5.

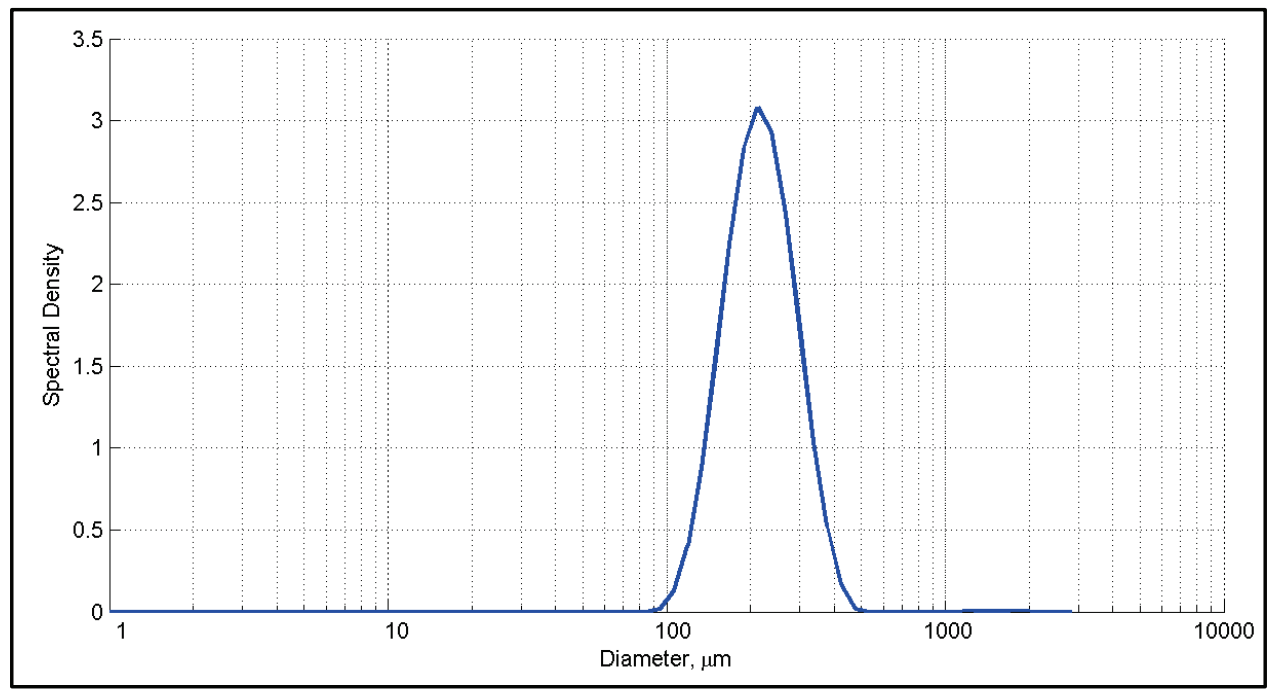


The cumulative size distribution indicating most sediments lie between $0.100 \mathrm{~mm}$ (100 microns) (0.0040 in.) and $0.500 \mathrm{~mm}$ (500 microns) (0.0198 in.) (Figure 4-25). The sample contains negligible amounts of silt or clay particles or any particles greater than medium sand. The relatively narrow distribution indicates the sample is sorted.

Figure 4-25. Plot of cumulative size distribution for Brazos MPI-5.

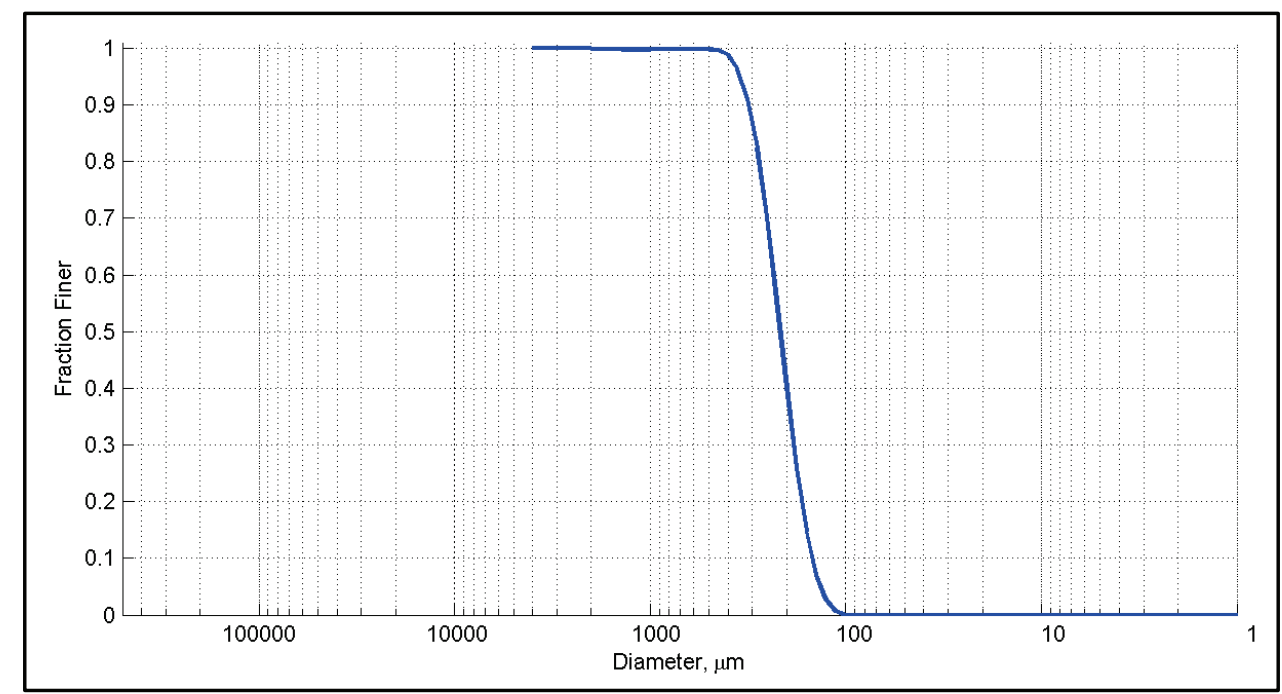

In general, the largest grains are in the inlet throat between the jetties (Figure 4-26). Offshore grain sizes are smaller and more uniform north of the jetty. There is a marked difference between the regions north and south of the jetties with larger grains to the north. The smallest size is $0.0059 \mathrm{~mm}$ (0.000232 in.) (5.9 microns) and is located in lower Laguna Madre south of the Brownsville Ship Channel at the entrance to South Bay, a shallow mud flat shoreward of the inlet. Silt size grains are also present in the Brownsville Ship Channel and the Intracoastal Waterway (ICW) near South Island, probably transported from adjacent flats that contain a higher fraction of silt. Grain size distribution in the southern part of Laguna Madre is very fine to fine sand in the ICW and on the shallow flat backing the barrier island (Figure 4-27). A small region of silt-sized particles lies on the shallow flats.

Upper Laguna Madre includes Mansfield Pass. The largest sizes are in the navigation channel between the jetties (Figure 4-28). Similar to the BSI, grain size is smaller offshore compared to the inlet channel. The GIWW north of Mansfield Pass contains very fine to fine sand intermixed with two regions of silt-sized particles. 
Figure 4-26. D50 for lower Laguna Madre including the BSI. Numbers denote sediment size in microns (from Google Earth https://www.google.com/earth/).

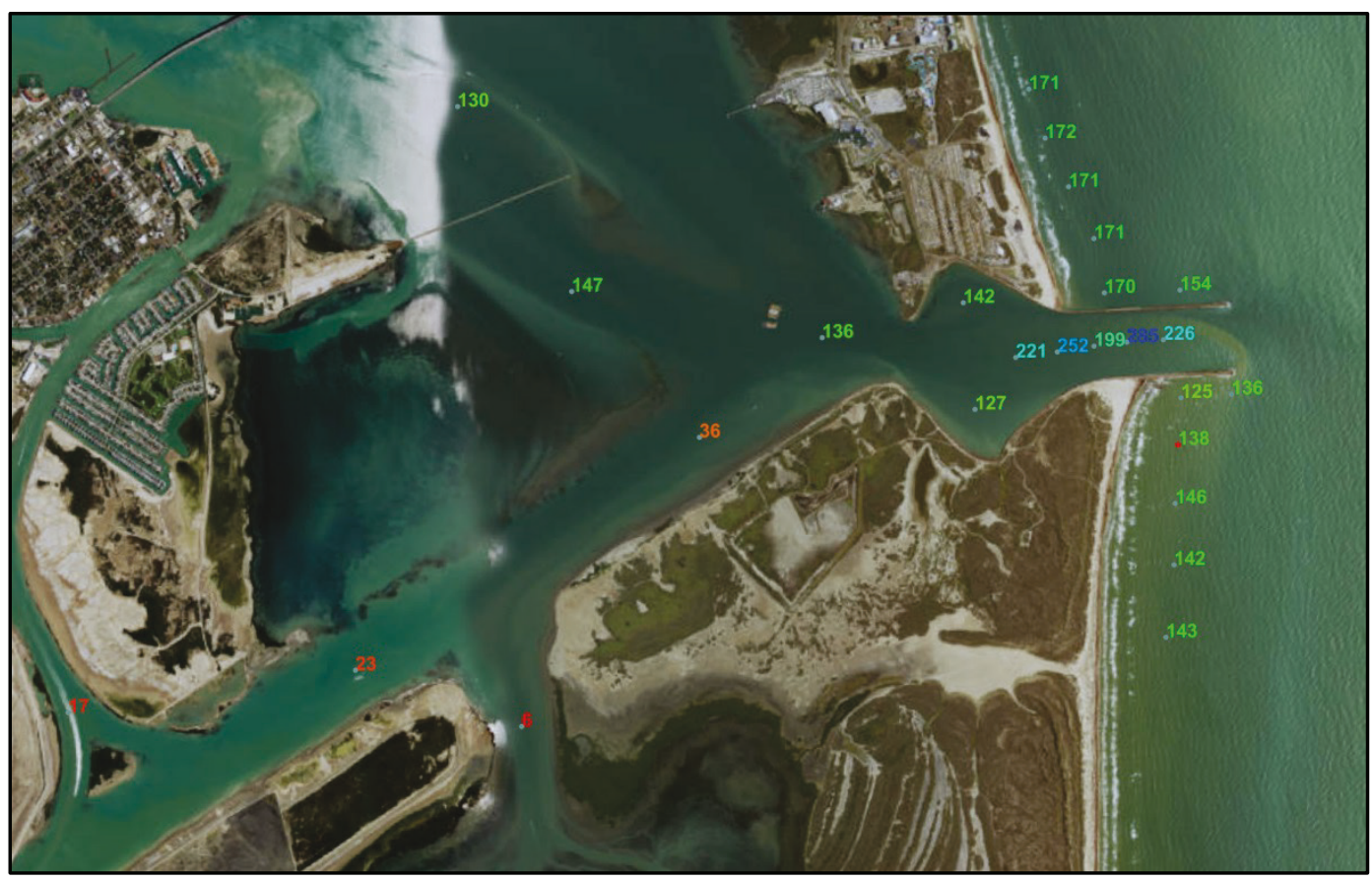

Figure 4-27. D50 for lower Laguna Madre. Numbers denote sediment size in microns (from Google Earth https://www.google.com/earth/).

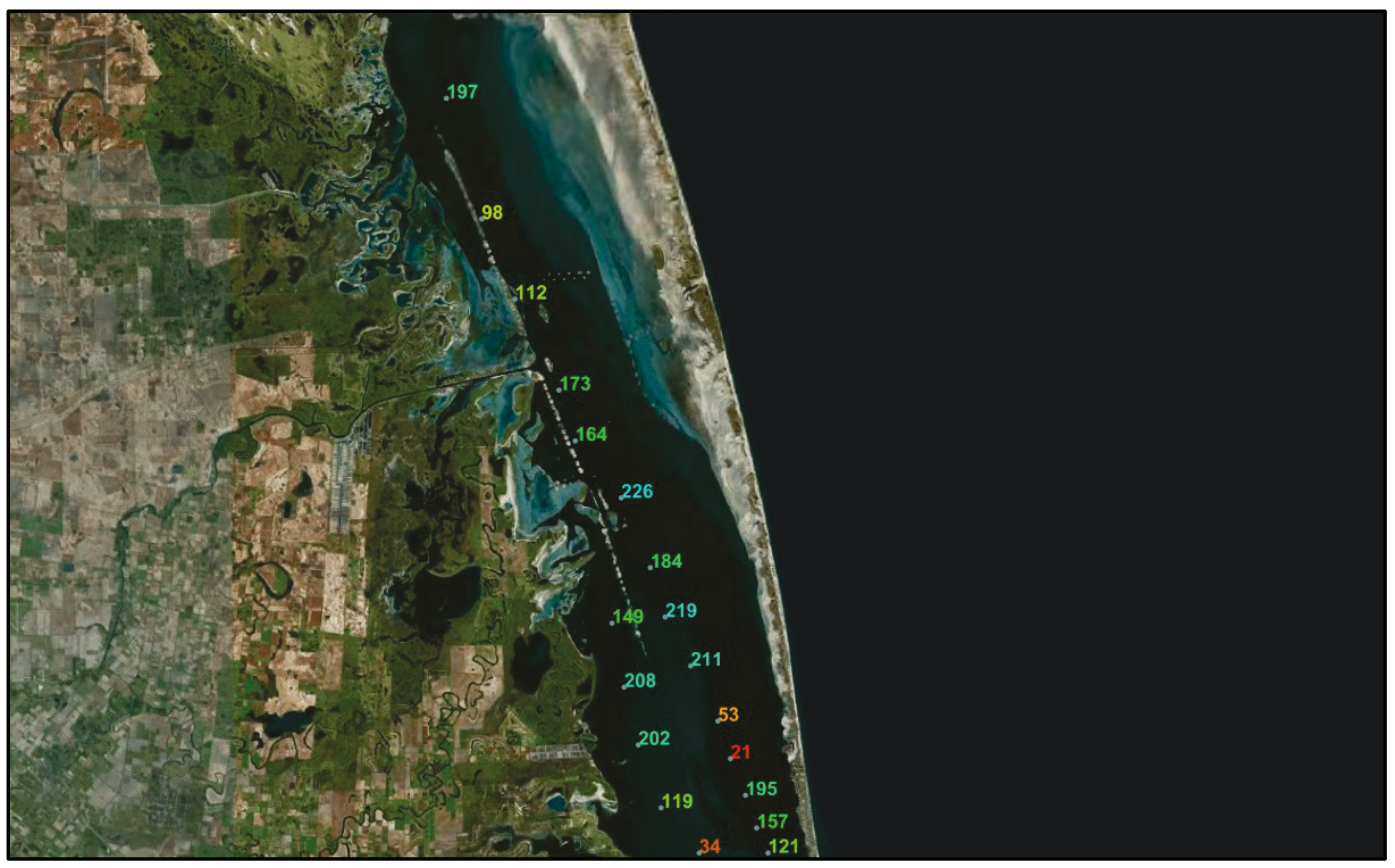

Overall, the largest grains (fine sands) are found in the inlet throat between the jetties, which represent a high energy environment driven by $\sim 1 \mathrm{~m} / \mathrm{s}(3.3 \mathrm{ft} / \mathrm{s})$ spring tides. Bed sediments offshore are slightly smaller (very fine sand) and consistent with grain size distribution throughout 
Laguna Madre along the GIWW. The tidal flats that back the barrier island and the mainland likewise contain fine sand, but intermittent pockets of silts are found in the shallow regions.

The grab samples were collected 3 months after the BSI was dredged, so the surface layer in that area may not represent the sediments that accumulate in the throat. Assuming offshore sources, the dredged sediment may be finer.

Figure 4-28. D50 for upper Laguna Madre including Mansfield Pass. Numbers denote sediment size in microns (from Google Earth https://www.google.com/earth/).

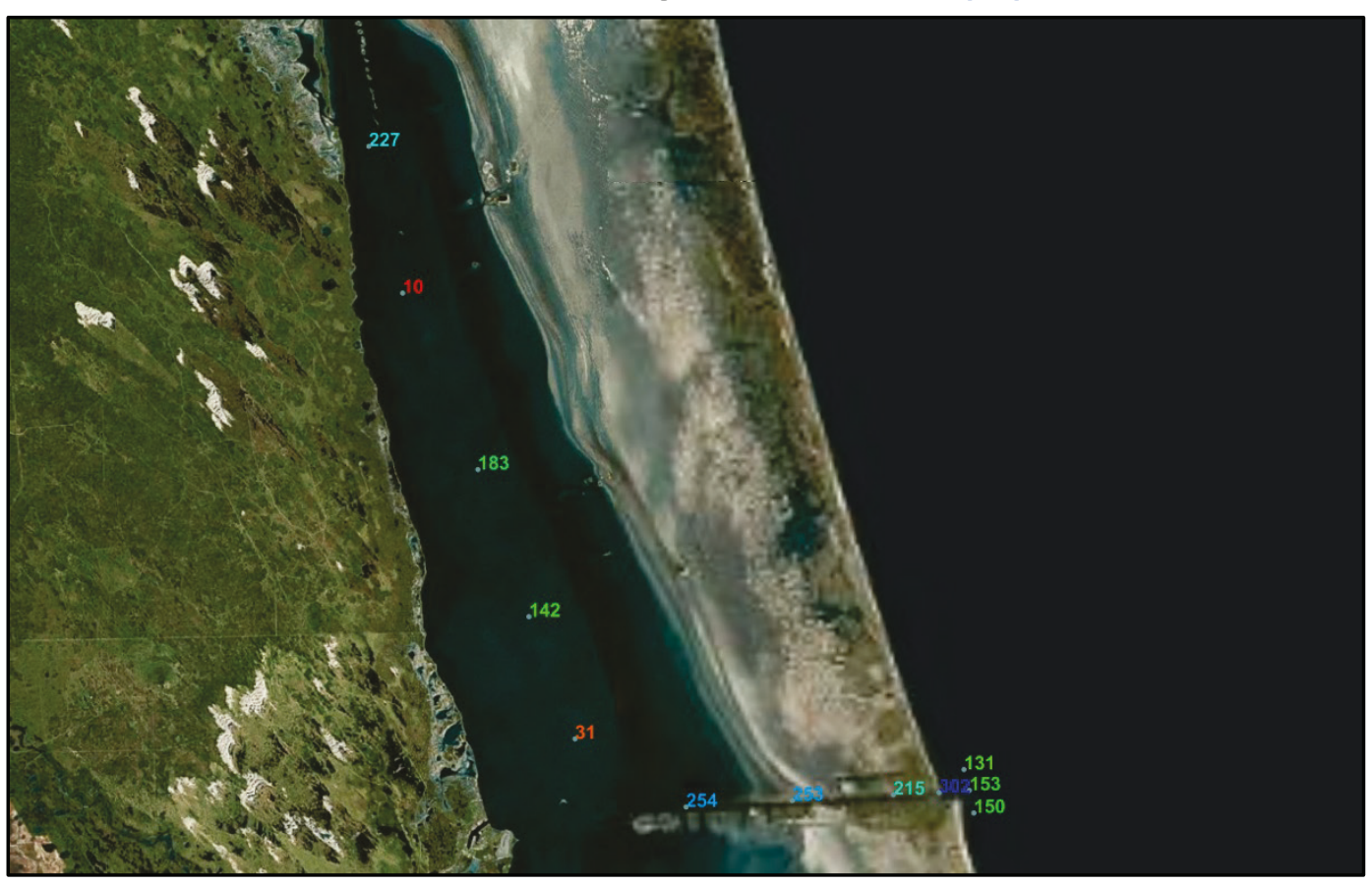

Bathymetry. Bathymetric surveys of the BSI, sections of the inner harbor, and adjacent inner-shelf were conducted in September 2014, March 2015 and July 2015 (Figure 4-29). The surveys follow emergency maintenance dredging in May 2014 in which the channel was dredged to its authorized depth of $13.4 \mathrm{~m}$ ( $44 \mathrm{ft})$ and width of $91.5 \mathrm{~m}$ (300 ft). 
Figure 4-29. Bathymetry snapshots during the 2014-2015 field deployment. (A) 14 September 2014, (B) 15 March 2015, and

(C) 07 July 2015. The dashed line (C) denotes a transect line from which a bathymetry profile is extracted. Water depths are in meters (from Google Earth https://www.google.com/earth/).

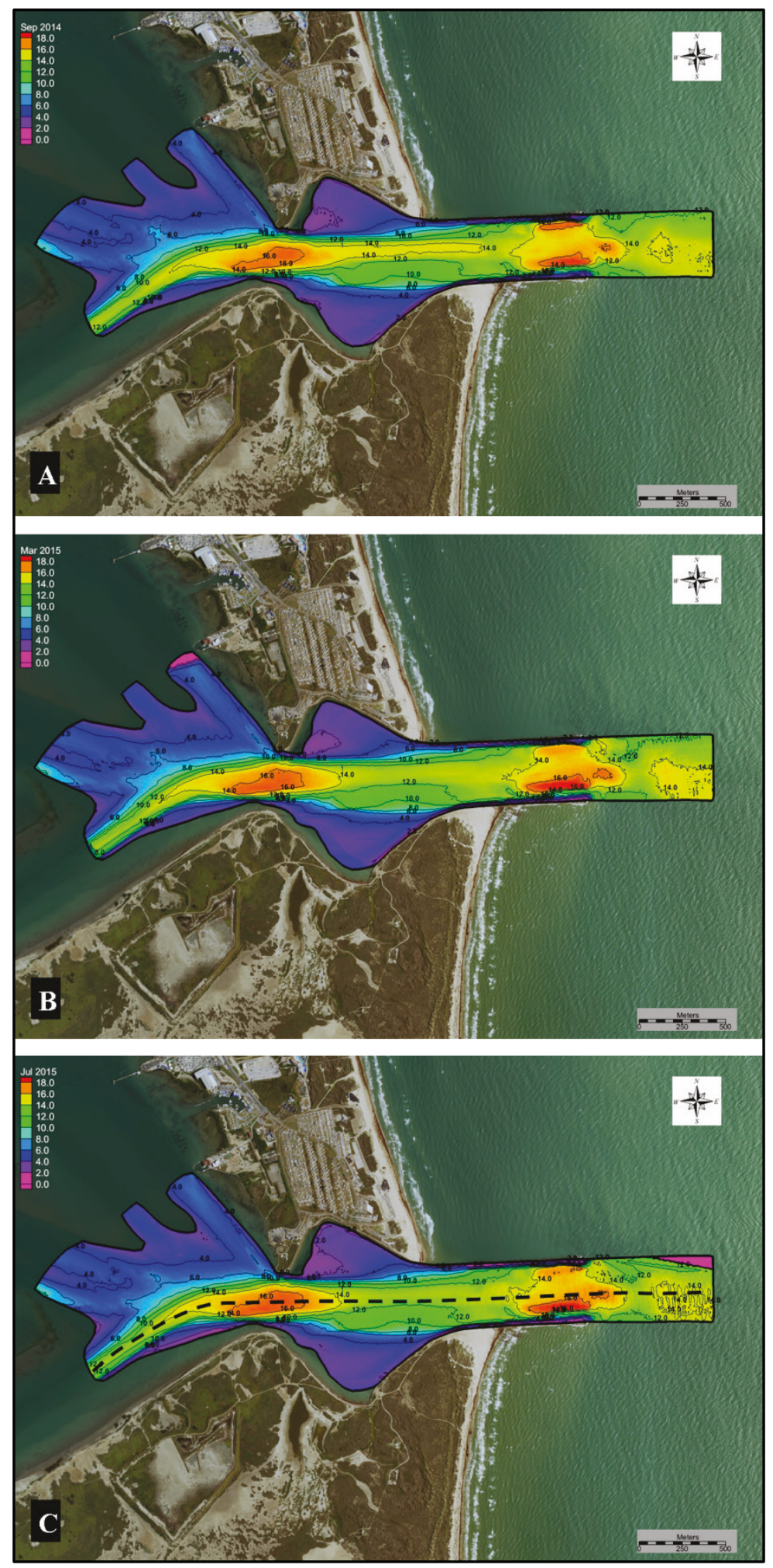


The survey conducted in September 2014 is the most representative of post-dredging conditions (Figure 4-29, A). Depths offshore and between the jetties extend laterally over a wide section of the inlet. The width of the

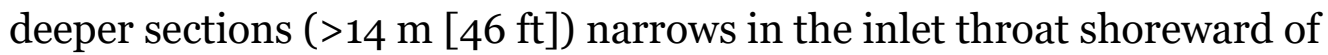
the jetties where the inlet forms a crenulate-shaped embayment. Depths in the narrow constriction shoreward of the embayment are deepest, exceeding $16 \mathrm{~m}$ (52 ft). In addition, two deep depressions are located on opposite sides of the inlet near the jetty tips.

The coverage area in lower Laguna Madre consists of four lobes that extend from the landward end of the inlet. The lower lobe follows the Brownsville Ship Channel, the adjacent lobe (in a clockwise sense) is the widest and follows a natural depression that extends northward into Laguna Madre, the third lobe follows a shallow depression, and the fourth lobe follows the channel leading to the South Padre Island Coast Guard Station. The deeper areas are separated by shoals that are too shallow for the survey vessel to operate, giving rise to the lobed projection of the coverage area.

By March 2015, channel infilling is seen near the landward end of the jetties and continuing into the crenulate embayment (Figure 4-29, B) as evident by the westward shift of the $14 \mathrm{~m}(46 \mathrm{ft})$ contour. The deep sections near the jetty tips have evolved such that the northern side is slightly shallower and the southern side is slightly deeper. Conditions in July 2015 are similar to March 2015 (Figure 4-29, C) indicating less bed change during this timeframe. The region offshore on the northern edge of the plot was not mapped during the July survey due to poor weather conditions, and the triangularly shaped outline is an artifact of grid interpolation.

Bed change. Bed change is computed by overlaying water depth measurements from two surveys and taking the difference. Bed change between September 2014 and July 2015 shows the greatest erosion at the tips of the jetties and greatest deposition in the inlet throat where it widens (Figure 4-30). Bed change is asymmetric with respect to the centerline axis of the inlet with a continuous line of erosion on the south side of the inlet. Net erosion along the south jetty continues into the embayment south of the navigation channel and then into the narrow constriction. While the average change at each of these areas is less than 
$0.5 \mathrm{~m}(1.6 \mathrm{ft})$, it does suggest that the natural configuration is for the deepest section to form south of the centerline.

The rectangular area clearly visible in Figure 4-30(A) denotes the location that was dredged in May of 2014. The majority of the sediment deposition in this area occurs between September 2014 and March 2015 (Figure 4-30, B), as the change between March and July 2015 is less pronounced (Figure 4-30, C). The data suggest that the initial morphological response to dredging occurs rapidly as the area begins to infill and then proceeds more slowly. This may be a response to seasonal changes in forcing as wave activity in the inlet during the winter months is significantly higher. After April 2015, the frequency of wave events is reduced and does not reach the same level as seen in January-March 2015 for the remainder of the record.

Incoming tidal currents carry sediment along the deep channel between the jetties. The flow diverges as it enters the crenulate embayment, reducing the magnitude of the along-channel current. Sediments begin to settle out and form a depositional layer in the deep navigation channel. Currents then accelerate through the constriction at the west end of the inlet before entering the bay. The stronger currents more easily transport sediment that did not settle in the flared region of the inlet and deliver them to the bay. The sequence is reversed during ebb, in which currents diverge and weaken after passing through the narrow constriction depositing sediment in the embayment. The flow then converges and accelerates in the region between the jetties transporting more sediment before exiting the inlet.

The erosion at the jetty tips may be a seasonal phenomenon driven by increased wave activity in the winter months combined with increased current speeds and rapid flow convergence/divergence during maximum flood/ebb. However, the erosion continues, although at a slower rate, at least through July 2015. This may be due to increased currents at the jetty tips in the aftermath of dredging and associated deeper channel allowing for stronger currents. The erosion timeline shows more erosion between September 2014 and March 2015 compared to March 2015 and July 2015. This is similar to the deposition timeline for the dredged area, indicating that erosion patterns at the jetty tips may be linked to dredging of the channel. 
Figure 4-30. Bed change in meters. Positive values denote deposition. Negative values denote erosion. (A) September 2014 to July 2015, (B) September 2014 to March 2015, (C) March 2015 to July 2015 (from Google Earth https://www.google.com/earth/).
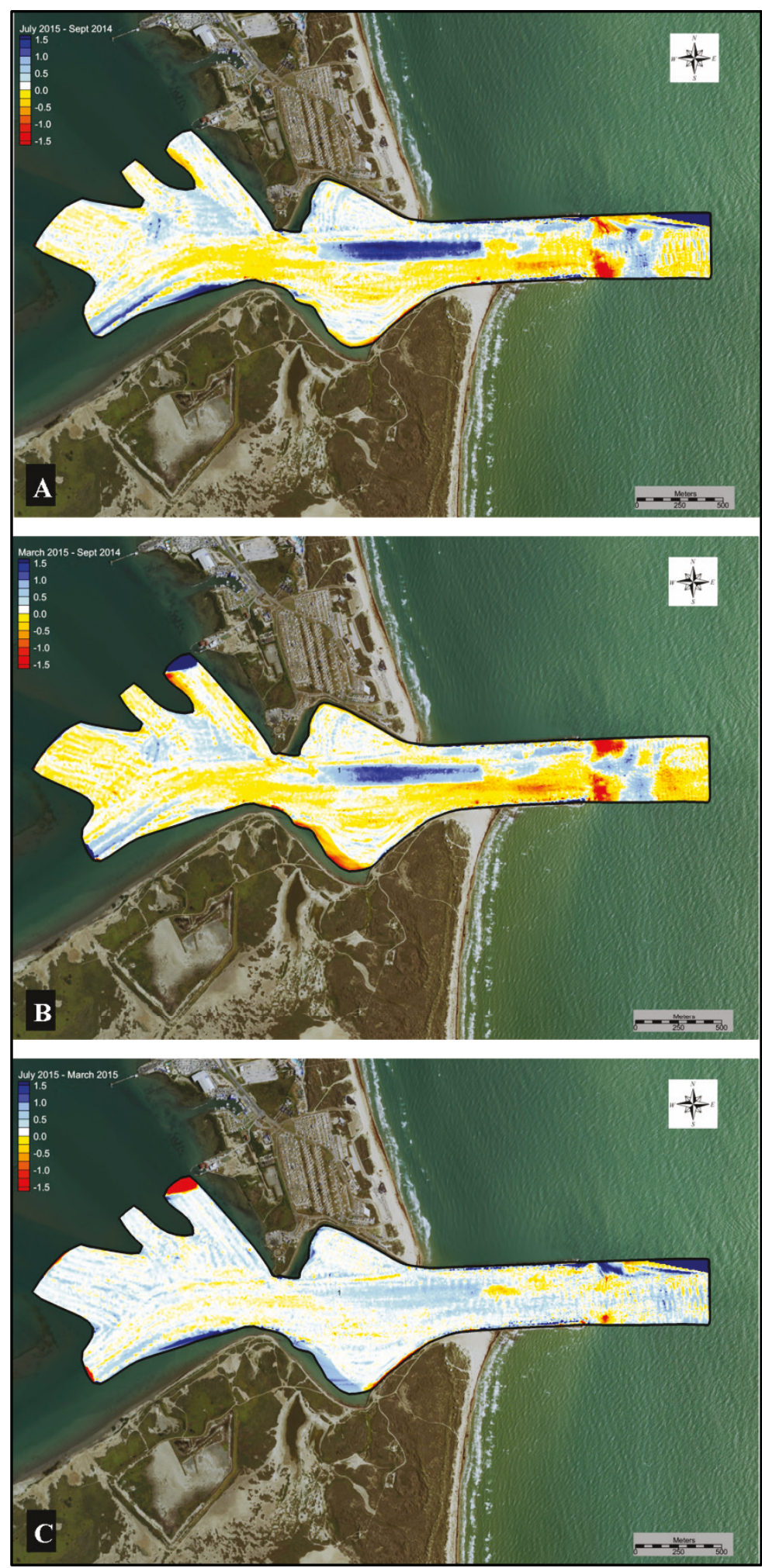
Navigation channel profiles. To examine deposition along the channel axis, depth profiles are constructed along a transect that runs from the offshore edge of the bathymetric survey, through the inlet, and to the shoreward end of the survey (see Figure 4-29, C). Bed change along the transect is computed by plotting successive profiles from the three surveys (Figure 4-31). The profiles indicate maximum shoaling of $1.3 \mathrm{~m}(4.3 \mathrm{ft})$ between September 2014 and July 2015, with the majority of sediment deposited between September 2014 and March 2015. The greatest deposition occurs in the inlet expansion consistent with the conceptual model discussed above in which flow expansion in the crenulent embayment leads to lower velocities and particle settling.

The region west of the embayment shows little change in bed elevation with slight deposition between o $\mathrm{m}$ (o ft) (along-channel distance) and $500 \mathrm{~m}(1,640 \mathrm{ft})$ and slight erosion between $500 \mathrm{~m}(1,640 \mathrm{ft})$ and $1,100 \mathrm{~m}$ $(3,610 \mathrm{ft})$. The region east of the embayment shows some erosion between 2,800 $\mathrm{m}(9,185 \mathrm{ft})$ and $3,100 \mathrm{~m}(10,170 \mathrm{ft})$ and deposition between $3,300 \mathrm{~m}(10,820 \mathrm{ft})$ and $3,400 \mathrm{~m}(11,150 \mathrm{ft})$.

Figure 4-31. Depth profile along the BSI Navigation Channel. The transect follows the centerline curve depicted in Figure 4-29, C. Depths are referenced to NAVD88.

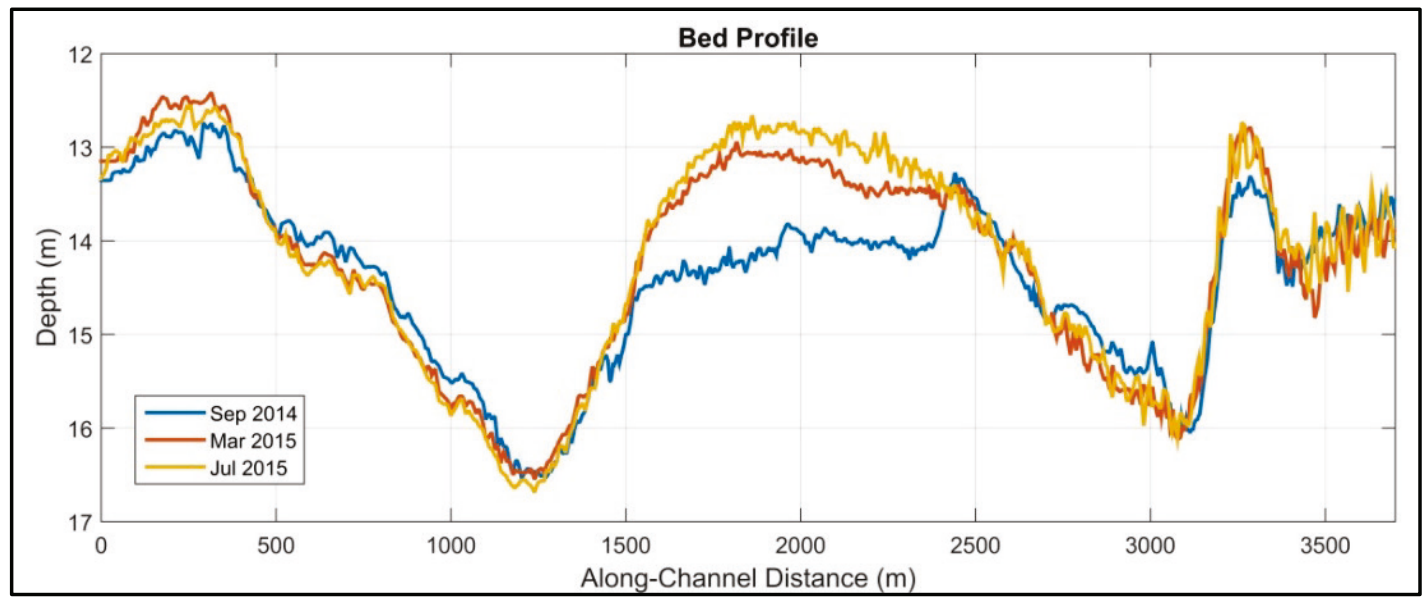




\section{Coastal Modeling System (CMS) Numerical Modeling}

Numerical simulations of the hydrodynamics and sediment transport within the BSI complex were completed using the CMS. CMS is an integrated suite of numerical models for simulating WSE, currents, waves, sediment transport, and morphology change at coastal inlets and entrances. CMS consists of a hydrodynamic model, CMS-Flow, and a spectral wave model, CMS-Wave. CMS-Flow and CMS-Wave were coupled through an internal coupling process whereby wave field information, including radiation stresses, is supplied to CMS-Flow for flow and sediment transport calculations. Currents, water levels, and morphology changes are passed backed to CMS-Wave to increase the accuracy of the wave transformation processes (Sánchez et al. 2011a,b).

\section{Previous numerical studies}

Hauck and Brown (1990) used a vertically integrated 2D numerical model RMA-2v to produce the hydrodynamics (water levels and velocities) for the existing channel condition of that time and three alternative channel designs, including the presently authorized configuration. The model was operated with winds and astronomical tides as boundary conditions to reproduce the maximum ebb and flood conditions to use in a subsequent ship simulator study. The RMA-2V model was verified to water levels and currents measured from 15-18 July 1980. The model was found to accurately reproduce velocities and tidal exchange in the project area but was unable to reproduce water levels accurately in the interior of Laguna Madre. Some of the poor response of the model in predicting the interior bay levels was hypothesized to be the result of difficulties in representing the dynamic wind field forcing on the lower Laguna Madre due to unknowns regarding wind speed and directions.

The Texas Water Development Board calibrated and validated TxBLEND, a 2D, depth-averaged hydrodynamic and salinity transport model for the Laguna Madre Estuary, which also includes Copano, Aransas, Corpus Christi, and Baffin Bays. TxBLEND was calibrated for hydrodynamic and salinity transport performance by using water velocity data collected in June 2007, surface elevation data from 1999 to 2004, and salinity records from 1991 to 1992, 1995 to 2002, 2003 to 2009, and 2008 to 2010. Simulated velocities were representative of observed velocities at most 
locations, except for Brazos Santiago Pass where measured velocities were smaller compared to simulated velocities. The model demonstrated reasonably good agreement with observed WSE throughout the Laguna Madre Estuary. Short-term, high-frequency variations in salinity fluctuations were less well represented by model than general, long-term trends.

Tate and Ross (2012) explored the hydrodynamic changes resulting from several possible enlargements of the channel using a 2D, depth-averaged implementation of the Adaptive Hydraulics numerical model code. This model included the inclusion of the Bahia Grande area. The model was validated using field data (WSE, discharge, and velocity values) from June 1997. The model is driven by tidal elevations applied at the ocean boundaries from the Gulf entrances at Brazos Santiago and Port Mansfield, river inflow at the Arroyo Colorado, and wind stresses at three locations. The model better represented the southern portion of the system in both discharge (although several stations had limited data, less than a tidal cycle) and WSE than the area to the north. Uncertain bathymetry data and unaccounted-for areas of wetting and drying are suspected to be the reasons for this decrease in model performance.

\section{Hydrodynamic models}

\section{CMS-Flow}

Model overview. CMS-Flow is a 2D, finite-volume model that solves the depth-integrated mass conservation and shallow-water momentum equations of water motion on a Cartesian grid. CMS-Flow is capable of simulating depth-averaged circulation, salinity, and sediment transport due to tides, wind, and waves and includes physical processes such as advection, turbulent diffusion, Coriolis force, wind and wave stress, bottom friction, and the influence of coastal structures. (More details on the hydrodynamic calculations can be referenced in Sánchez et al. [2014]).

Grid development. The CMS-Flow grid is located in the Texas South State Plane Coordinate System (FIPS 4205), with the origin at 410097.6, 5029497.1 and an azimuth of $346^{\circ}$. The computational grid is a nonuniform telescoping Cartesian grid, which allows for local refinement by splitting a rectangular cell into four, smaller subcells. The telescoping CMS-Flow grid for modeling the BSI complex is shown in Figure 5-1. The grid has a total number of 77,766 cells, comprised of 59,652 ocean cells and 18,114 land cells. 
Figure 5-1. Telescoping CMS-Flow grid (from Google Earth https://www.google.com/earth/).

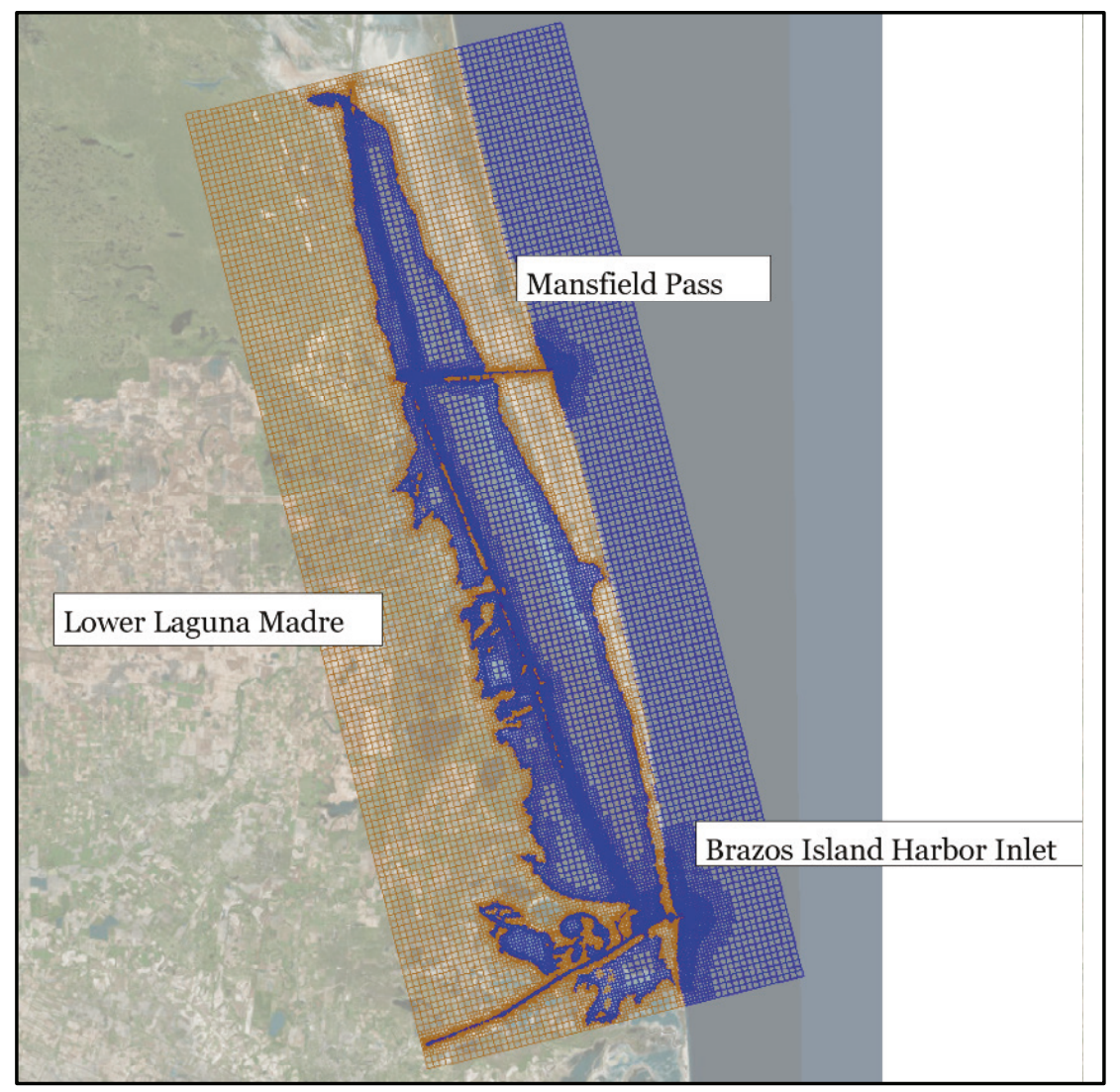

Finer sub-cell resolutions were defined in areas close to the BSI study area, within smaller channels, and areas of high flows. The grid was defined such that transitions between grid resolutions were gradual and never exceeded more than one refinement level (e.g., coarser grid resolutions were achieved by decreasing the adjacent grid resolution by a factor of 2 ). The finest grid

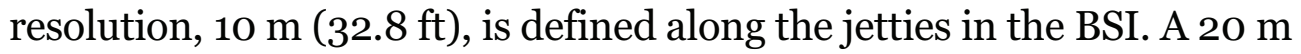
(65.6 $\mathrm{ft}$ ) resolution is found along the jetties of Mansfield Pass and within the inlet throat of the BSI. These $20 \mathrm{~m}(65.6 \mathrm{ft})$ resolutions transition to $40 \mathrm{~m}(131.2 \mathrm{ft})$ to define the intercostal waterway and the BSI and Mansfield Pass Navigation Channels. An $80 \mathrm{~m}$ (262.4 ft) resolution along the channels allows for gradual transitions to coarser resolutions within Laguna Madre's interior and defines the land-water boundaries of smaller features, such as the estuaries, along the BSI Navigation Channel. The $160 \mathrm{~m}$ (524.8 ft) resolution is found primarily along the land-water boundaries of Laguna Madre. The $160 \mathrm{~m}(524.8 \mathrm{ft})$ resolution transitions to areas of $320 \mathrm{~m}$ $(1,049.6 \mathrm{ft})$, which then transition to areas of $640 \mathrm{~m}(2099.2 \mathrm{ft})$, the coarsest resolution. The $640 \mathrm{~m}(2,099.2 \mathrm{ft})$ resolution is found in the central interior of Laguna Madre, inland areas, and in the offshore. The resolutions of the CMS-Flow grid are identified in Figure 5-2. 
Figure 5-2. Resolutions of telescoping CMS-Flow grid (from Google Earth https://www.google.com/earth/).

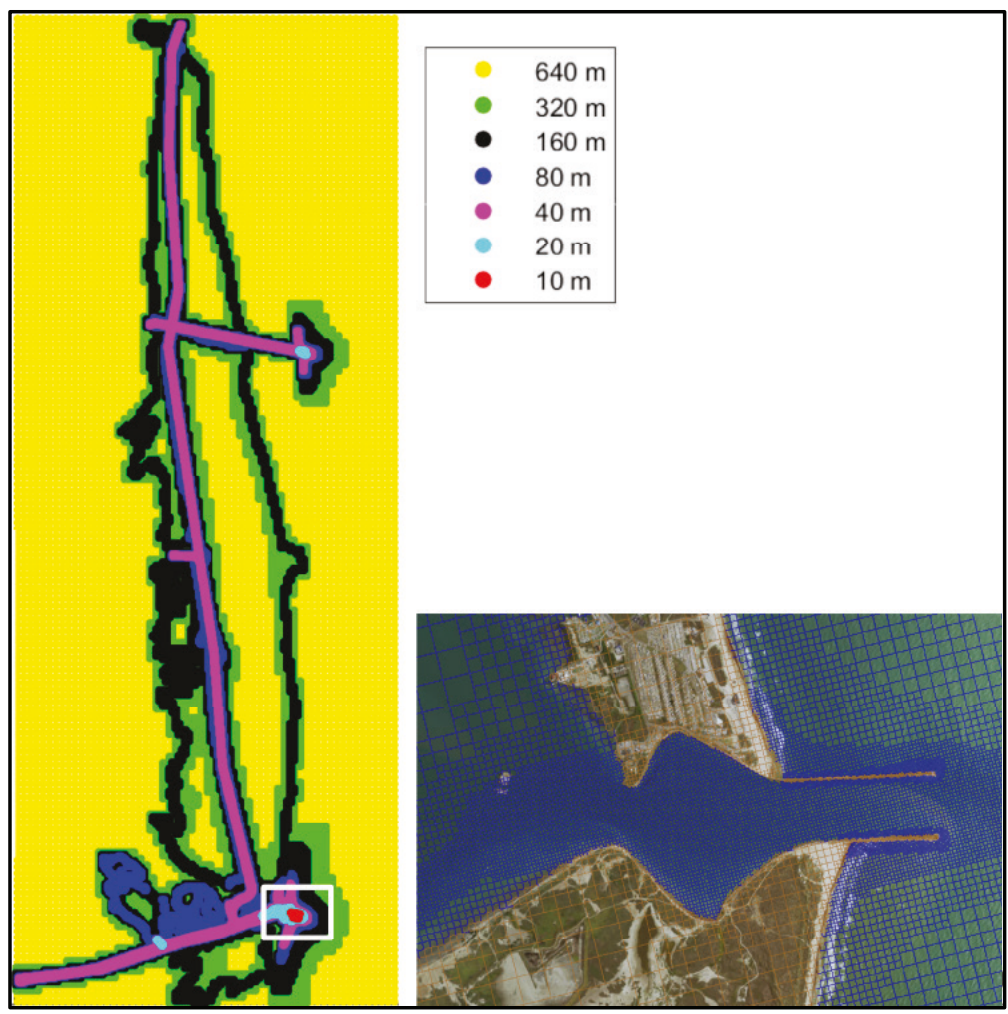

Bathymetry. The base elevations to populate the CMS-Flow grid were extracted from the Federal Emergency Management Agency Texas Joint Storm Surge Study ADCIRC Mesh. This ADCIRC mesh included both topography and bathymetry. Bathymetry within the BSI was updated with multi-beam survey data collected in September 2014 (Figure 5-3). The depths of the ADCIRC mesh and the multi-beam survey were relative to NAVD88, and a value of $-0.06 \mathrm{~m}(-0.2 \mathrm{ft})$ was used as the conversion from NAVD88 to mean sea level (MSL), which was derived from NOAA tidal station 8779748 at the South Padre Island Coastal Guard Station, Texas. The final model bathymetry of the entire CMS-Flow grid relative to MSL is shown in Figure 5-4. The successful incorporation of the multi-beam bathymetry into the CMS was verified by comparing model bathymetry to the September field data along a centerline transect within the BSI (Figure 5-4). 
Figure 5-3. Multi-beam bathymetry survey collected in September 2014 (from Google Earth https://www.google.com/earth/).

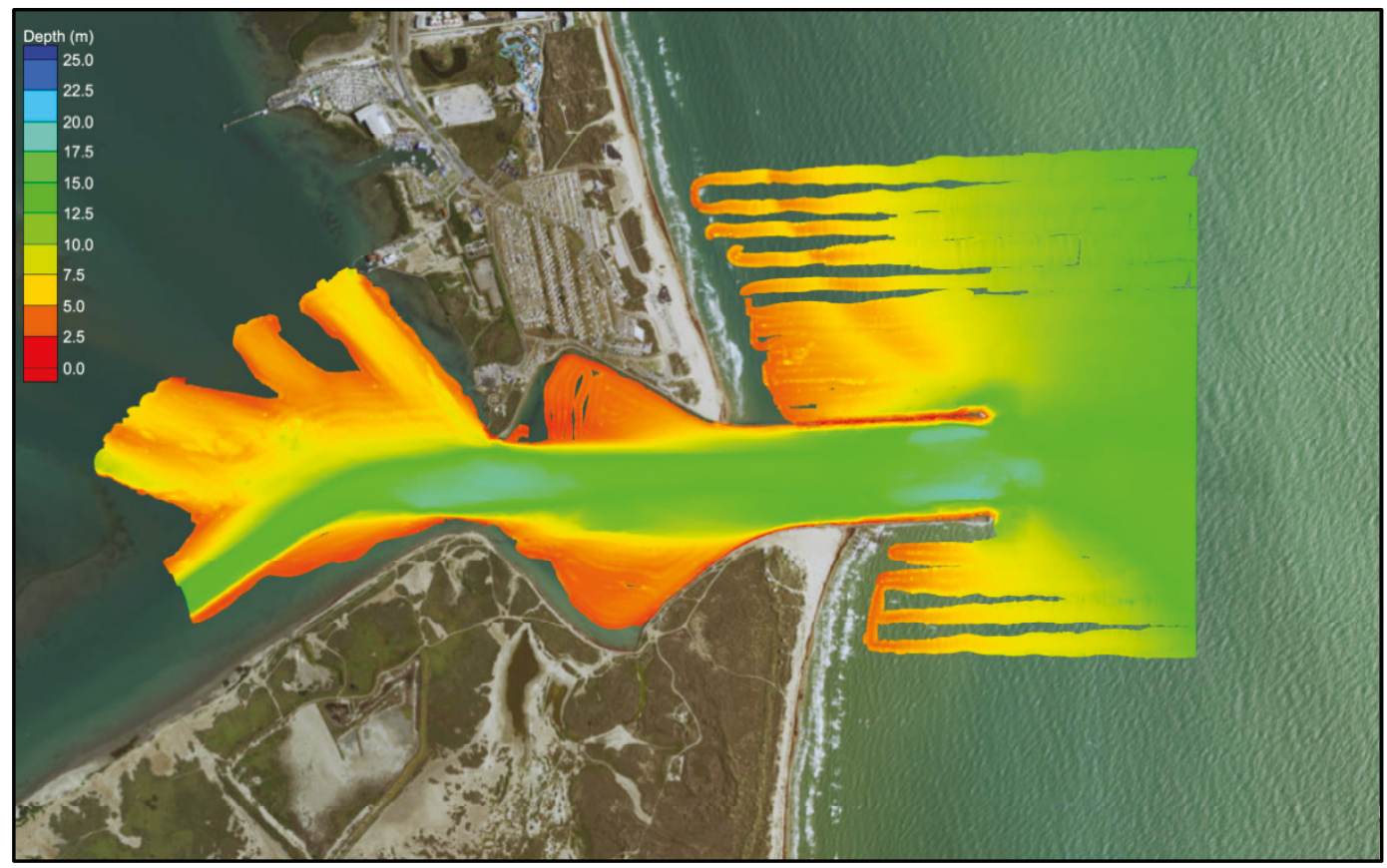

Figure 5-4. CMS-Flow bathymetry (left) with verified incorporation of multi-beam survey data into CMS (right) (from Google Earth https://www.google.com/earth/).

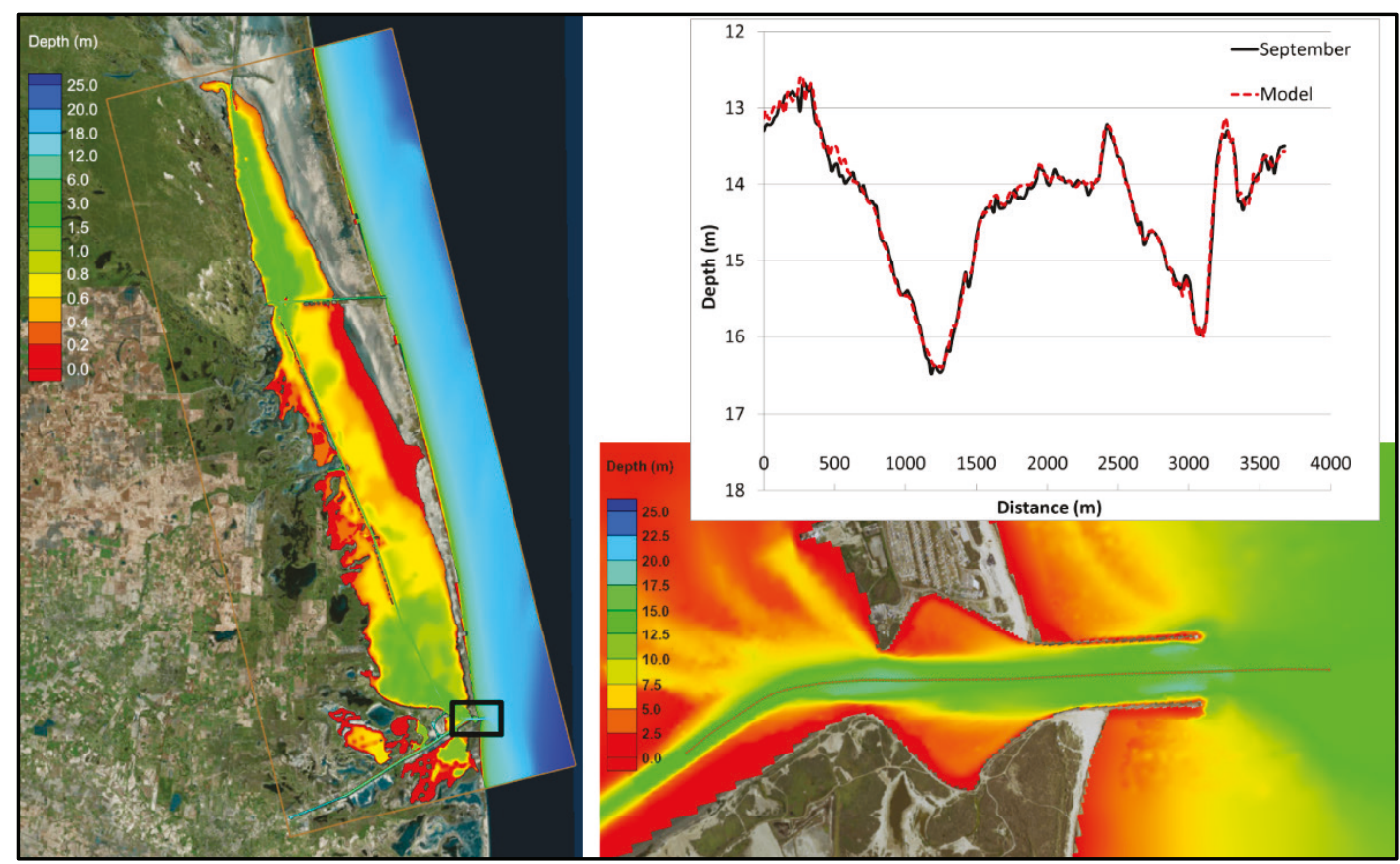

Bottom friction. The bottom friction of the CMS-Flow grid is specified as a spatially variable Manning's $n$ coefficient, as shown in Figure $5-5$. The coefficient values were selected based on Tate and Ross (2012) and calibration to measured data at available tidal stations. 
Figure 5-5. CMS-Flow Manning's $n$ (from Google Earth https://www.google.com/earth/).

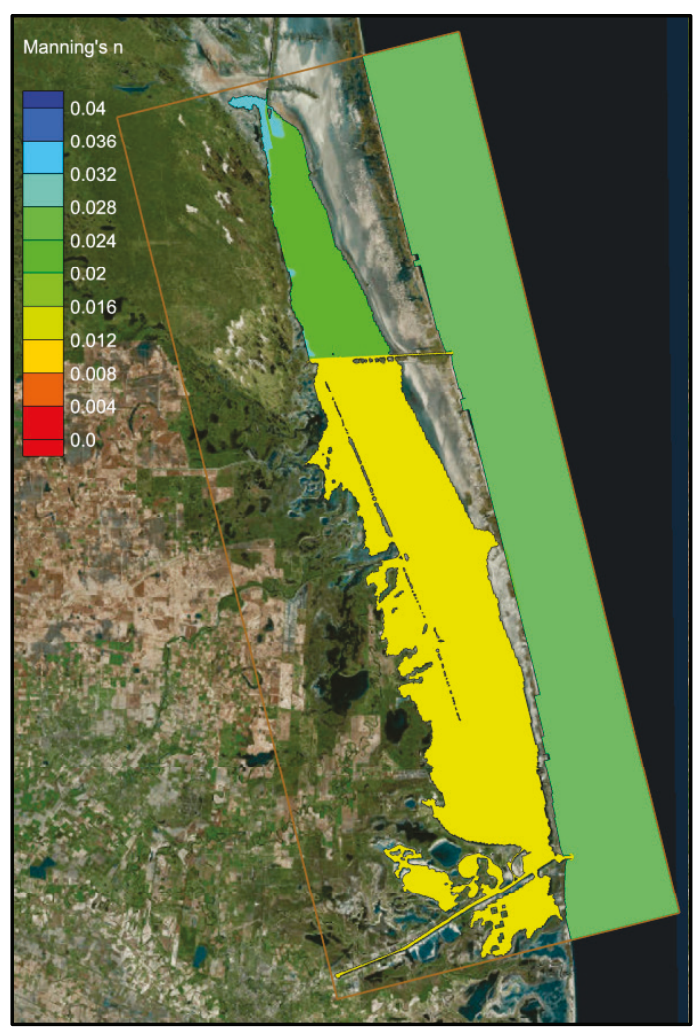

Forcing conditions. The CMS-Flow model was forced with water elevation time series data from NOAA tidal Station 8775870 at Bob Hall Pier in Corpus Christi, TX. Although NOAA 8775870 is well north of the study area, this station is the closest station located in the Gulf outside of the extensive southern Texas barrier island complex. The $6 \mathrm{~min}$ historical data was downloaded relative to MSL and sampled to half-hour intervals.

A spatially constant wind forcing was applied to the CMS-Flow domain. The NOAA station selected was Realitos Peninsula, 8779280, due to its relatively complete data record and centralized location to the entire domain. Again, 6 min wind speed and direction data were sampled to halfhour intervals to force the model. Freshwater inflow boundary conditions were considered to be insignificant to the hydrodynamic considerations of this study.

Model parameters. CMS-Flow has many user-specified parameters, coefficients, and options, which are specified within the model graphical user interface (GUI) or as model cards. As many options were left default, the options used are presented in Appendix C. For the sediment modeling, 
CMS-Flow was executed for a year, starting on 12 September 2014 at 12:00 a.m. and spun-up for 1 day to allow the hydrodynamics to reach equilibrium. The hydrodynamic time step for CMS-Flow was $300 \mathrm{~s}$.

Data output and save points. Hydrodynamic data, including WSE and velocity, were exported hourly for the entire grid. Select cells were chosen to output data more frequently, every $30 \mathrm{~min}$. These selected cell locations correspond to the locations of existing TCOON and NOAA tide gages as well as tide gages deployed as part of the field data collection effort.

\section{CMS-Wave}

Model overview. CMS-Wave is a 2D, phase-averaged spectral wave model based on the wave-action balance equation (Mase 2001):

$$
\begin{aligned}
& \frac{\partial\left(C_{x} N\right)}{\partial x}+\frac{\partial\left(C_{y} N\right)}{\partial y}+\frac{\partial\left(C_{\theta} N\right)}{\partial \theta} \\
& =\frac{\kappa}{2 \sigma}\left[\left(C C_{g} \cos ^{2} \theta N_{y}\right)_{y}-\frac{C C_{g}}{2} \cos ^{2} \theta N_{y y}\right]-\epsilon_{b} N-S
\end{aligned}
$$

where $\mathrm{N}=\mathrm{E}(\sigma, \theta) / \sigma$ is the wave-action density to be solved and is a function of frequency $\sigma$ and direction $\theta$. Other parameters are defined as the following:

$$
\begin{aligned}
x, y= & \text { coordinates } \\
C= & \text { wave celerity } \\
C_{g}= & \text { wave group velocity } \\
\kappa= & \text { empirical parameter representing the intensity of diffraction } \\
& \text { effect } \\
\varepsilon_{\mathrm{b}}= & \text { parameterization of wave breaking dissipation } \\
S= & \text { energy source and sink terms. }
\end{aligned}
$$

Capabilities of CMS-Wave include wave shoaling, refraction, diffraction, reflection, transmission over structures, depth-limited breaking, dissipation, wave-wave interaction, wave-current interaction, and wavestructure interactions. (Refer to the CMS-Wave documentation [Lin et al. 2008] for additional model features and technical details).

Grid development. The CMS-Wave grid developed for this work is a non-uniform Cartesian grid located in the State Plane Coordinate System, 
Texas South (FIPS 4205) projection. A non-uniform CMS-Wave grid contains variable rectangular cells and allows for finer resolution in nearshore areas of interest. For this application, the coarsest resolution was $200 \mathrm{~m}(656 \mathrm{ft})$, which transitions to $20 \mathrm{~m}(65.6 \mathrm{ft})$ within the BSI. The grid's origin is (453118.1,5053974.8), and the grid is rotated counterclockwise from the $x$-axis by $181.7^{\circ}$. The grid has an expanse of $21,113.4 \mathrm{~m}(69,252 \mathrm{ft})$ in the $x$-direction and $16,868.4 \mathrm{~m}(55,325 \mathrm{ft})$ in the $y$-direction. The grid's offshore boundary was extended to the $30 \mathrm{~m} \mathrm{(98.4}$ $\mathrm{ft}$ ) depth contour. Wave interactions with the bottom at this offshore extent are relatively small, particularly in comparison to the importance of wave generation. The location of the CMS-Wave grid with respect to the CMS-Flow grid is shown in Figure 5-6, with a closeup of the CMS-Wave grid and bathymetry in Figure 5-7. The darker areas in Figure 5-7 are the variable rectangular cells transitioning from a maximum resolution of $200 \mathrm{~m}(656 \mathrm{ft}$ ) along the model domain fringes to the finest resolution of $20 \mathrm{~m}(65.6 \mathrm{ft})$ within the BSI. The bathymetry of the CMS-Wave grid was interpolated from the same MSL dataset to populate the CMS-Flow grid and included the recent multi-beam bathymetry.

Figure 5-6. Location of CMS-Wave grid with respect to CMS-Flow domain (from Google Earth https://www.google.com/earth/).

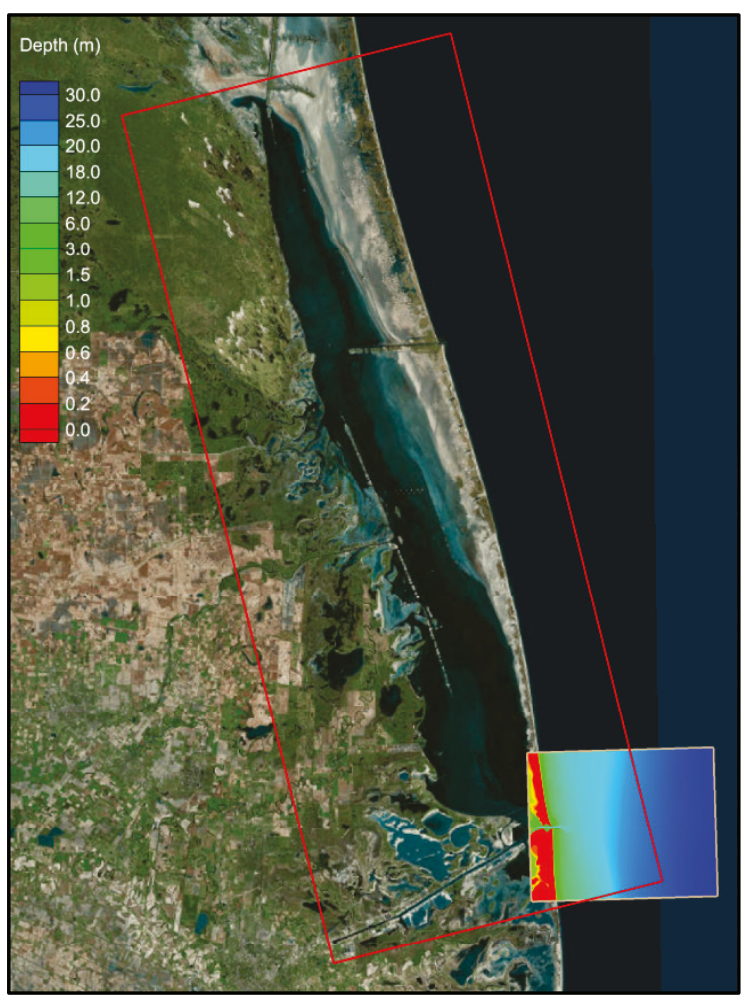


Figure 5-7. Non-uniform CMS-Wave grid and bathymetry (from Google Earth https://www.google.com/earth/).

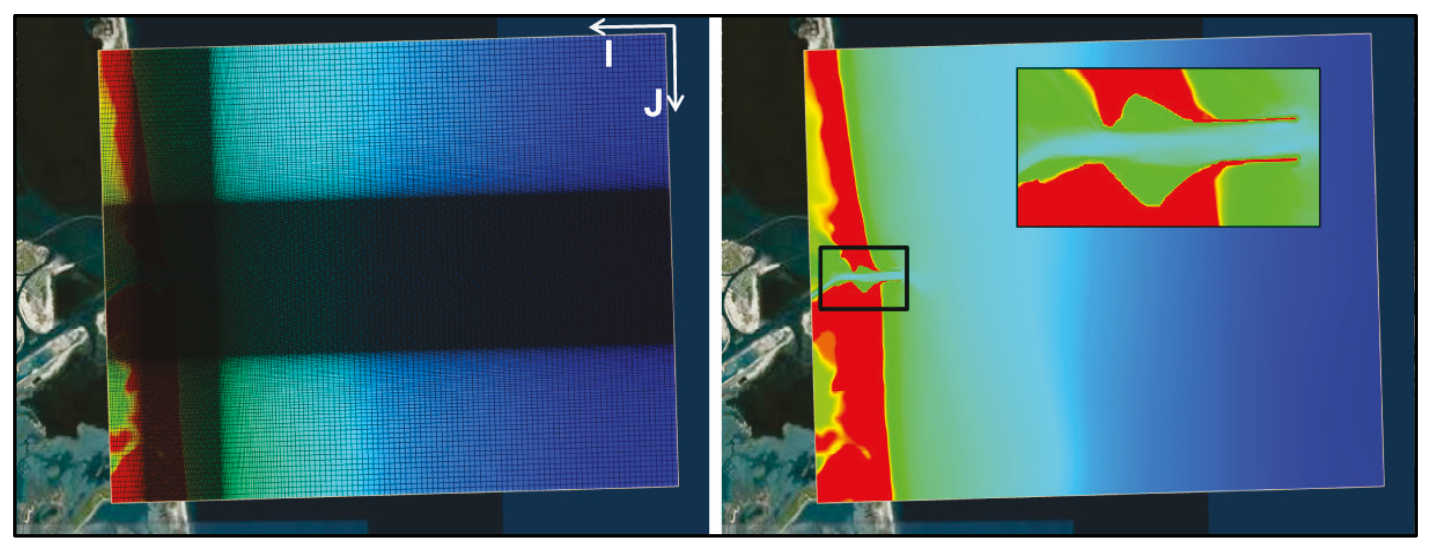

Forcing conditions. Offshore wave and spatially constant wind forcing for the CMS-Wave domain were obtained from the National Data Buoy Center buoy 42020, which is 69 statute miles (6o nautical miles) southsoutheast of Corpus Christi, TX. Wave spectra from 42020, located at a

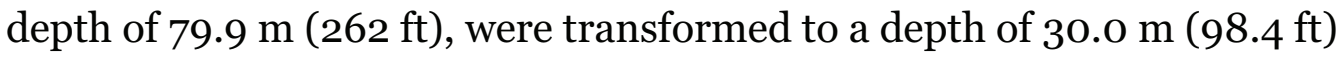
to be applied along the offshore boundary of the CMS-Wave domain. The number of discrete frequency bands was 40 bands, progressing from a low frequency of 0.06 hertz $(\mathrm{Hz})(\mathrm{T}=16.7 \mathrm{~s})$ to a high frequency of $0.45 \mathrm{~Hz}(\mathrm{~T}$ $=2.2 \mathrm{~s}$ ) with a constant frequency increment of $0.01 \mathrm{~Hz}$. Because the simulations span multiple months, CMS-Wave was executed in fast mode to minimize simulation time. Fast-mode CMS-Wave runs at least five times faster by reducing the number of directional bins for half-plane simulations from 35 ( $5^{\circ}$ angular resolution) to 7 ( $25^{\circ}$ angular resolution). As a consequence, the wave direction in fast mode is expected to be less accurate because the directional calculation is based on fewer bins. Like CMS-Flow, the model was executed for a year, starting on 12 September 2014 at 12:00 a.m. and run at 2-hour (hr) steering intervals for the sediment modeling.

Data output and save points. Wave data (e.g., wave height, peak wave period, and mean wave direction) were exported for each grid cell during each time-step. In addition to wave parameters, wave spectra were outputted at specific cell locations. The selected cell locations correspond to the locations of the inner and outer AWAC deployed from August 2014 to September 2015. 


\section{Coupled CMS-Flow and CMS-Wave}

The CMS hydrodynamic modeling effort used both CMS-Flow and CMSWave, coupled together to determine the sediment transport due to tidal and wave conditions. The two-way coupling process for this effort was driven internally by the CMS (referred to as inline coupling) and is illustrated in Figure 5-8. This inline coupling process is performed as follows:

1. CMS-Wave is run the first two time-steps, and the wave information is passed to CMS-Flow.

2. The wave height, period, wave dissipation, radiation stress gradients, and wave unit vectors are interpolated spatially from the CMS-Wave grid to the CMS-Flow grid for flow and sediment transport calculations.

3. CMS-Flow is run until the next steering interval, and wave variables are linearly interpolated throughout time during the specified steering interval. At each flow time-step, variables such as wave length and bottom orbital velocities are updated using the water depths and current velocities.

4. Water levels, current velocities, and bed elevations are estimated for the next wave time-step and are interpolated from the CMS-Flow grid to the CMS-Wave grid.

5. CMS-Wave is run again for the following time-step.

6. Steps $2-5$ are repeated until the end of the simulation.

Figure 5-8. CMS-Flow and CMS-Wave inline coupling process.

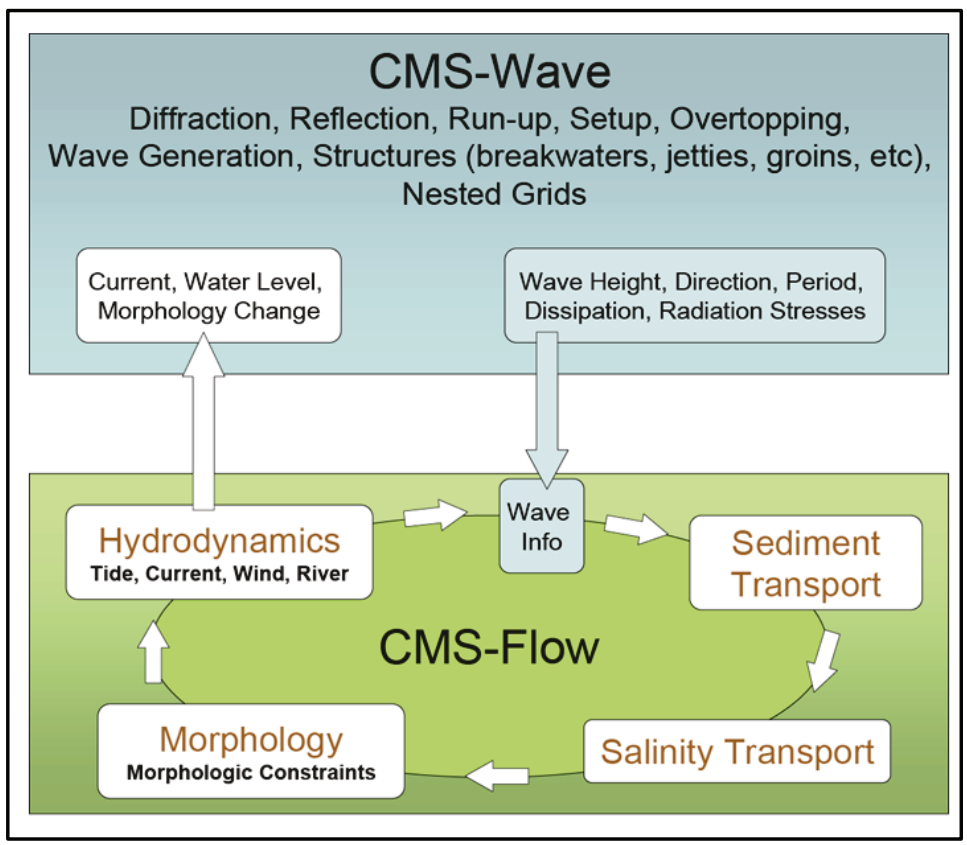




\section{Sediment model}

\section{Model overview}

A single-size, non-equilibrium total-load transport model was applied within CMS-Flow to perform sediment transport:

$$
\frac{\partial}{\partial t}\left(\frac{h C_{t}}{\beta_{t}}\right)+\frac{\partial\left(h U_{j} C_{t}\right)}{\partial x_{j}}=\frac{\partial}{\partial x_{j}}\left[v_{s} h \frac{\partial\left(r_{s} C_{t}\right)}{\partial x_{j}}\right]+\alpha_{t} \omega_{s}\left(C_{t^{*}}-C_{t}\right)
$$

where:

$$
\begin{aligned}
h & =\text { water depth } \\
U_{j} & =\text { current velocity } \\
C_{t} & =\text { total-load sediment concentration } \\
v_{s} & =\text { horizontal sediment mixing coefficient } \\
r_{s} & =\text { fraction of suspended load in total load } \\
C_{t^{*}} & =\text { equilibrium total-load sediment concentration } \\
\alpha_{\mathrm{t}} & =\text { total-load adaptation coefficient } \\
\omega_{\mathrm{s}} & =\text { sediment fall velocity } \\
C_{t^{*}} & =\text { equilibrium total-load concentration. }
\end{aligned}
$$

In the above equation, the first term represents the temporal variation of $\mathrm{C}_{\mathrm{t}}$, the second term represents the horizontal advection, the third term represents the horizontal diffusion and dispersion of suspended sediments, and the last term represents the erosion and deposition. In this model, the sediment transport is separated into current- and wave-related transports. The transport due to currents includes the stirring effect of waves, and the wave-related transport includes the transport due to asymmetric oscillatory wave motion as well as steady contributions by Stokes drift, surface roller, and undertow. The current-related bed and suspended transports are combined into a single total-load transport equation, thus reducing the computational costs and simplifying the bed change computation.

The fractional bed change is calculated as

$$
\rho_{s}\left(1-p_{m}^{\prime}\right) \frac{\partial z_{b}}{\partial t}=\alpha_{t} \omega_{s}\left(C_{t}-C_{t^{*}}\right)+\frac{\partial}{\partial x_{j}}\left(D_{s} q_{b} \frac{\partial z_{b}}{\partial x_{j}}\right)
$$


where:

$$
\begin{aligned}
\rho_{s} & =\text { sediment density } \\
p_{m}^{\prime} & =\text { bed porosity } \\
Z b & =\text { bed elevation with respect to vertical datum } \\
D_{s} & =\text { empirical bed-slope coefficient } \\
q_{b k} & =\text { bed-load mass transport rate magnitude. }
\end{aligned}
$$

The van Rijn bed-load and suspended-load sediment transport rates were applied:

$$
\begin{gathered}
q_{b^{*}}=f_{b} \rho_{s} 0.015 U h\left[\frac{U_{e}-U_{c r}}{\sqrt{(s-1) g d_{50}}}\right]^{1.5}\left(\frac{d_{50}}{h}\right)^{1.2} \\
q_{s^{*}}=f_{s} \rho_{s} 0.012 U d_{50}\left[\frac{U_{e}-U_{c r}}{\sqrt{(s-1) g d_{50}}}\right]^{2.4} d_{*}^{-0.6}
\end{gathered}
$$

where:

$$
\begin{aligned}
q_{b^{*}} & =\text { equilibrium bed-load transport rate } \\
f_{b} & =\text { bed-load scaling factor } \\
U_{e} & =\text { effective depth-averaged velocity } \\
U_{c r} & =\text { critical depth-averaged velocity for incipient motion } \\
s & =\text { sediment specific gravity or relative density } \\
g & =\text { gravitational constant } \\
d & =\text { grain size } \\
q_{s^{*}} & =\text { equilibrium suspended-load transport rate } \\
f_{s} & =\text { suspended-load scaling factor } \\
d^{*} & =\text { dimensionless grain size. }
\end{aligned}
$$

(More details of the sediment transport model are presented by Sánchez et al. [2014]).

\section{Model parameters}

The bed-load and suspended-load scaling factors serve as calibration factors for improving model results compared to measured bathymetry and were set to a value of 0.8 . Because focus is on shoaling within the inlet, the sediment material size was defined by taking the average median grain size, 
D50, of bed samples within the inlet throat (samples S-30 through S-34). The single sediment D50 size specified within the model was $0.24 \mathrm{~mm}$ (0.0095 in.). The bed composition was further defined using an average 9oth percentile diameter, D90, of $0.55 \mathrm{~m}$ (0.022 in.). The sediment density was set as 2,650 kilograms $/ \mathrm{m}^{3}$ ( 165 pounds/ $\mathrm{ft} 3$ ), which is often assumed to be the density of natural sands, with a porosity of 0.4. A hard bottom dataset was applied in the CMS-Flow model to prevent hot spots of rapid, unrealistic erosion, particularly around the jetties. Non-erodible cells were specified along the jetties, as seen in Figure 5-9. The sediment component of CMS-Flow has many user-specified parameters, coefficients, and options, which are specified within the model GUI or as model cards. The sediment options used are presented in Appendix C. To avoid initial bed erosion, the start time of morphology change was delayed $24 \mathrm{hr}$ such that the end of the spin-up time matched the start time of the morphology change and time of initial bathymetry (13 September 2014). With the implicit solver of the CMS, the sediment and morphologic time-step are set to the hydrodynamic time-step.

\section{Data output and save points}

Bed morphology change for the CMS-Flow grid was exported daily.

Figure 5-9. Specified non-erodible hard bottom dataset indicated by red cells.

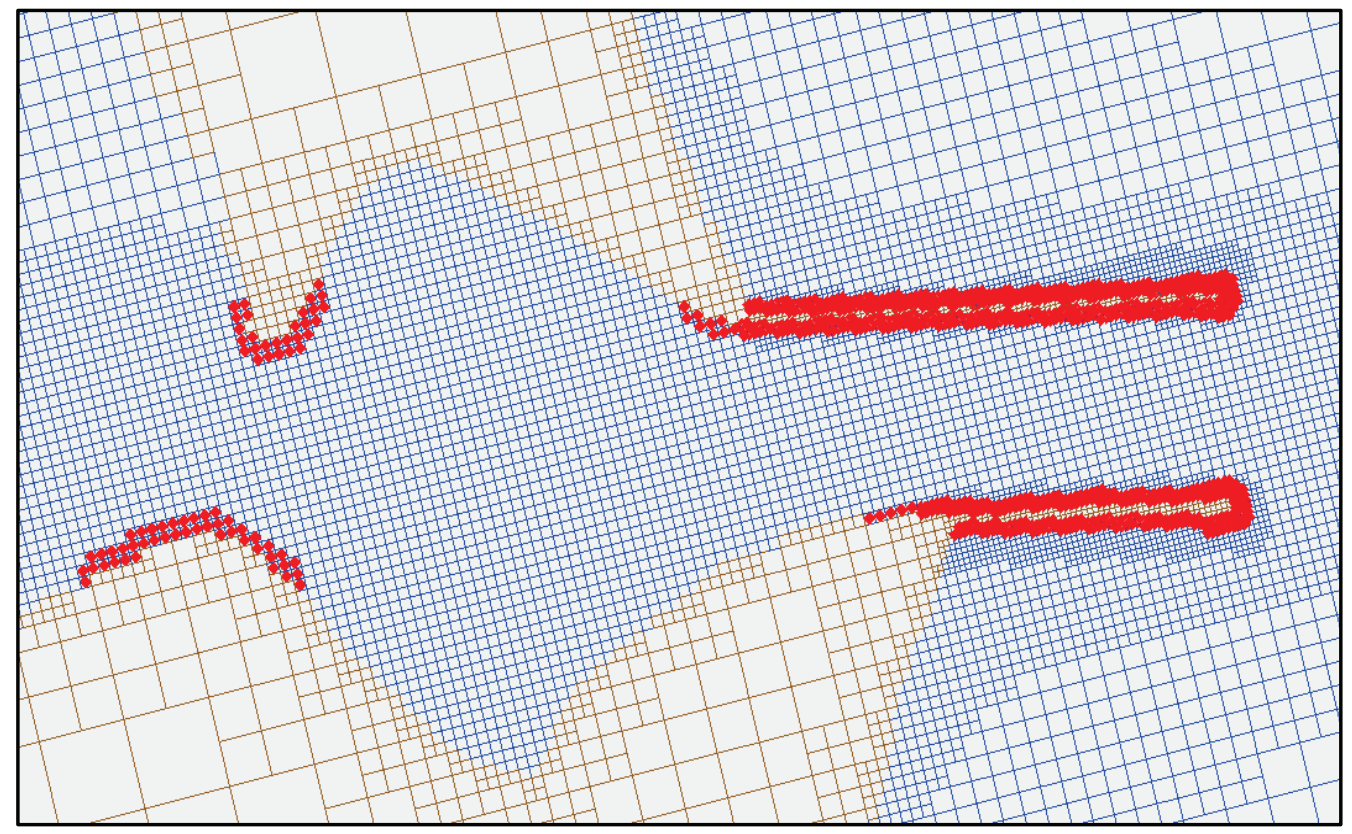




\section{Numerical Model Evaluation}

\section{General considerations}

Model evaluation was performed to ensure CMS-Flow and CMS-Wave predicts the hydrodynamics and morphological change of the study area. Model performance is influenced by the accuracy of the governing equations, the forcing functions specified at open-water boundaries (e.g., tidal constituents, offshore wave energy) and across the domain (e.g., winds), representation of the study area (e.g, bathymetry, shoreline delineation), and values selected for model parameters, such as bottom friction. The hydrodynamic and sedimentation evaluation for this project consists of comprehensive comparisons of model results to available measurements.

\section{Available hydrodynamic measurements}

The locations of measurement sites for hydrodynamic data from 2014 to 2015 are shown in Figure 6-1. The measurements for model evaluation were mined from numerous sources, including CHL, NOAA (Port Isabel, $26.0617 \mathrm{~N}, 97.2150 ; 8779770$ ), and TCOON. Gathered data consisted of water levels, water velocity, and integral wave parameters. All data are relative to Coordinated Universal Time.

Primary water levels were obtained at half-hour intervals for the TCOON gages and at 6 min intervals for the NOAA gage; these 6 min data were later subset to half-hour intervals to match the output of the TCOON gages. Data referenced to the model datum, MSL, were obtained wherever possible. However, data obtained for Rincon and Port Mansfield were referenced to NAVD88. To convert these data to MSL, conversion factors were obtained using the station datum and calculated as -0.12 and -0.07 for Rincon and Port Mansfield, respectively. Tide gages deployed by CHL were also referenced to NAVD88. The conversions to MSL for these locations are unknown; thus, the data were aligned such that the water surface fluctuations were approximately the same mean (e.g., the bias between the model results and measurements was forced to zero). The CHL tide gages sampled water levels every $15 \mathrm{~min}$. The NOAA, TCOON, and CHL gage locations were specified in CMS-Flow as observation sites. Water levels were produced every $30 \mathrm{~min}$ by CMS-Flow at these sites and were paired to measurements within a 5 min tolerance. 
AWACs deployed by CHL collected current velocity, water level, and wave information, including wave height, peak period, and wave direction. Current velocity and water level measurements were collected every 10 min and compared to half-hourly outputs from CMS-Flow within a 5 min tolerance. Wave parameters were outputted from CMS-Wave every $2 \mathrm{hr}$ and paired to hourly AWAC measurements within a 30 min tolerance.

Figure 6-1. Location of measurements for model evaluation. TCOON gages are represented by red symbols, NOAA gages are represented by blue symbols, and $\mathrm{CHL}$ gages are represented by green symbols. Teardrop symbols are water level gages, and circular symbols are AWACs (from Google Earth https://www.google.com/earth/).

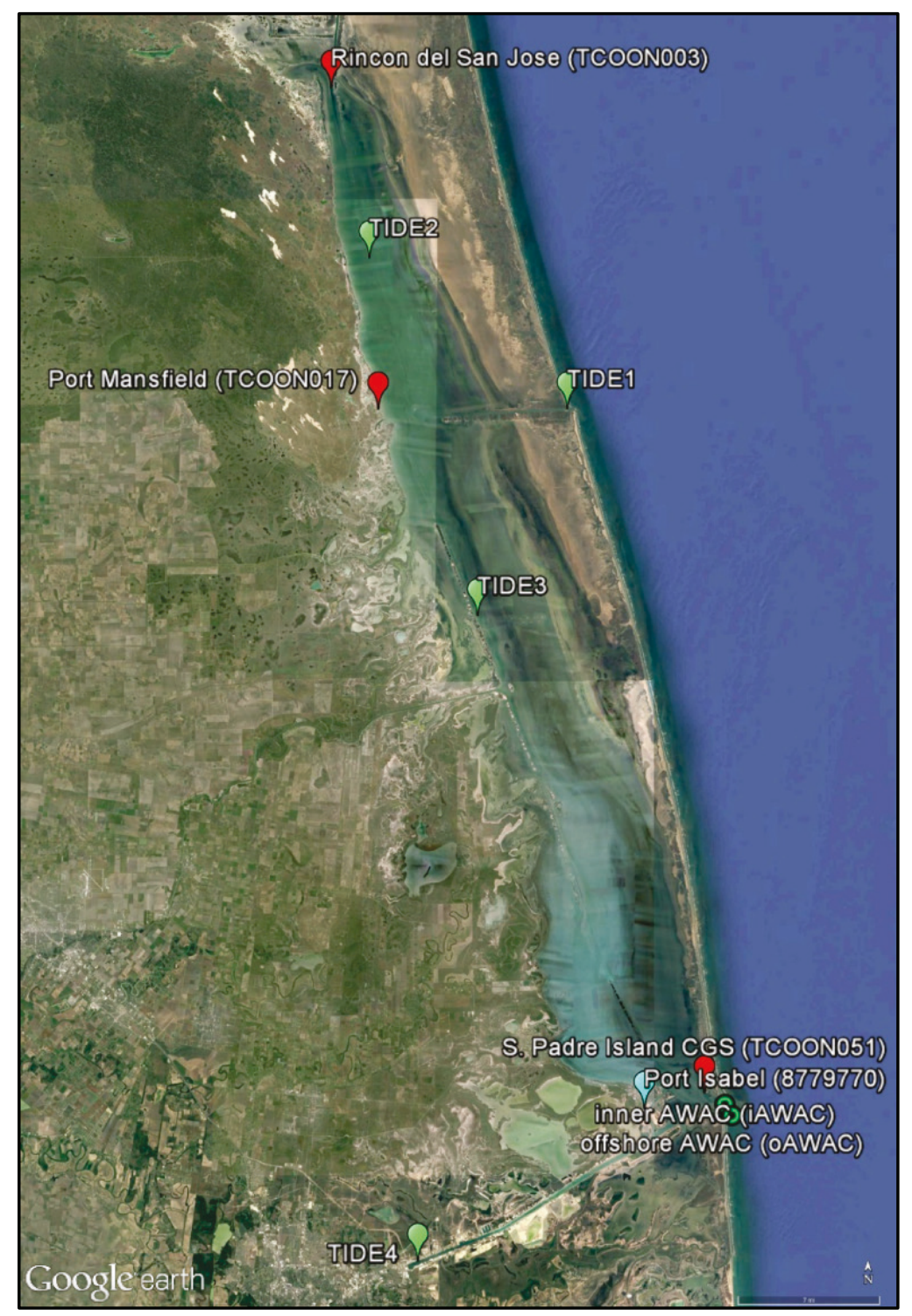




\section{Evaluation timeframes}

\section{August-23 September 2014}

The first period for model evaluation was 25 August-23 September 2014, which corresponds to the first deployment of the CHL instruments. During this timeframe, the AWAC deployed inside the inlet (iAWAC) was entirely operational whereas the acoustic sensors of the AWAC offshore of the inlet (oAWAC) were operational until September 2. To model this timeframe, the coupled CMS-Flow and CMS-Wave model was started 25 August 2014 with a half-day spin-up and concluded 25 September 2014.

Water levels. Comparisons of modeled water levels to measured water levels are displayed in Figure 6-2 through Figure 6-9, beginning with the gage farthest from the study site (Rincon) and proceeding to the gage closest to the study site (S. Padre Island). The top panel is a comparison of the water level time series, and the bottom panel is a scatter diagram with the line of best fit plotted. For each gage, a series of statistics including (1) the bias (model-measured), (2) the root-mean-square error (RMSE), (3) the correlation, and (4) the Willmott's index of agreement were calculated (Willmott et al. 2012). The upper limit of Willmott's index is 1.0 and indicates perfect model performance.

Figure 6-2. Water level comparison at Rincon for 25 August - 23 September 2014.
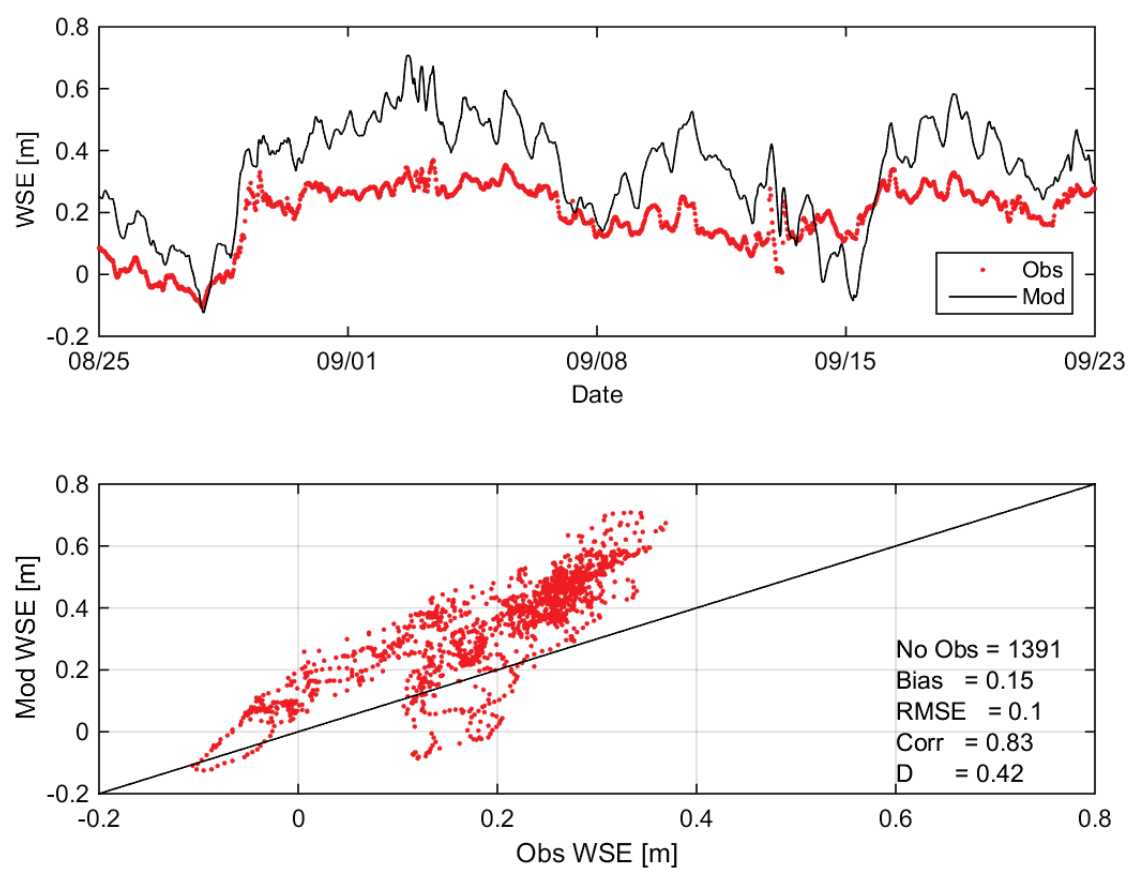
Figure 6-3. Water level comparison at TIDE2 for 25 August - 23 September 2014.
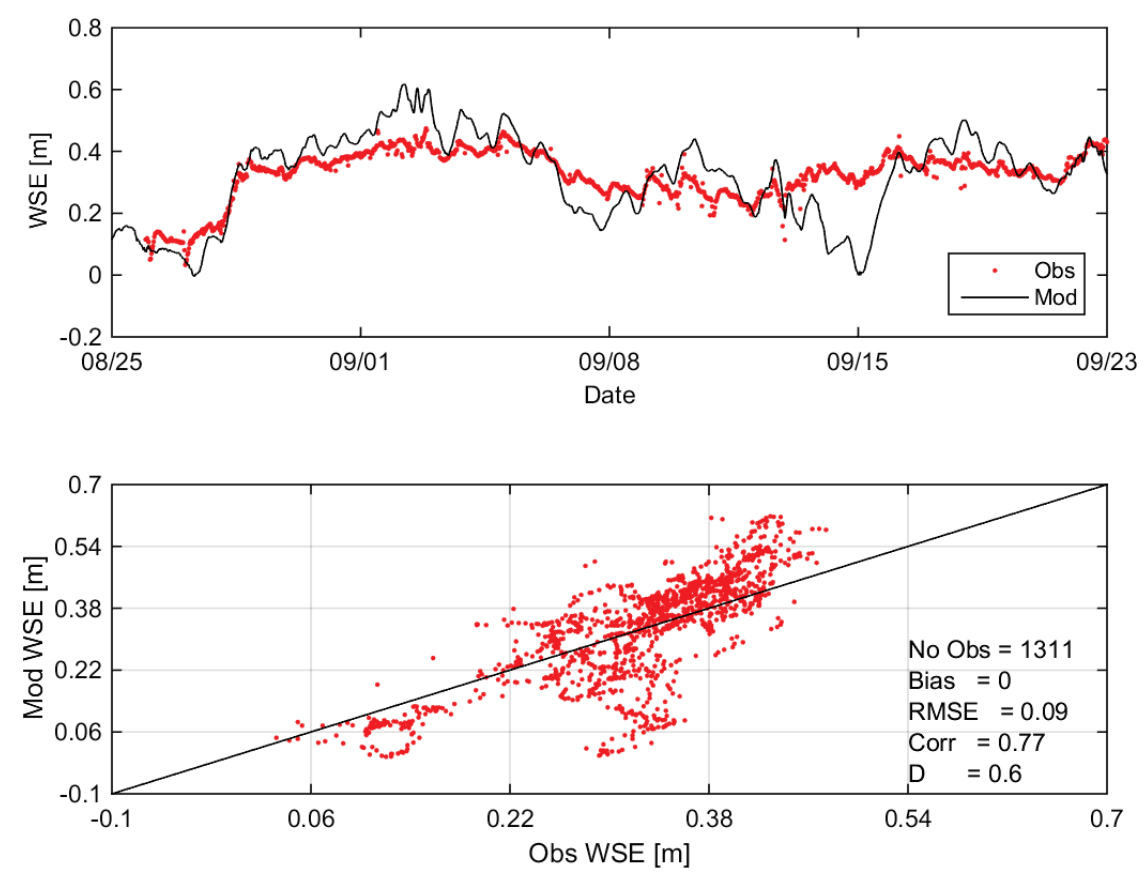

Figure 6-4. Water level comparison at Port Mansfield for 25 August - 23 September 2014.
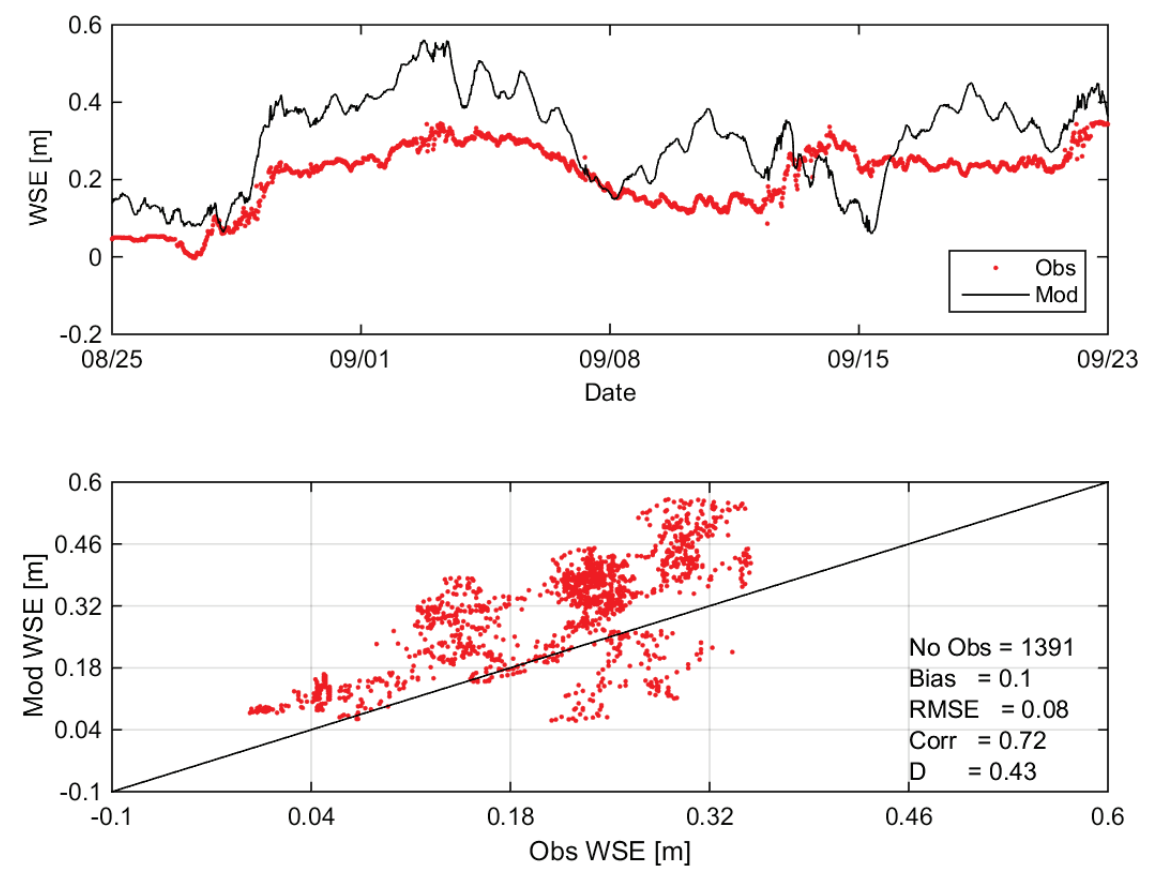
Figure 6-5. Water level comparison at TIDE1 for 25 August - 23 September 2014.
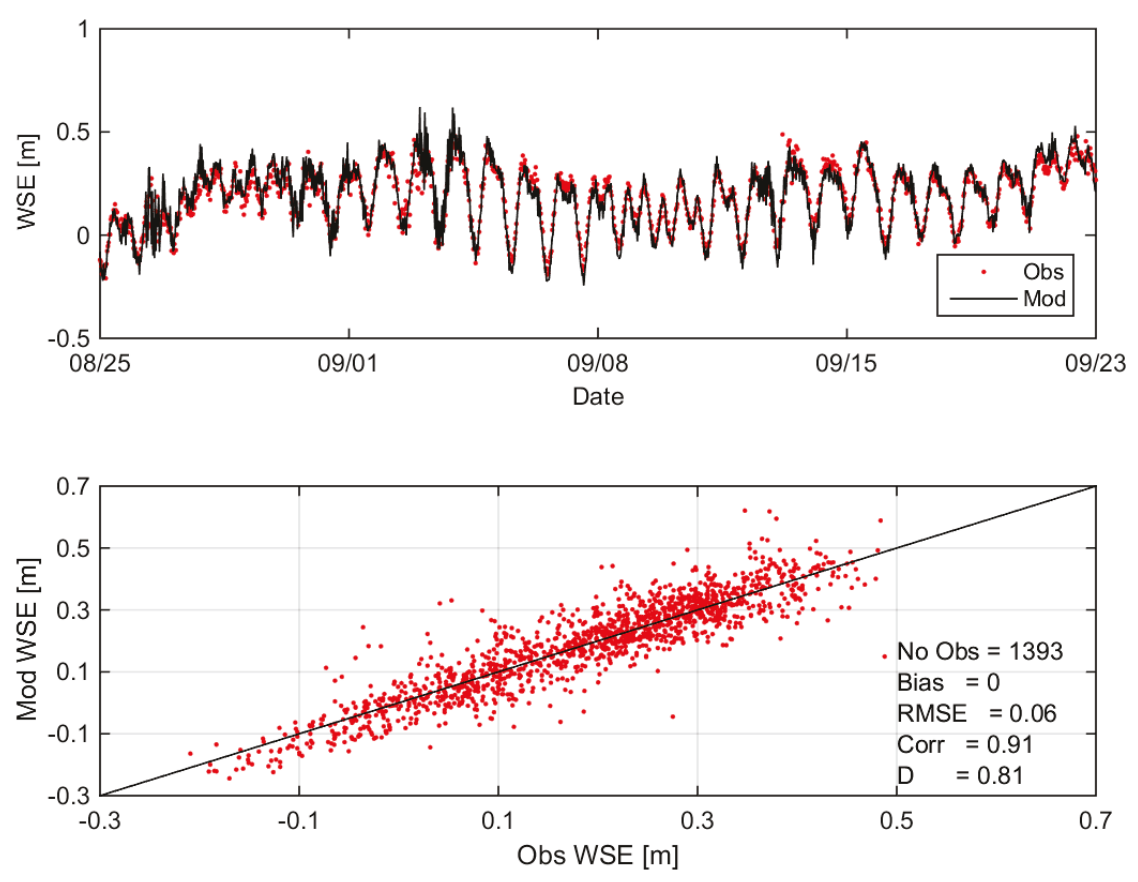

Figure 6-6. Water level comparison at TIDE3 for 25 August - 23 September 2014.
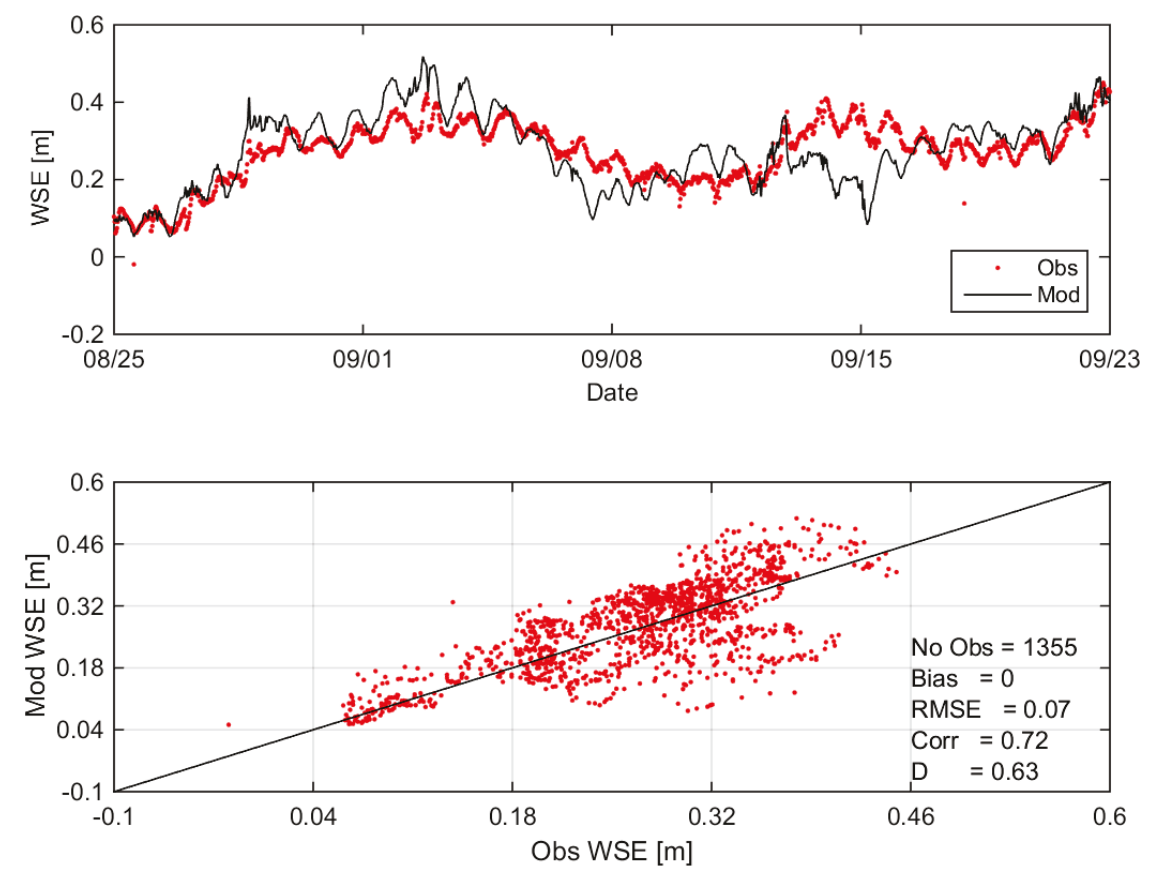
Figure 6-7. Water level comparison at Port Isabel for 25 August - 23 September 2014.
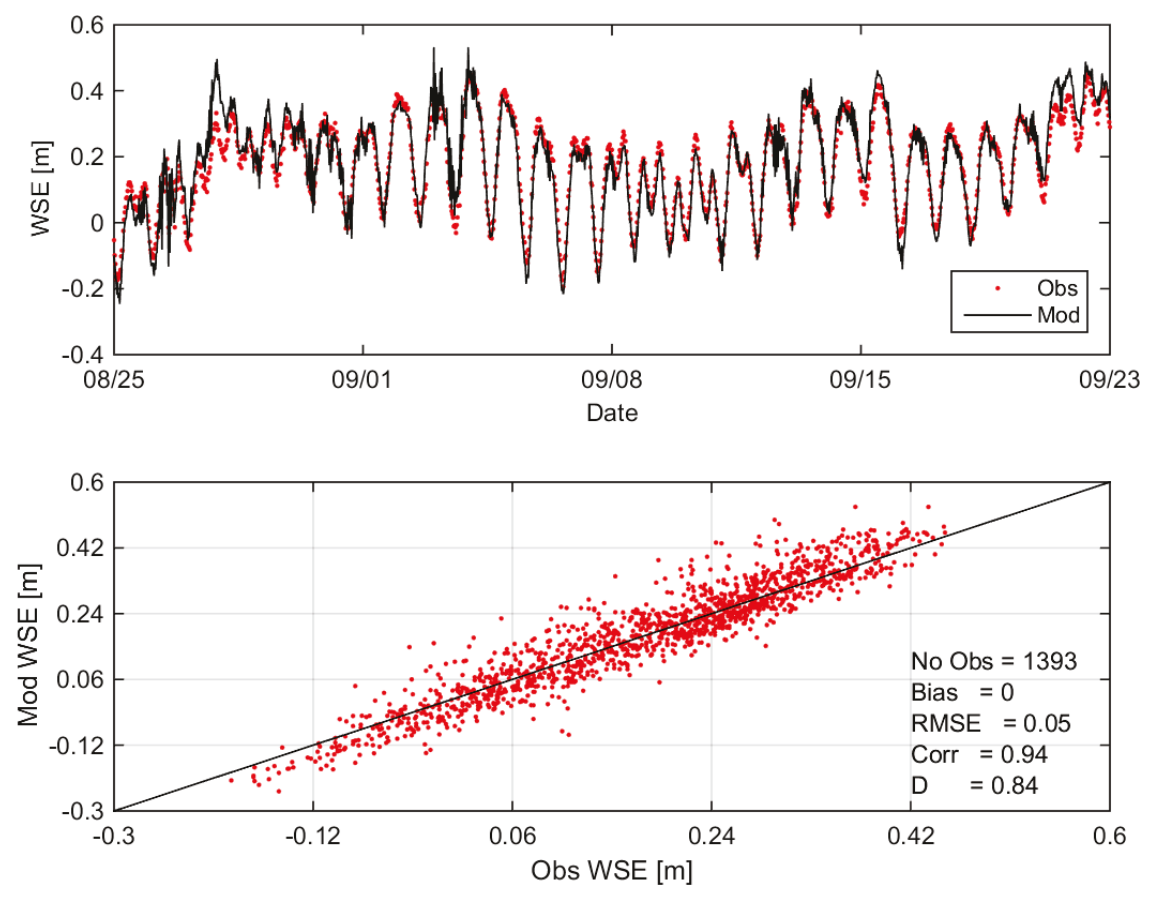

Figure 6-8. Water level comparison at TIDE4 for 25 August - 23 September.
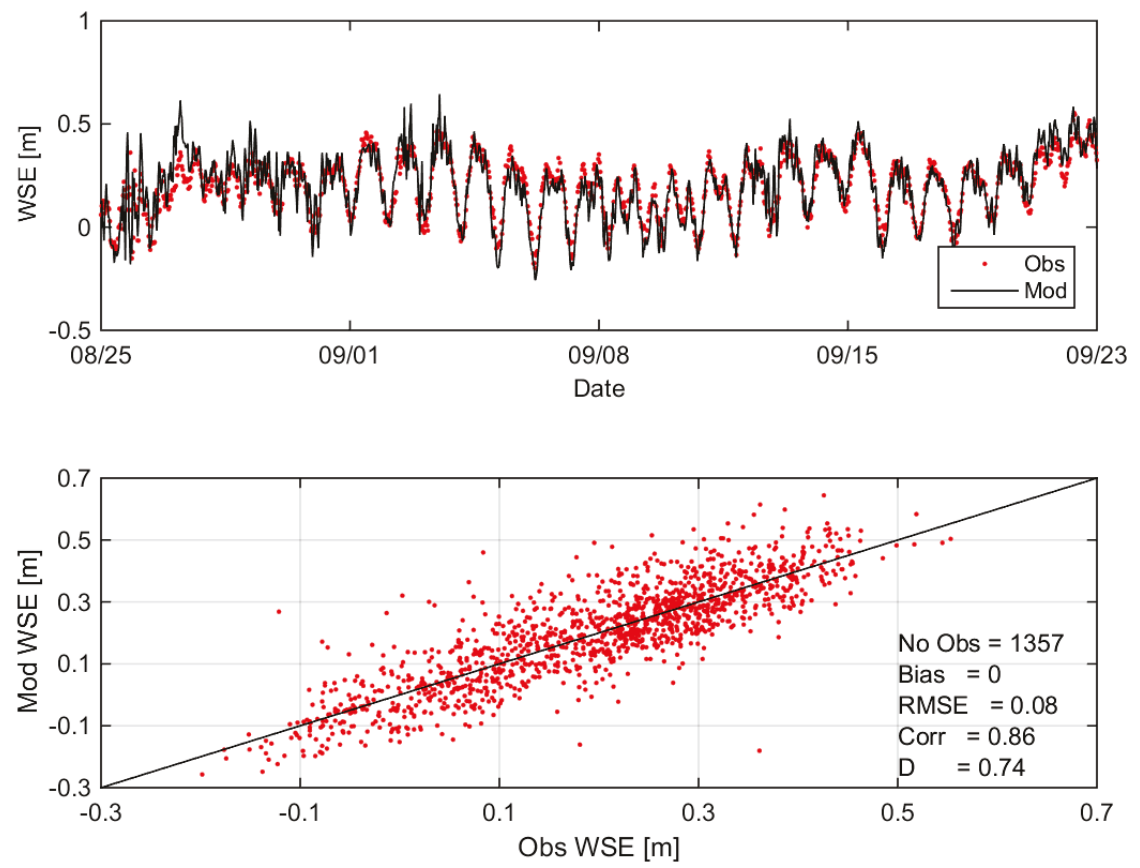
Figure 6-9. Water level comparison at S. Padre Island for 25 August - 23 September 2014.
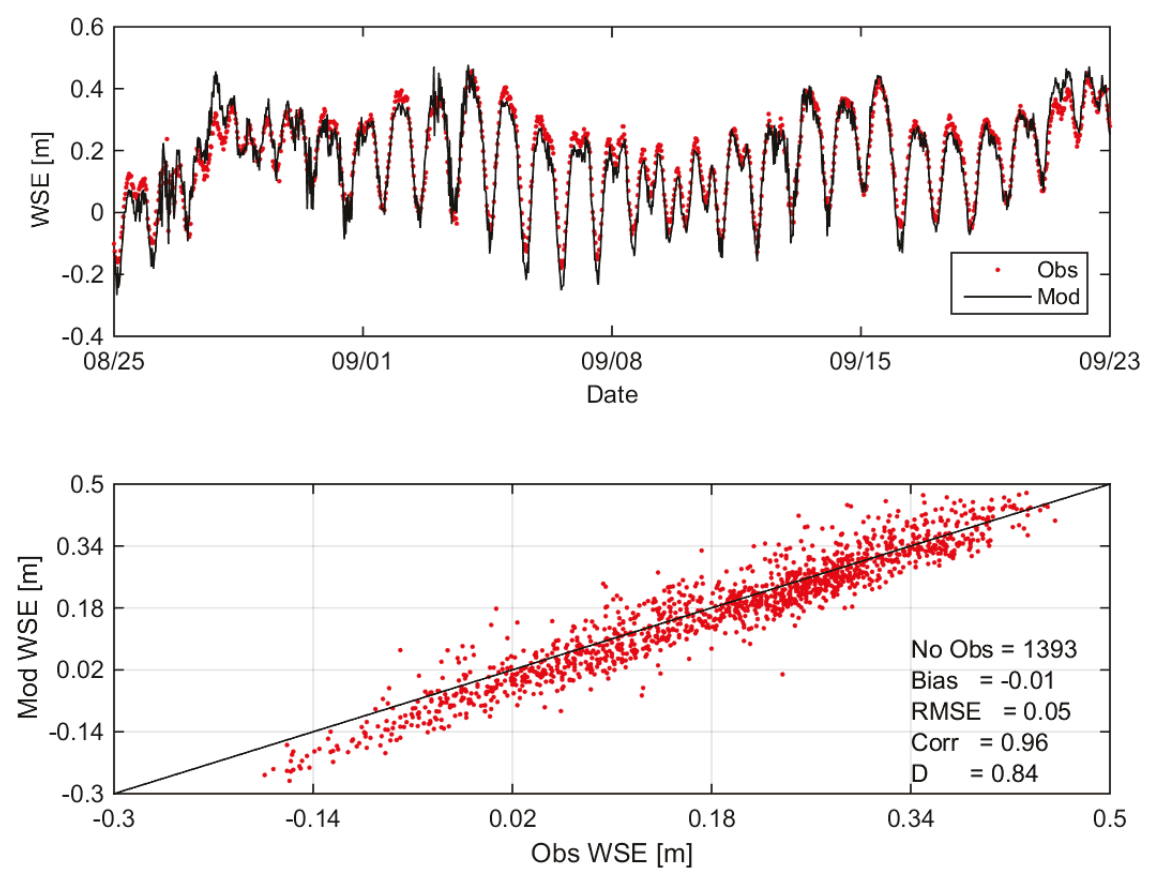

Reviewing Figure 6-2 through Figure 6-9, there is a noticeable dependence of model performance on the location of the site. At the northernmost interior gages (Rincon, TIDE2, Port Mansfield), the model does a poor job capturing the water level trend at all three sites. The biases at Rincon and Port Mansfield are $0.15 \mathrm{~m}(0.49 \mathrm{ft})$ and $0.10 \mathrm{~m}(0.33 \mathrm{ft})$, respectively, indicating CMS-Flow is slightly overestimating the mean observations. Looking at the bottom scatter plot for these sites, model results relative to the line of best fit are widely scattered as represented by the highest RMSEs; the RMSE for Rincon, TIDE2, and Port Mansfield are $0.10 \mathrm{~m}$ $(0.33 \mathrm{ft}), 0.09 \mathrm{~m}(0.29 \mathrm{ft})$, and $0.08 \mathrm{~m}$ (0.26 ft), respectively. As expected, the Willmott indices at these sites are relatively low, with values of 0.42 for Rincon, 0.60 for TIDE2, and 0.43 for Port Mansfield. Model accuracy improves slightly at TIDE3, which is shown to have a slightly stronger tidal signal. TIDE3 has an RMSE equal to $0.07 \mathrm{~m}(0.23 \mathrm{ft})$, a correlation of 0.72 , and a Willmott index of 0.63 .

Approaching the Mansfield Pass Inlet, there is noticeable improvement in model performance at TIDE1 compared to the interior gages (Figure 6-5). The model does a good job capturing the strong tidal signal at TIDE1; the RMSE decreased to $0.06 \mathrm{~m}(0.20 \mathrm{ft})$, and the Willmott index increased to o.81 compared to the interior sites. 
Similar to Mansfied Pass, model performance improves with sites closer to the Brazos Harbor Inlet. The strong tidal signal observed at 8779770 , TIDE4, and S. Padre Island are well modeled by CMS-Flow. The biases at these sites are very small and approach zero (the largest bias is $-0.01 \mathrm{~m}$ $(-0.03 \mathrm{ft})$ at $\mathrm{S}$. Padre Island). Of these sites, the largest RMSE $(0.08 \mathrm{~m}$ [0.26 ft]) and lowest Willmott index (0.74) is found at TIDE4, the terminal end of the channel. The sites 8779770 and S. Padre Island have RMSE values of $0.05 \mathrm{~m}(0.16 \mathrm{ft})$ and Willmott indices of 0.84 , indicating good model performance.

One reason for improved model performance near the inlets is the stronger tidal signal. Water fluctuations of the upper bay are driven predominantly by winds rather than tides, and CMS-FLOW performs better at sites with stronger tidal signals. Although comparisons to data begin to falter farther from the Brazos Harbor Inlet, note that CMS-Flow simulated the water level elevation in the Brazos Harbor Inlet study area and its vicinity with a high degree of accuracy.

Velocities. Comparisons of modeled velocity to measured velocity are displayed in Figure 6-10 through Figure 6-12, beginning with the offshore AWAC (oAWAC) followed by the in-channel AWAC (iAWAC). The sign of the magnitude indicates direction, where (+) is east and north and (-) is west and south.

Comparisons of modeled to measured east-west and north-south depthaveraged velocities are shown in Figure 6-10 for oAWAC. The acoustic sensors for measuring velocity were operational from August 25 to 2 September 2014. The fluctuations in the east and north measurements prior to September 2 are not well captured by the model, particularly for the north-south velocities. Immediately before its failure on September 2, the AWAC measured a significant increase in velocity in both the east and north direction that is not captured by CMS-Flow. The velocity increased to approximately $0.5 \mathrm{~m} / \mathrm{s}(1.6 \mathrm{ft} / \mathrm{s})$ for the east and $1.4 \mathrm{~m} / \mathrm{s}(4.6 \mathrm{ft} / \mathrm{s})$ for the north. Following its failure, the oAWAC reports a handful of sporadic measurements that are unreliable. Statistics were not calculated for the oAWAC due to the paucity of measured data for this deployment. 
Figure 6-10. East-west (top) and north-south (bottom) velocity comparisons at oAWAC for

25 August - 23 September 2014.

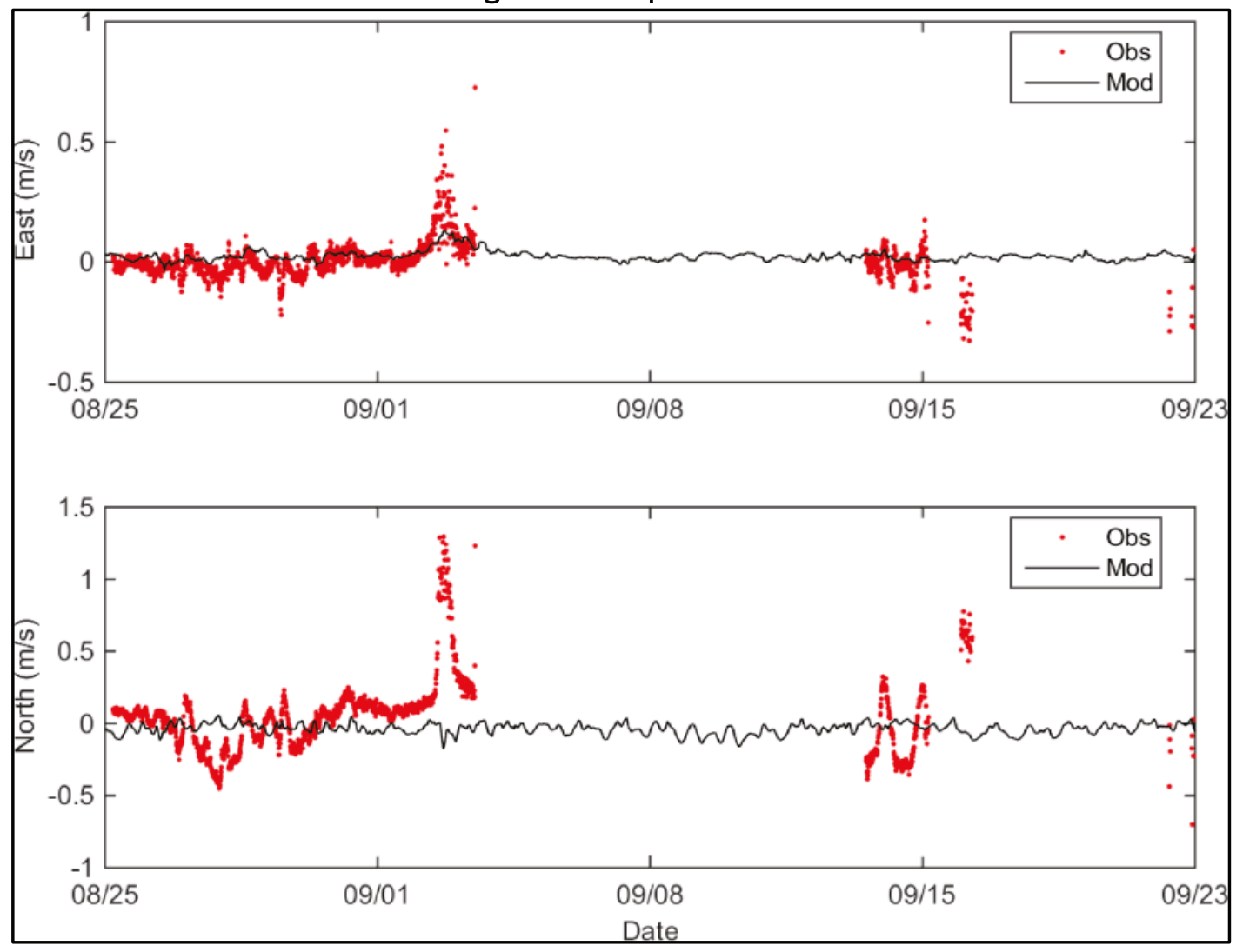

Comparisons of modeled to measured east-west depth-averaged velocities are shown in Figure 6-11 for iAWAC. The iAWAC was operational from 25 August to 23 September 2014. The Brazos Harbor Inlet is oriented eastwest, and CMS-Flow captures the magnitude and phasing of the dominant flow direction very well (Figure 6-11). The model does a better job simulating the magnitude of the ebb current (+, outgoing flow) compared to the flood current (-, incoming flow); the flood currents are noticeably underestimated between 25 August and 1 September and approximately 15 September and overestimated approximately 8 September. The data mostly lie along the line of best fit although there is some scatter, resulting in an RMSE of $0.22 \mathrm{~m} / \mathrm{s}(0.72 \mathrm{ft} / \mathrm{s})$, a correlation of 0.89 , and a Willmott index of 0.79 . 
Figure 6-11. East-west velocity comparisons at iAWAC for 25 August - 23 September 2014.
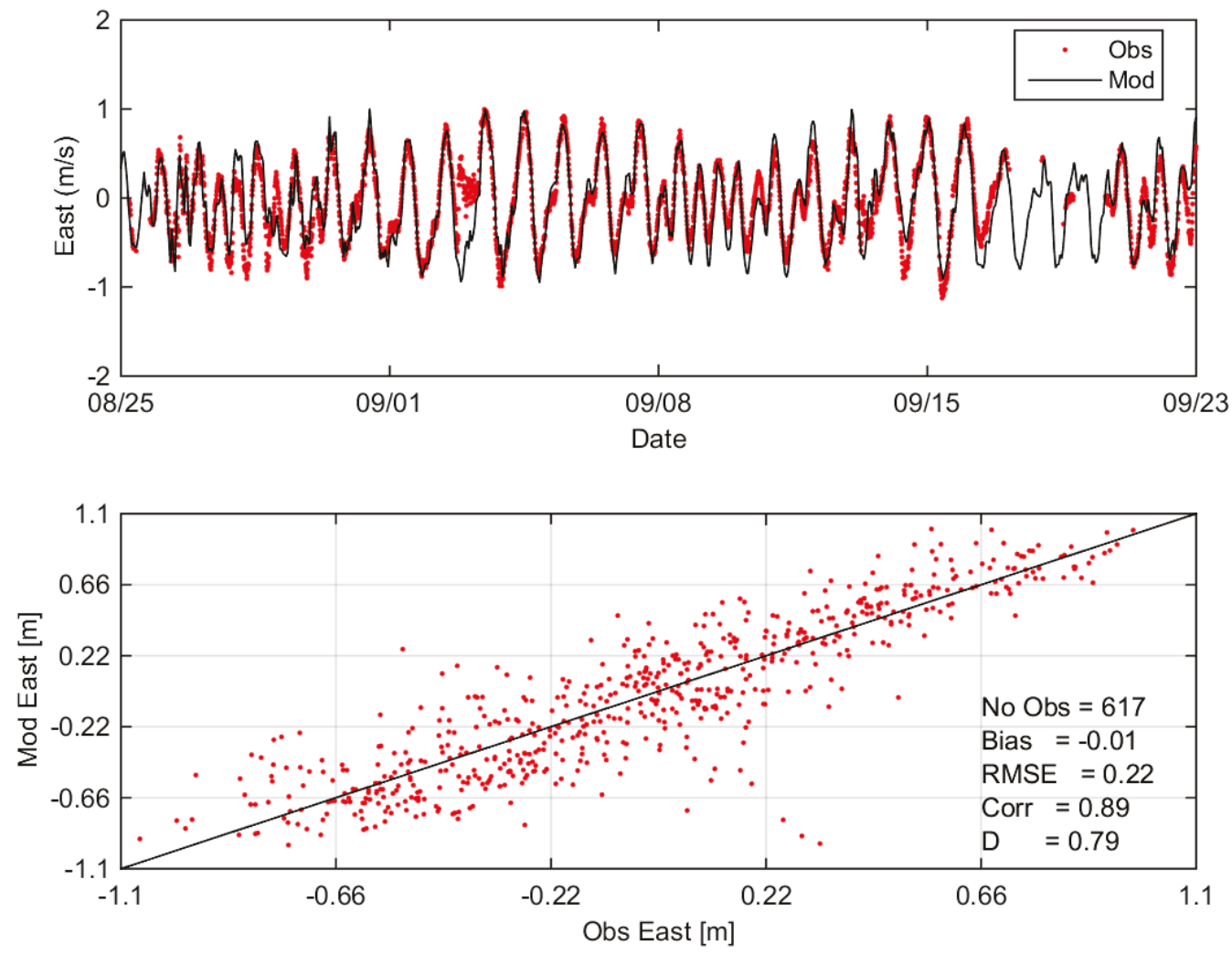

Comparisons of modeled to measured north-south depth-averaged velocities are shown in Figure 6-12 for iAWAC. Comparing Figure 6-11 and Figure 6-12 shows the magnitudes of the north-south measurements are much smaller compared to the east-west measurements due to the orientation of the inlet; the east-west velocities approach $1 \mathrm{~m} / \mathrm{s}(3.28 \mathrm{ft} / \mathrm{s})$ while the north-south velocities are less than $0.2 \mathrm{~m} / \mathrm{s}(0.66 \mathrm{ft} / \mathrm{s})$. There is more scatter in the measurements themselves compared to the east-west measurements, which is clearly evident approximately September 2. The variability in the measurements themselves likely contribute to the slightly worse performance of CMS-Flow for the north-south compared to the east-west, with an RMSE of $0.05 \mathrm{~m} / \mathrm{s}(0.16 \mathrm{ft} / \mathrm{s})$, a correlation of 0.83 , and a Willmott index of 0.7. In general, CMS-Flow performed well in reproducing the currents within the BSI during this timeframe. 
Figure 6-12. North-south velocity comparisons at iAWAC for 25 August - 23 September 2014.
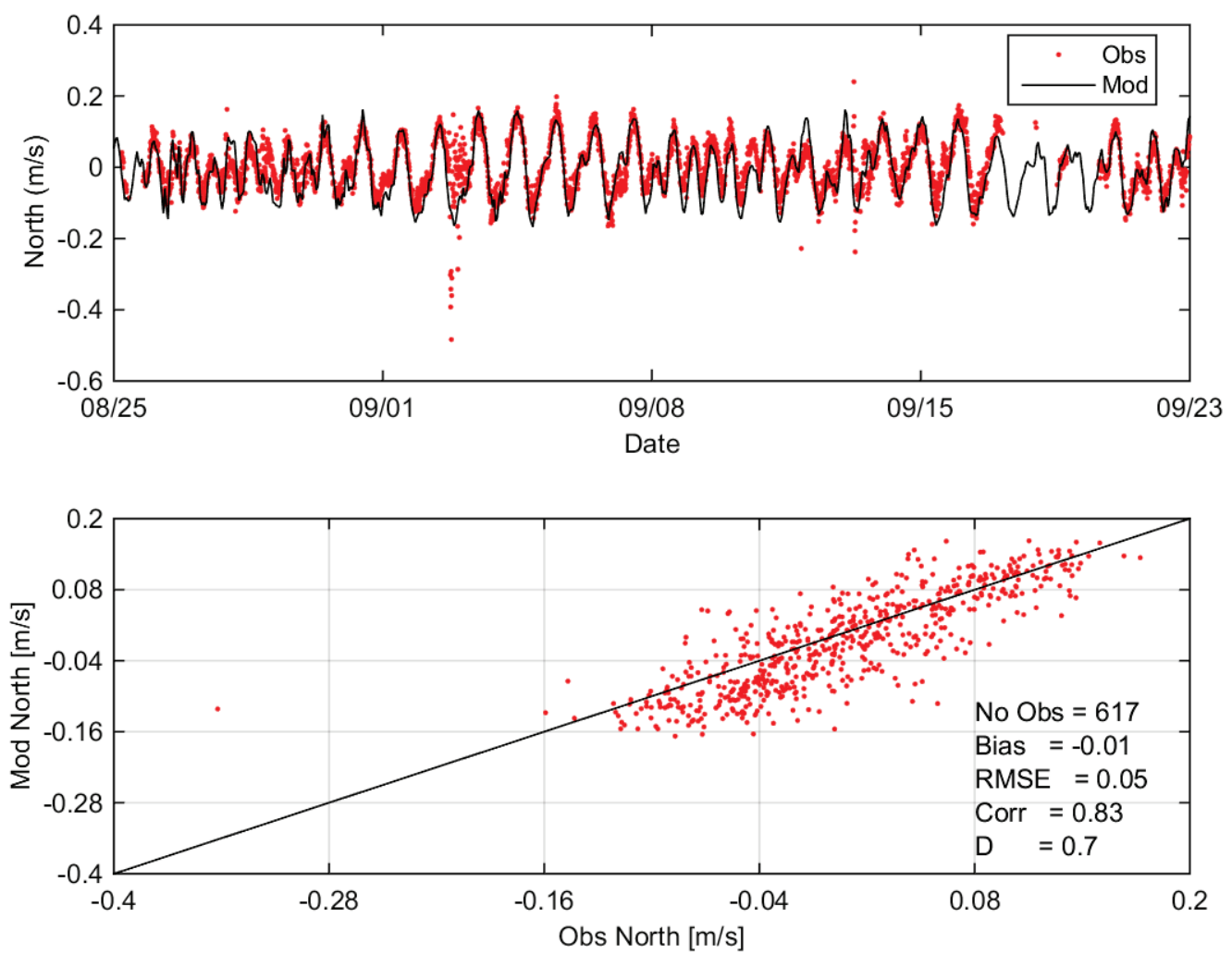

Figure 6-13 compares the range of velocities in both the east-west and north-south directions at iAWAC to model results. Although CMS-Flow does not capture the variability of the measurements, the range of velocities in the east-west and north-south direction in the Brazos Harbor Inlet is well represented. 
Figure 6-13. Velocity excursion at iAWAC for 25 August - 23 September 2014.

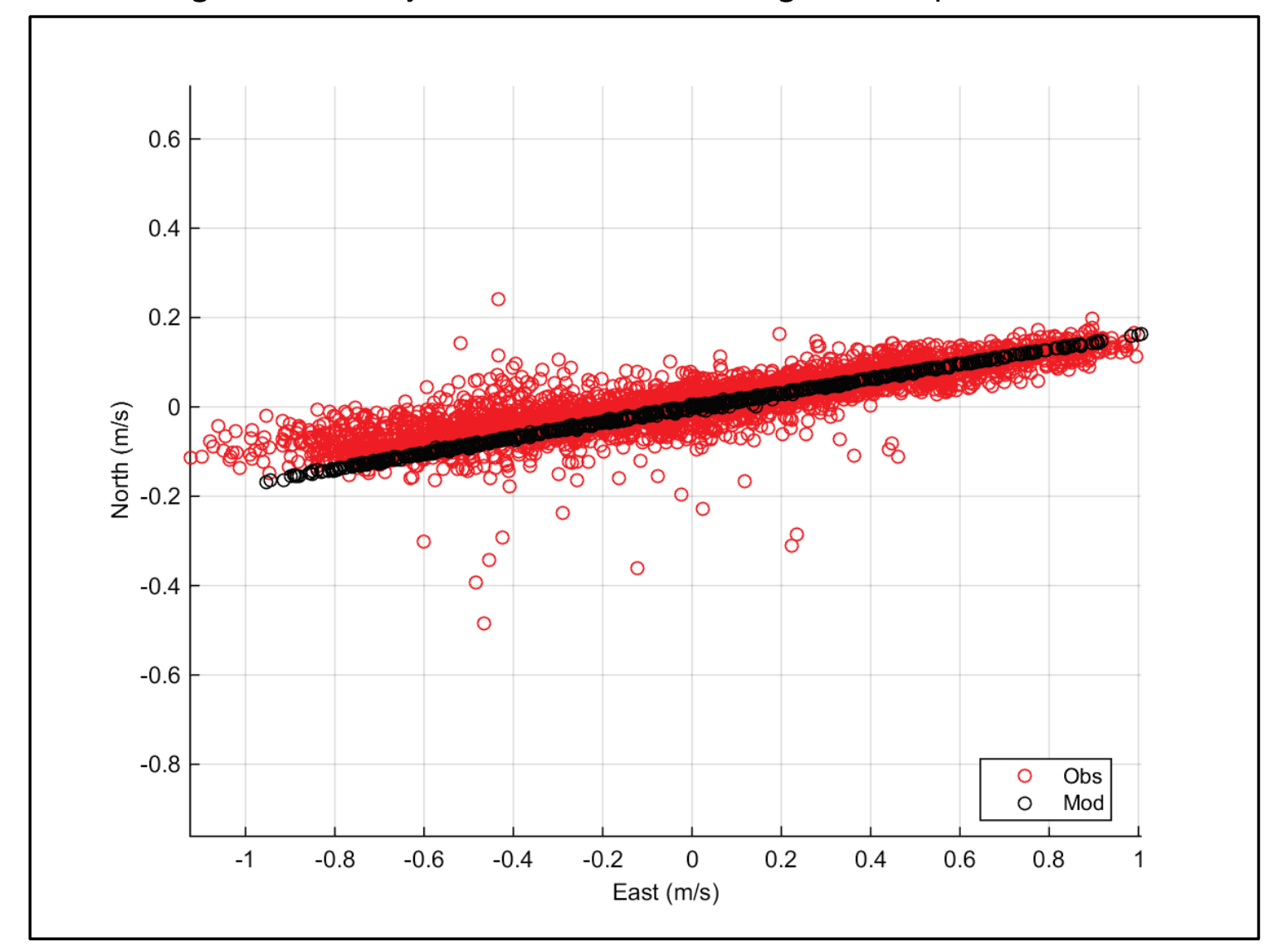

Waves. Comparisons of modeled to measured waves are displayed in Figure 6-14 and Figure 6-15, beginning with the offshore AWAC (oAWAC) followed by the inner AWAC (iAWAC). Comparisons of modeled to measured wave parameters are shown in Figure 6-14 for oAWAC. The acoustic measurements of the offshore AWAC failed on September 2, resulting in the inability of the instrument to measure wave direction as seen in the bottom panel of Figure 6-14. However, the pressure sensor continued to operate, and scalar wave parameters (e.g., significant wave height and peak period) were extracted from these data. The bias, RMSE,

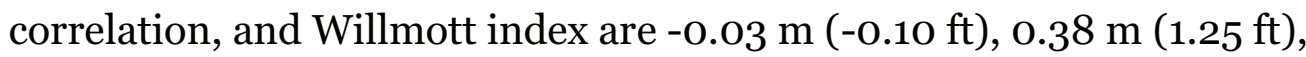
0.76 , and 0.68 for significant wave height $\left(\mathrm{H}_{\mathrm{mo}}\right)$, and $-0.07 \mathrm{~s}, 0.95 \mathrm{~s}, 0.83$, and 0.72 for peak period $\left(\mathrm{T}_{\mathrm{p}}\right)$. In general, the trends in $\mathrm{H}_{\mathrm{mo}}$ and $\mathrm{T}_{\mathrm{p}}$ at oAWAC are well represented by CMS-Wave. 
Figure 6-14. Wave comparisons at oAWAC from 25 August - 23 September 2014.
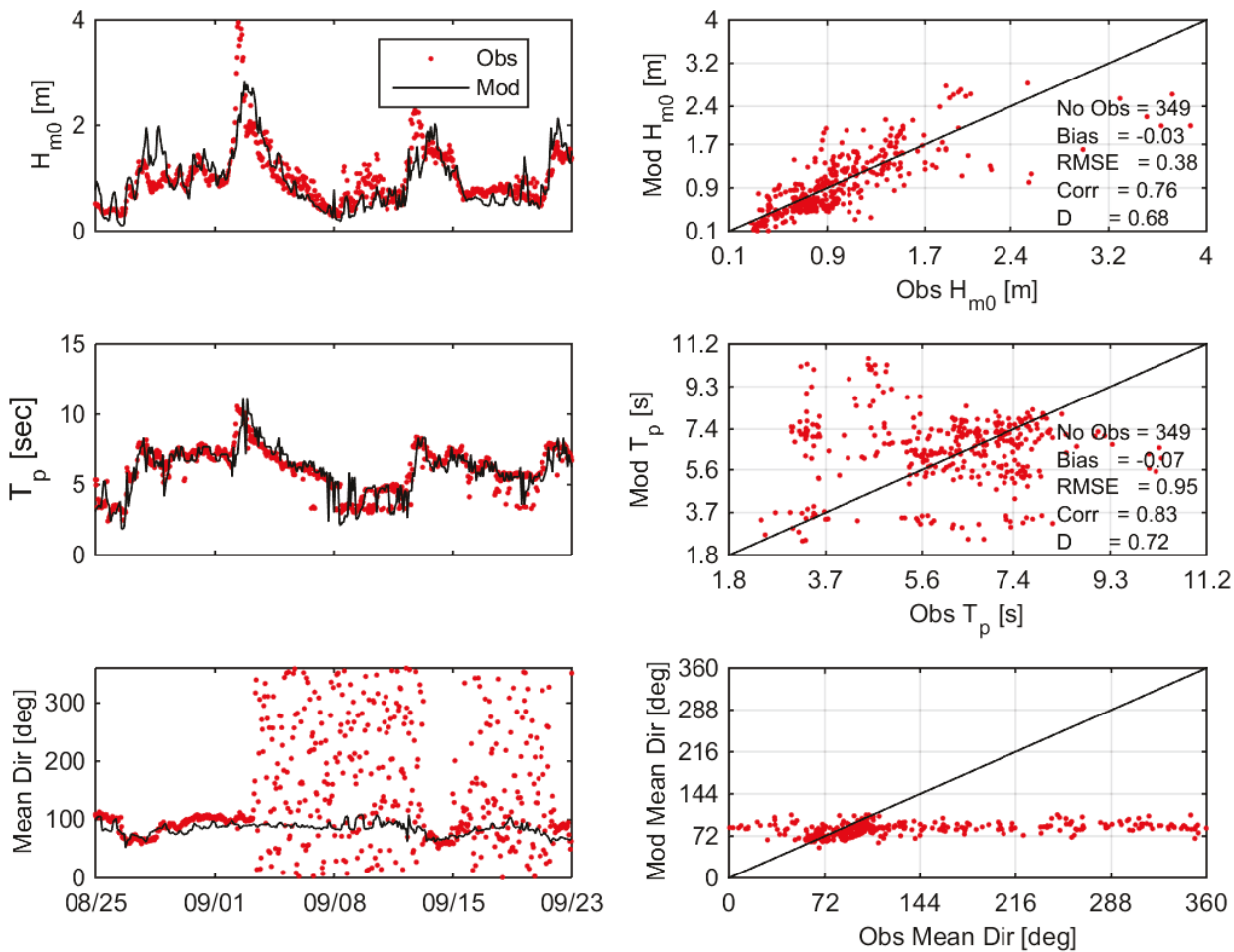

Comparisons between CMS-Wave results and measurements for iAWAC are shown in Figure 6-15. CMS-Wave slightly overestimated the mean wave height at iAWAC compared to oAWAC (larger positive bias of $0.12 \mathrm{~m}$ [0.39 ft]), but continued to capture the trend in $\mathrm{H}_{\text {mo }}$ within the inlet. From August 26 to September 9, the model results for $\mathrm{T}_{\mathrm{p}}$ are noticeably greater than the measurements, contributing to the overall positive bias of $0.44 \mathrm{~S}$ and an RMSE of $1.4 \mathrm{~s}$ for the evaluation duration. The model results for $\mathrm{H}_{\text {mo }}$ are better than $\mathrm{T}_{\mathrm{p}}$ as indicated by the improvement in bias, RMSE, correlation, and Willmott index. The mean wave direction was relatively constant inside the inlet and simulated well by CMS-Wave. 
Figure 6-15. Wave comparisons at iAWAC from 25 August - 23 September 2014.

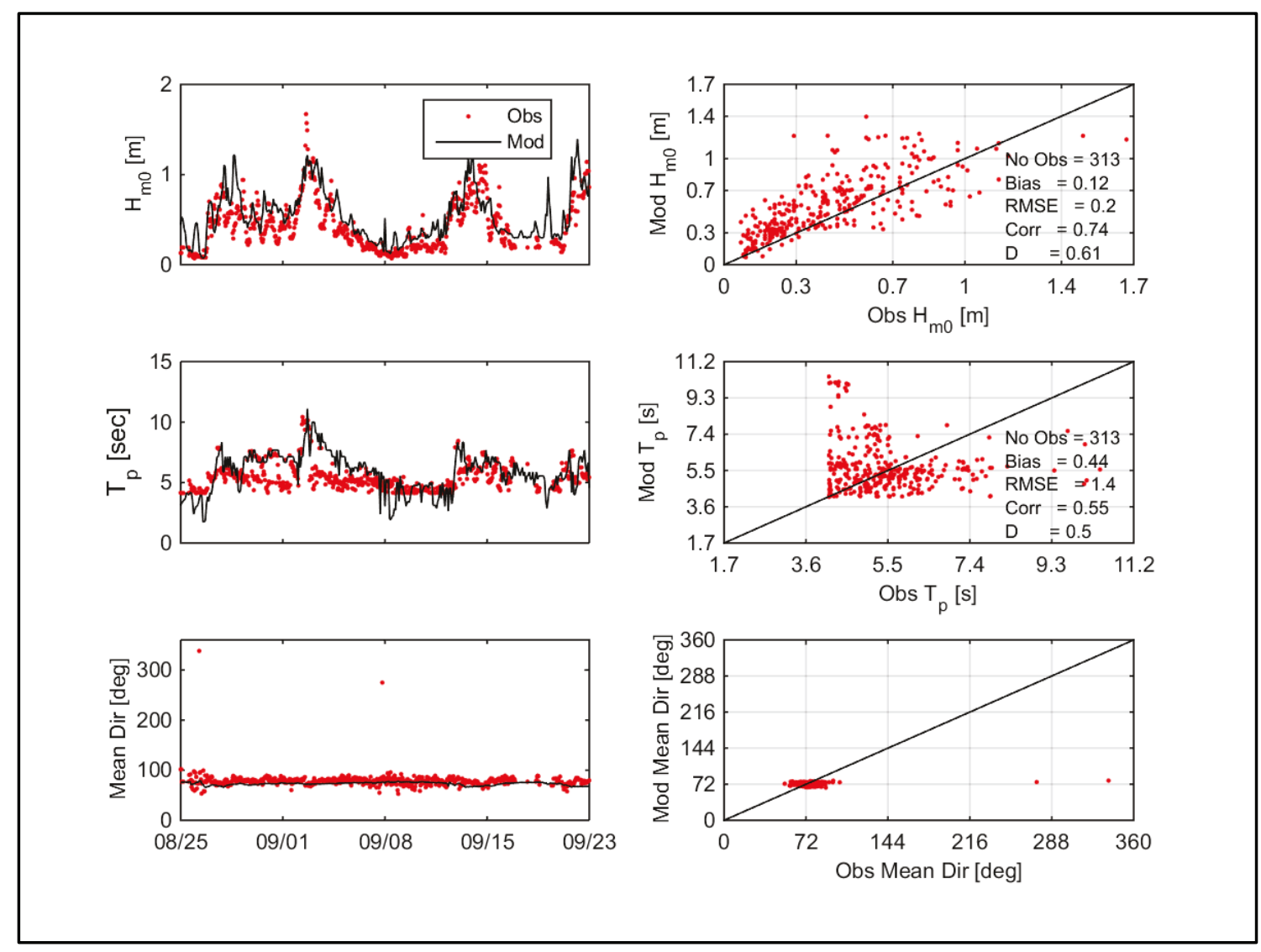

Reviewing Figure 6-14 and Figure 6-15, the timing of the peak wave heights for both AWACS are similar and correspond to the timing of the peak current at oAWAC prior to sensor failure (Figure 6-10). It was originally hypothesized that the increase in currents might be due to a trolling ship snaring the oAWAC; however, the peaks overlapping in at least two locations suggest a storm event. One known storm occurring during this time frame was Tropical Storm Dolly, which began as a tropical depression on September 1 while over the Bay of Campeche and made landfall in Tamaulipas on September 3 (Figure 6-16). As the nearest tidal, wind, and offshore wave forcing was gathered well north of the inlet, the storm representation in the models would be limited, if not omitted, leading to the underestimation of the peak currents, especially the north direction (Figure 6-10), and wave heights found in Figure 6-14 and Figure 6-15. 
Figure 6-16. Best track positions for Tropical Storm Dolly, 1-3 September 2014 (after Beven [2015]).

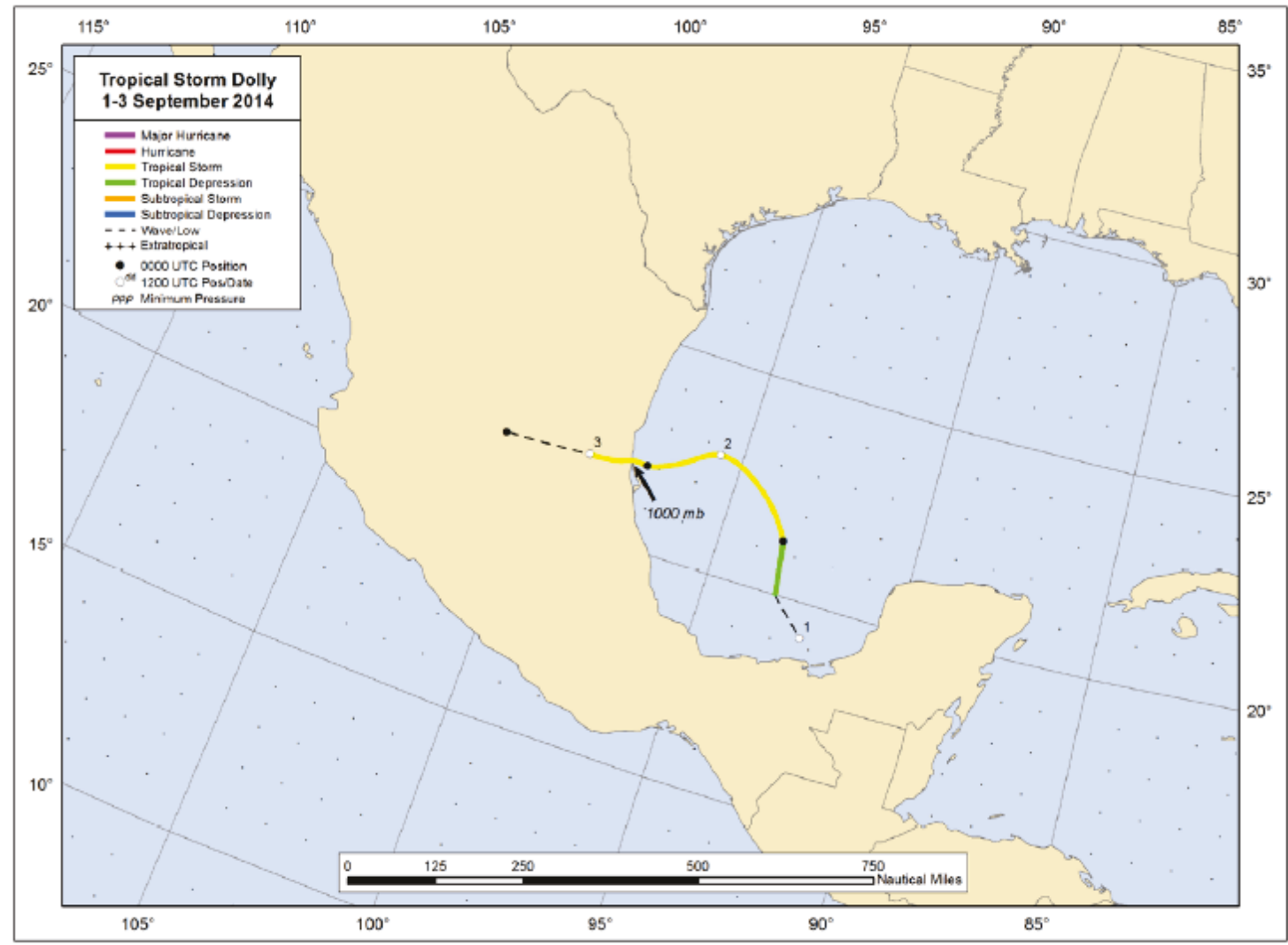

\section{December 2014 - 27 March 2015}

The second period for model evaluation was 7 December 2014 - 27 March 2015, which corresponds to the second deployment of the CHL instruments. During this timeframe, both AWACs were entirely operational. To model this timeframe, the coupled CMS-Flow and CMSWave model was started 6 December 2014 with a half-day spinup and concluded 28 March 2015.

Water levels. Comparisons of modeled to measured water levels are displayed in Figure 6-17 through Figure 6-24, beginning with the gage farthest from the study site (Rincon) and proceeding to the gage closest to the study site (S. Padre Island). 
Figure 6-17. Water level comparison at Rincon for 7 December 2014 - 27 March 2015.
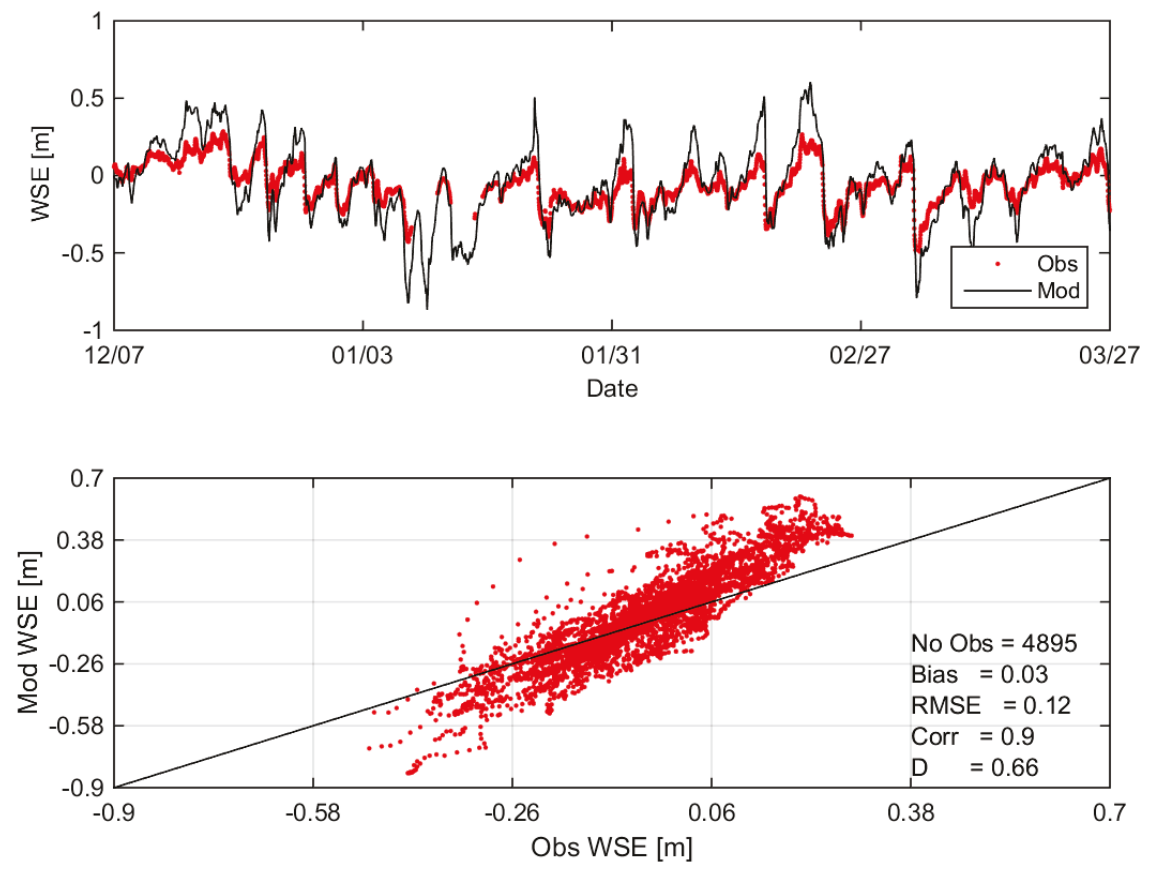

Figure 6-18. Water level comparison at TIDE2 for 7 December 2014 - 27 March 2015.
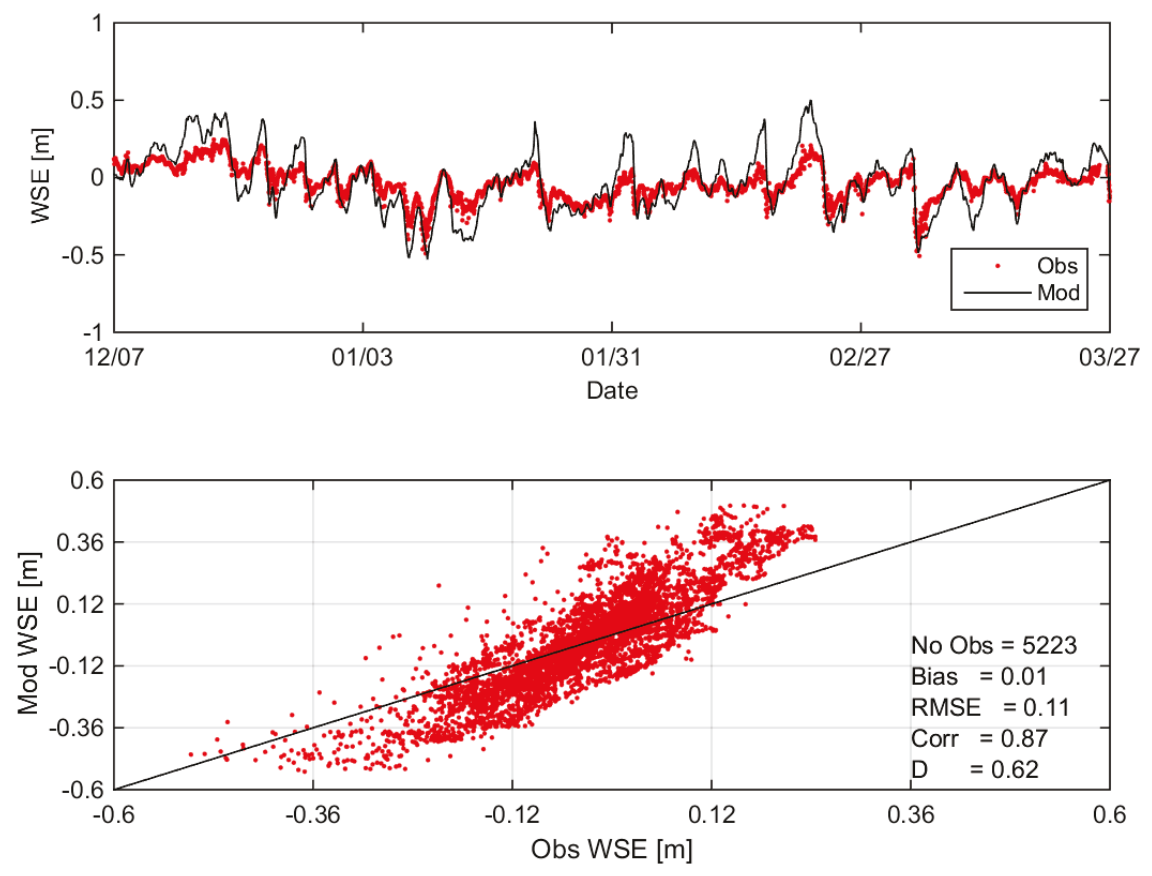
Figure 6-19. Water level comparison at Port Mansfield for 7 December 2014 -

27 March 2015.
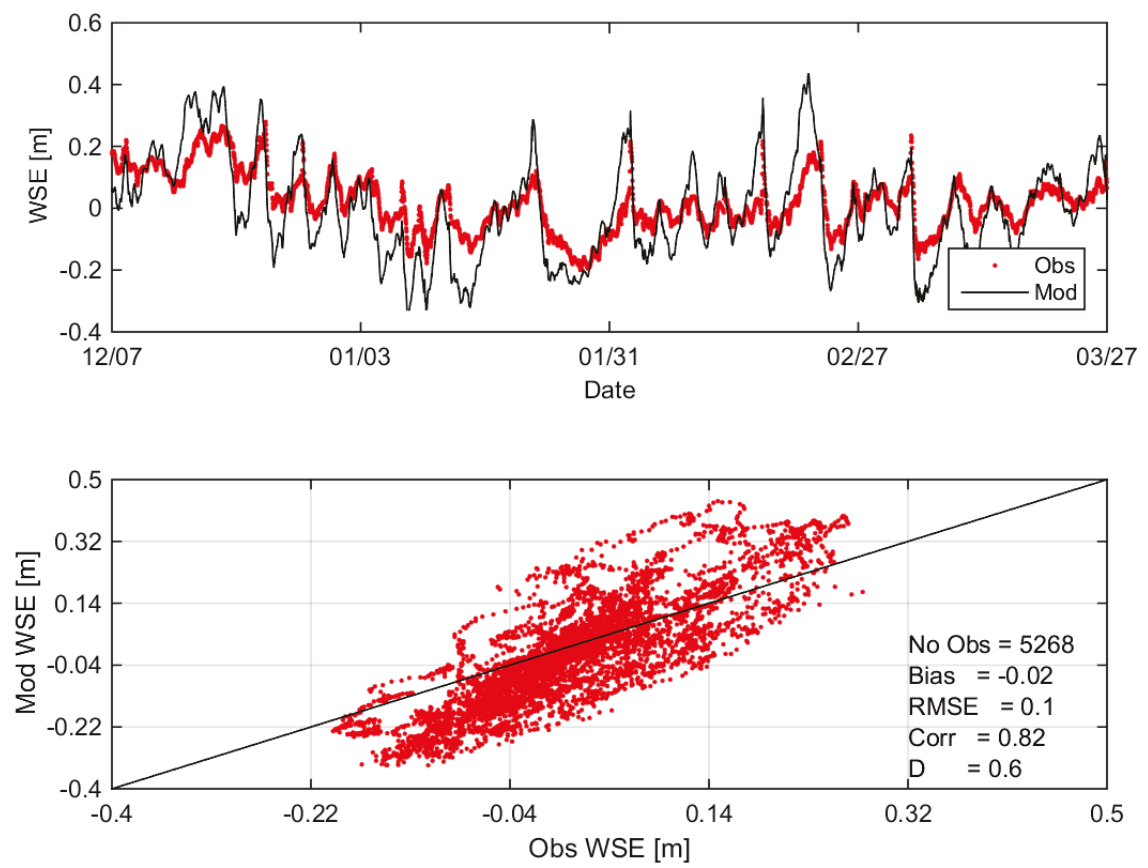

Figure 6-20. Water level comparison at TIDE1 for 7 December 2014 - 27 March 2015.
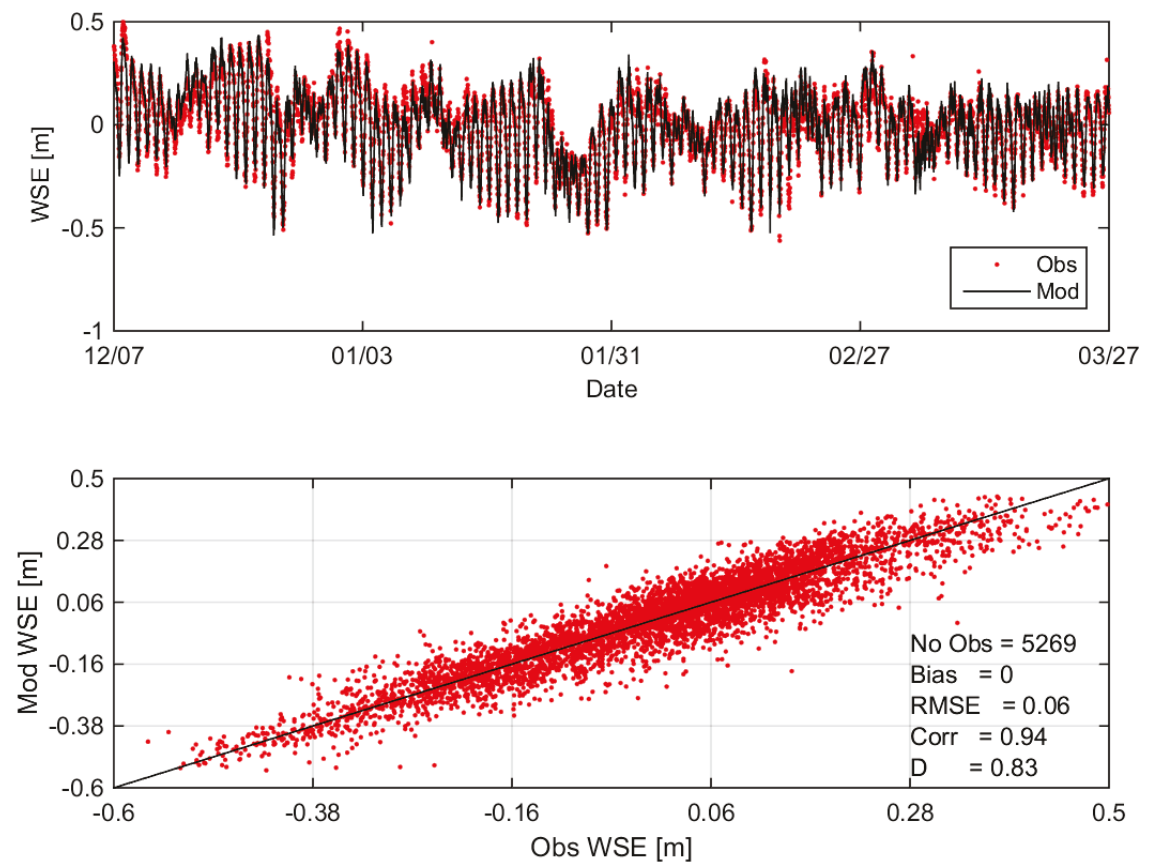
Figure 6-21. Water level comparison at TIDE3 for 7 December 2014 - 27 March 2015.
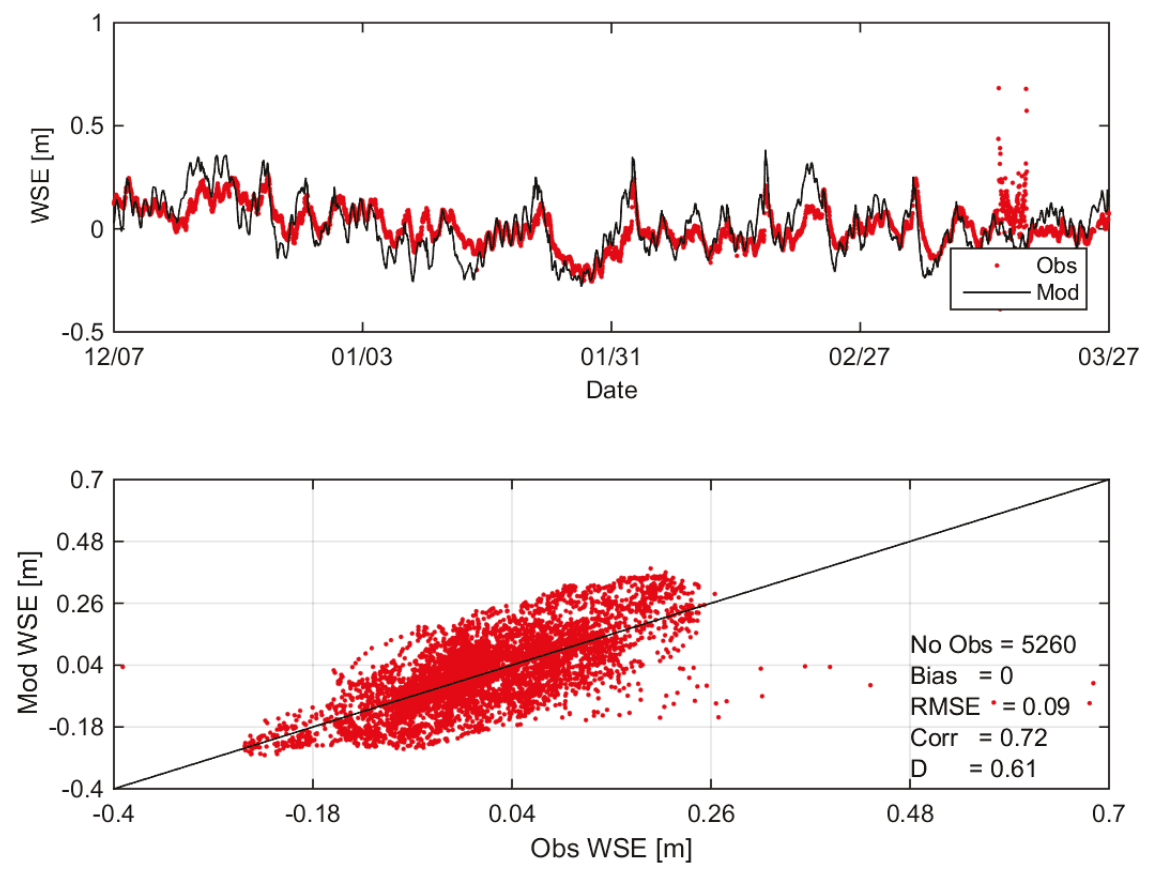

Figure 6-22. Water level comparison at Port Isabel for7 December 2014 - 27 March 2015.
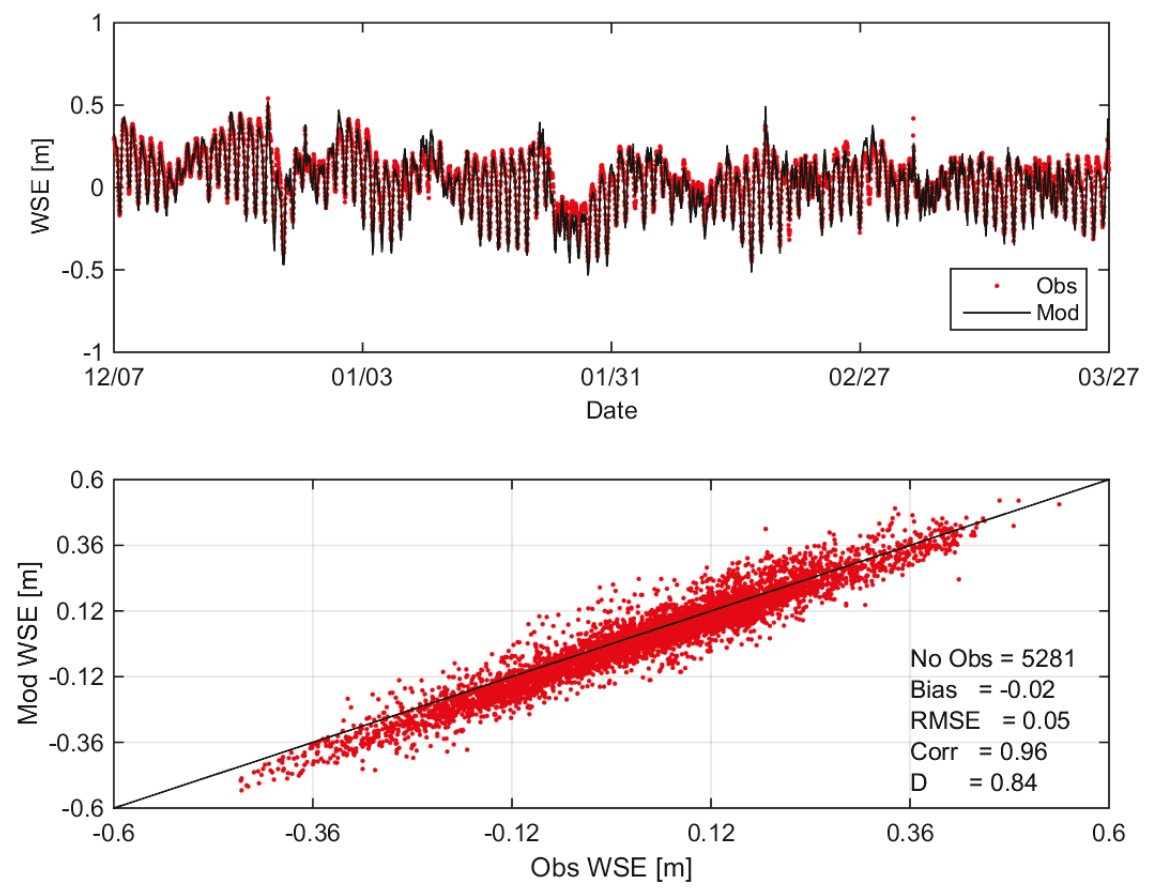
Figure 6-23. Water level comparison at TIDE4 for 7 December 2014 - 27 March 2015.
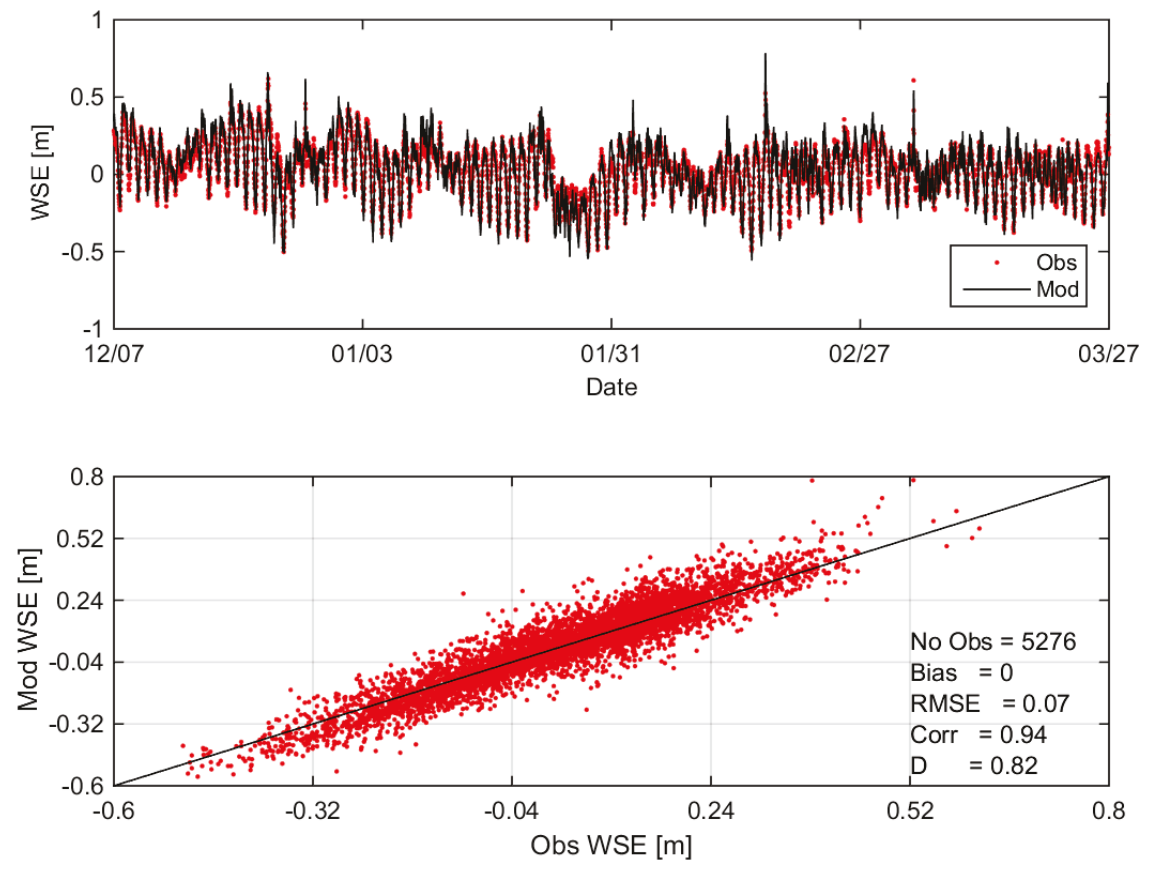

Figure 6-24. Water level comparison at S. Padre Island for 7 December 2014 - 27 March 2015.
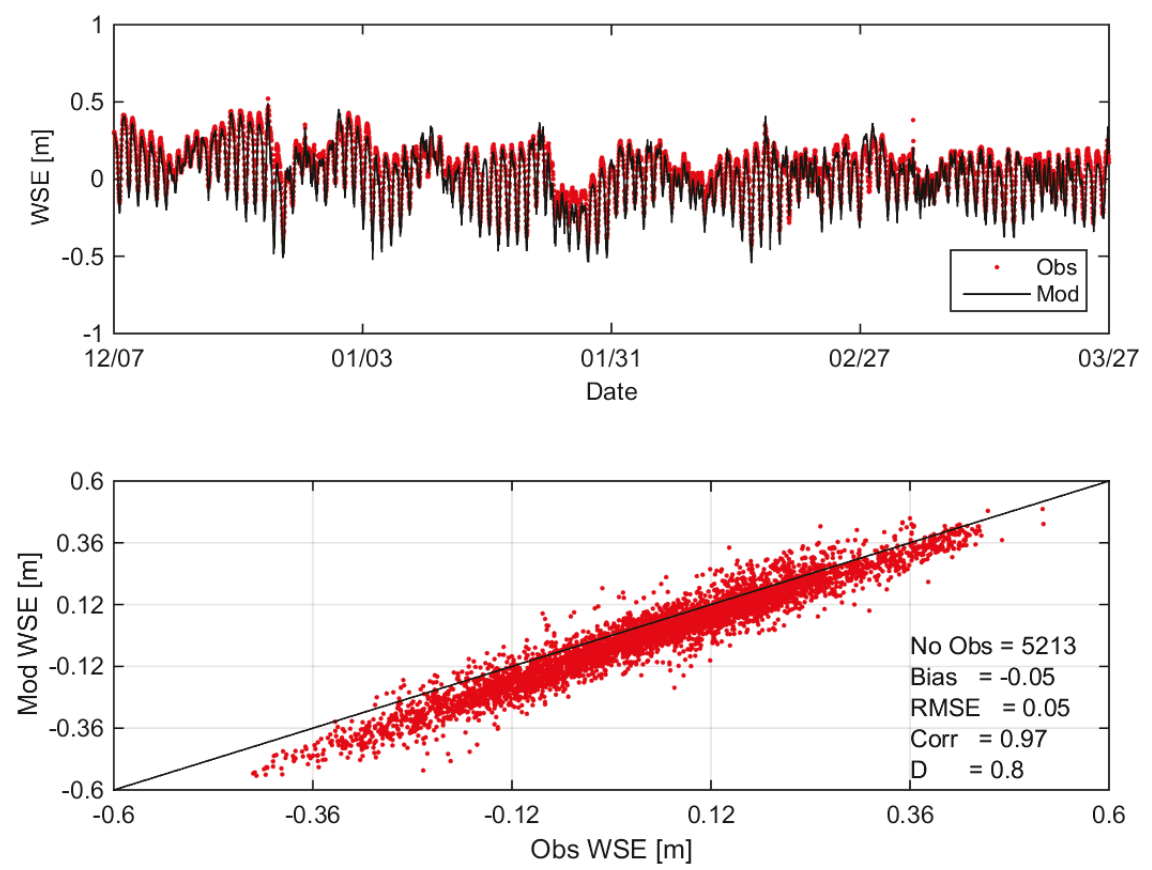
Figure 6-17 through Figure 6-24 show a noticeable dependence of model performance on the location of the site. CMS-Flow improves at capturing the trend in water elevation at the wind-dominated interior gages (Ricon, TIDE2, Port Mansfield) compared to the August-September evaluation. The biases at Rincon and Port Mansfield are very small at $0.03 \mathrm{~m}(0.10 \mathrm{ft})$ and $-0.02 \mathrm{~m}(-0.06 \mathrm{ft})$, respectively. The RMSE among the three sites is nearly identical (0.12 m [0.39 ft] at Rincon, $0.11 \mathrm{~m}$ [0.36 ft] at TIDE2, and $0.10 \mathrm{~m}[0.33 \mathrm{ft}]$ at Port Mansfield). The correlation and Willmott indices are higher than the August-September evaluation, with correlations between 0.8 and 0.9 and Willmott indices between 0.6 and 0.7. Unlike the August-September evaluation, model performance does not improve greatly at TIDE3. TIDE3 has an RMSE of $0.09 \mathrm{~m}$ ( $0.30 \mathrm{ft})$, a correlation of 0.72 , and a Willmott index of 0.61 .

Model accuracy significantly improved at TIDE1 near Mansfield Pass compared to the interior gages due to the stronger tidal signal (Figure 6-20). Performance is comparable to the August-September evaluation, with low RMSE (0.06 m [0.20 ft]), high correlation (0.94), and high Willmott index (o.83).

CMS-Flow demonstrated high accuracy at tide gages in the vicinity of Brazos Harbor Inlet. The strong tidal signals at Port Isabel, TIDE4, and S. Padre Island are well captured by CMS-Flow with model results lying in close proximity along the line of best fit. The model very slightly underestimates the mean at Port Isabel and S. Padre Island with small biases of $-0.02 \mathrm{~m}(-0.06 \mathrm{ft})$ and $-0.05 \mathrm{~m}(-0.16 \mathrm{ft})$, respectively. The largest RMSE of $0.07 \mathrm{~m}(0.23 \mathrm{ft})$ is again found at TIDE4, the terminal end of the channel. The correlation at all three sites exceeds 0.9, and the Willmott indices exceed 0.8 , indicating good model performance in the vicinity of the Brazos Harbor Inlet.

Velocities. Comparisons of modeled velocity to measured velocity are displayed in Figure 6-25 through Figure 6-28, beginning with the offshore AWAC (oAWAC) followed by the inner-channel AWAC (iAWAC). The sign of the magnitude indicates direction, where $(+)$ is east and north and $(-)$ is west and south.

Comparisons of modeled to measured east-west depth-averaged velocities are shown in Figure 6-25 for oAWAC. CMS-Flow does a good job capturing the average of the east-west velocity as indicated by the small bias $(0.03 \mathrm{~m} / \mathrm{s}$ 
$[0.10 \mathrm{ft} / \mathrm{s}])$. However, the fluctuations about the mean are poorly modeled. Looking at the scatter plot, the model-to-measurements point cloud is nearly horizontal due to the fact that the model results stayed relatively constant throughout the timeframe compared to the measurements. CMSFlow misses a peak event of approximately $0.5 \mathrm{~m} / \mathrm{s}(1.64 \mathrm{ft} / \mathrm{s})$ occurring near 26 February 2014. The poor model performance is reflected in the statistics, with a correlation of 0.19 and a Willmott index of 0.32 .

Figure 6-25. East-west velocity comparisons at oAWAC for 7 December 2014 27 March 2015.
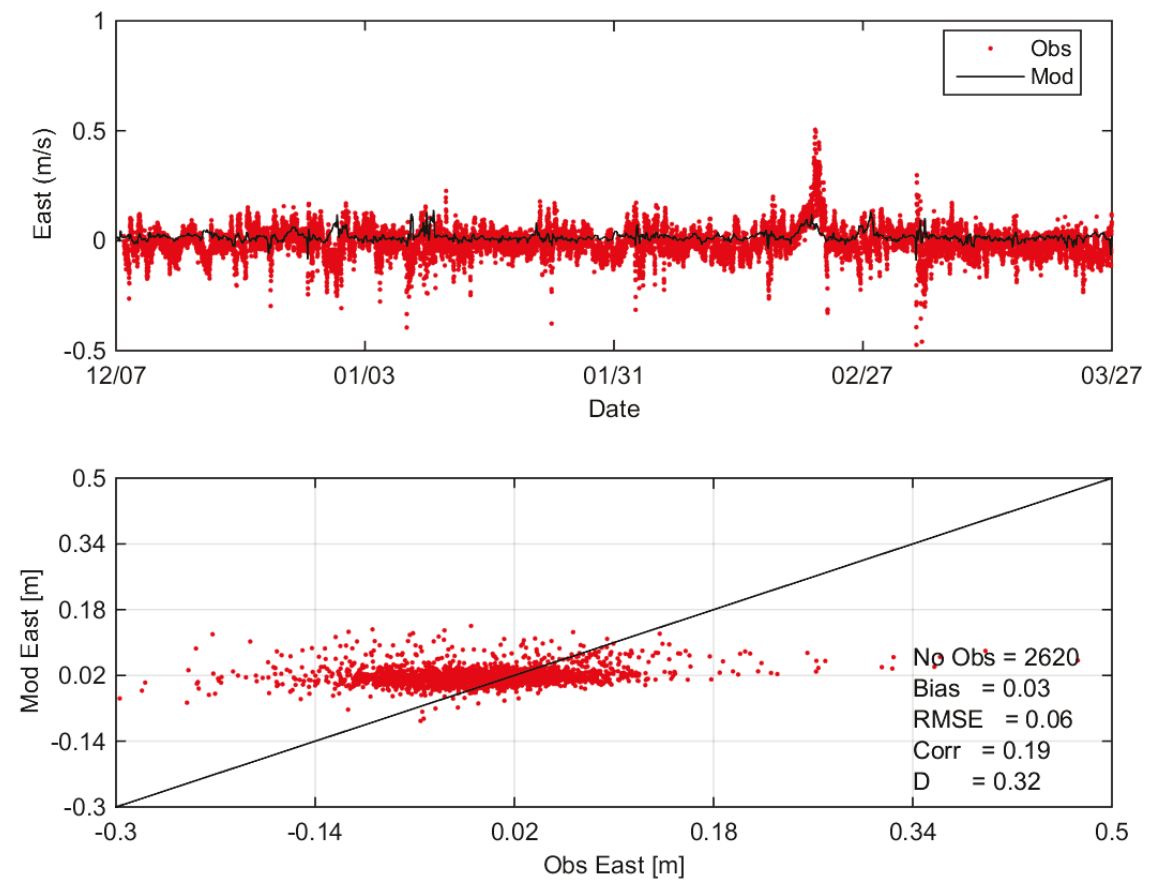

Comparisons of modeled to measured north-south depth-averaged velocities are shown in Figure 6-26 for oAWAC. Similar to the east-west comparisons, CMS-Flow models the overall average well (low bias of $-0.02 \mathrm{~m} / \mathrm{s}$ [-0.06 ft/s]), but is clearly unable to capture the variability of the measurements. The poor performance is reflected in the low statistics with an RMSE of $0.23 \mathrm{~m} / \mathrm{s}(0.75 \mathrm{ft} / \mathrm{s})$, a negative correlation, and a nearly zero Willmott index. The main reasons for the poor performance at the offshore AWAC are the small offshore domain and the CMS-Flow boundary forcing. The model domain is unable to simulate the larger currents of the Gulf of Mexico basin and is further limited with 8775870 located close to shore and significantly north of the study area in Corpus Christi. 
Figure 6-26. North-south velocity comparisons at oAWAC for 7 December 2014 - 27 March 2015.
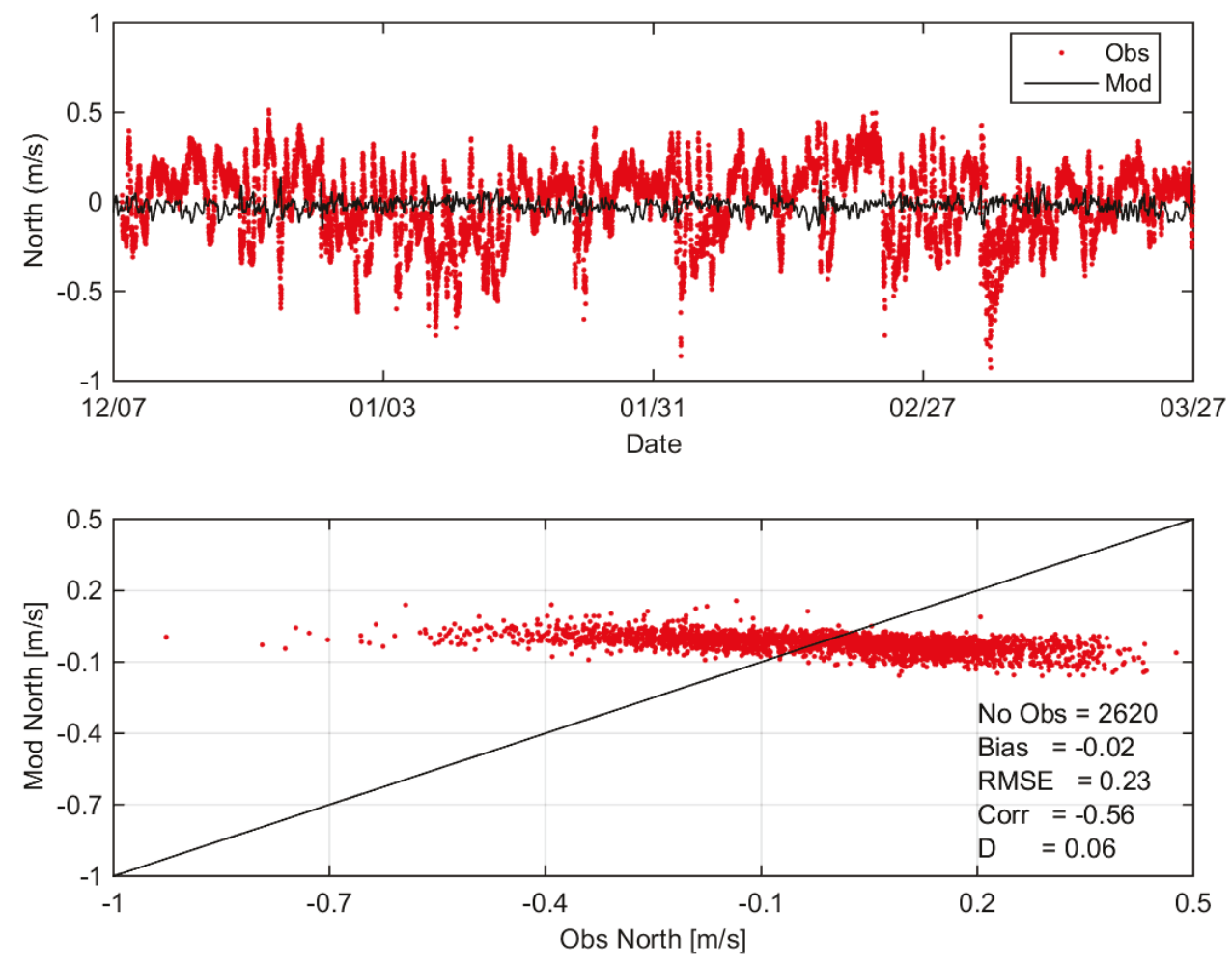

Comparisons of modeled to measured east-west depth-averaged velocities are shown in Figure 6-27 for iAWAC. The performance of CMS-Flow greatly improves inside the inlet compared to the offshore. CMS-Flow models the phasing of the east-west currents very well throughout the evaluation period. The model underestimates the magnitude of the flood currents (-) more often than the ebb currents (+). Unlike the oAWAC, the measurements generally follow the line of best fit. In general, CMS-Flow does a good job capturing the east-west velocities in Brazos Harbor Inlet, with a bias of $0.04 \mathrm{~m} / \mathrm{s}(0.13 \mathrm{ft} / \mathrm{s})$, an RMSE of $0.22 \mathrm{~m} / \mathrm{s}(0.72 \mathrm{ft} / \mathrm{s})$, a correlation of 0.91 , and a Willmott index of 0.8 . 
Figure 6-27. East-west velocity comparisons at iAWAC for 7 December 2014 - 27 March 2015.
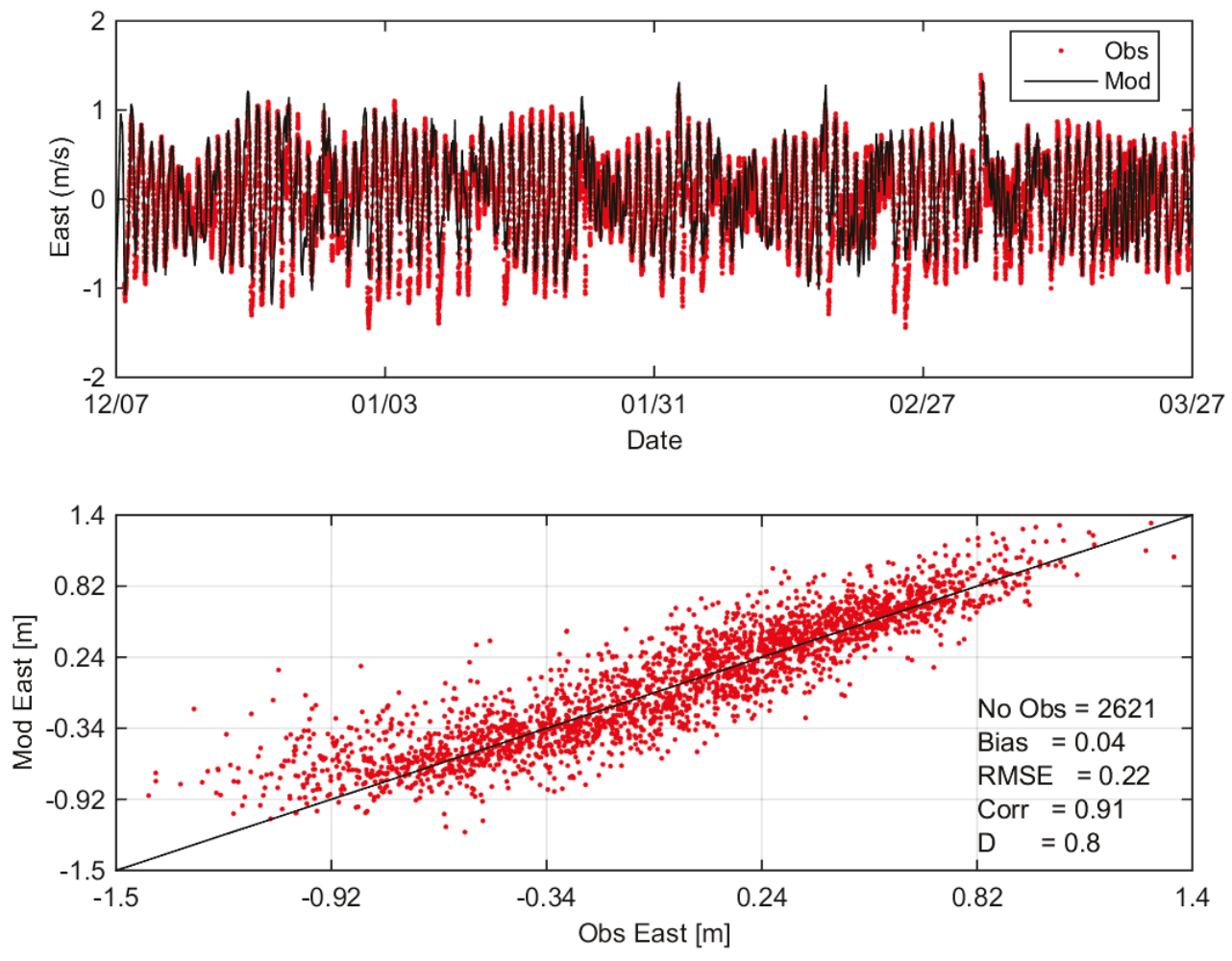

Comparisons of modeled to measured north-south depth-averaged velocities are shown in Figure 6-28 for iAWAC. The magnitudes of the north-south velocities are much smaller than the dominant east-west direction. CMS-Flow models the phasing of the north-south currents very well. The model underestimates both the ebb (+) and flood (-) currents, resulting in the scatter seen along the line of best fit. The bias is nearly zero (-0.01 $\mathrm{m}$ [-0.03 ft]). The performance of CMS-Flow greatly improves inside the inlet compared to oAWAC, as seen in the RMSE (0.04 m/s $[0.13 \mathrm{ft} / \mathrm{s}])$, correlation (o.88), and Willmott index (0.77). 
Figure 6-28. North-south velocity comparisons at iAWAC for 7 December 2014 - 27 March 2015.
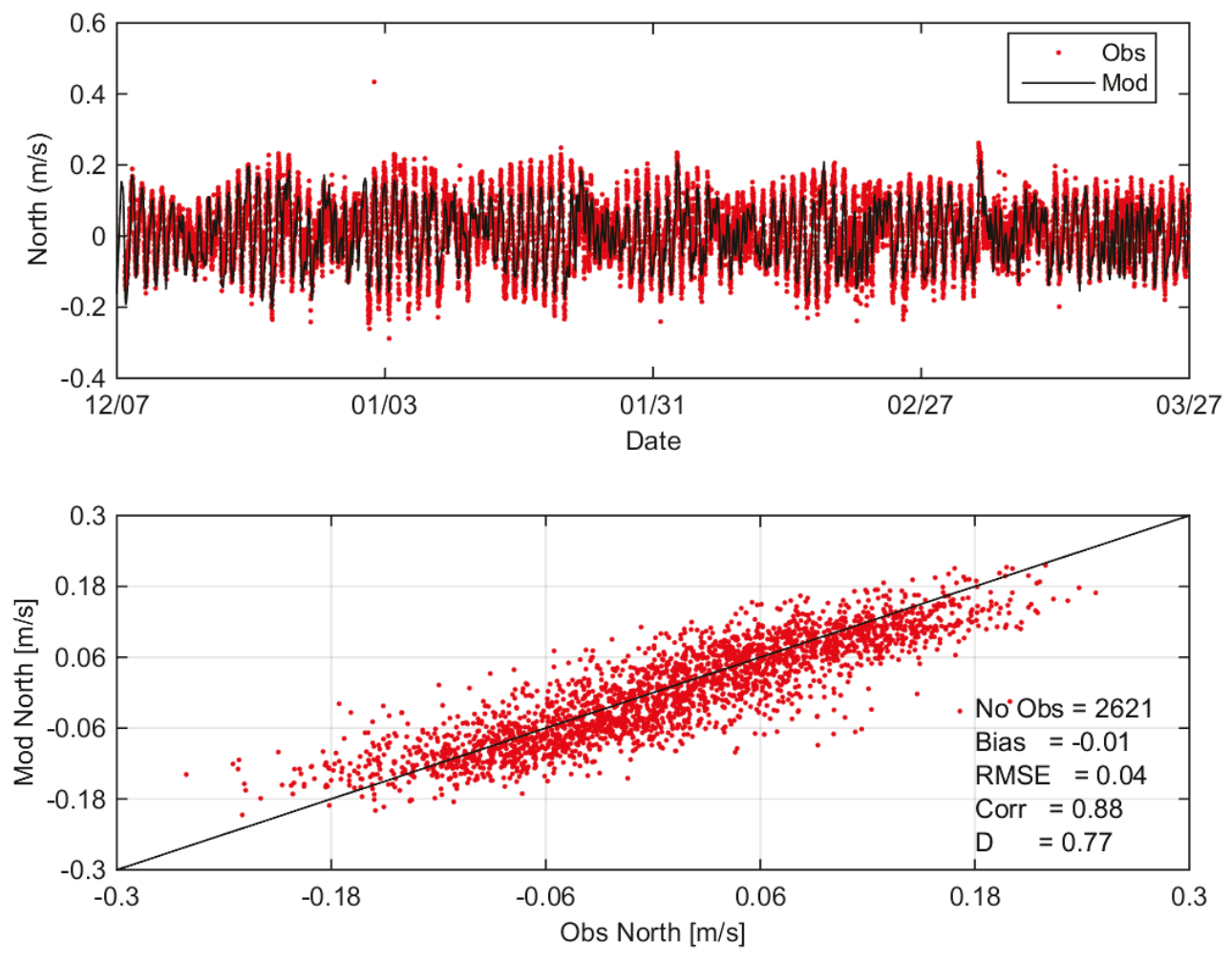

Figure 6-29 compares the range of velocities in both the east-west and north-south directions at iAWAC to model results. The model underestimates the south and west velocities more than the north and east velocities. Although CMS-Flow does not capture the variability of the measurements, the range of velocities in the east-west and north-south direction in the Brazos Harbor Inlet is well represented. 
Figure 6-29. Velocity excursion at iAWAC for 7 December 2014 - 27 March 2015.

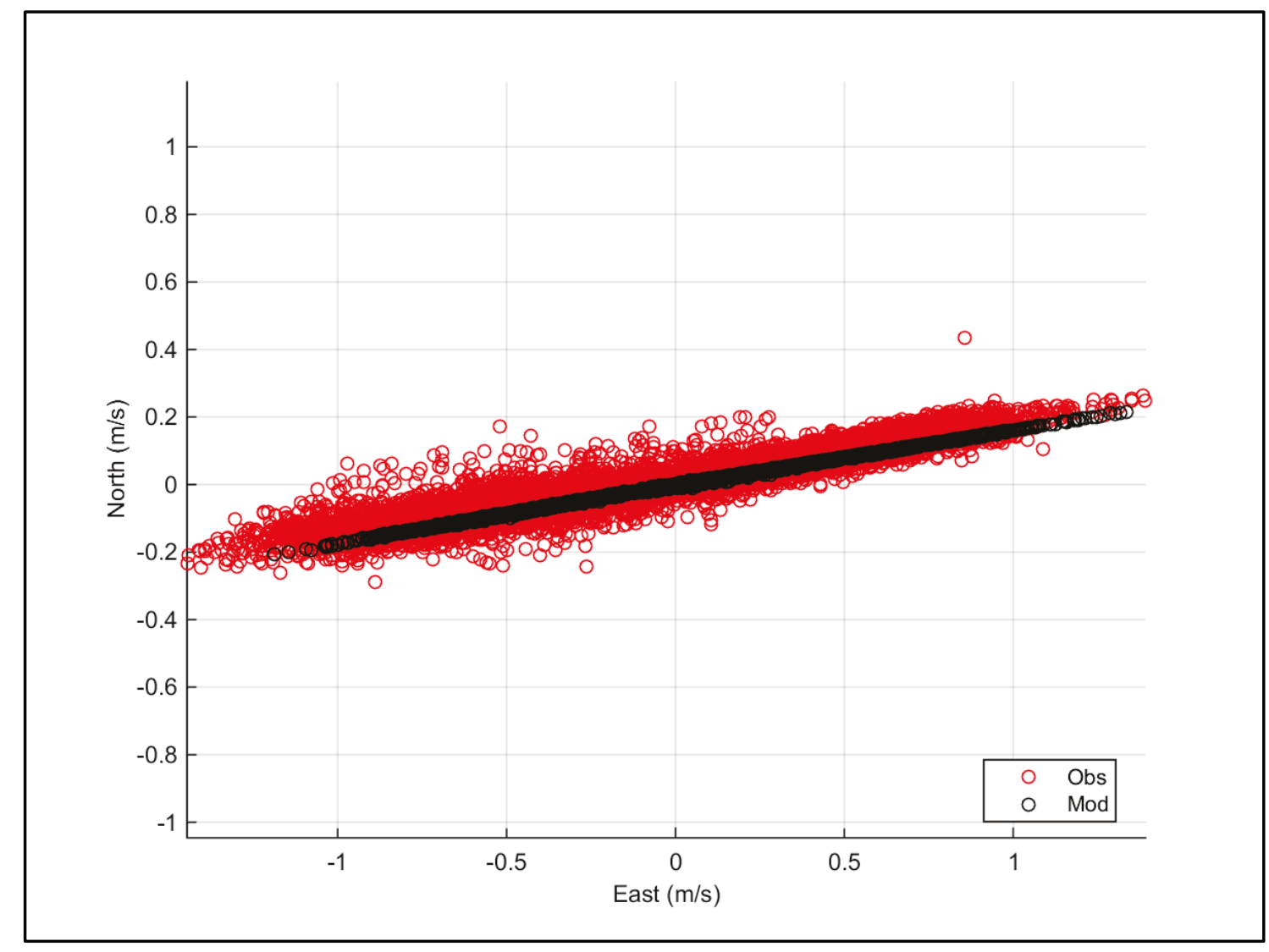

Waves. Comparisons of modeled to measured waves are displayed in Figure 6-30 and Figure 6-31, beginning with the offshore AWAC (oAWAC) followed by the inner-channel AWAC (iAWAC).

Figure 6-30 shows a comparison of modeled to measured wave parameters for oAWAC. There is an error in wave direction for the first measurement that is corrected for the remainder of the duration. Except for a missed local peak after February 27, CMS-Flow does a good job modeling the significant wave height $\mathrm{Hmo}$. The bias is nearly zero, the RMSE is $0.29 \mathrm{~m}$ ( $0.95 \mathrm{ft}$ ), the correlation is 0.89 , and the Willmott index is 0.8 . For peak period $\mathrm{T}_{\mathrm{p}}$ and mean direction, CMS-Flow performs slightly worse compared to $\mathrm{H}_{\mathrm{mo}}$. Although measurements along the line of best fit are widely scattered, CMS-Flow captures the general trend in $\mathrm{T}_{\mathrm{p}}$ very well. The bias, RMSE, correlation, and Willmott index are $0,1.69 \mathrm{~s}, 0.31$, and 0.44 , respectively. For mean wave direction, the measurements show more variation than the model results, resulting in the nearly horizontal orientation of the data to the line of best fit. 
Figure 6-30. Wave comparisons at oAWAC from 7 December 2014 - 27 March 2015.
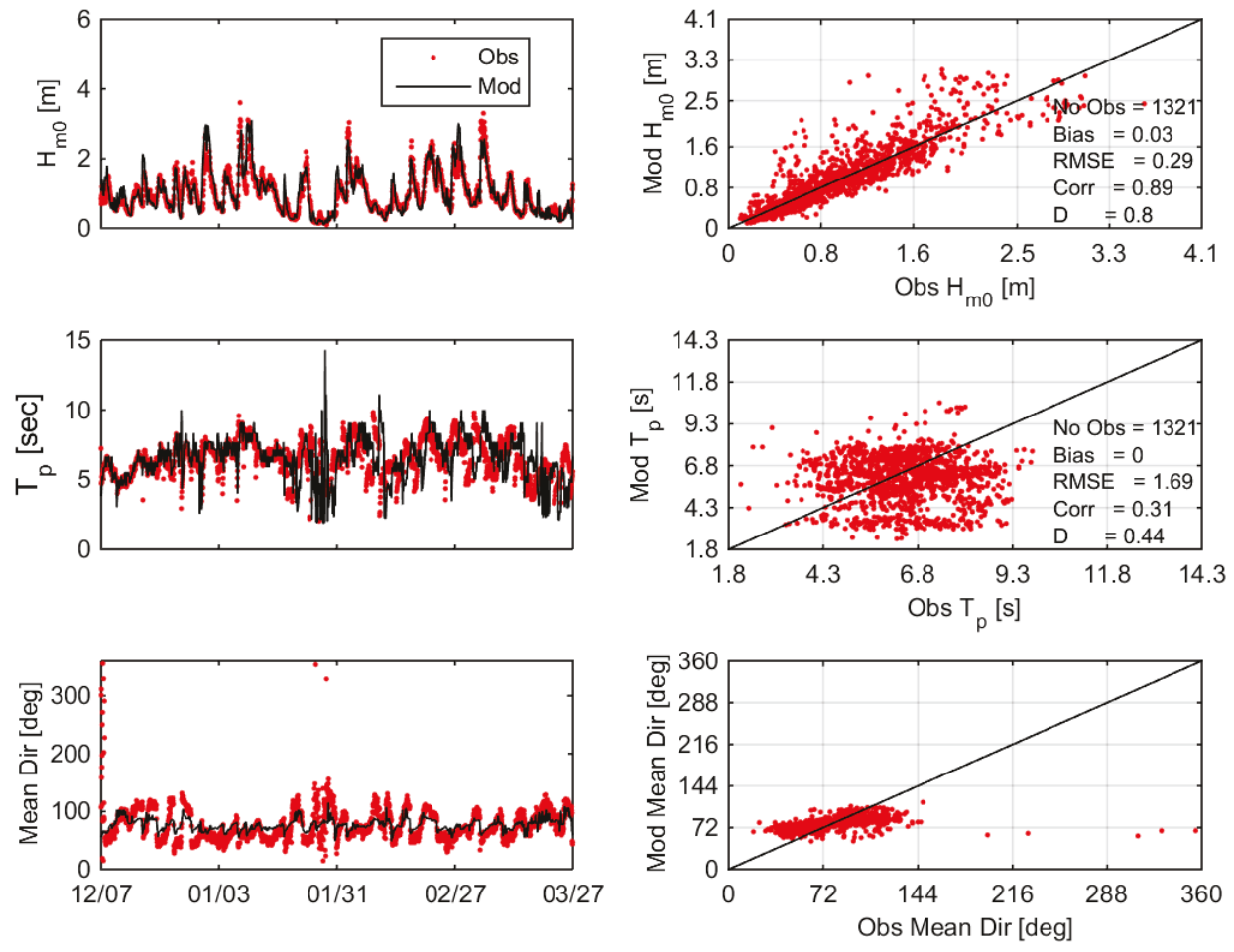

Comparisons between CMS-Wave results and measurements for iAWAC are shown in Figure 6-31. CMS-Wave performs slightly better at oAWAC compared to iAWAC for all wave parameters but continued to capture the wave climate within the inlet. CMS-Flow does a good job modeling the trends in significant wave height $\mathrm{H}_{\text {mo }}$ but slightly overestimates the mean, as indicated by a $0.09 \mathrm{~m}(0.30 \mathrm{ft})$ positive bias. The statistics for $\mathrm{H}_{\mathrm{mo}}$ are an RMSE of $0.22 \mathrm{~m}$ (0.72 ft), a correlation of 0.79 , and a Willmott index of o.67. Looking at peak period $\mathrm{T}_{\mathrm{p}}$, there is much scatter compared to the line of best fit. The bias for $\mathrm{T}_{\mathrm{p}}$ is $0.18 \mathrm{~s}$, the RMSE is $1.31 \mathrm{~s}$, the correlation is 0.64 , and the Willmott index is 0.64 . The measurements for mean wave direction are highly variable compared to the measurements although the mean wave direction observations remain within a narrow range. 
Figure 6-31. Wave comparisons at iAWAC from 7 December 2014 - 27 March 2015.
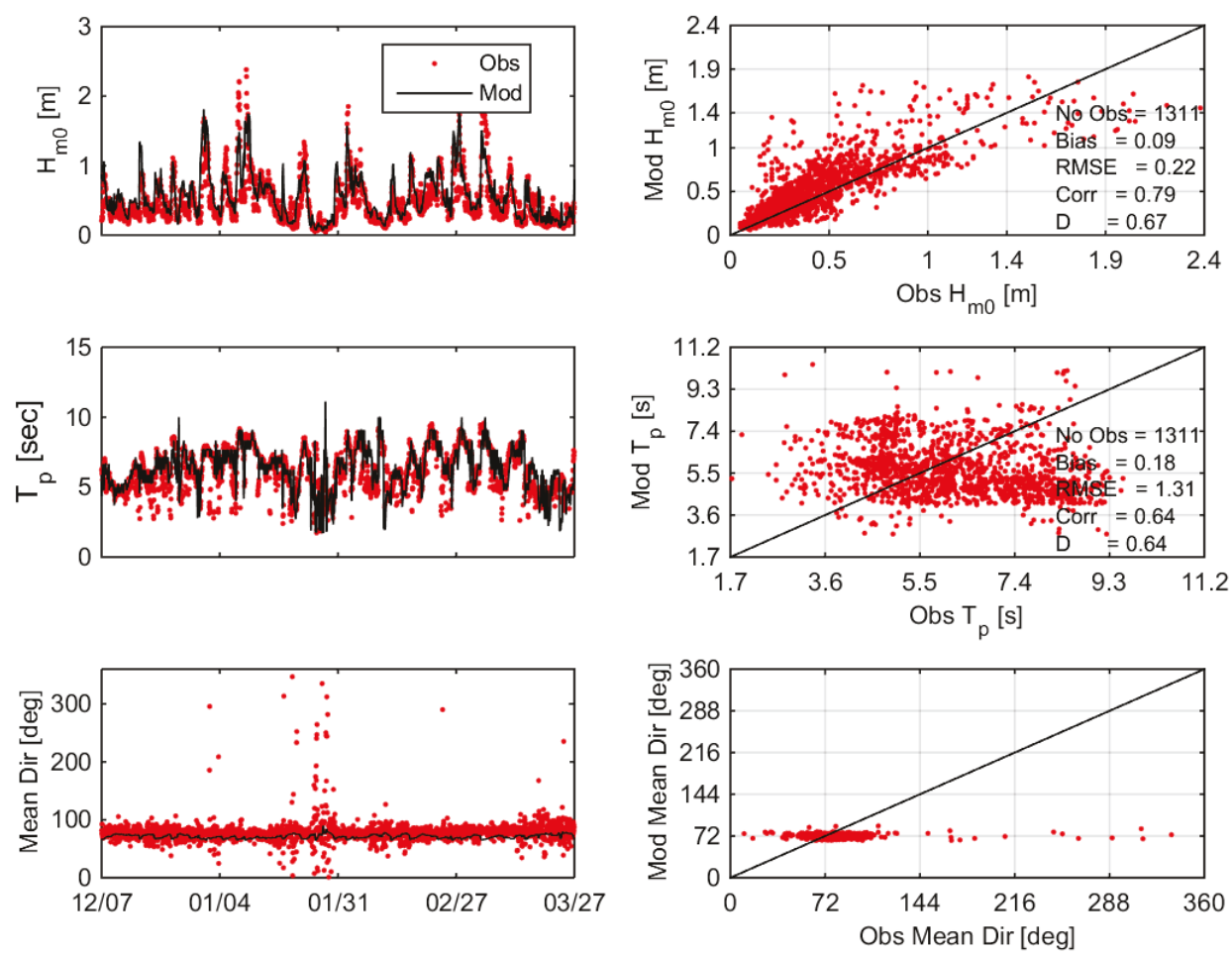

\section{Sediment evaluation of Base Case (present condition)}

Analysis of model results for the present condition of the channel, henceforth referred to as the Base Case in this technical report, is needed to evaluate the effects of the modeled alternatives. Bathymetry along a centerline transect was extracted to compare the bed evolutions predicted by the model to the survey data. Following the initial survey on 13 September 2014, bathymetry was collected by multi-beam sonar on 25 March 2015 and 7 July 2015. A comparison of the extracted model and survey bathymetry for September 2014, March 2015, and July 2015 is shown in Figure 6-32. The survey data, referenced to NAVD 88, were converted to MSL using a value of $-0.06 \mathrm{~m}$ $(-0.20 \mathrm{ft})$, as described in Chapter 5 . The data are overlaid the transect distance to provide a spatial reference of bed change. 
Figure 6-32. Predicted and surveyed bathymetry for September 2014 (yellow), March 2015 (blue), and July 2015 (green).

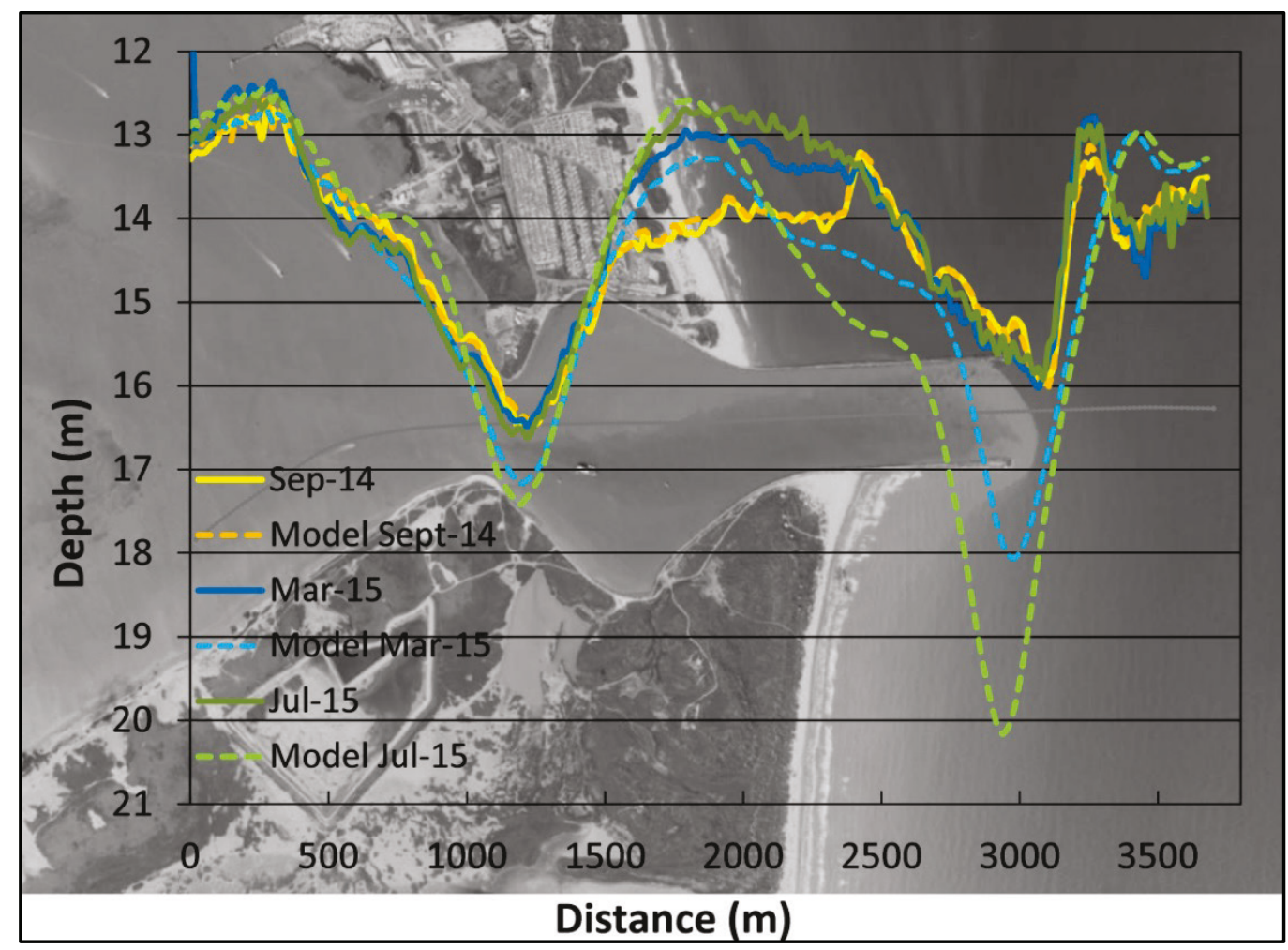

The September 2014 survey served as the initial model bathymetry, as previously mentioned in Chapter 6, and thus the model bathymetry closely resembles the measured bathymetry. Looking at the March survey, there is considerable deposition within the $1,500-2,500 \mathrm{~m}(4,920-8,200 \mathrm{ft})$ transect reach, with the channel shoaling by nearly $1 \mathrm{~m}(3.3 \mathrm{ft})$ over a 7 -month period. Within the beginning of this reach $(1,500-2,100 \mathrm{~m}[4,920-6,890 \mathrm{ft}])$, the model predicts a similar, albeit slightly lower, bed deposition. Outside the $1,500-2,500 \mathrm{~m}(4,920-8,200 \mathrm{ft})$ reach, the model clearly shows some areas of active bed erosion although surveys indicate a stable bathymetry. The model captures the stable bathymetry from $0-1,000 \mathrm{~m}(\mathrm{o}-3,28 \mathrm{oft})$. In the 1,000-1,500 $\mathrm{m}(3,280-4,920 \mathrm{ft})$ reach, the model erodes the bed by approximately $0.5 \mathrm{~m}(1.6 \mathrm{ft})$ compared to the March survey. The model erodes rather than deposits in the 2,100-2,500 $\mathrm{m}(6,890-8,200 \mathrm{ft})$ reach, flattening a local shoal around $2,500 \mathrm{~m}(8,200 \mathrm{ft})$. The largest discrepancy between survey and model results is between the tips of the jetties (approximately 3,000 $\mathrm{m}[9,840 \mathrm{ft}]$ ), where the model erodes the bed by approximately $2 \mathrm{~m}$ (6.6 ft). Both the July survey and model results evolve similarly to that of March. The July survey shows additional deposition in the $1,500-2,500 \mathrm{~m}(4,920-8,200 \mathrm{ft})$ reach, although the amount of deposition is less than half a meter and is significantly less than the September-March 
timeframe. The model accurately predicts the deposition in the 1,500$2,100 \mathrm{~m}(4,920-6,890 \mathrm{ft})$ reach. Not evident in the surveys, however, are the persistent areas of erosion predicted by the model, particularly the 2,100$3,300 \mathrm{~m}(6,890-10,825 \mathrm{ft})$ reach between the jetties. The channel erosion predicted by the model between the jetty tips, approximately $4 \mathrm{~m}(13.1 \mathrm{ft})$ in nearly 10 months, is almost certainly unrealistic. An inspection into the currents, which were extracted from a single point between the jetties, showed reasonable magnitudes, reaching a maximum of $1.5 \mathrm{~m} / \mathrm{s}(4.9 \mathrm{ft} / \mathrm{s})$ (Figure 6-33). Further attempts to diagnose and prevent this rapid erosion by the model were unsuccessful.

Figure 6-33. Current magnitude extracted from location (435561.3, 5044970.0) between the tips of the jetties.

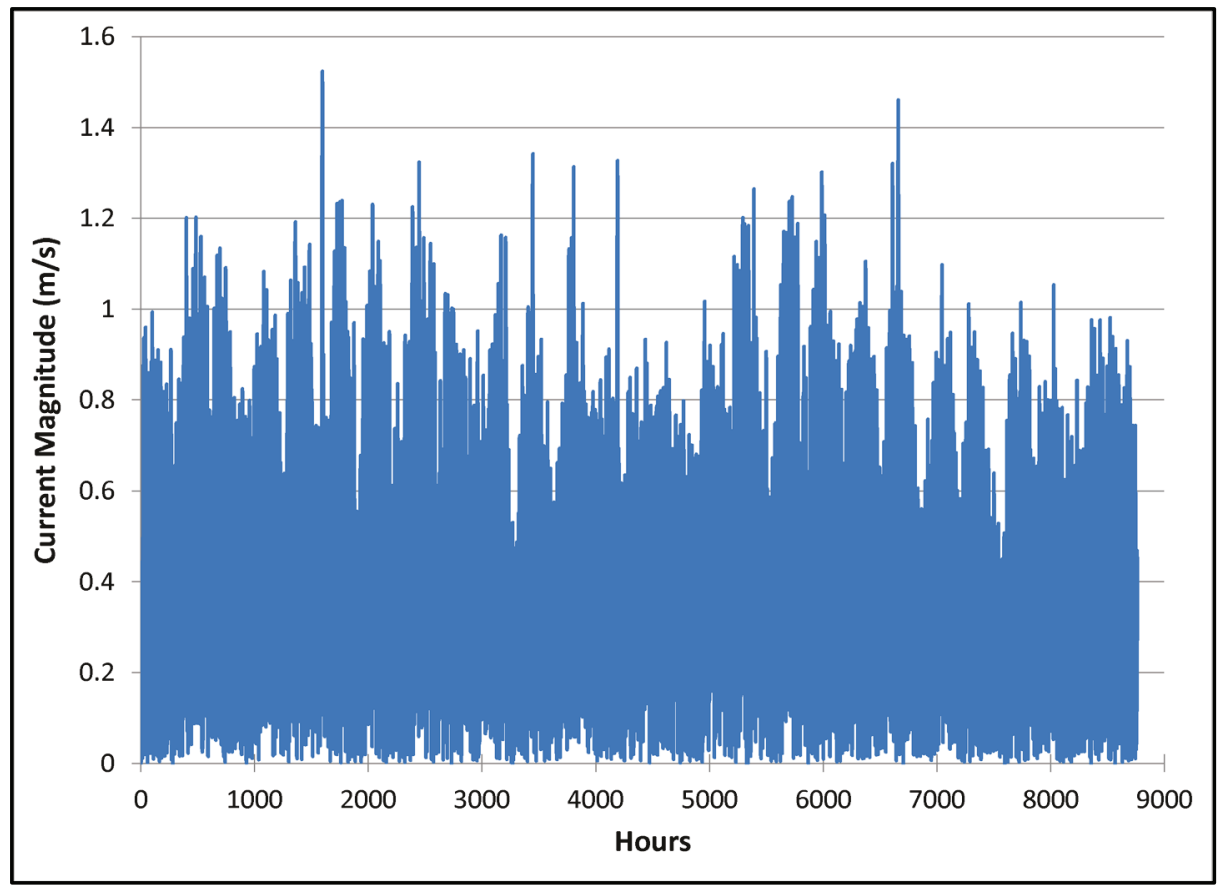

A comparison of the measured to modeled bed change for the inlet extent is shown in Figure 6-34. The bed change predicted by the model is much more active than the measurements. The active areas of bed change in the measurements are large limited to shoaling within the channel and scouring around the jetty tips whereas the extent of predicted bed change encompasses nearly the entire area except the crenulate embayments. A plot of modeled bed change with a greater legend range is also shown in Figure 6-34. The magnitude of bed change predicted by the model is on the order of meters rather than centimeters within Laguna Madre, along the channel, within and near the constriction shoreward of the crenulate embayments, and between the jetty tips. Although the bed change of the 
model could have been lessened by decreasing the bed-load and suspended-load scaling factors, ensuring the model predicted the same magnitude of shoaling within the project area as was observed took precedence over areas of lesser interest.

Figure 6-34. Measured (top) and modeled (center and bottom) bed change.

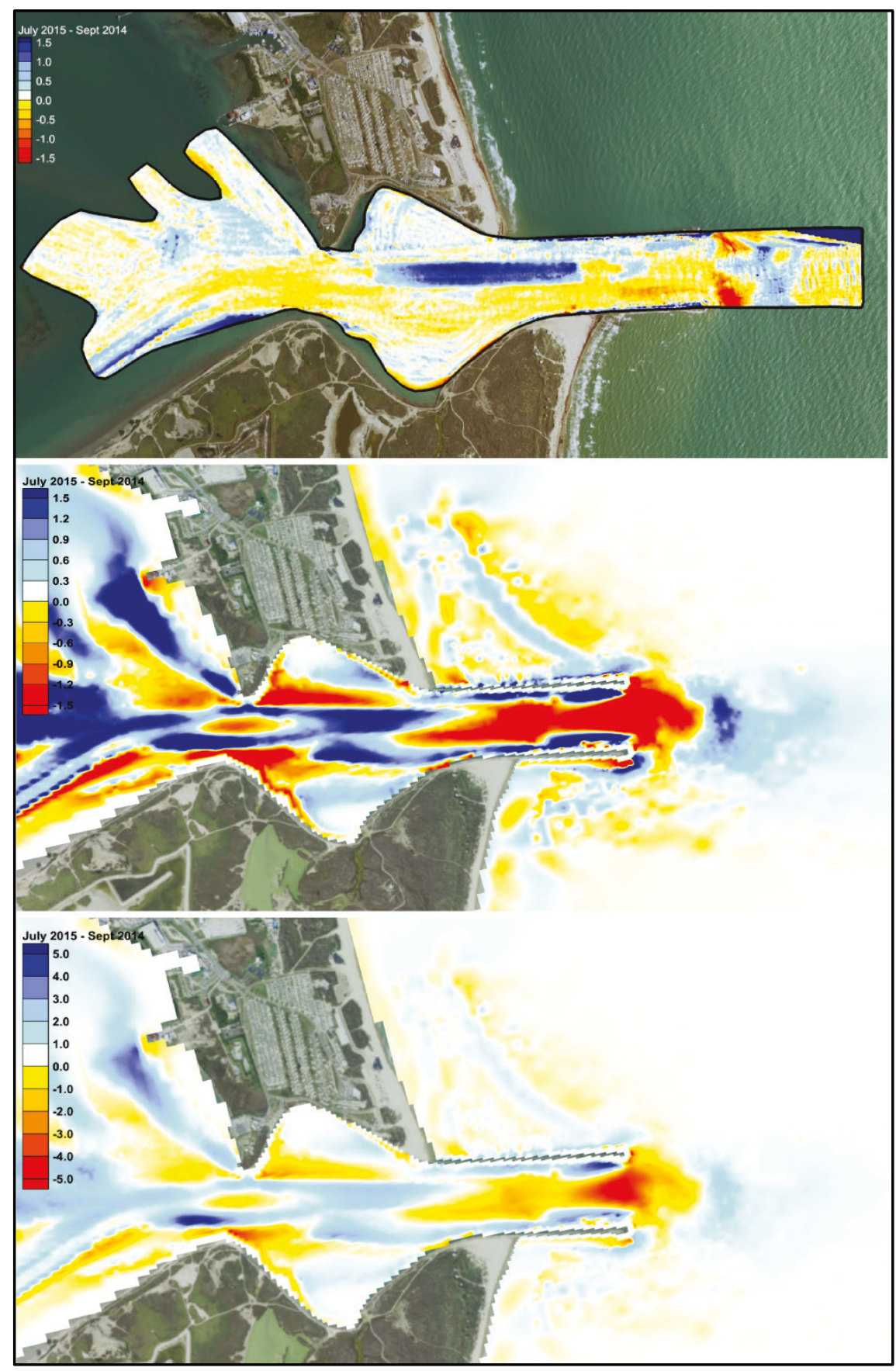




\section{Sedimentation patterns of the system}

The general sediment transport patterns within the Brazos region are described within this chapter to identify the source of sediment depositing within the area of concern. The sediment transport processes responsible for shoaling include the sediment flux into the inlet and the accumulation of deposited sediment in the navigation channel. The currents and waves must be forceful enough to transport sediment towards the shoal but then be reduced enough to allow sediment to deposit.

\section{Previous studies}

A general description of sediment transport patterns within the area was presented in McGowen et al. (1977). In this study, it was shown that the sediment transport patterns outside of the inlet can be described by Figure 6-35. The figure shows that south of Brazos, sediment moves northward towards the inlet along shore and that transport continues north to a zone of convergence that is reached near Corpus Christi. Sediment from the northern coastline is transported southward.

Figure 6-35. Simplified pattern of net longshore sediment transport along the Texas coast (from McGowen et al.

[1977]; after Watson [1971]).

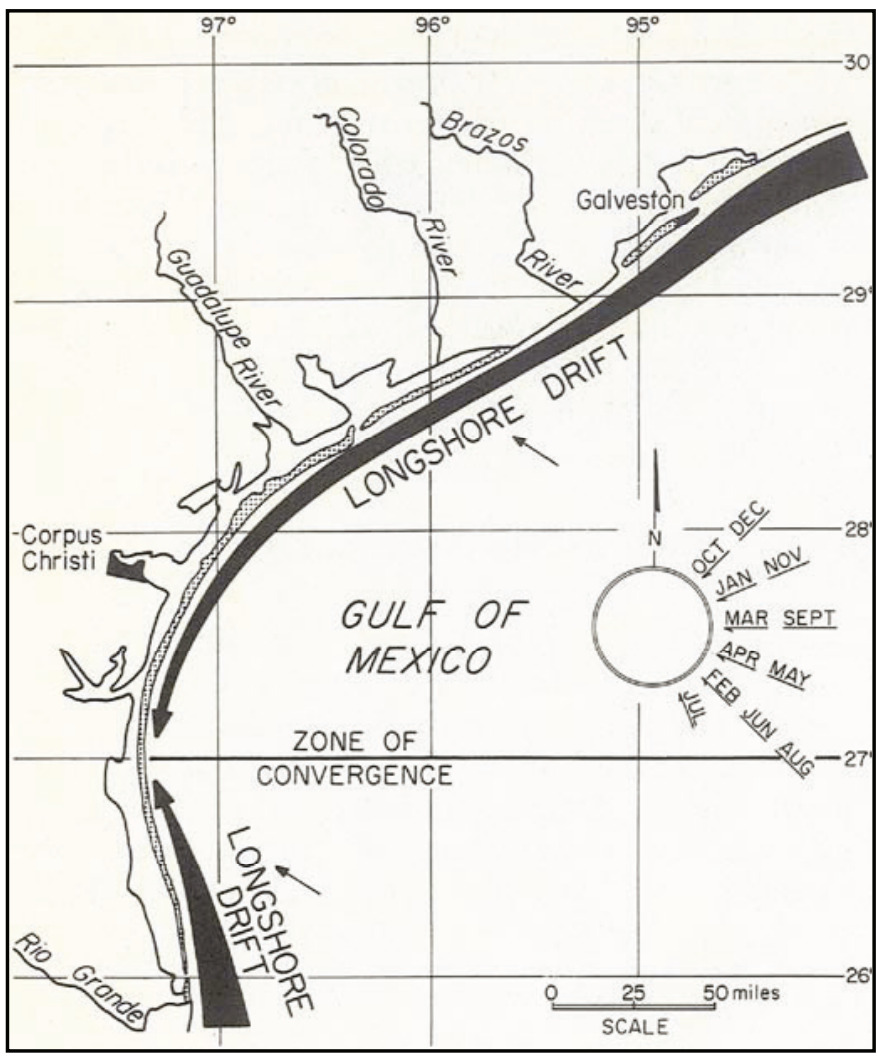


In HDR (2009), a conceptual sediment budget was developed that showed similar patterns. Figure 6-36 depicts the annual net sediment transport quantities with arrows indicating direction. The sediment budget was developed using historical data such as dredging records and shoreline change measurement. In addition, bathymetric data, estimation of sediment transport rates, and knowledge of engineering activities were taken into account. The study shows that overall alongshore transport is towards the north on both the southern and northern side of the inlet. Sediment that moves northward towards the inlet has the potential to be transported into the inlet.

Figure 6-36. HDR (2009) conceptual sediment budget, 1980 - 2008.

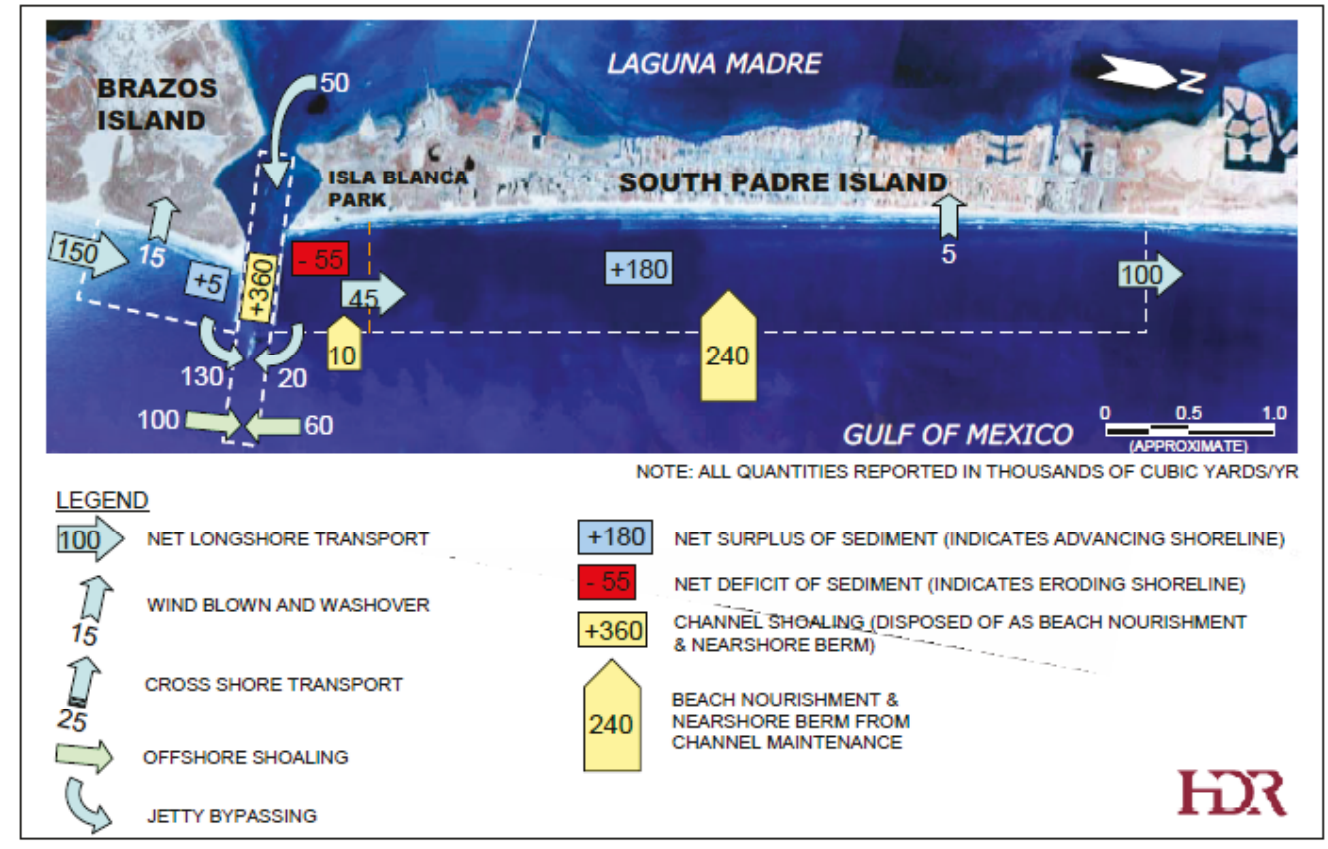

\section{Base Case numerical modeling results}

The numerical results from this study confirm these transport pathways. To illustrate this agreement, sediment transport roses were developed. The rose diagram was created to show the frequency of sediment transport magnitude over the modeled year plotted by sediment transport direction. The color bands represent sediment transport magnitude ranges. The direction of the longest spoke shows the direction in which sediment is transported with the greatest frequency. To create these roses, time series of sediment transport magnitude and direction were extracted from the Base Case numerical solution. The locations of the rose diagram positions are shown in Figure 6-37. 
Figure 6-37. Rose diagram selected locations.

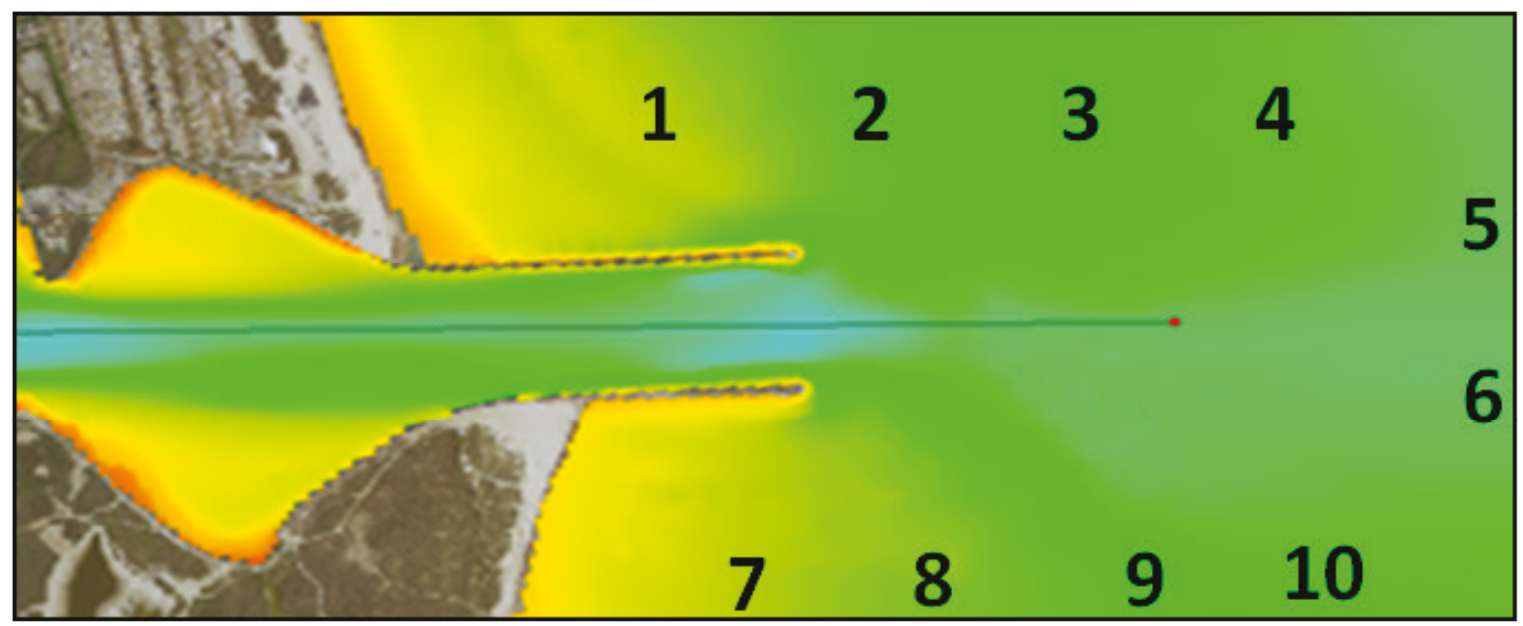

Sediment transport rose results are shown in Figure 6-38 at the 10 selected locations. As expected at point 1 (north of the jetty), it is evident that the dominant direction of transport is to the north and some transport westward. This trend is continued south of the jetties with locations 7 and 8. Farther off shore the magnitudes appear to decrease, and the dominant flow direction is less discernable. Points 5 and 6 show no preferred direction. Points 2 and 3 seem to have a preferred southern component. Potentially, the influence of the jetty dynamics are still impacting the transport patterns at those points. That would be consistent with the results from the HDR (2009) conceptual sediment budget. 
Figure 6-38. Sediment transport rose diagrams.
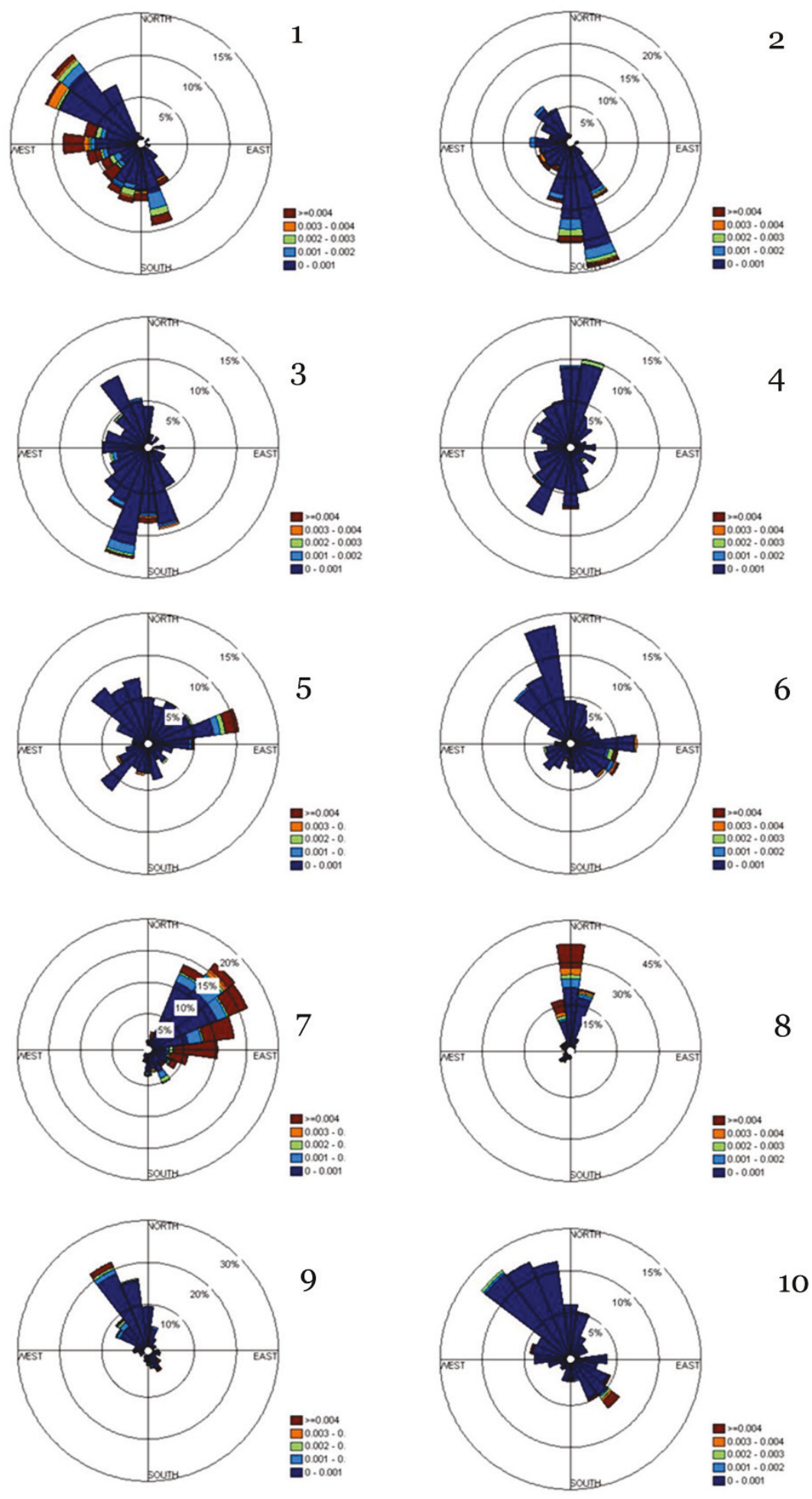
To further confirm the numerical solution, a sediment budget from the CMS simulations is constructed by encompassing the BSI entrance with three offshore boundary lines and computing the cumulative flux normal to each section. The lines are depicted in Figure 6-39, and when adjoined with the shoreline, form a closed system. Any sediment deficit or surplus within the boxed region represents the flux to or from the inlet entrance or accumulation/erosion in the defined area.

Figure 6-39. Transect locations for sediment transport calculations.

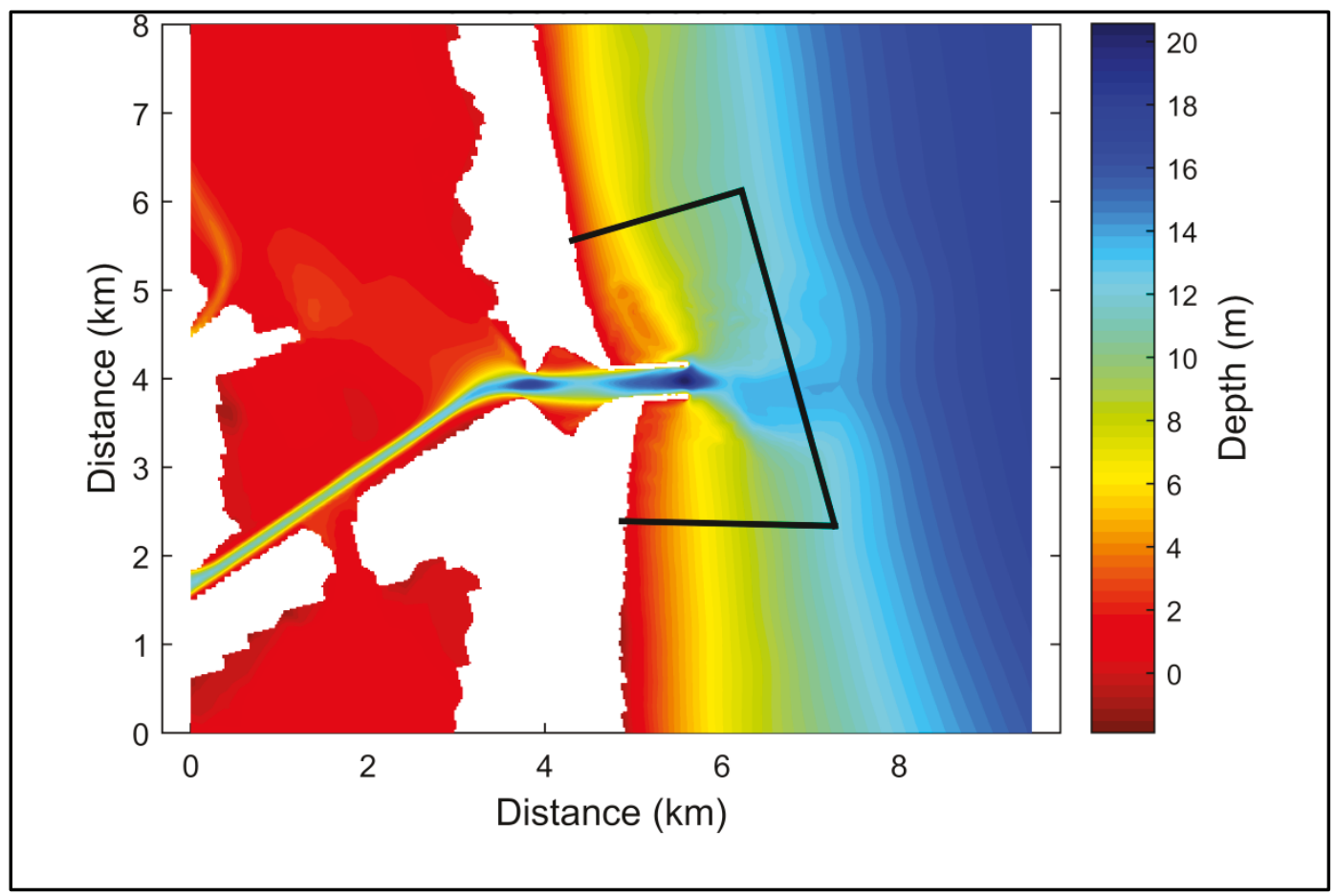

The Base Case is used to illustrate the cumulative flux over the course of the simulation (Figure 6-40). The cross-shore flux (offshore) is an order of magnitude less than the alongshore flux, meaning the predominant sediment transport mode is the alongshore component. At the beginning of the simulation, there is a net, yet weak, transport in the southerly direction both north and south of the inlet. The transport switches direction at both locations between October and December but remains relatively weak. By mid-December, the transport is directed towards the south and increases through the winter. By March the net volume change is reduced. A strong convergence between the north and south transects occurs during this time indicating a larger quantity of sediment is being supplied by the north compared to weaker losses south of the inlet. By the end of April, the longshore transport switches direction towards the north. The northward transport continues through the remainder of the 
simulation but at a reduced rate between July and September. The transport south of the inlet is greater than the transport north of the inlet, indicating convergence in the boxed area that encompasses the inlet entrance. Between January and the end of the simulation, the net transport directs sediment towards the inlet, where it is either deposited in the nearshore region or transported into the inlet throat. A similar pattern is seen in the other alternatives, but the total change during the simulation varies. The model results indicate that alongshore transport supplies sediment to the inlet and that over the course of the simulation the net transport is towards the north.

Figure 6-40. Cumulative sediment transport encompassing the BSI. Positive/negative values denote total sediment volume flux surplus/deficit. The curves represent the total sediment flux expressed in terms of cumulative volume normal to the transect lines integrated through time.

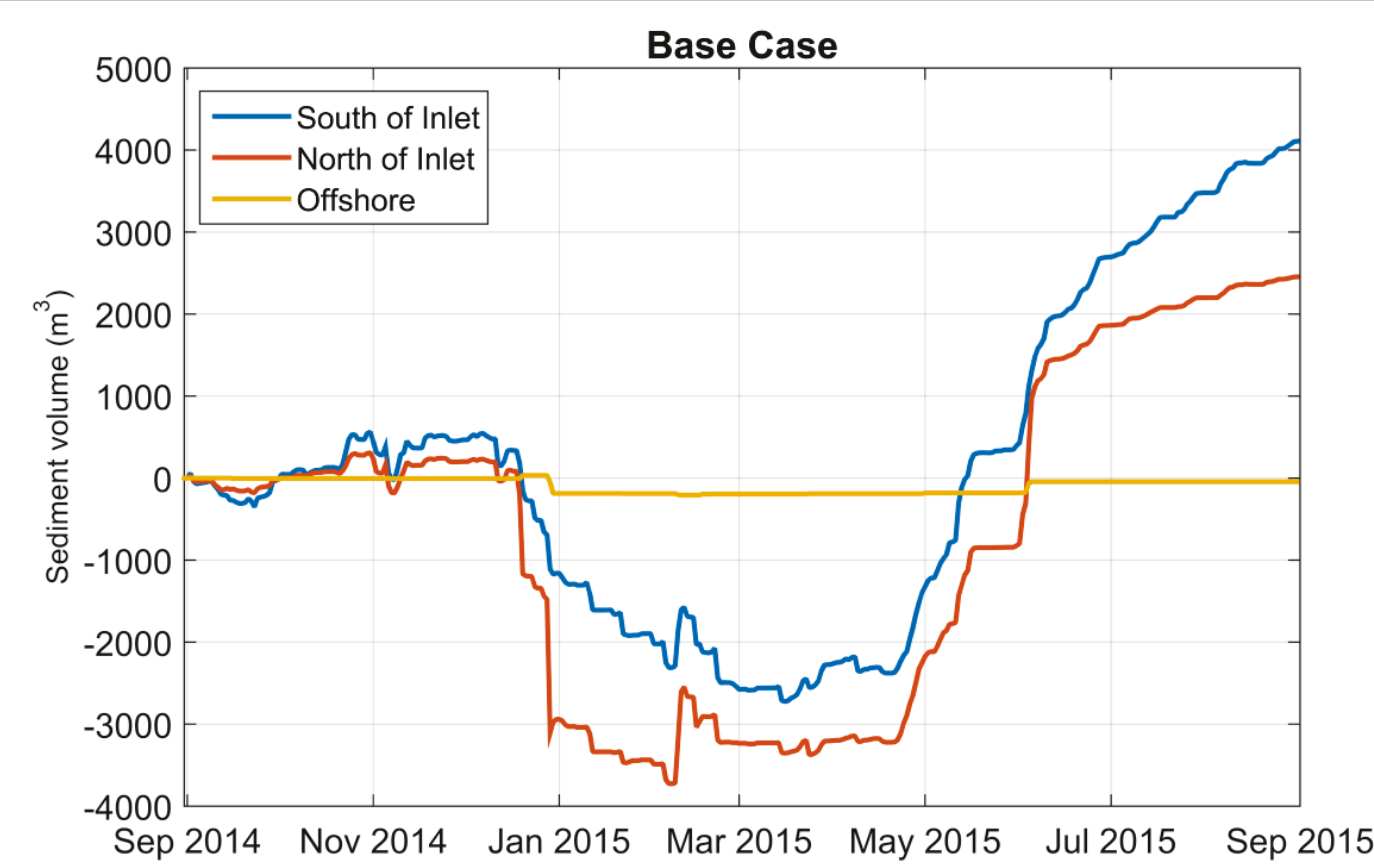




\section{Hydrodynamics of the Lower Laguna Madre/Brazos Santiago/Mansfield System}

The Lower Laguna Madre hydrodynamic system, as discussed here, consists of the lagoon and the two inlets, Mansfield Pass and Brazos Santiago Inlet. It is unusual in the degree to which flows are dominated by winds rather than tides, fresh-water inflow, or other factors.

\section{Shoal location within Brazos Santiago Inlet}

Tidal velocities are nearly uniform along the portion of Brazos Santiago Inlet where the jetties are straight and parallel. However, where the sides of the inlet flare out, the currents slow down. In Figure 7-1, tidal velocity curves for 6 days (12-18 September 2014), obtained from the numerical model, are plotted on vertical axes at nine along-channel stations. These values represent cross-channel and vertical average velocities. The tidal velocities for the westernmost station (o+ooo) and the four easternmost stations $(-3+000,-3+600,-4+400$, and $-5+200)$ have similar values. The velocities at stations $-0+800$ and $-2+400$ range between $70 \%$ and $80 \%$ of the parallel jetty velocities, and velocities at stations $-1+400$ and $-2+000$, near the widest flare of the jetties, drop to $50 \%-60 \%$ of the parallel jetty values.

Flood shoals at inlets typically form at the landward end of the inlet channel where flood currents first start to drop as the flow enters a broad bay or estuary. Thus, a persistent shoal that forms in the region of station $-2+000$ to $-2+400$ in this inlet is expected, and this explanation is the reason that this deposition area is referred to as the flood shoal in this report. 
Figure 7-1. Inlet flow velocities at different along-channel locations in Brazos Santiago Inlet.

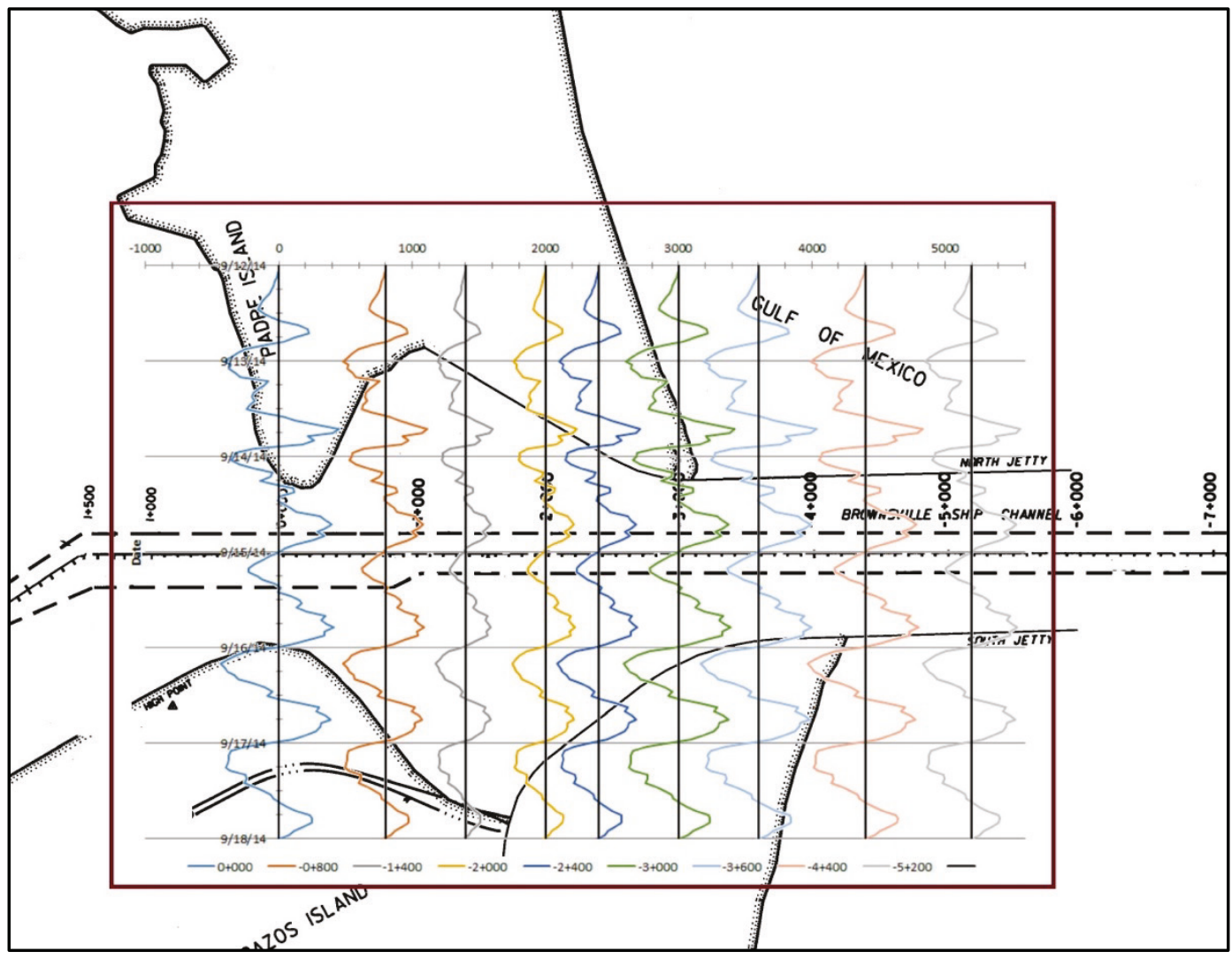

Tides

The location of nine tide gages within the Lower Laguna Madre system are presented in Chapter 4 and are also displayed in Figure 7-2 to make it easier to follow the discussion. The tide gage at Port Isabel, near Brazos Santiago Inlet, is National Ocean Service station 8779770, part of the NOAA system of tide gages operated around the country. The tide gage stations CHL TIDE1, TIDE2, TIDE3, and TIDE4 were deployed for this study by ERDC/CHL. TIDE1 was located at the Gulf entrance of the Mansfield Channel $56.4 \mathrm{~km}$ (35 miles) north of Port Isabel. TIDE2 was positioned approximately halfway between Port Mansfield and the Land Cut at the northern end of Lower Laguna Madre, $71.7 \mathrm{~km}$ (44.5 miles) north of Port Isabel. TIDE3 was located south of Port Mansfield, $41.3 \mathrm{~km}$ (25.7 miles) north of Port Isabel, and TIDE4 was located at Brownsville Harbor, $21.5 \mathrm{~km}$ (13.4 miles) southwest of Port Isabel. 
Figure 7-2. Tide stations in Lower Laguna Madre used in this present study (from Google Earth https://www.google.com/earth/).

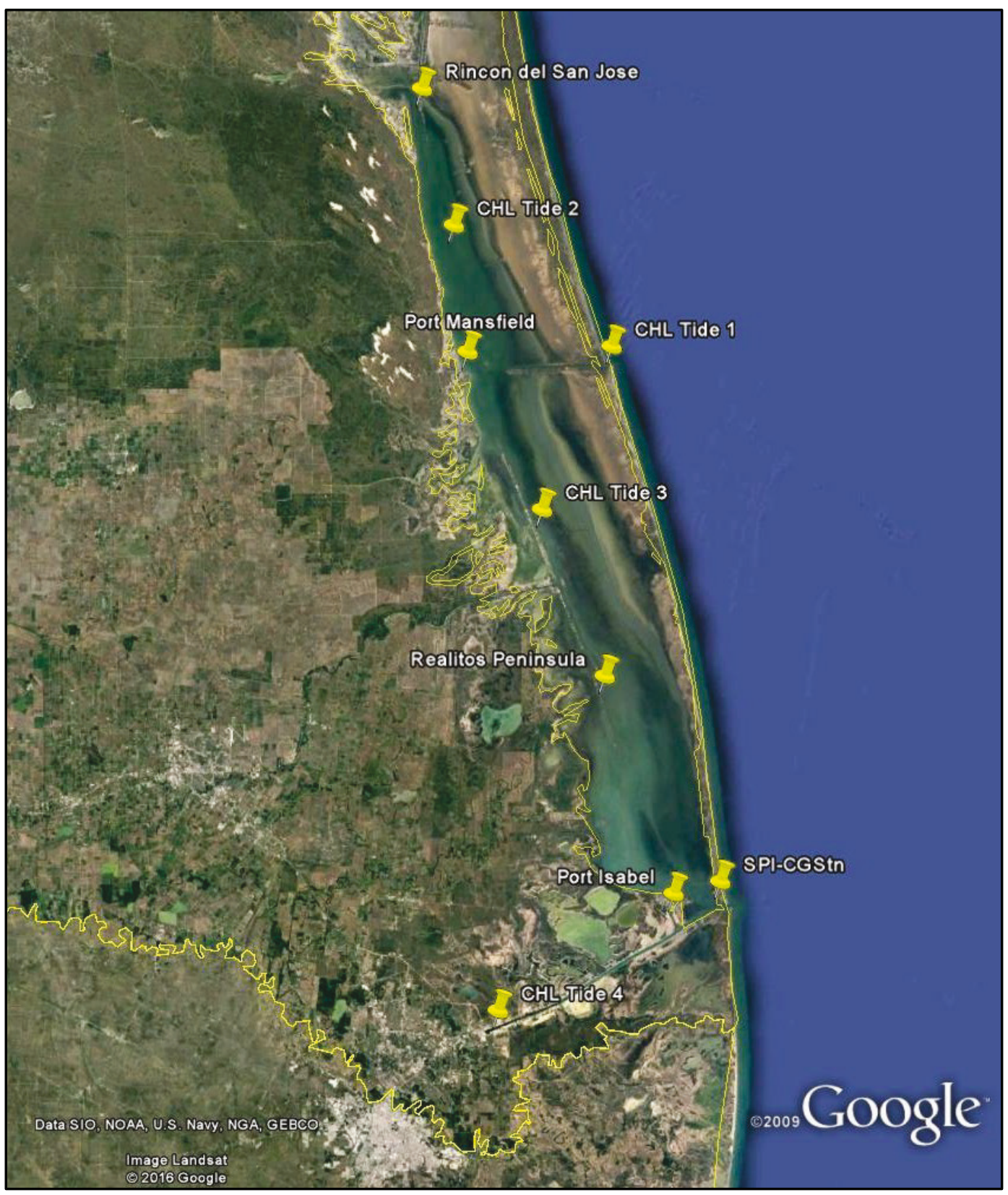

Four stations were operated by TCOON. The South Padre Island Coast Guard Station gage was located on South Padre Island near Brazos Santiago Inlet, $5 \mathrm{~km}$ (3.1 miles) east of Port Isabel. The Realitos Peninsula gage is in Laguna Madre, $23.2 \mathrm{~km}$ (14.4 miles) north of Port Isabel. The Port Mansfield gage is $58.9 \mathrm{~km}$ (36.6 miles) north of Port Isabel and 14.8 $\mathrm{km}$ (9.2 miles) west of TIDE1 at the Mansfield Channel entrance to the Gulf. Last, Rincon (del San Jose) is at the northern end of Lower Laguna Madre, $85.7 \mathrm{~km}$ (53.2 miles) north of Port Isabel. Unfortunately, the 
TCOON stations were operational only during the early part of the field data collection portion of this study.

Tides along the south Texas coast are of low amplitude, diurnal (one high and one low per day) and are subject to regional low-frequency oscillations that are generated in the Gulf of Mexico. These factors are seen in the Port Isabel measured WSE, shown in Figure 7-3 and Figure 7-4.

Figure 7-3. Measured hourly WSEs for October 2014 at Port Isabel.

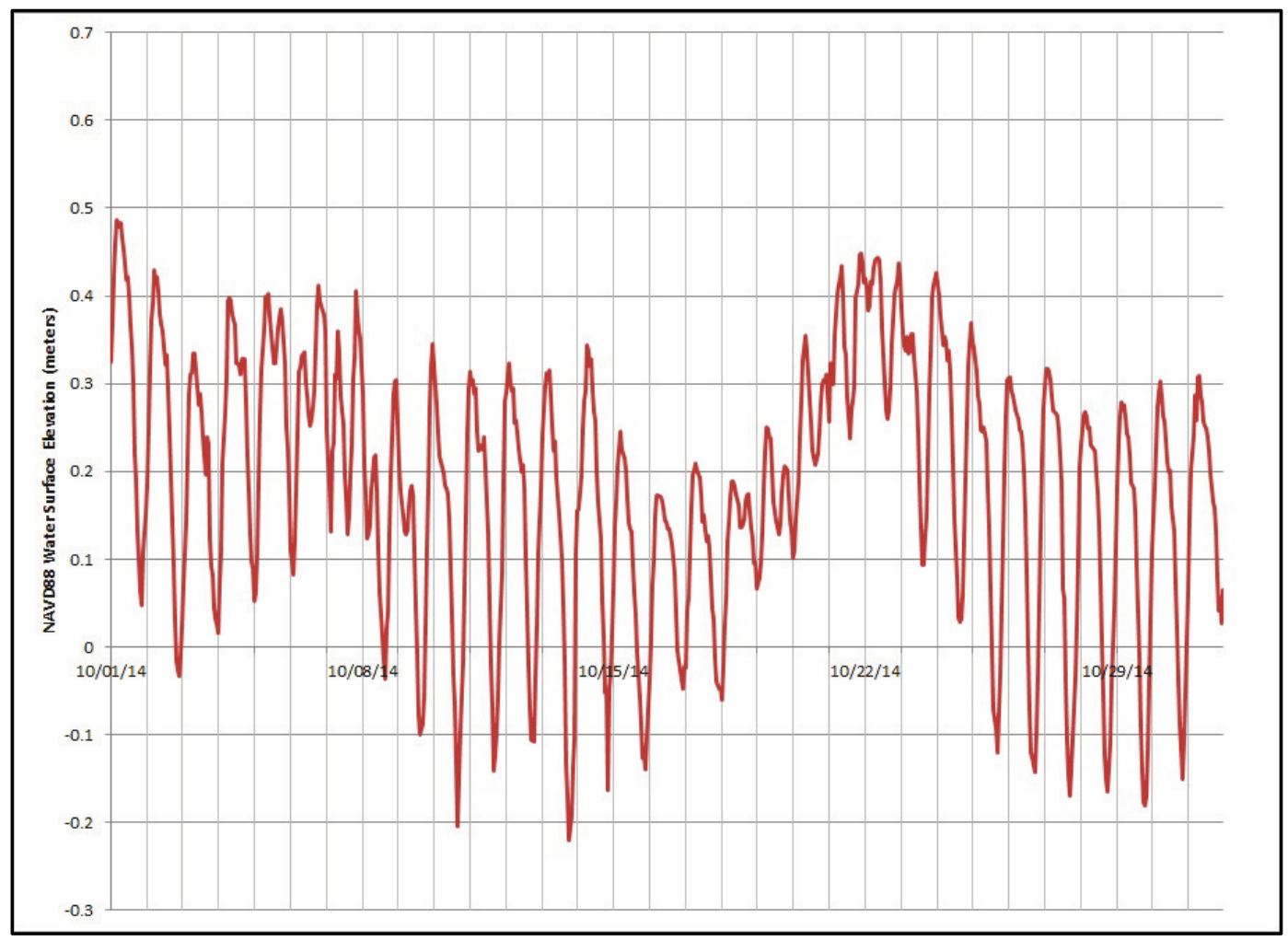

Figure 7-3 shows the Port Isabel WSE for October 2014. The diurnal nature of one high and one low tide per day clearly stands out. The spring tide range (near the 14th and 28th of the month) is approximately $0.5 \mathrm{~m}$ $(1.5 \mathrm{ft})$. NOAA lists the mean diurnal range for this gage as $0.42 \mathrm{~m}(1.37 \mathrm{ft})$ (https://tidesandcurrents.noaa.gov/stationhome.html?id=8779770). Though inside the lagoon, this amplitude is only slightly less than the tide range in the Gulf, as shown by the tide range of $0.50 \mathrm{~m}(1.63 \mathrm{ft})$ at the open coast gage on the Bob Hall Pier, 168 km (105 miles) to the north, near Corpus Christi (https://tidesandcurrents.noaa.gov/stationhome.html?id=8775870). The tides at the two locations are also essentially in phase. 
Figure 7-4. Low-pass filtered tide data at Port Isabel.

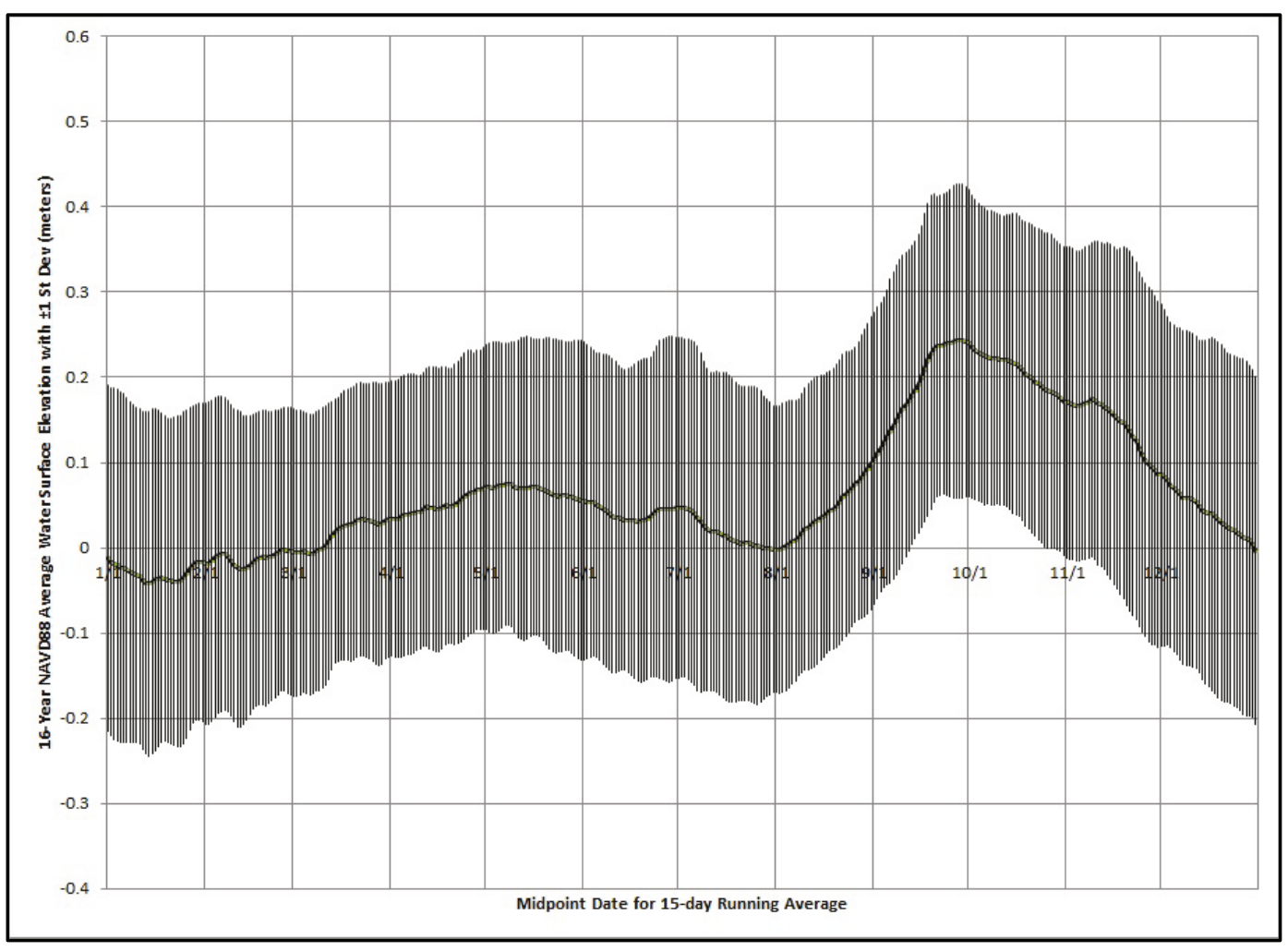

The black line in Figure 7-4 shows the seasonal trend in the WSE. The data have been averaged over 16 years (2000-2015) and also smoothed over a 15-day running window. This process smooths out the year-to-year variation in the data and also removes the diurnal fluctuations. This figure shows that a yearly peak in the mean water level occurs in October with a lesser peak in May and with intervening troughs in January and August. This is a regional trend mostly caused by seasonal variations in the mean water elevation in the Gulf and thus can be seen in all the gages in Laguna Madre. However, there is significant year-to-year variation in this trend as shown by the width of the \pm 1 Standard Deviation band in this figure and also by the yearly variations in WSE shown in Figure 7-4.

Figure 7-5 shows the October 2014 measured WSE data for the gages near Brazos Santiago Inlet. The South Padre Island-Coast Guard Station gage is not shown in this figure, as at this resolution it completely covers the Port Isabel curve, and thus the two are essentially identical. The Coast Guard Station, Port Isabel, TIDE4 (Brownsville Harbor) and TIDE1 (Gulf entrance to Mansfield Channel) (Figure 7-2) all have curves that are very similar in amplitude and phase. There is little variation in the amplitude or phase of the tide between its arrival at Mansfield Pass (TIDE1 gage) and its 
arrival at Brazos Santiago Inlet. Because Brazos Santiago Inlet is a deep draft channel (12.8 $\mathrm{m}$ [42 ft]), the Gulf tide is able to pass through the inlet, past the Coast Guard Station and Port Isabel, and able to travel the length of the Brownsville Shipping Channel to Brownsville Harbor with minimal friction causing little loss in amplitude or distortion in phase. However, as the tide wave travels north from the bottom end of the shallow Laguna Madre (average depth $1.4 \mathrm{~m}$ [4.6 ft], Table 2-2), it loses substantial amplitude by the time it reaches the Realitos Peninsula gage. The NOAA website (https://tidesandcurrents.noaa.gov/stationhome.html?id=8779280) lists the diurnal range as $0.17 \mathrm{~m}(0.56 \mathrm{ft})$, which is only $41 \%$ of the diurnal range at Port Isabel. However, at this location, the diurnal tide signal is still clearly evident.

Figure 7-5. October 2014 WSE data for tide gages near Brazos Santiago Inlet.

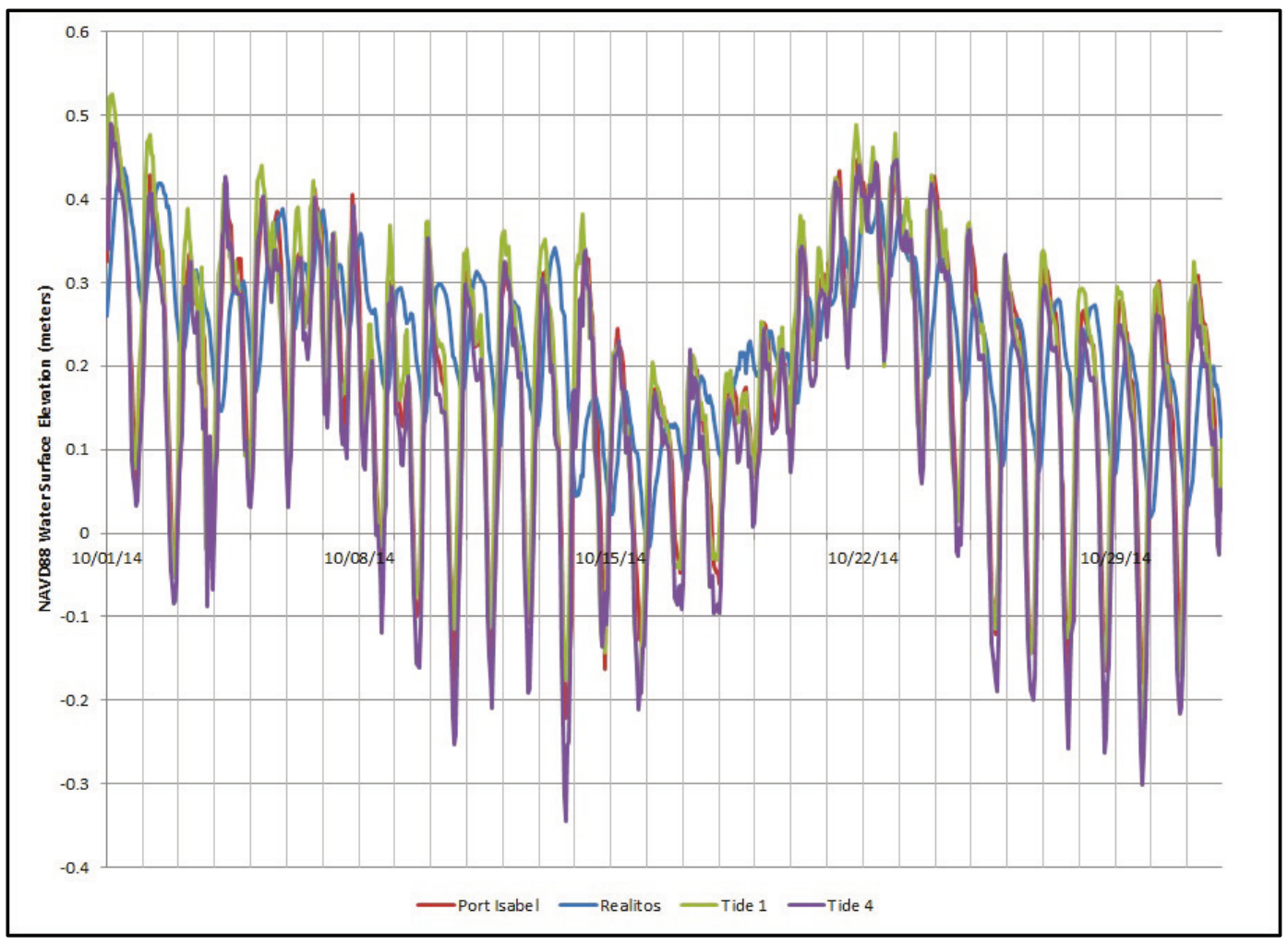

Contrast Figure 7-5 above with Figure 7-6 below. This figure shows October 2014 elevation data from gages at the northern end of the lagoon. The Realitos Peninsula gage data are shown on both figures for reference. In Figure 7-6, the gages are listed in the legend from south to north. It is seen that the Realitos gage shows water surface variations that are primarily controlled by the diurnal tide. However, gages to the north of it 
show that the tidal influence has nearly dropped to zero and that variations in water elevation are much more dominated by wind stress.

In particular, note that the Port Mansfield gage is only $14.8 \mathrm{~km}$ (9.2 miles) west of the TIDE1 gage at the Gulf and that the two sites are connected by the straight Mansfield Channel. The tidal energy arriving at Mansfield Pass is almost completely lost as it propagates to Port Mansfield. In contrast, for example, almost none of the tidal energy that arrives at Port Isabel is lost as it travels the $27.4 \mathrm{~km}$ (17 miles) along the Brownsville Ship Channel to Brownsville Harbor. The primary difference between the two channels is their depths (12.8 m [42 ft] for the Brownsville Ship Channel and 1.8-3.7 m [6-12 ft] for the Mansfield channel), though channel width (91.5 m [300 ft] for the Brownsville Ship Channel vs. $38.1 \mathrm{~m}$ [125 ft] for Mansfield Channel) is also a factor. This illustrates the important non-linear dissipative effect that friction has in shallow channels. NOAA has studied the tides in Laguna Madre and has classified the tides in the northern portion of Lower Laguna Madre (and also in the southern portion of Upper Laguna Madre) as nontidal (Gill et al. 1995).

Figure 7-6. WSE data for October 2014 from gages at the north end of Lower Laguna Madre.

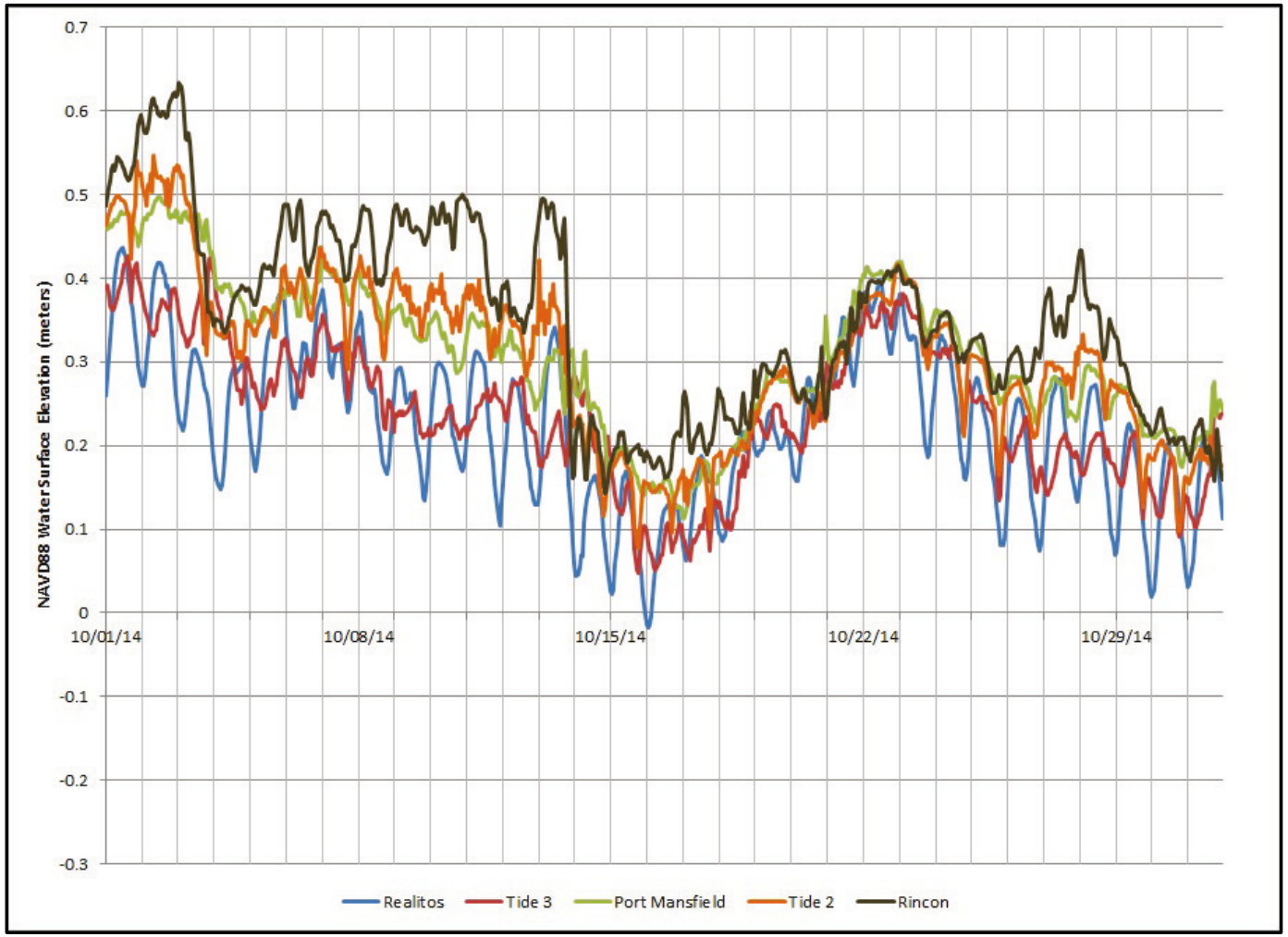




\section{Winds}

The yearly average wind speeds in South Texas are generally the strongest of any location in the continental United States, as shown in Figure 7-7 (NREL 2011). There is also a gradient in the wind speeds over the study area. Winds at the northern end of Lower Laguna Madre are generally stronger than winds at the southern end, as shown in Table 7-1, which shows measured data from three tide stations for the model year of September 2014 to September 2015. This table should be read as follows: at Port Isabel, $5 \%$ of the time the wind speeds are less than $1.4 \mathrm{~km} / \mathrm{hr}$ (1.6 miles $/ \mathrm{hr}$ ), and $95 \%$ of the time they are less than $18.1 \mathrm{~km} / \mathrm{hr}$ (20.8 miles/hr). At Rincon, at the north end, those values rise to $5 \%$ of the time the speeds are less than $4.9 \mathrm{~km} / \mathrm{hr}$ ( $5.6 \mathrm{miles} / \mathrm{hr}$ ), and $95 \%$ of the time they are less than $41.2 \mathrm{~km} / \mathrm{hr}$ (47.4 miles/hr). The numerical model used in this study was driven using mid-range values of wind speed from Realitos Peninsula.

Figure 7-7. Average wind speeds in the United States (from NREL, U.S. Department of Energy https://windexchange.energy.gov/maps-data?height=80m).

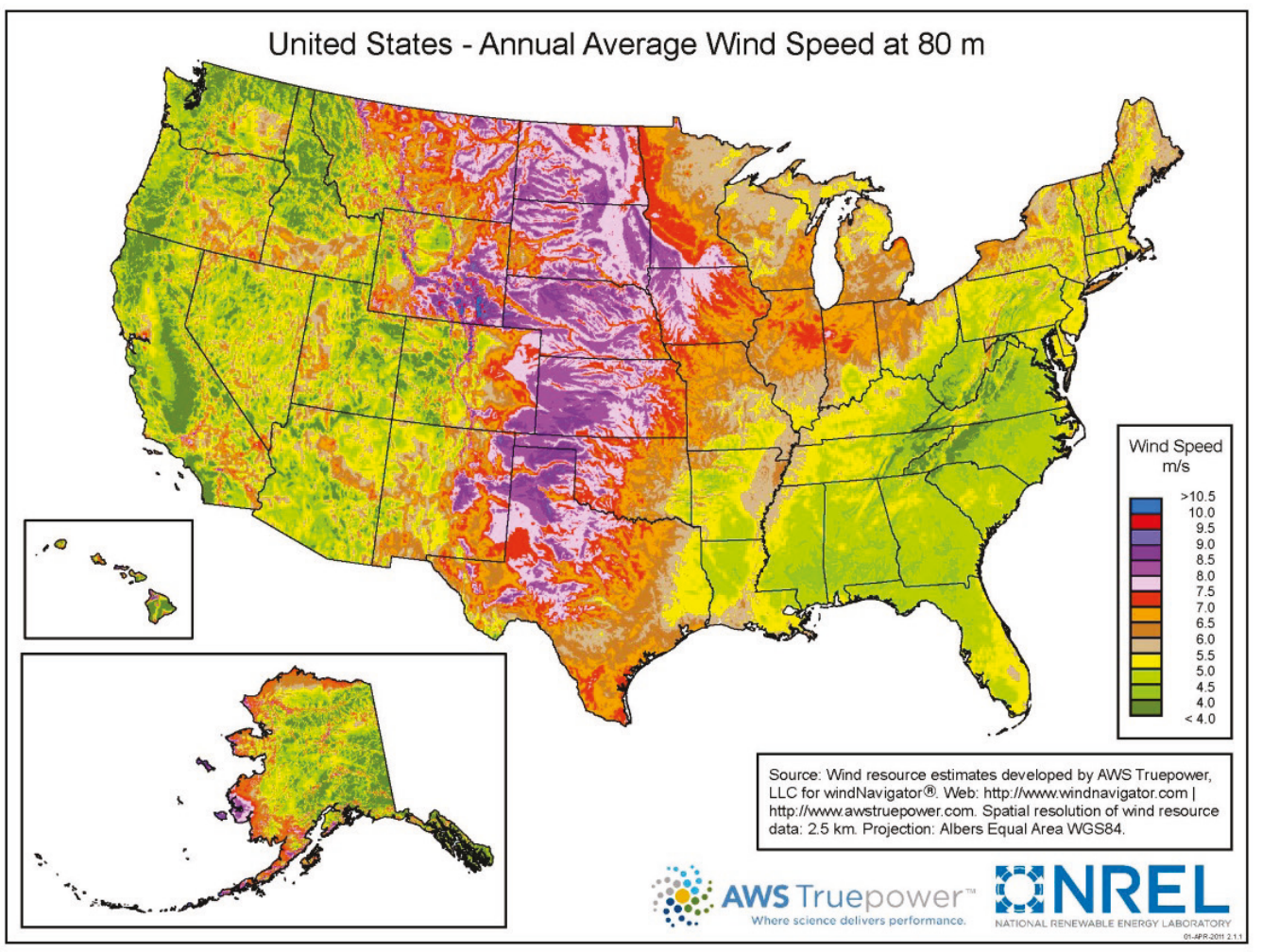


Table 7-1. Comparative wind speeds from south to north in Laguna Madre.

\begin{tabular}{|c|c|c|c|c|c|c|}
\hline \multirow{2}{*}{$\begin{array}{l}\% \text { of Time } \\
\text { Wind } \\
\text { Speed } \\
\text { Less Than }\end{array}$} & \multicolumn{2}{|c|}{ Port Isabel } & \multicolumn{2}{|c|}{ Realitos } & \multicolumn{2}{|c|}{ Rincon } \\
\hline & $\begin{array}{l}\text { Wind } \\
\text { Speed } \\
(\mathrm{m} / \mathrm{s})\end{array}$ & $\begin{array}{l}\text { Wind } \\
\text { Speed } \\
\text { (ft/s) }\end{array}$ & $\begin{array}{l}\text { Wind } \\
\text { Speed } \\
(\mathrm{m} / \mathrm{s})\end{array}$ & $\begin{array}{l}\text { Wind } \\
\text { Speed } \\
\text { (ft/s) }\end{array}$ & $\begin{array}{l}\text { Wind } \\
\text { Speed } \\
(\mathrm{m} / \mathrm{s})\end{array}$ & $\begin{array}{l}\text { Wind } \\
\text { Speed } \\
\text { (ft/s) }\end{array}$ \\
\hline $5 \%$ & 0.7 & 2.4 & 2.1 & 3.5 & 2.5 & 4.2 \\
\hline $10 \%$ & 1.4 & 4.6 & 3.1 & 10.1 & 3.8 & 6.4 \\
\hline $20 \%$ & 2.4 & 7.9 & 4.3 & 14.2 & 5.6 & 9.4 \\
\hline $30 \%$ & 3.3 & 10.8 & 5.3 & 17.4 & 7.3 & 12.3 \\
\hline $40 \%$ & 4.1 & 13.5 & 6.2 & 20.4 & 8.8 & 14.8 \\
\hline $50 \%$ & 4.8 & 15.7 & 7.1 & 23.3 & 10.4 & 17.5 \\
\hline $60 \%$ & 5.6 & 18.4 & 8.1 & 26.5 & 12.3 & 20.8 \\
\hline $70 \%$ & 6.3 & 20.6 & 9.3 & 30.6 & 14.2 & 24.0 \\
\hline $80 \%$ & 7.2 & 23.6 & 11.4 & 37.5 & 16.5 & 27.8 \\
\hline $90 \%$ & 8.4 & 27.5 & 14.6 & 47.8 & 19.2 & 32.4 \\
\hline $95 \%$ & 9.3 & 30.6 & 16.9 & 55.5 & 21.2 & 35.8 \\
\hline
\end{tabular}

The wind climatology also shows a marked seasonality. For most of the year, winds blow from the south-southeast, and this condition is particularly persistent during the summer (Figure 7-8). This pattern is usually interrupted several times during the winter by cold fronts that move into south Texas. These generally bring cold winds from the northnorthwest, and these blows, which are usually stronger than the southsoutheast winds, tend to last for several days. The number, timing, intensity, and duration of these cold fronts vary from year to year in marked contrast to the nearly trade wind-like invariance of the summer south-southeast winds. Figure 7-7 shows that during the winter of 20142015, there was more cold front activity in December, January, and March than there was in November or February.

Figure 7-9 shows a wind rose for the entire model year and compares the dominant directional wind pattern with the orientation of Lower Laguna Madre. This serendipitous alignment allows the wind to move tremendous amounts of water up and down the length of the lagoon and to be the dominant factor in controlling the WSE, particularly at the north end where the tidal influence is reduced by friction. 
Figure 7-8. Monthly wind roses at Realitos Peninsula for model time period.

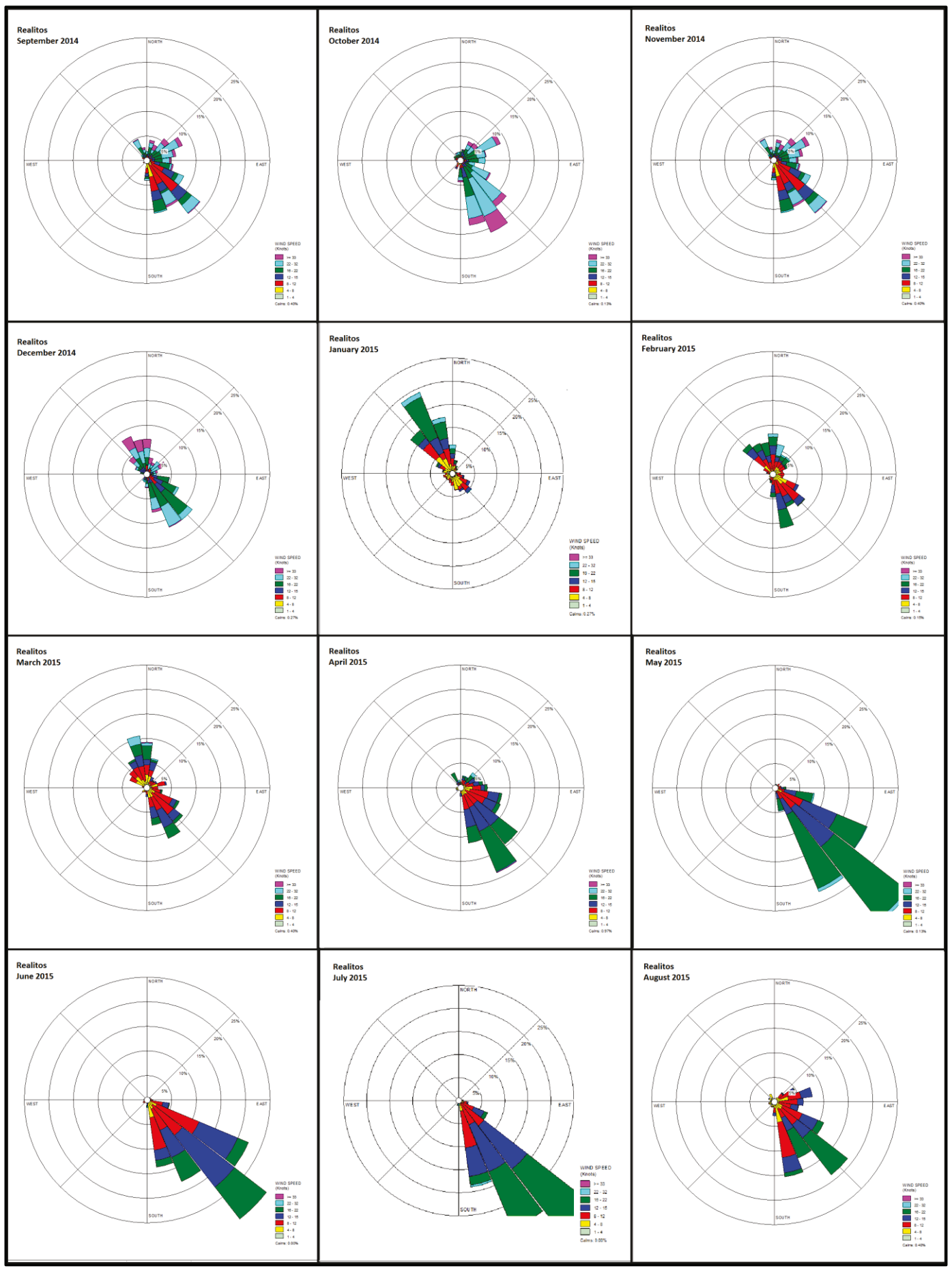


Figure 7-9. Yearly wind rose for Realitos Peninsula with Lower Laguna Madre for alignment comparison.

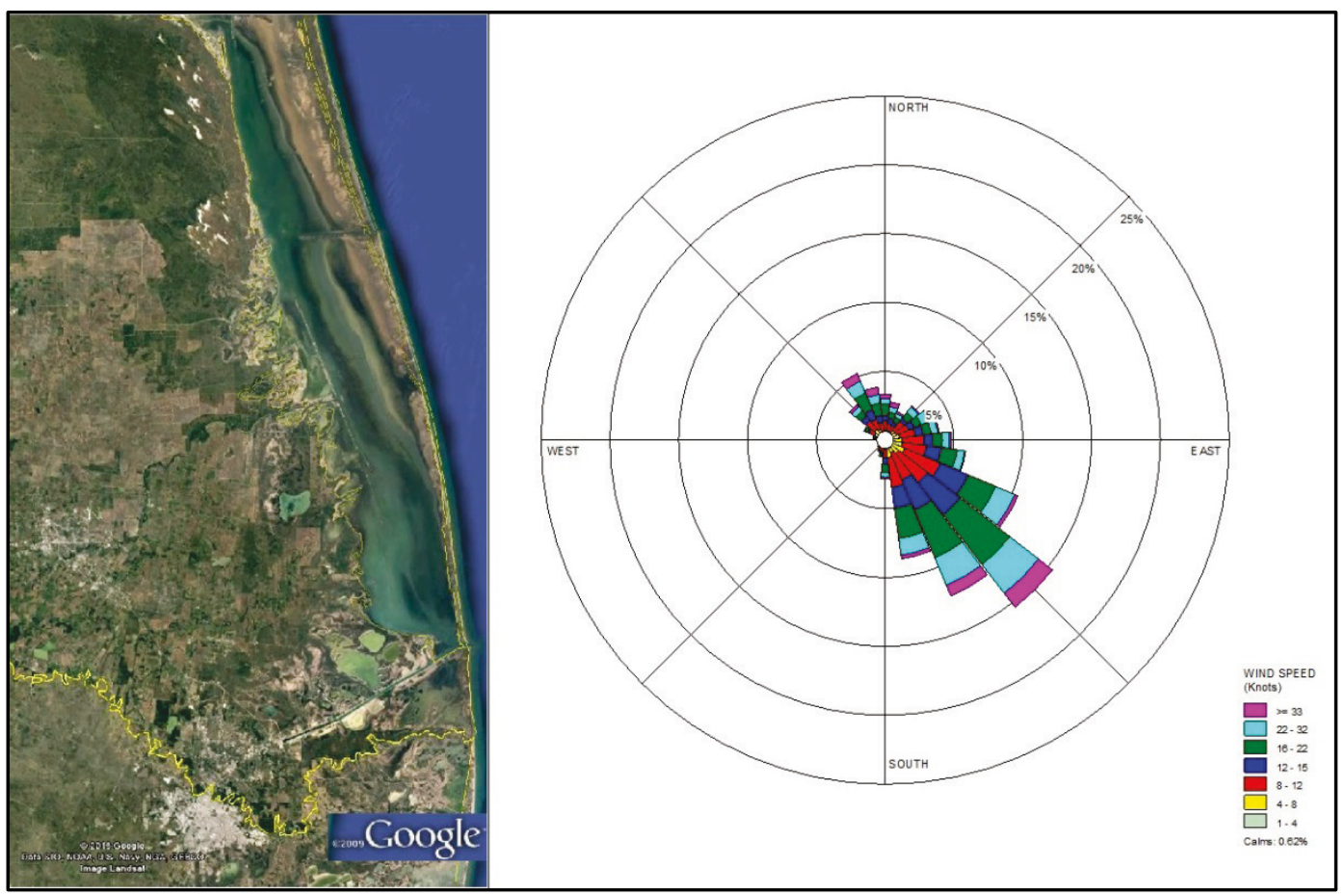

\section{Water surface elevations (WSE)}

One of the effects of wind stress along the axis of Laguna Madre is to move water toward one end of the lagoon or the other. Figure 7-10 shows WSE data for October 2014 for three gages, Port Isabel at the south end of Laguna Madre, Port Mansfield near the middle of the lagoon, and Rincon at the northern end, plus wind direction data measured at the Realitos gage. Values for WSE (the red, green, and blue lines) are shown on the left vertical axis and for direction (purple squares) on the right vertical axis.

For the first 3 days of the month, the wind is blowing from the south to north (wind directions near $180^{\circ}$ ). On these days, the WSE is highest at Rincon, lowest at Port Isabel, with Port Mansfield in the middle. This is also the case between October 6th and 15th and on the 27th through the 29th. The wind is from the north (wind directions near $0^{\circ}$ or $360^{\circ}$ ) on October $4^{\text {th }}$ and $5^{\text {th }}$, on the $15^{\text {th }}$, on the 20th through the $25^{\text {th }}$, and on the 3oth and 31st. On these days the water levels at Rincon and Port Mansfield are below the high tides at Port Mansfield. 
Figure 7-10. October 2014 WSE at south, mid, and north ends of Lower Laguna Madre, plus wind direction (from the Realitos Peninsula gage).

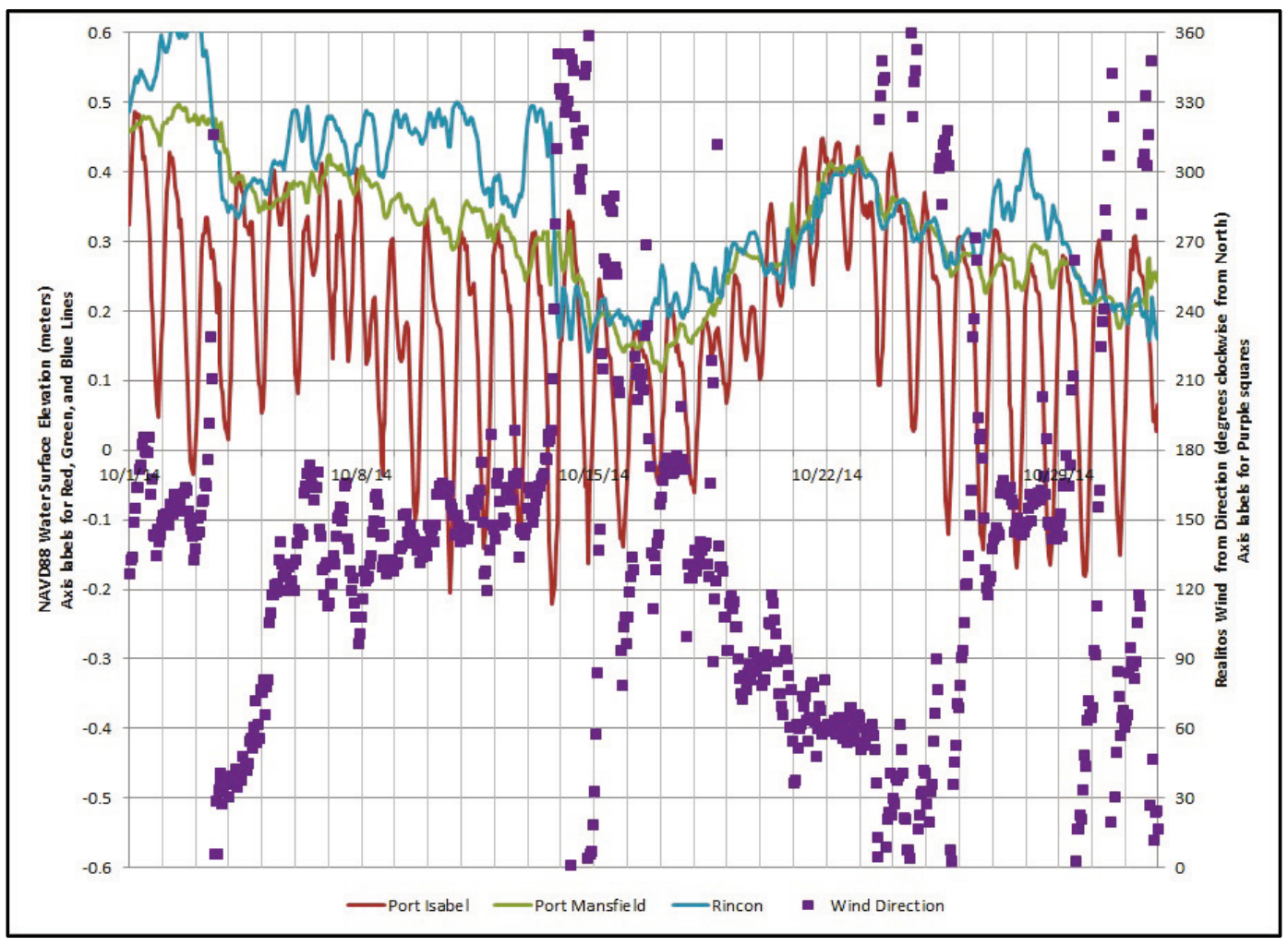

\section{Water volumes}

The effect of wind stress pushing water to either the northern or southern end of Lower Laguna Madre has an impact, sometimes dramatic, on the flow through the two inlets. Figure 7-11 shows the numerical model results for the cumulative flow through Brazos Santiago Inlet over the model year. The sign convention used by the model is that all eastward and northward flows are positive while southward and westward flows are negative. This graph shows that between mid-September and the end of October approximately 0.5 cubic kilometer $(\mathrm{cu} \mathrm{km})$ (o.12 cubic mile [cu mile]) more water flowed through the inlet from the Gulf to Laguna Madre on flood flows than returned to the Gulf on the ebb flows. Then, from the beginning of November until mid-March the net flow was seaward, with approximately $1.5 \mathrm{cu} \mathrm{km}$ ( $0.36 \mathrm{cu}$ mile) more water flowing out of the inlet to the Gulf than came in on the flood tides. Then, dramatically, during the 7 months between mid-March and midSeptember, approximately $7.5 \mathrm{cu} \mathrm{km}$ (1.8 cu miles) more water flowed through the inlet into Laguna Madre than out of it into the Gulf. Figure 712 compares the model results for the cumulative volume flows through both Brazos Santiago Inlet and Mansfield Pass. This figure shows a 
mirror-imaged match for the net flows through the two inlets. When the net flow through Brazos was landward (flood flow) into Laguna Madre, there was a near equal net ebb flow out of Mansfield into the Gulf, and vice versa.

Figure 7-11. Numerical model data showing the cumulative volume flow (in cubic kilometers) through Brazos Santiago Inlet over the model year. Positive flows are seaward (ebb) flows; negative flows are landward (flood) flows.

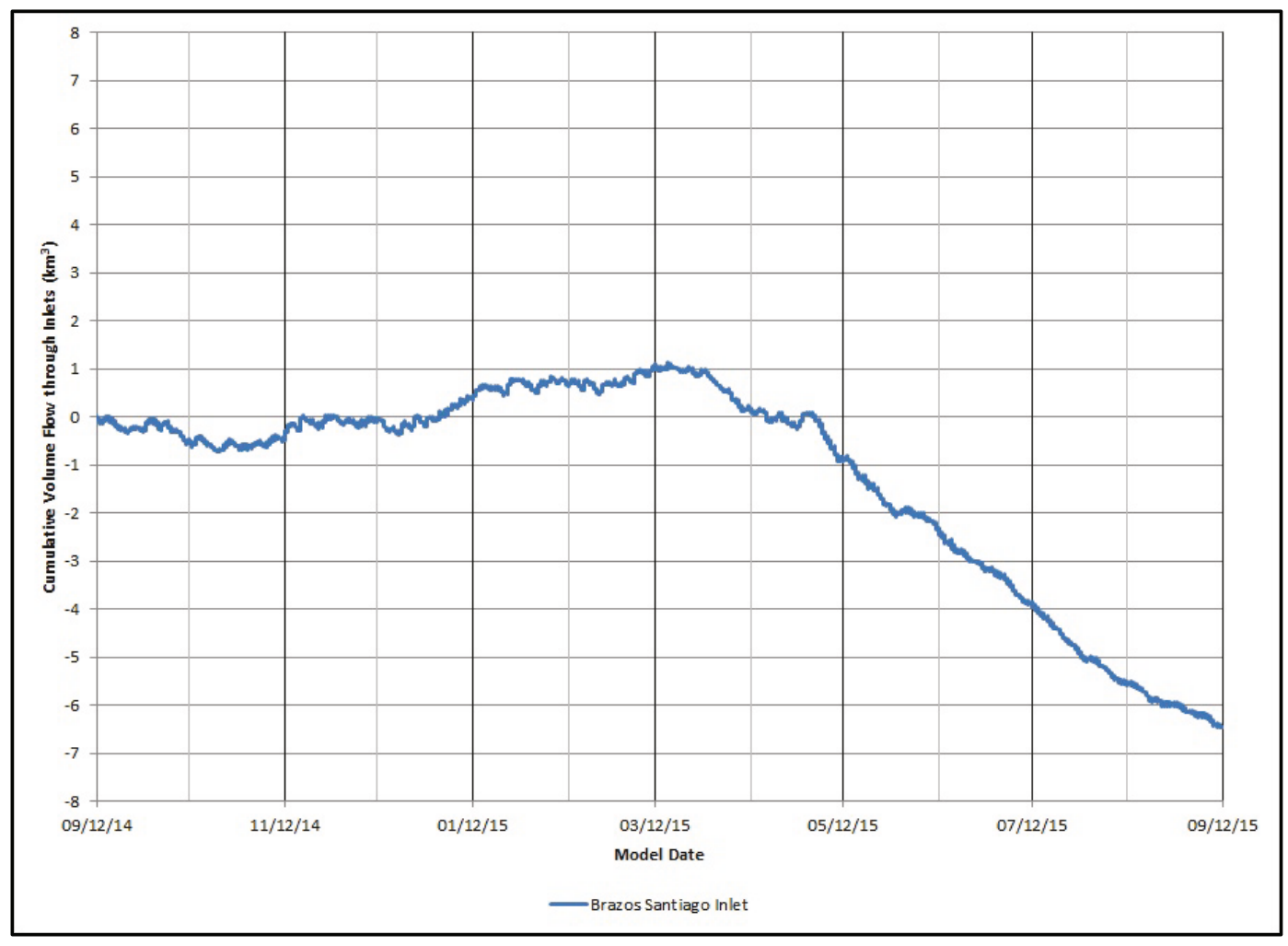


Figure 7-12. Numerical model data showing the cumulative volume flow through both Brazos Santiago Inlet and Mansfield Pass over the model year. Positive flows are net seaward (ebb) flows; negative flows are net landward (flood) flows.

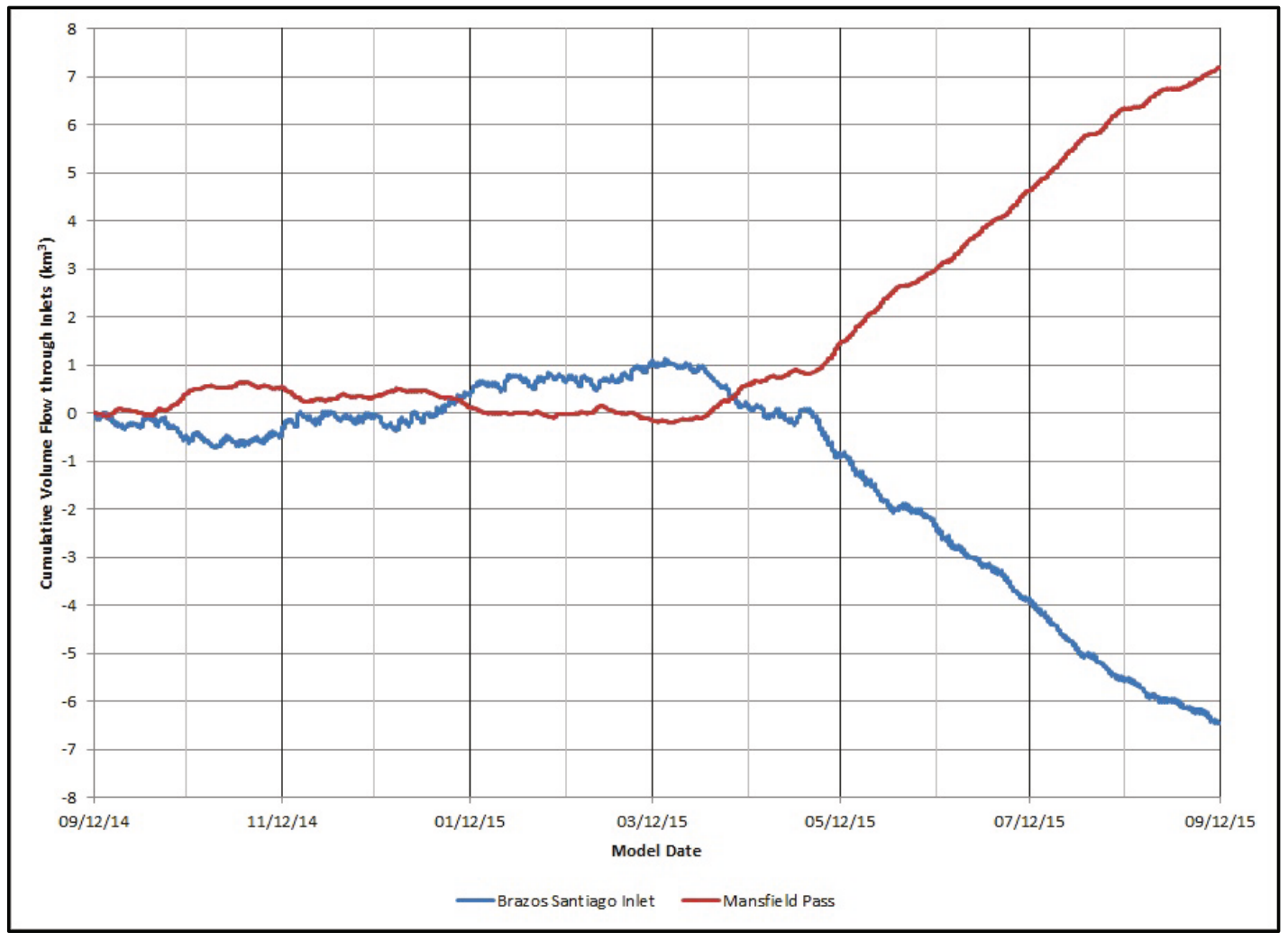

Figure 7-13 presents the flow volumes through Brazos Santiago Inlet in a different way. The blue line shows the total (gross) amount of water that flows through the inlet on both the flood and the ebb on a monthly basis. Thus, the leftmost point on the blue curve indicates that a total volume of $4.52 \mathrm{cu} \mathrm{km}$ $\left(4.52 \times 10^{9} \mathrm{cu} \mathrm{m}\right)\left(1.08 \mathrm{cu}\right.$ miles $\left.\left[1.6 \times 10^{11} \mathrm{cu} \mathrm{ft}\right]\right)$ of water flowed through the inlet between 12 September and 12 October 2014. Throughout the year, gross monthly flows through the inlet ranged from a little less than $4 \mathrm{cu} \mathrm{km}$ (0.96 cu mile) to a little more than $5 \mathrm{cu} \mathrm{km} \mathrm{(1.2} \mathrm{cu} \mathrm{miles).}$

The red line represents the monthly difference in the flood and ebb flows (the net). The left-most red point indicates that for the month centered on 29 September 2014, the flood flows exceeded ebb flows by a little more than $0.5 \mathrm{cu} \mathrm{km}$ (0.12 cu mile). (The numerical model convention is that flood flows from the inlets into Laguna Madre are negative.) Throughout the year, the maximum monthly net flows ranged from approximately $1 \mathrm{cu} \mathrm{km} \mathrm{(0.24} \mathrm{cu} \mathrm{mile)} \mathrm{into} \mathrm{the} \mathrm{Gulf} \mathrm{to} 2 \mathrm{cu} \mathrm{km} \mathrm{(0.48} \mathrm{cu} \mathrm{mile)} \mathrm{into} \mathrm{the}$ lagoon. 
The ratio of net to gross flow is shown by the green line, which uses the scale on the right-hand axis. The green curve indicates that over the course of the year, at times extra ebb flows into the Gulf (ebb flows not balanced by flood flows) accounted for $20 \%$ of the total inlet flows while at other times, extra flood flows accounted for as much as $40 \%$ of the total inlet flow.

Figure 7-13. Monthly gross and net flow volumes through Brazos Santiago Inlet over the model year.

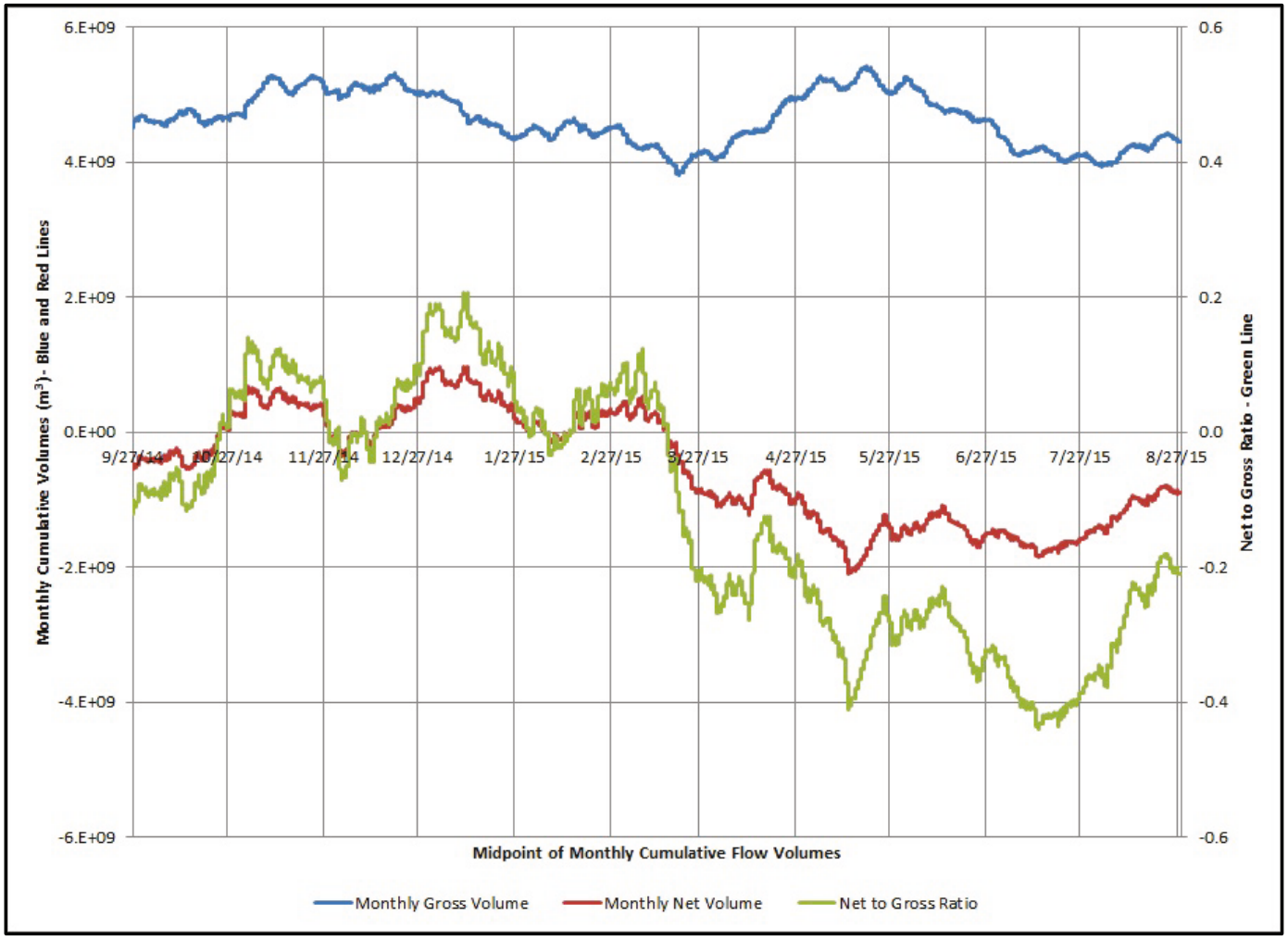

Figure 7-14 shows the same type of information for flow volumes in Laguna Madre, as they cross a line extending across the lagoon at Realitos Peninsula. In Laguna Madre, the sign convention is that northward flows are positive and southward flows are negative. While the magnitude of the gross flow in the lagoon is much less than in Brazos Santiago Inlet, the net volume curve has a mirror-image shape to that of the inlet. Flows volumes at other Laguna Madre locations that were also north of Brazos Santiago Inlet and south of Mansfield Pass were quite similar. Laguna Madre transects that were north of Mansfield Pass had tiny values for both gross and net flows. 
Figure 7-14. Monthly gross and net along-channel flow volumes through Laguna Madre at Realitos Peninsula over the model year.

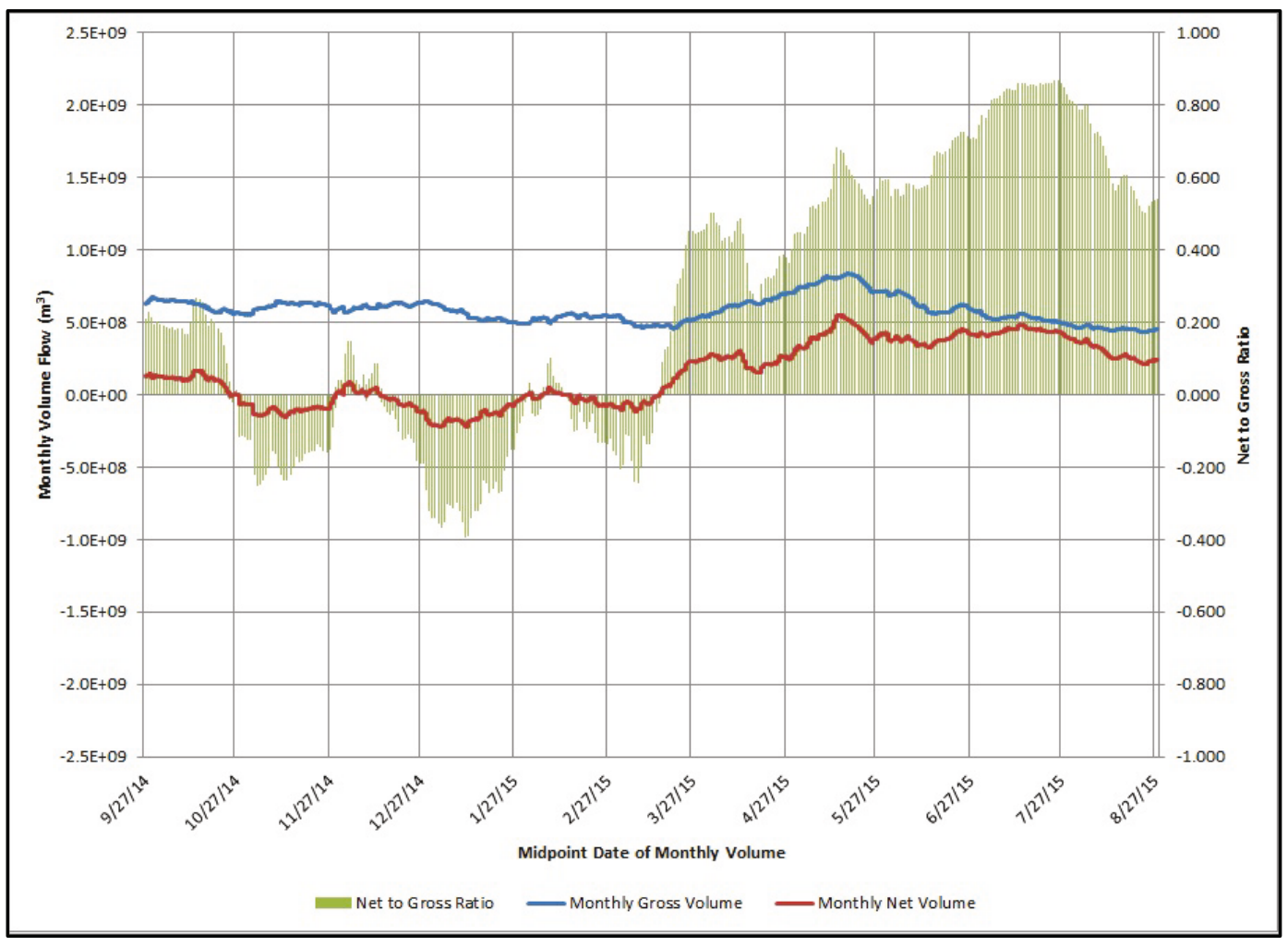

Figure 7-15 shows flow gross and net flow volumes through Mansfield Pass. Mansfield Pass is a much smaller inlet than Brazos Santiago. Thus, the smaller gross volume flow (between 0.24 and $0.48 \mathrm{cu}$ mile/month [ 1 and $2 \mathrm{cu} \mathrm{km} /$ month]) is expected. However, the net volume flow is also a much greater percentage of the gross. This becomes extreme during the summer when the net flow almost equals the gross. This is the time when winds constantly push water into the northern end of Lower Laguna Madre, and as it tries to escape, it forces the flow through Mansfield Pass to almost always be ebbing. At these times, Mansfield pass more resembles a river mouth than a typical inlet. 
Figure 7-15. Monthly gross and net flow volumes through Mansfield Pass over the model year.

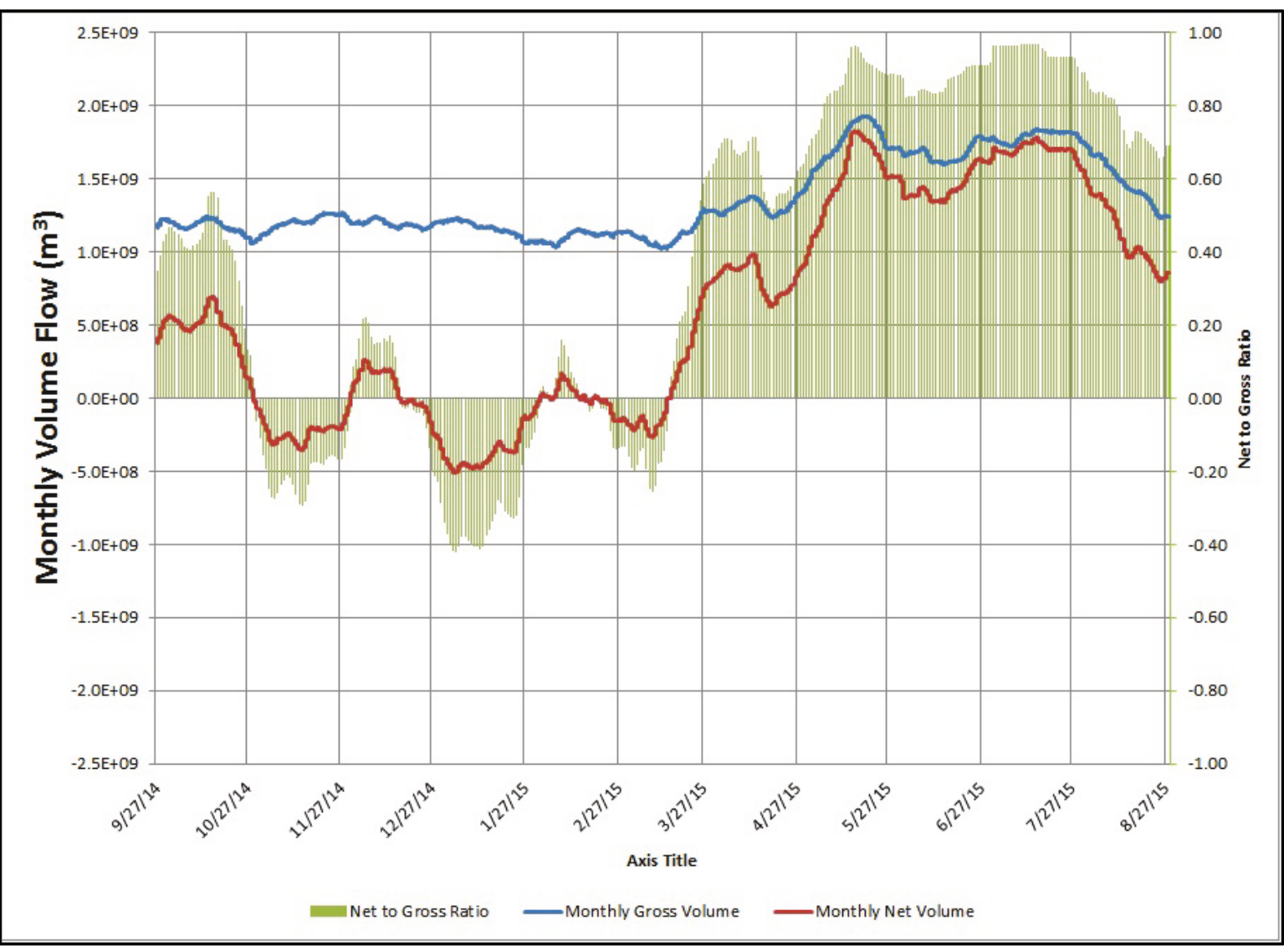

This type of behavior is also shown in Figure 7-16, which shows yearly flow velocities through Mansfield Pass over the model year. This plot shows that there are a few times during the winter when the flow direction can be continuously into the inlet for a few days at a time. However, during the summer, there are several stretches when there is no flood flow. At these times, water is continuously flowing toward the Gulf. 
Figure 7-16. Yearly velocity time series through Mansfield Pass.

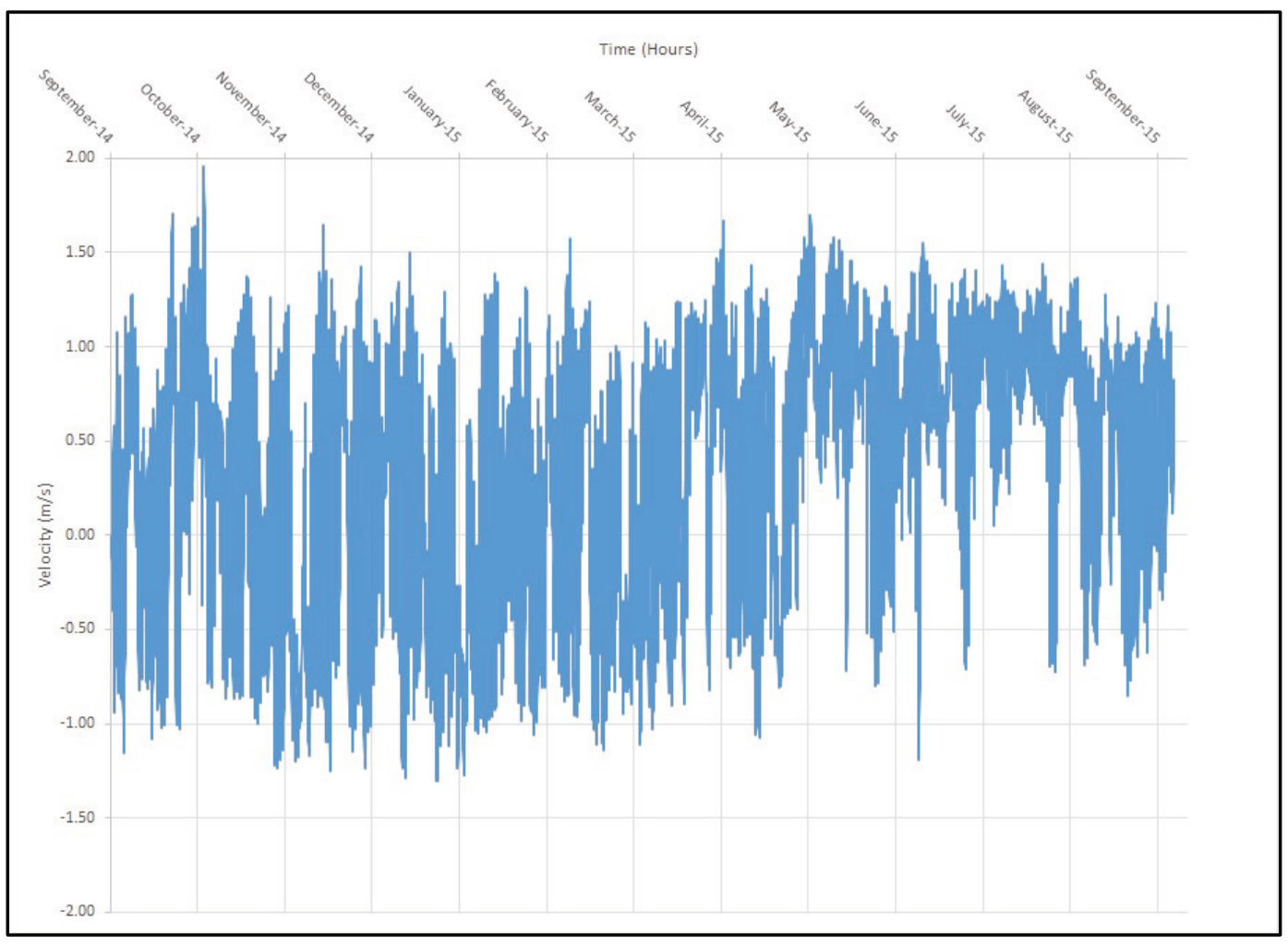

In addition to using the numerical model to examine alternatives, which are discussed in Chapter 8, the model was also run with the winds completely turned off to further investigate their importance as a driving term for the hydrodynamics of this system. The model results at Mansfield Pass for this scenario are shown in Figure 7-17. Here, the tidally driven gross transport is nearly constant throughout the year at approximately $1 \mathrm{cu} \mathrm{km}$ per month, which is in agreement with the minimum gross transport values shown in Figure 7-15. However, the net transport is dramatically different. For this scenario, there basically is no net transport, which is the expectation for an isolated inlet: one which does not pass water to and from other inlets or have significant fresh water inflow, etc. 
Figure 7-17. Monthly gross and net flow volumes through Mansfield Pass over the model year for the scenario in which the model winds have been turned off.

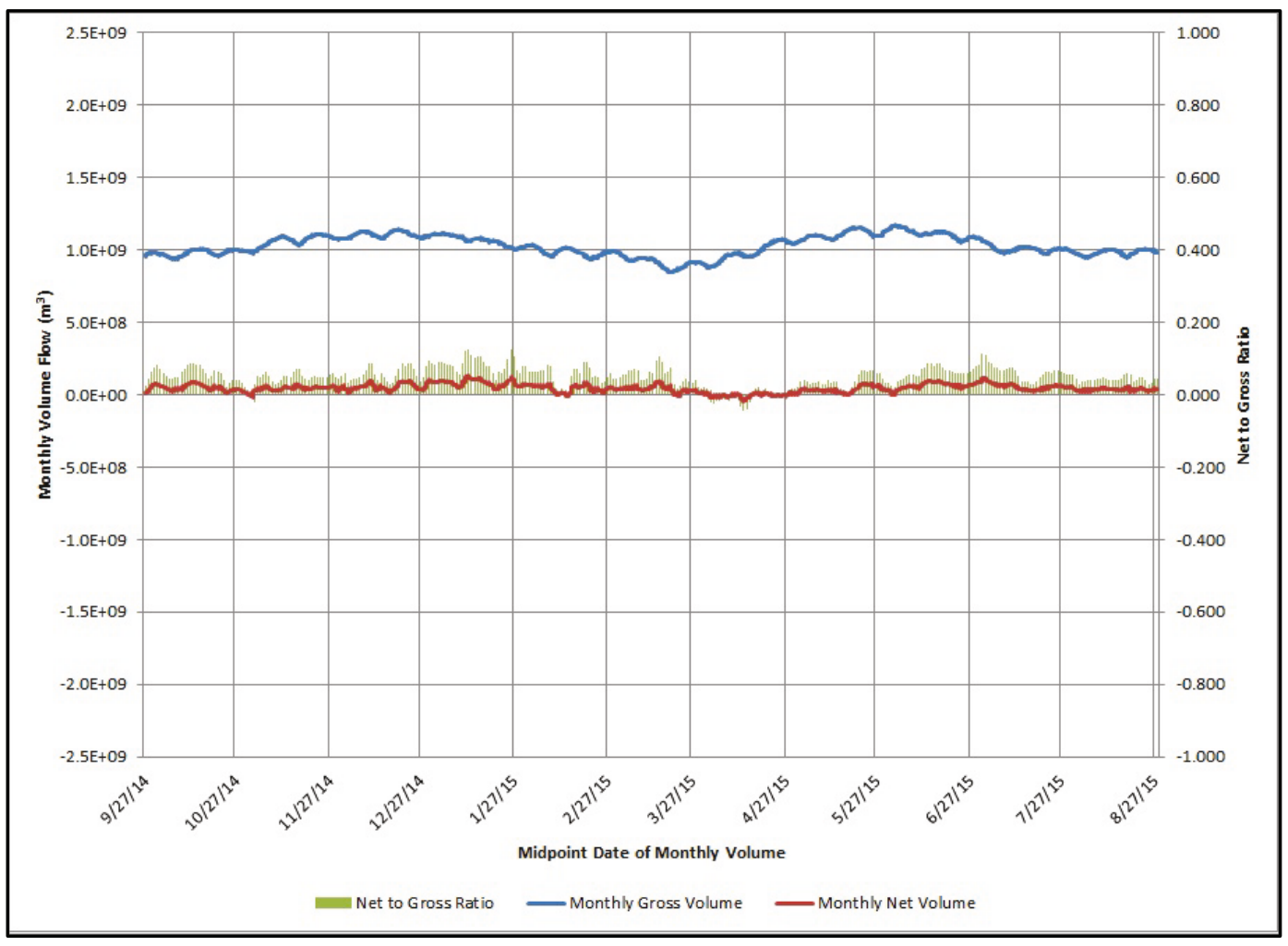

\section{Summary}

This chapter discusses the hydrodynamics of Lower Laguna Madre and focuses on how wind plays a dominant role in driving the system. There is a marked seasonality to the winds. During winter, south Texas typically experiences a series of cold fronts that blow southward down Laguna Madre, which sets up a counterclockwise circulation system. Water driven southward down Laguna Madre flows into the Gulf of Mexico through Brazos Santiago Inlet. This water is replaced by water flowing inward from the Gulf through Mansfield Pass and into the northern end of Lower Laguna Madre. This counter-clockwise circulation has year-to-year variability because of the fluctuating nature of the cold fronts.

In the summer, a more significant clockwise system forms. The daily southeast winds drive water north in Laguna Madre. This water escapes into the Gulf through Mansfield Pass, and it is replaced by an inflow of water into the south end of Laguna Madre from the Gulf through Brazos Santiago Inlet. This system is shown schematically in Figure 7-18. 
Figure 7-18. Schematic of seasonal circulation patterns in Lower Laguna Madre (from Google Earth https://www.google.com/earth/).

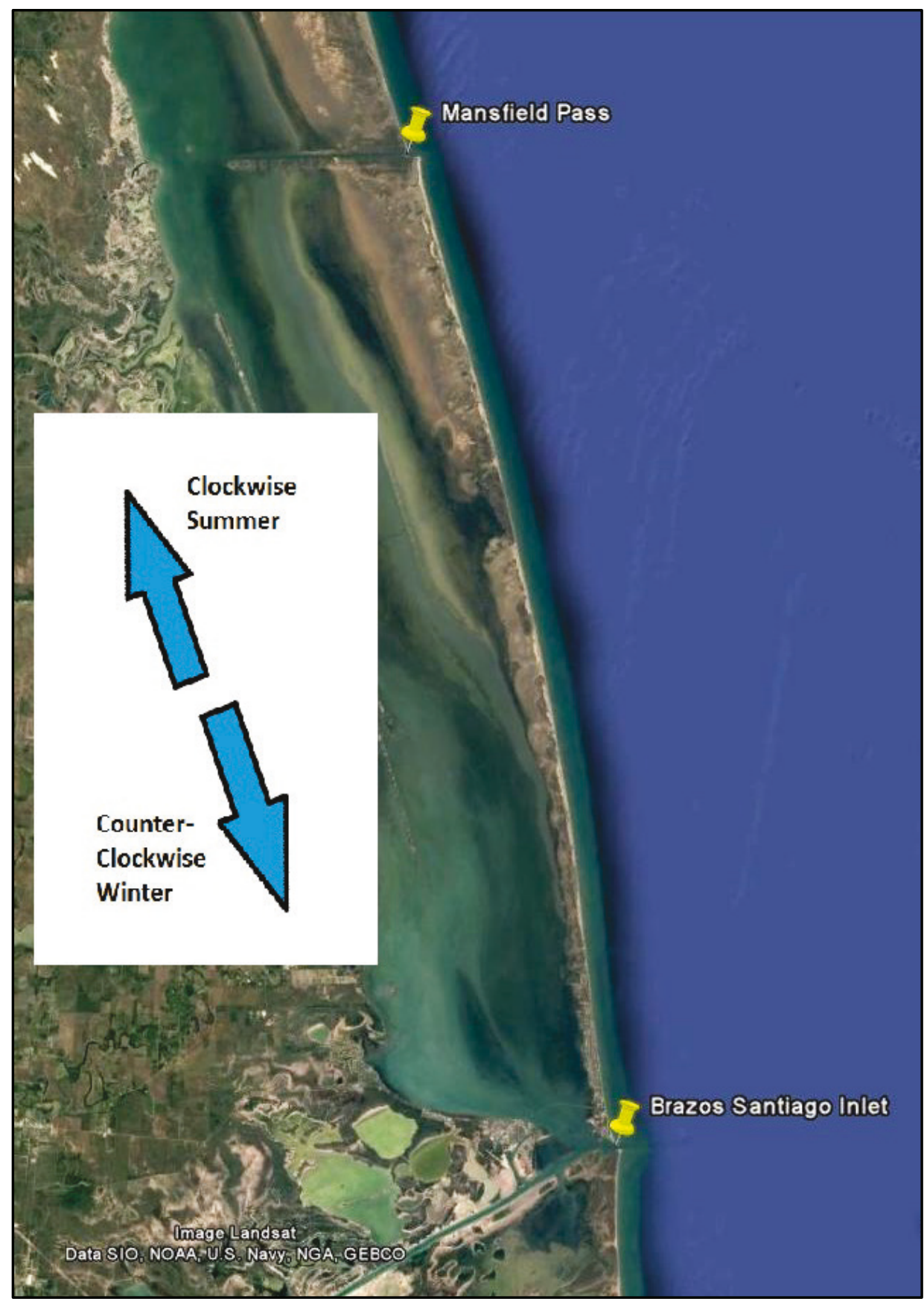

This continuous replacement of lagoon water with new water from the Gulf appears to be a relatively unknown or at least underappreciated aspect of the Laguna Madre hydrodynamics. The wind-driven flow in the lagoon appears to be a generally accepted fact. For example: 
In summer, waters of the Gulf move northward through the lagoon with increasing salinity due to evaporation. In winter, flow is southward. (Breuer 1962)

However, it appears to also be generally accepted that, because of the lack of fresh water inflow, residence times of water in the lagoon are extremely long, on the order of decades (e.g., TDWR 1983; Longley 1994; Schoenbaechler and Guthrie 2011). This Lagoon-Gulf water exchange has many important consequences for the ecology of the region, including the following:

- It mitigates the lagoon's hypersalinity.

- It flushes pollutants from the lagoon.

- It supplies fully oxygenated water to the lagoon.

- It provides nutrient exchange between the lagoon and the Gulf.

- It provides a mechanism for larval transport.

During times when water is blown southward in Laguna Madre, it does not tend to pile up at the south end of the bay. Brazos Santiago Inlet is large enough so that this water can pass through it into the Gulf, as seen by the lack of localized seasonal fluctuation in MSL at the Port Isabel tide gage. Likewise, during the summer, Brazos Santiago Inlet can import sufficient water from the Gulf to keep from causing a drawdown in the southern end of the lagoon. While Brazos Santiago Inlet can keep up with the windforced water needs at the south end of the lagoon, it does this at a cost of a marked asymmetry in the flow through the inlet.

Mansfield Pass, being a smaller inlet, has a harder time keeping up with the need to exchange water between the lagoon and the Gulf. This is seen in variations in water levels recorded at the tide gages in the northern end of the lagoon and in the unidirectional flows through the inlet.

Mansfield Pass appears to be the choke-point of the circulation system. If the hydrodynamics of the system are ever understood well enough to be able to optimize the competing biological, sociological, and economic needs of all interested parties, it is likely that the flow through the system will be regulated by controlling the depth of Mansfield Pass.

It is possible that no other lagoon system in the world is as totally dominated by wind forcing as Lower Laguna Madre. This is caused by the 
necessary near-optimal alignment of several key features. These include the following:

- The lagoon shape is a long, slender rectangle without branches.

- The lagoon has exactly two inlets, one at each end.

- The lagoon is very shallow, so there is much friction and no stratification.

- There are two dominant wind directions, and they happen to be approximately $180^{\circ}$ apart from each other.

- The wind directions align with the long axis of the lagoon.

- Wind speeds are relatively strong.

- Tides are diurnal, of low amplitude in the Gulf, and dissipate to near zero in much of the lagoon.

- There is inconsequential fresh-water inflow for most years. 


\section{Alternatives Analysis}

\section{Selection of alternatives}

To assist the CESWG in the management of its dredging program at the BSI, several alternatives have been proposed that have the potential to modify the sediment transport and sediment deposition patterns within the inlet, specifically focusing on the region where the major shoaling issues occur. Broadly, these alternatives can be grouped as changes to Mansfield Pass, changes to the present BSI jetty configuration, and changes to the present dredging practices at the inlet. In addition to running the numerical model described in Chapters 4 and 5 for the Base Case, the model has also been run for most, but not all, of these alternatives.

Seven additional alternatives has been selected to be compared with the existing Base Case (present condition) Alternative that have potential for better managing the shoaling issues in the BSI. The Base Case is considered to be a do-nothing alternative. These are the following:

1. Base Case (present condition)

2. Close Mansfield Pass Alternative

3. Deepen Mansfield Pass Alternative

4. Seaward Jetty Extension Alternative

5. Interior Jetty Straightening Alternative

6. Heighten Jetties Alternative

7. In-Channel Sediment Trap Alternative

8. Dedicated Dredging Plant and Distribution System Alternative

Each of these is discussed in detail below.

\section{Along-channel stationing}

This chapter of the report uses the established stationing system developed by CESWG (Figure 8-1) to locate various along-channel features. Along-channel distances are in feet and positive distances increase to the west. The zero position is at the approximate intersection of the west end of the BSI with the southeast corner of Laguna Madre. For easy reference, Table 8-1 lists useful along-channel locations. 
Figure 8-1. CESWG stationing system for Brazos Santiago Inlet and the Brownsville Ship Channel.

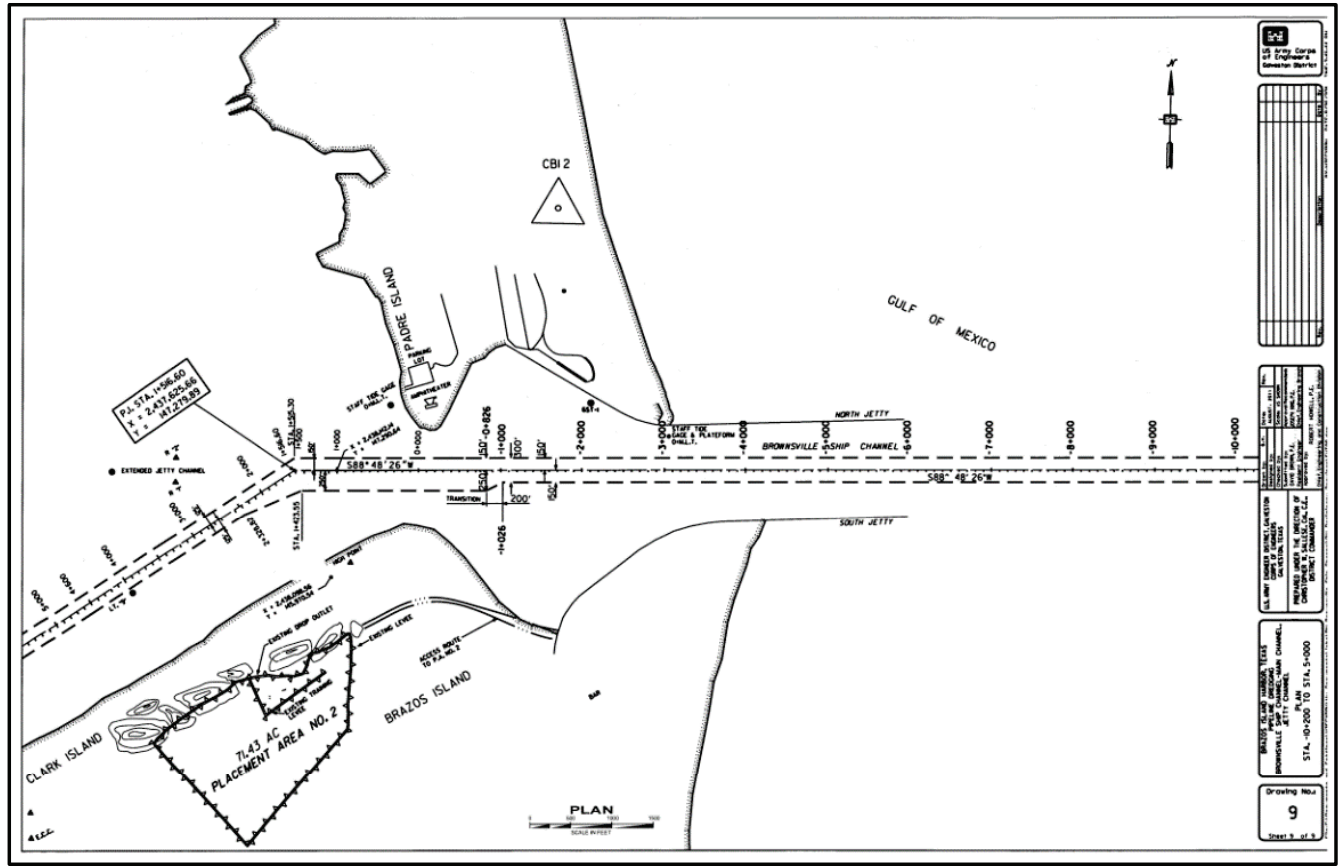

Table 8-1. Location of key along-channel features.

\begin{tabular}{|r|l|}
\hline Position (ft) & Feature \\
\hline$-12,000$ & Approximate seaward limit of dredged channel extension into the Gulf of Mexico \\
\hline$-6,000$ & Seaward Jetty tips \\
\hline$-4,200$ & Approximate shoreline position on adjacent beach of south of Inlet \\
\hline$-3,000$ & Approximate shoreline position on adjacent beach north of inlet \\
\hline$-2,200$ & Approximate high point in channel flood shoal \\
\hline$-1,700$ & Location of maximum southward bulge in South Jetty \\
\hline$-1,050$ & Location of maximum northward bulge in North Jetty \\
\hline 0 & Stationing origin, intersection of Laguna Madre with Brazos Santiago Inlet \\
\hline $1,516.60$ & Location of change in channel alignment \\
\hline 89,500 & Western limit of channel at Brownsville Harbor \\
\hline
\end{tabular}

\section{Executive summary assessment of alternatives}

Table 8-2 gives a concise overview of the results of the analysis of the alternatives. The following sections discuss each alternative in detail. This table tries to not only briefly state how the flood shoal will respond to the alternative but to also provide a broader overview of the impacts that are likely to occur if the alternative is implemented. In some cases these other 
impacts are expected to far outweigh any shoaling rate reduction benefits provided by the alternative.

The purpose of this study has been to examine the hydrodynamics and sediment dynamics of the BSI, with specific emphasis on the shoaling in the inlet, and the alternatives were selected with that objective in mind. It is not an intent of the study to include a detailed examination of the environmental, sociological, or economic implications of the alternatives. However, these aspects are mentioned in this table and in the sections below in a brief and qualitative way where the authors are aware of them.

\section{Base Case}

Modeling results for the alternatives discussed below are compared to the Base Case to determine if the alternative decreased the shoaling rate on the flood shoal. Results are discussed in terms of the change in channel depth at the flood shoal and in terms of the accumulated volume of the shoal.

Figure 8-2 shows the decrease in controlling channel depth at the flood shoal over the model year for the Base Case. The red line that follows the channel thalweg between stations $0+000$ and $-3+000$ in the inlet layout portion of Figure 8-2 shows the location for the data presented in the inset graph. The inset graph shows the sediment accumulation along the channel thalweg over the model year in monthly increments. The bottom line in the graph shows the channel depth at the beginning of the model run in September 2014, and the top line shows the depth at the end of the model run, a year later. This graph shows that there was a maximum decrease of approximately $1.5 \mathrm{~m}(5 \mathrm{ft}$ ) in the channel depth (from approximately 14.0 to $12.5 \mathrm{~m}$ [ 46 to $41 \mathrm{ft}$ ]) over the course of the model year. The graph also shows that channel sediment accumulation is not constant over the year. Accumulation is slowest between January and April and fastest between April and July. In the plots in the following sections that compare an alternative to the Base Case, the March 2015 channel depth line in Figure 8-2 is repeated as a dashed orange line, and the September 2015 channel depth line is repeated as a dashed blue line. 
Table 8-2. Brief overview of alternatives.

\begin{tabular}{|c|c|c|c|c|c|}
\hline$\#$ & Alternative & $\begin{array}{l}\text { Brazos Santiago Flood } \\
\text { Shoal Dredging Impacts }\end{array}$ & $\begin{array}{l}\text { Additional Positive } \\
\text { Considerations }\end{array}$ & $\begin{array}{l}\text { Additional Negative } \\
\text { Considerations }\end{array}$ & Initial Assessment \\
\hline 1 & $\begin{array}{l}\text { Base Case (present } \\
\text { condition) }\end{array}$ & $\begin{array}{l}\text { No change from present } \\
\text { operations. }\end{array}$ & & & \\
\hline 2 & Close Mansfield Pass & $\begin{array}{l}\text { Minor decrease in } \\
\text { shoaling rate. }\end{array}$ & & $\begin{array}{l}\text { Serious negative } \\
\text { environmental impacts. Local } \\
\text { opposition likely. }\end{array}$ & $\begin{array}{l}\text { Not recommended for further } \\
\text { consideration. }\end{array}$ \\
\hline 4 & Seaward Jetty Extension & $\begin{array}{l}\text { Minor effects on shoaling } \\
\text { rate. }\end{array}$ & & $\begin{array}{l}\text { Significant jetty construction } \\
\text { costs would be anticipated. }\end{array}$ & $\begin{array}{l}\text { Not recommended for further } \\
\text { consideration. }\end{array}$ \\
\hline 5 & $\begin{array}{l}\text { Interior Jetty } \\
\text { Straightening }\end{array}$ & $\begin{array}{l}\text { Major decrease in } \\
\text { shoaling rate at the } \\
\text { present shoal location. }\end{array}$ & $\begin{array}{l}\text { There may be environmental } \\
\text { beneficial uses for the } \\
\text { abandoned portions of the } \\
\text { channel. }\end{array}$ & $\begin{array}{l}\text { Likely shift of the flood shoal } \\
\text { location to where it is more } \\
\text { difficult and costly to supply } \\
\text { sediments to South Padre } \\
\text { Island beaches. Likely } \\
\text { incompatible with the } \\
\text { development of Alternative } 8 .\end{array}$ & $\begin{array}{l}\text { Worth additional study as part of a } \\
\text { comprehensive sand management } \\
\text { plan. }\end{array}$ \\
\hline 6 & Heighten Jetties & Unknown impacts. & & & $\begin{array}{l}\text { Worth additional study as part of a } \\
\text { comprehensive sand management } \\
\text { plan. }\end{array}$ \\
\hline 7 & $\begin{array}{l}\text { In-Channel Sediment } \\
\text { Trap }\end{array}$ & $\begin{array}{l}\text { Little change in shoaling } \\
\text { rate. }\end{array}$ & $\begin{array}{l}\text { Increased time between } \\
\text { required dredging events = } \\
\text { reduced dredge mobilization } \\
\text { costs. May be combined with } \\
\text { Alternative } 8 . \text { Implementation } \\
\text { should be relatively straight- } \\
\text { forward. }\end{array}$ & $\begin{array}{l}\text { May require congressional } \\
\text { authorization to allow deeper } \\
\text { channel depth. }\end{array}$ & $\begin{array}{l}\text { Recommended for further } \\
\text { consideration. }\end{array}$ \\
\hline 8 & $\begin{array}{l}\text { Dedicated Dredge Plant } \\
\text { and Distribution System }\end{array}$ & $\begin{array}{l}\text { Expected to control } \\
\text { sedimentation and } \\
\text { eliminate times of draft } \\
\text { restrictions for vessels } \\
\text { transiting inlet. }\end{array}$ & $\begin{array}{l}\text { Can be developed as a key } \\
\text { component of the delivery } \\
\text { system of sediment to South } \\
\text { Padre Island beaches. }\end{array}$ & $\begin{array}{l}\text { Requires substantial } \\
\text { additional development to } \\
\text { assess feasibility and optimize } \\
\text { design. }\end{array}$ & $\begin{array}{l}\text { Worth additional study as part of a } \\
\text { comprehensive sand management } \\
\text { plan. }\end{array}$ \\
\hline
\end{tabular}


Figure 8-2. Monthly growth of the flood shoal over the model year (September 2014 September 2015) for the Base Case.

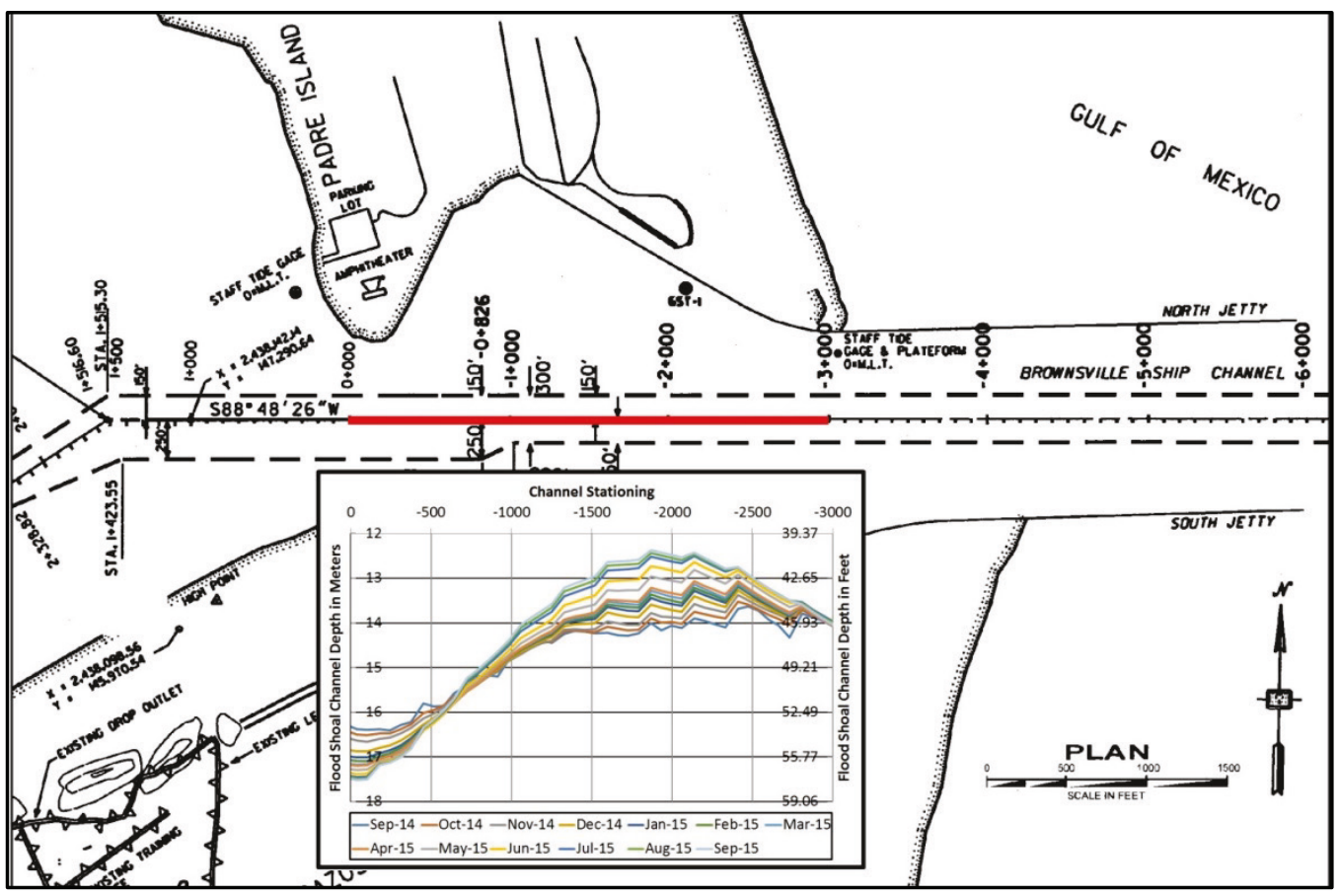

Figure 8-3 shows the amount of sediment accumulation in the channel through the model year for the Base Case. The inset figure shows the location where the volume calculation was made. This volume accumulation within this box is approximately half of the total amount of sediment dredged in an average year.

As with Figure 8-2, the accumulation rate is lowest in the January-April time frame and greatest in the April-July time frame. This is consistent with the reversing yearly circulatory flow in the Laguna Madre system described in Chapter 7. 
Figure 8-3. Base Case cumulative channel shoaling volume through the model year. Inset shows the location of the shoaling volume calculation box.

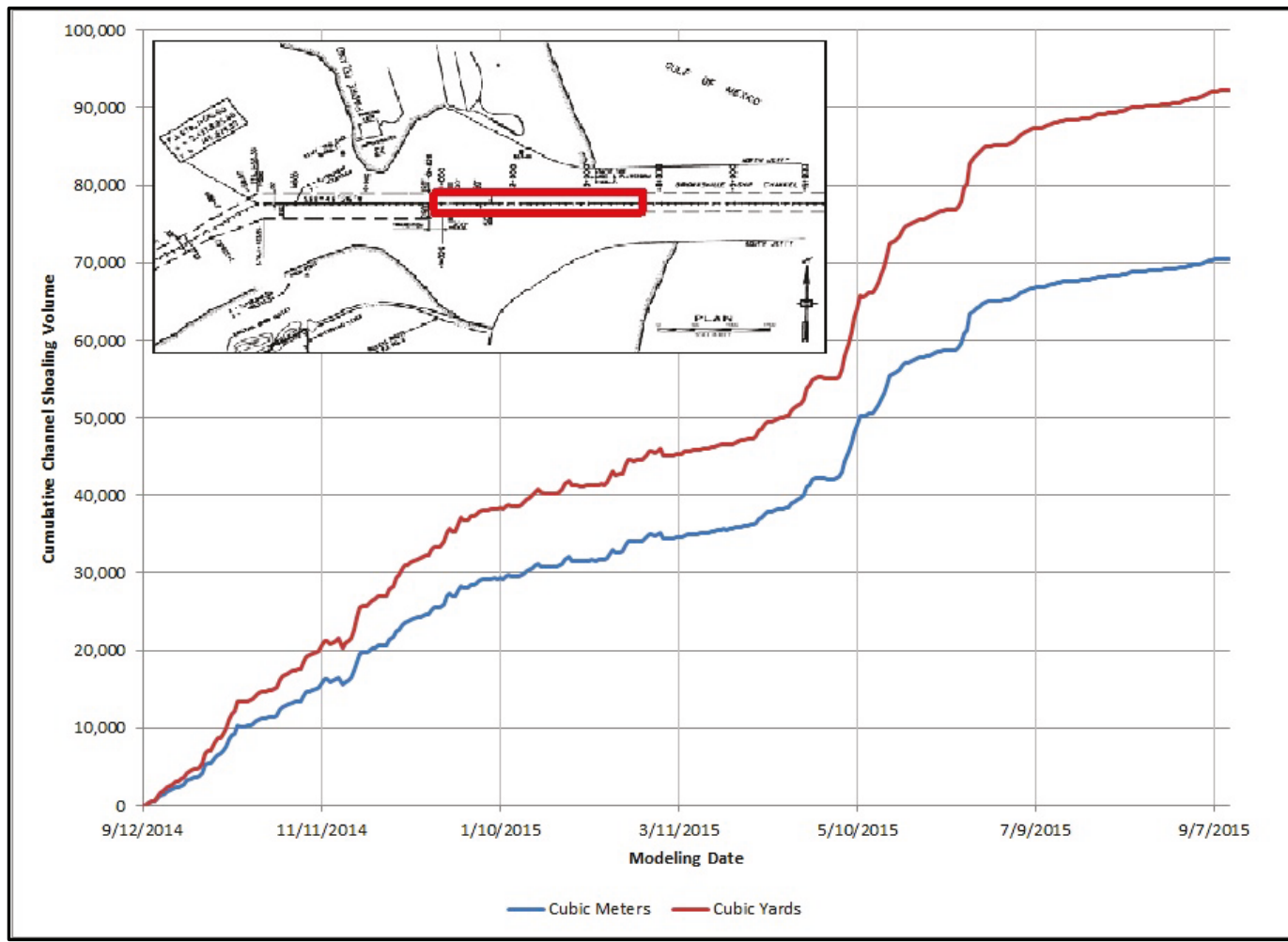

\section{Close Mansfield Pass Alternative}

\section{Description of the alternative}

As discussed in Chapter 7, the wind has a significant impact on the flow through the BSI. The tide causes daily flows into and out of the inlet, but these flood and ebb flows are nearly balanced. However, the wind drives a circulation flow through the system. During the winter months there is a counterclockwise circulation with net flow coming in through Mansfield Pass, then south down the Laguna Madre and exiting into the Gulf of Mexico through the BSI. This net flow reverses direction (runs clockwise) during the summer months and becomes stronger. A net flow enters through the BSI, flows north through the Laguna Madre, and exits at Mansfield Pass. This reversing net flow causes less sediment to be brought into the BSI from the nearshore zone and deposited on the flood shoal during the winter months and more carried in and deposited during the summer months. Therefore, changing this circulation pattern by changing the flow conditions through Mansfield Pass can be expected to change the deposition pattern on the Brazos Santiago flood shoal. 
This type of wind-driven circulation pattern can be set up whenever two or more inlets are connected to the same bay. The fact that it can affect the sedimentation rate at either of both of the inlets has been discussed by several authors, including Boon and Byrne (1981), Aubrey and Speer (1985), and Ranasinghe and Pattiaratchi (2000).

Two model runs were made that included changes to Mansfield Pass to assess the impacts that this would have on the shoaling in the BSI. One run was made with Mansfield Pass closed (which allowed no flow through the inlet). The opposite alternative is discussed in the section below.

\section{Modeling results}

Figure 8-4 compares the model estimates of the BSI shoaling for the Close Mansfield Alternative compared with the Base Case. Similar figures below compare the Base Case BSI Navigation Channel shoaling with the shoaling for other individual alternatives. In both the left and right panels, the light-gray background image shows the inlet shoreline and the two lightgray dashed horizontal lines show the edges of the channel. Compare these panels with Figure 8-1 for reference. Both panels cover the portion of the channel from station $0+000$ on the left side to station $-3+000$ on the right.

For the left-hand panel of Figure 8-4, the two colored dashed lines show the growth of the flood shoal for the Base Case, and the two colored solid lines show the growth of the flood shoal for the Close Mansfield Alternative. In this figure (and in many of the similar figures below), the dashed lines are nearly completely hidden by the solid lines. This indicates that there is very little difference in the results for the Base Case and for the Close Mansfield Alternative. The orange dashed and solid lines show the shoaling conditions after the model has run for 6 months, from September 2014 to March 2015, and the two blue lines show the shoaling conditions after the model has run for 1 year, from September 2014 to September 2015.

The same information is shown in a different way in the right-hand panel of Figure 8-4. This panel shows the difference between the two alternatives after 6 months and after a year as filled areas. The difference is calculated as the [Alternative minus the Base Case]. If that value is positive, the filled area is above the zero line (the alternative increases the shoaling rate), and if negative, it is below the zero line (alternative decreases shoaling). For example, the blue areas in the right-hand panel show that after a year, 
there is a little more deposition for the Close Mansfield Alternative between stations $-1+000$ and $-2+000$ than for the Base Case, while farther landward and farther seaward, the reverse is true.

Figure 8-4. Change in channel depth for the Close Mansfield Alternative compared to the Base Case.

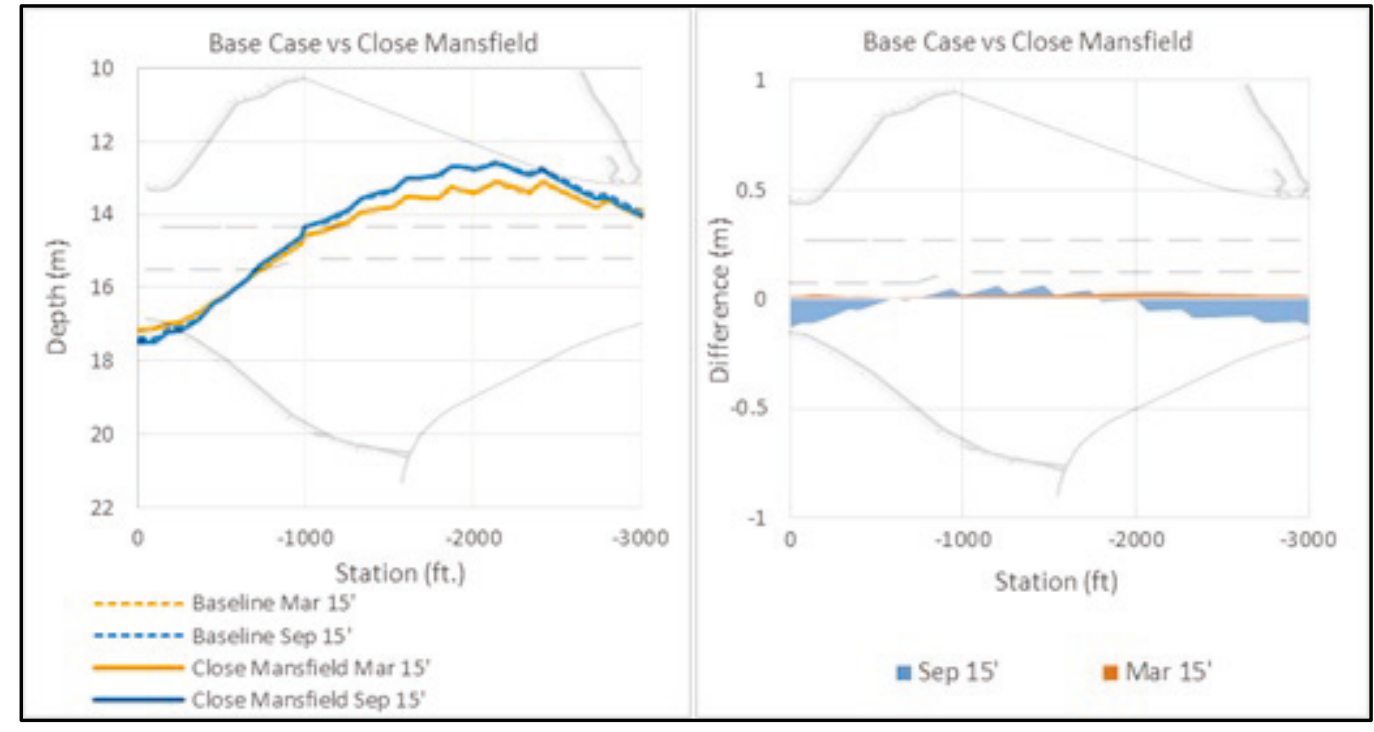

Figure 8-5 shows the differences in the shoaling volumes between this alternative and the Base Case. The modeling results indicate that if Mansfield Pass were closed, then the BSI flood shoal would grow slightly faster during the winter, but slower during the summer, with the total yearly growth being less than for the Base Case. 
Figure 8-5. Differences in the model-predicted shoaling volume through time for the Close Mansfield Alternative compared to the Base Case.

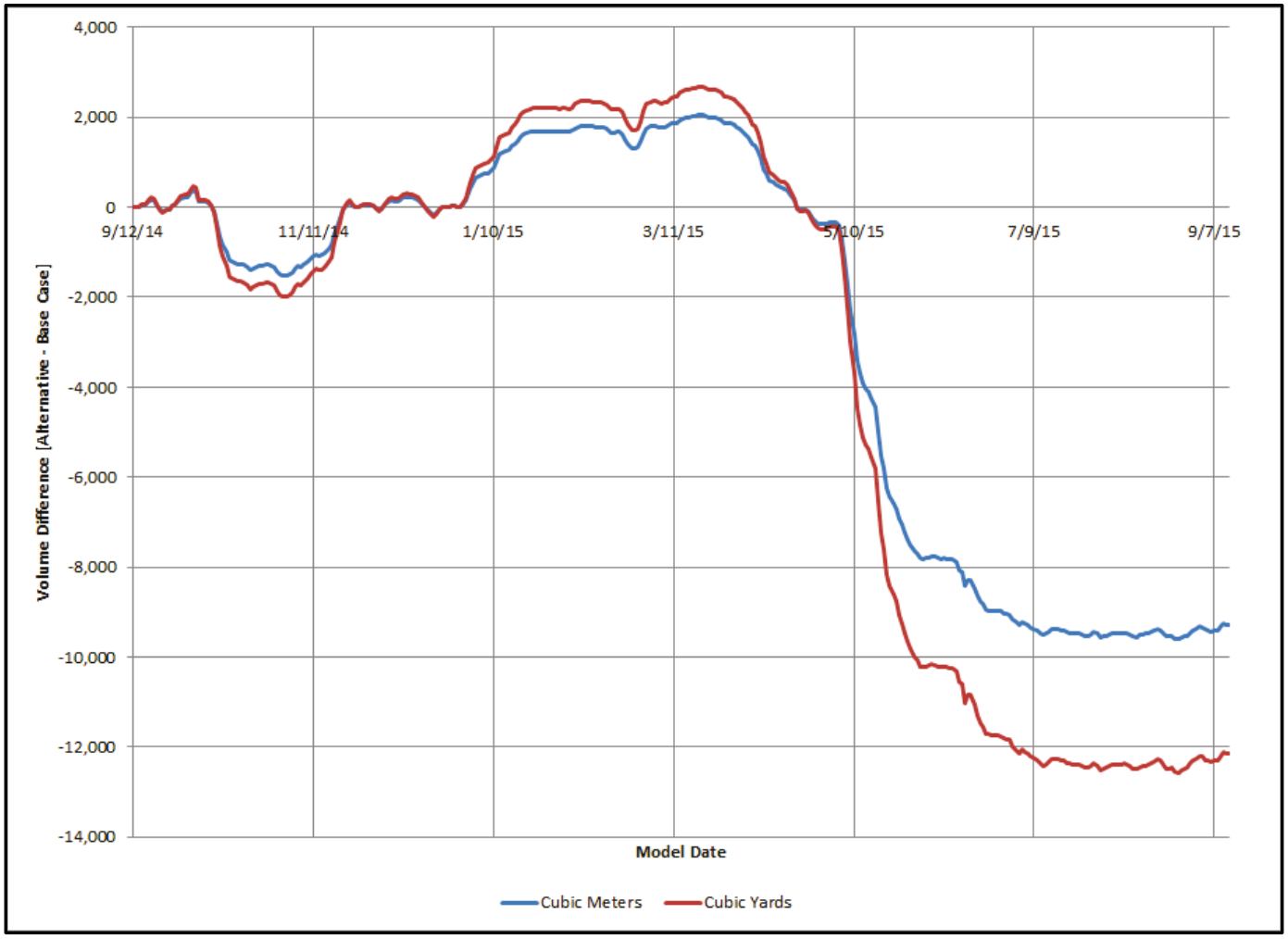

\section{Discussion}

Figure 8-5 indicates that closing Mansfield Pass could be expected to contribute to approximately a $15 \%$ shoaling decrease in the shoaling volume throughout the BSI. However, counterintuitively, Figure 8-4 suggests that where the shoaling rates are greatest, the high spots in the channel might be slightly higher if Mansfield Pass were closed.

There are also significant environmental impacts that would need to be carefully considered before closing Mansfield Pass. Laguna Madre is a hypersaline lagoon because evaporation exceeds rainfall plus freshwater inflow. Typical salinity levels in the Gulf of Mexico are near 35 parts per thousand (ppt), but prior to the opening of Mansfield Pass in the 1960s, salinity levels regularly exceeded 60-70 ppt in the northern portions of Lower Laguna Madre. However, after Mansfield Pass was opened, salinity maximums are typically in the range of $40-50 \mathrm{ppt}$. Individual species react differently to exposure to hypersaline conditions. However, extreme hypersalinity clearly decreases species diversity. Closing Mansfield Pass would be expected to return the lagoon to the higher levels of salinity. 
The wind-driven circulation patterns in the lagoon system (flow counterclockwise in winter and clockwise in summer, see Chapter 7) lead to a replacement of the hypersaline lagoon water with lower salinity water from the Gulf of Mexico. This current also flushes pollutants and lowoxygen water from the lagoon. Closing Mansfield Pass would cut off this circulation pattern. Additional consequences could include the disruption of fish migration patterns. It is expected that these types of environmental concerns would significantly exceed any benefits derived from decreasing the shoaling rate in the BSI.

\section{Deepen Mansfield Pass Alternative}

\section{Description of the alternative}

See the description in the alternative above for the explanation of why either of these two alternatives would be expected to influence the shoaling rate in the BSI. Deepening Mansfield Pass would be expected to increase the circulation through the lagoon system (counterclockwise in winter and clockwise in summer; see Chapter 7). This alternative was modeled with Mansfield Pass deepened from its present depth of 1.8-

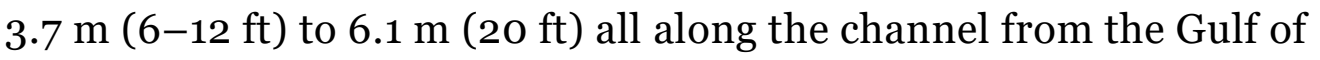
Mexico to the channel's intersection with the GIWW adjacent to Port Mansfield.

\section{Modeling results}

Figure 8-6 shows how the channel depths over the flood shoal can be expected to change if the Deepening Mansfield Pass Alternative is implemented. The increased shoaling would lead to the channel high spot

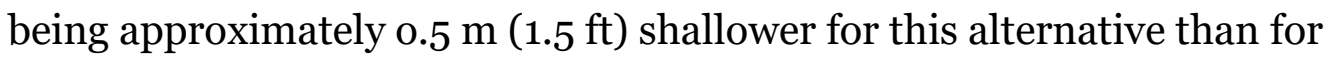
the Base Case 1 year after dredging. Figure 8-7 indicates that the total shoaling volume would increase by $3,520 \mathrm{~m}^{3}\left(4,600 \mathrm{yd}^{3}\right)$, which is an increase of approximately $5 \%$. 
Figure 8-6. Change in channel depth for the Deepen Mansfield Alternative compared with the Base Case.

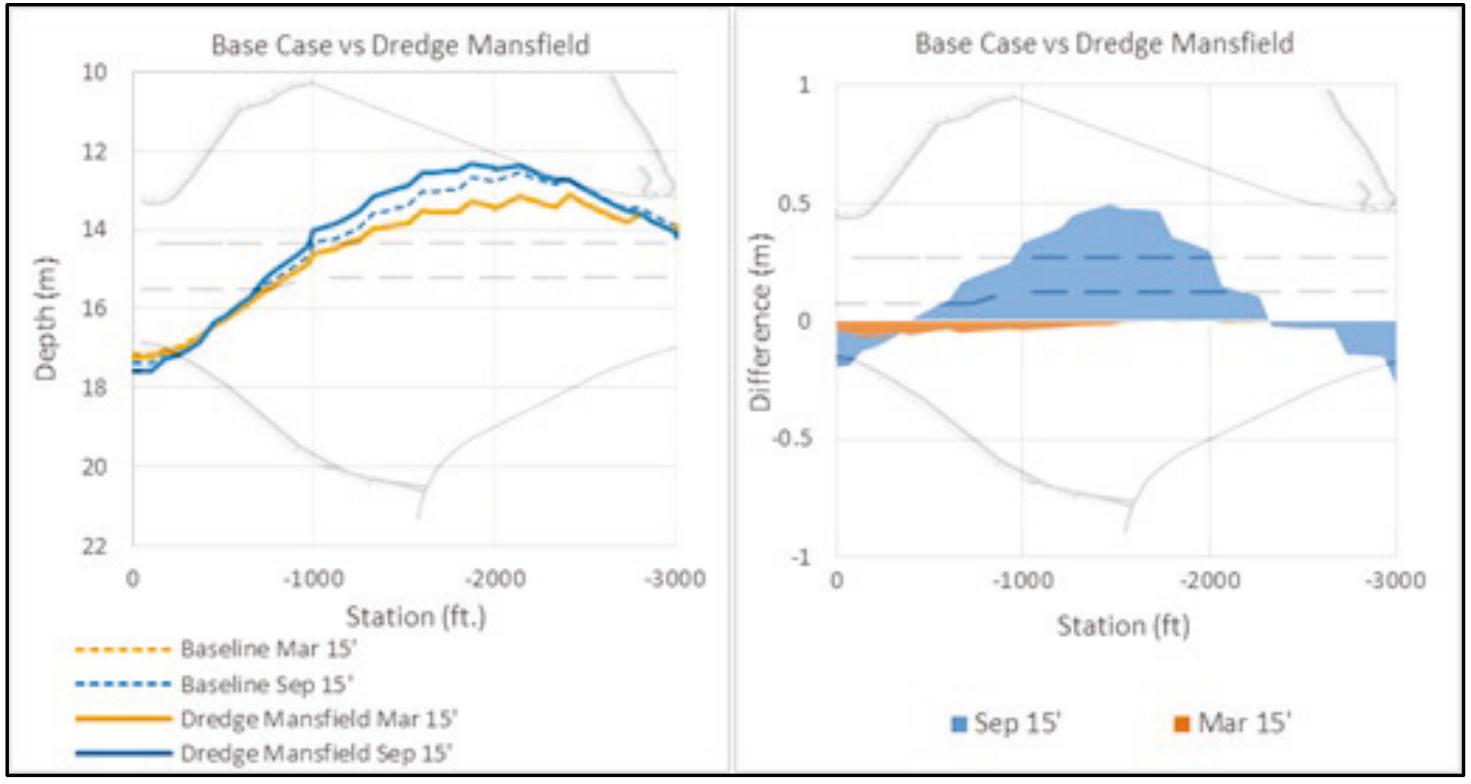

Figure 8-7. Differences in the model-predicted shoaling volume through time for the Dredge Mansfield Alternative compared to the Base Case.

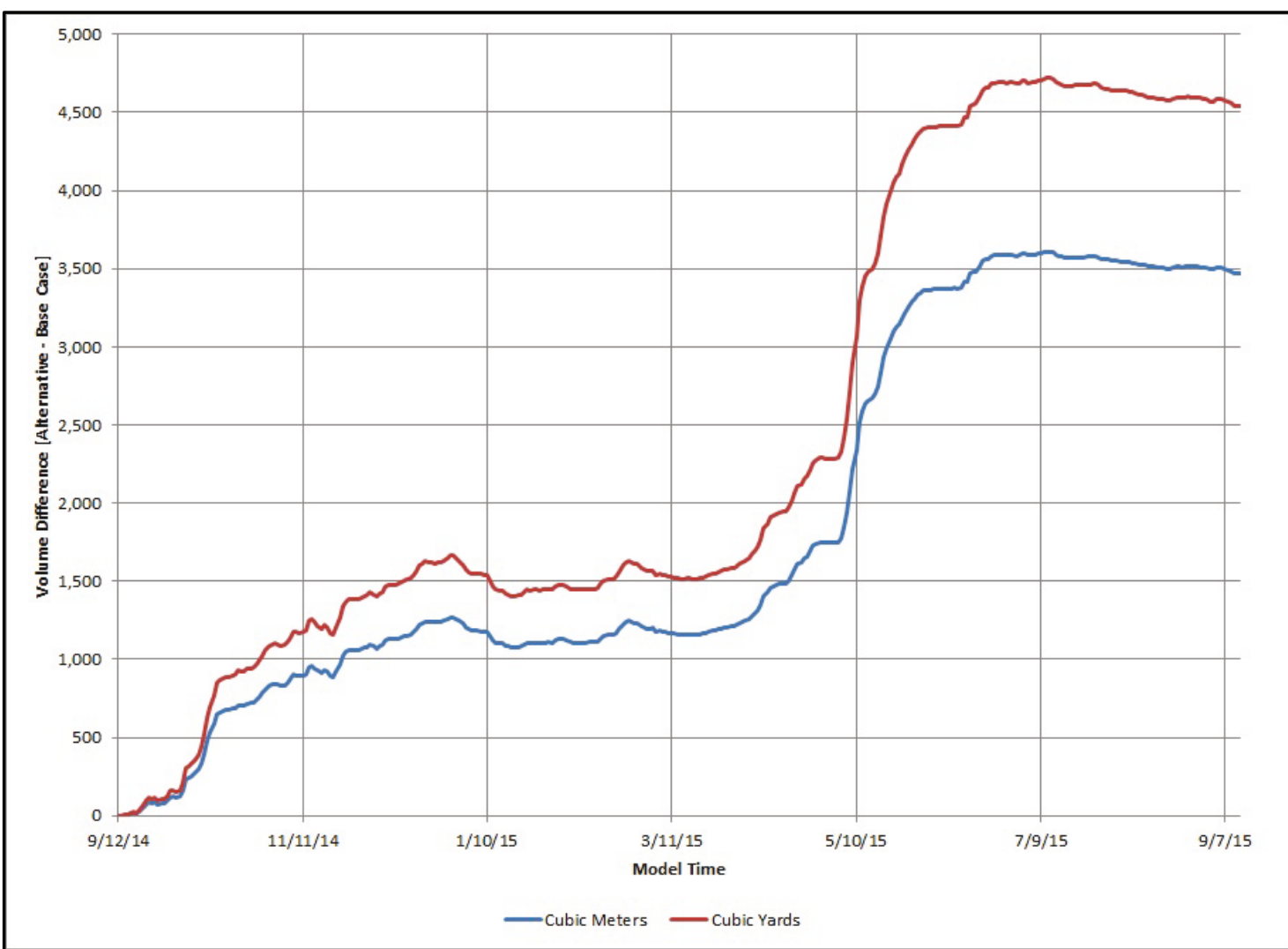




\section{Discussion}

This study has shown that deepening Mansfield Pass would increase the costs of channel maintenance at the BSI. This would occur because deepening Mansfield Pass would increase the circulation through the Brazos-Laguna Madre-Mansfield system (counterclockwise in winter and clockwise in summer; see Chapter 7). However, this increased circulation would also be expected to provide environmental benefits in the form of improved water quality. A deeper inlet is also favored by the residents of Port Mansfield, as this would allow the inlet to be traversed by larger vessels (PAAC 2015).

\section{Seaward Jetty Extension Alternative}

\section{Description of the alternative}

The flood shoal in the BSI is mostly derived from sediment that was previously in the nearshore zone near the mouth of the inlet. Modifying the pathway for that sediment by extending the jetties farther seaward into the Gulf of Mexico can be expected to alter the rate of delivery of sediment to the flood shoal by altering the sediment pathway and altering the amount of sediment that ends up on the shoal versus the amount of sediment that bypasses the inlet and continues north ending up in the nearshore zone and on the beaches of South Padre Island.

For this alternative, both the North and South Jetty ends were extended $152 \mathrm{~m}$ (500 ft) seaward of their present positions, as shown in Figure 8-8. 
Figure 8-8. Brazos Santiago Inlet showing the Seaward Jetty Extension Alternative in red (from Google Earth https://www.google.com/earth/).

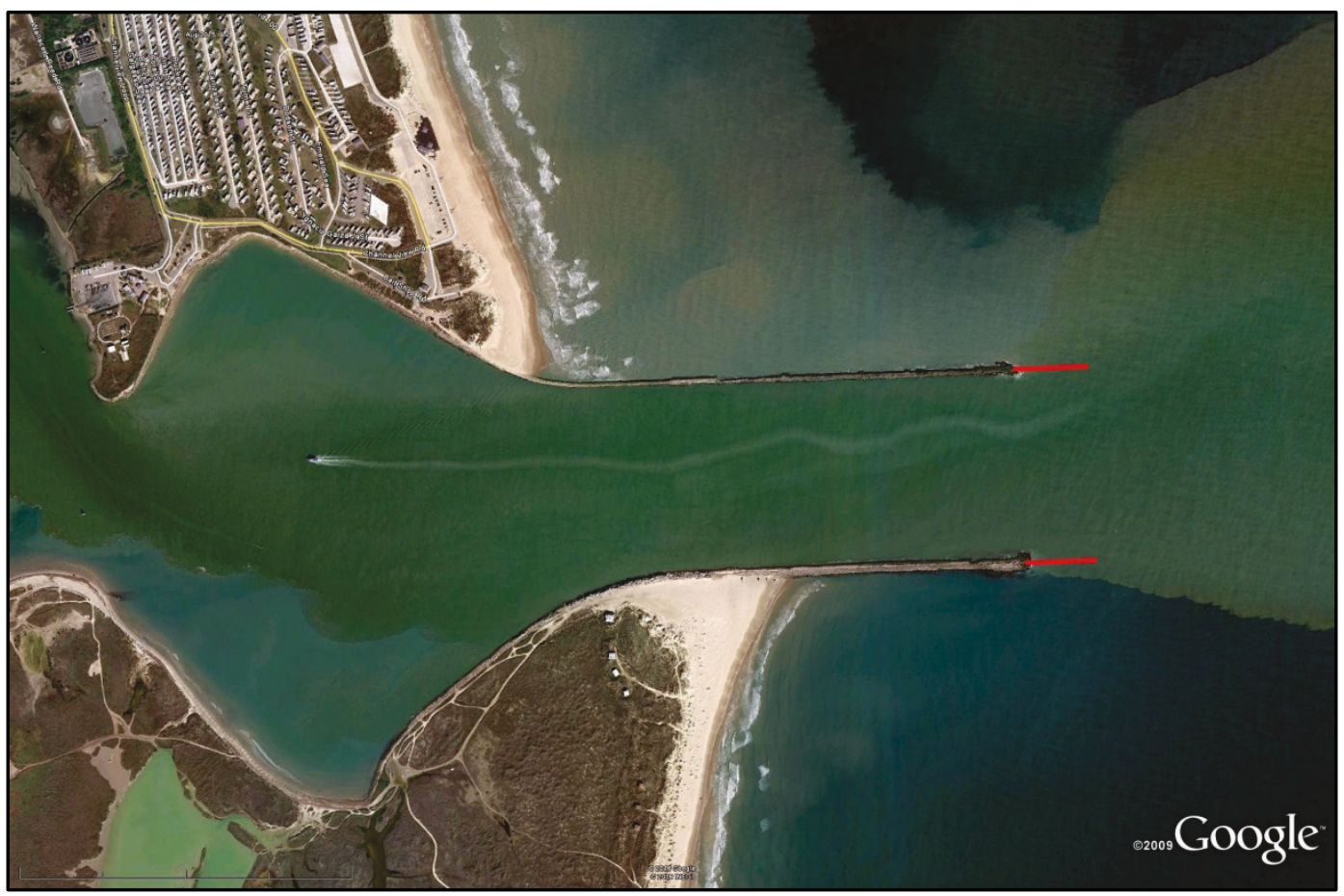

\section{Modeling results}

Figure 8-9 shows that there is a small decrease in the controlling depth of the channel through the flood shoal over the first 6 months compared to the Base Case shoaling rate, but over a full year, the controlling channel depth is approximately $0.08 \mathrm{~m}(0.25 \mathrm{ft})$ shallower than for the Base Case. Figure 8-10 shows a small decrease in the total volume of material accumulating on the flood shoal. This volume accumulation is approximately $3 \%$ less than for the Base Case.

\section{Discussion}

The results of this alternative analysis did not demonstrate any result other than minor changes in the shoaling rate. In addition, the model was run for only 1 year, and it was not clear that nearshore bathymetry in the vicinity of the jetties had equilibrated to the new jetty length over that time period. Thus, a longer model run time would be required to definitively demonstrate what future shoaling rates could be expected. It was also assumed that any dredging reduction benefits from this alternative would be small compared to the jetty construction costs, which are expected to be significant, but this study did not perform an economic analysis. 
Figure 8-9. Change in channel depth for the Seaward Jetty Extension Alternative compared with the Base Case.

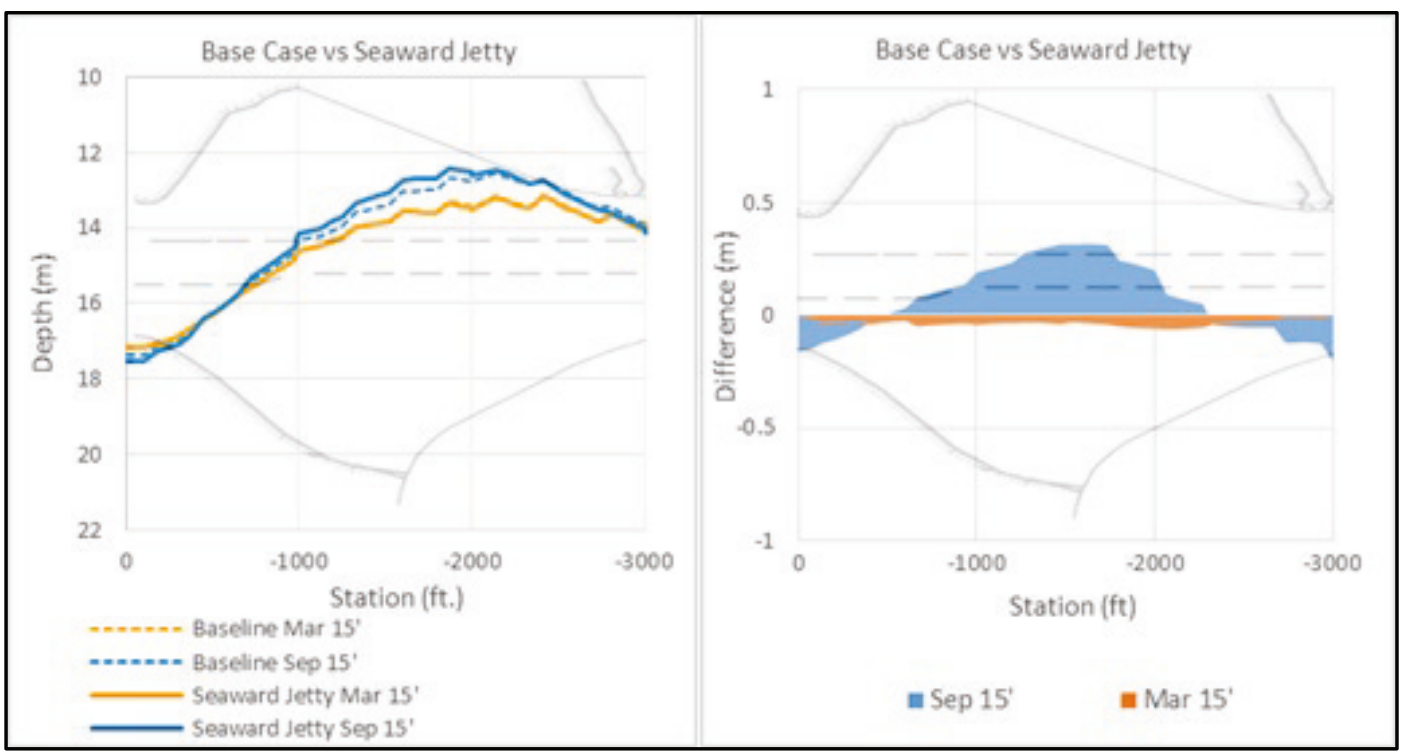

Figure 8-10. Differences in the model-predicted shoaling volume through time for the Seaward Jetty Extension Alternative compared to the Base Case.

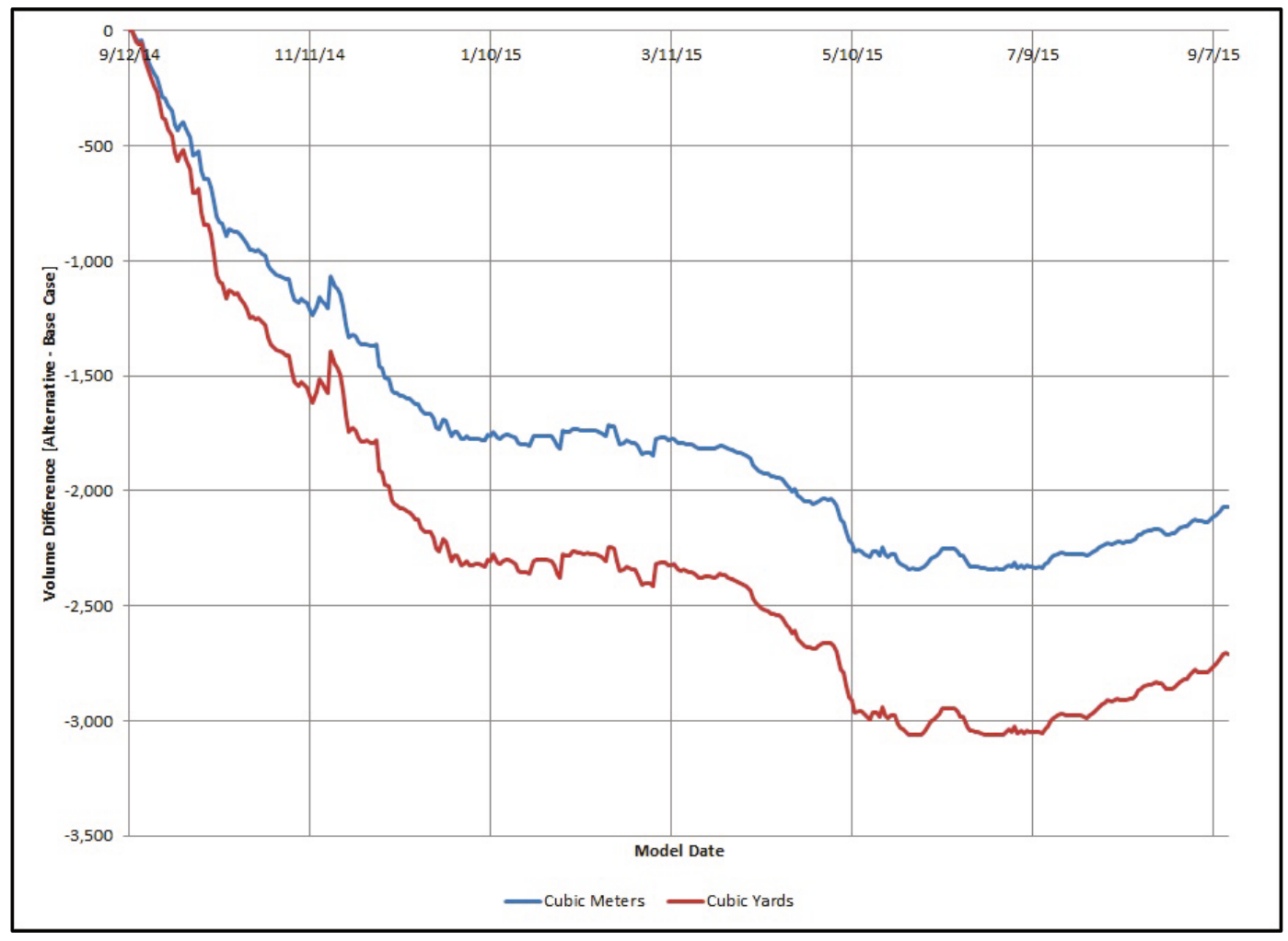




\section{Interior Jetty Straightening Alternative}

\section{Description of the alternative}

As shown in Chapter 7, the flood shoal in the BSI is located where it is because this is the location where the flow velocities of the water moving through the inlet decrease and drop a portion of the sediment load they are carrying. The water velocities slow down because the jetties widen at this location.

This alternative models the conditions at the inlet if the interior portion of the jetties were straightened, removing the influence of the bulges in the north and south shorelines. This alternative is shown schematically in Figure 8-11. The model results for this alternative with the straight and parallel jetties through the length of the inlet show that the current velocities remain essentially constant through the whole inlet.

Figure 8-11. Brazos Santiago Inlet showing the Interior Jetty Straightening Alternative in red (from Google Earth https://www.google.com/earth/).

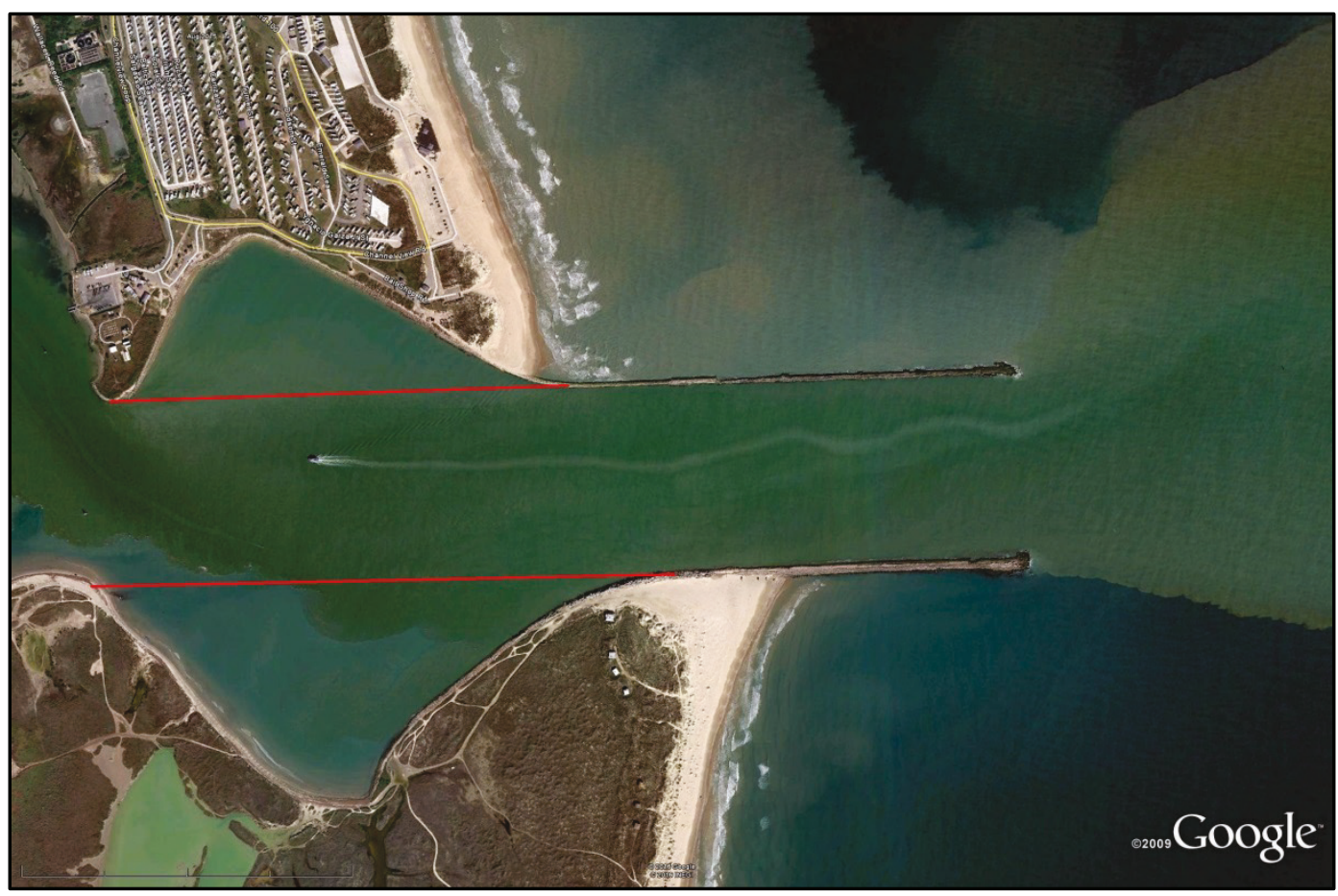

\section{Modeling results}

For this alternative, because the currents do not slow down, the inlet flood shoal does not grow in the region of Channel Station -2200. Rather, Figure 8-12 shows that the channel erodes at that location over the course 
of the model year. The controlling depth for the channel is shallowest at the beginning of the model run. Also, by comparing Figure 8-13 with Figure 8-3, it is seen that sediment is eroded from what is the flood shoal for the other alternatives.

Figure 8-12. Change in channel depth for the Interior Jetty Straightening Alternative compared with the Base Case.

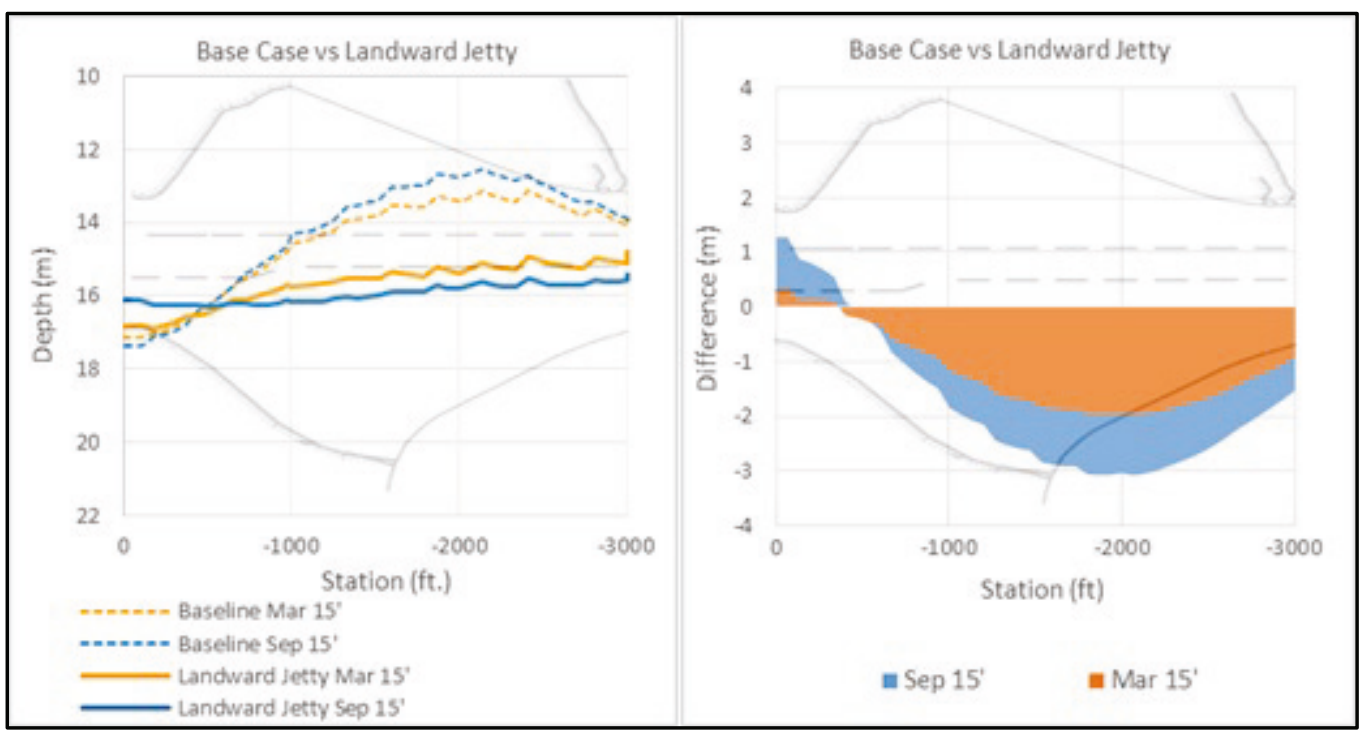

Figure 8-13. Differences in the model-predicted shoaling volume through time for the Interior Jetty Straightening Alternative compared to the Base Case.

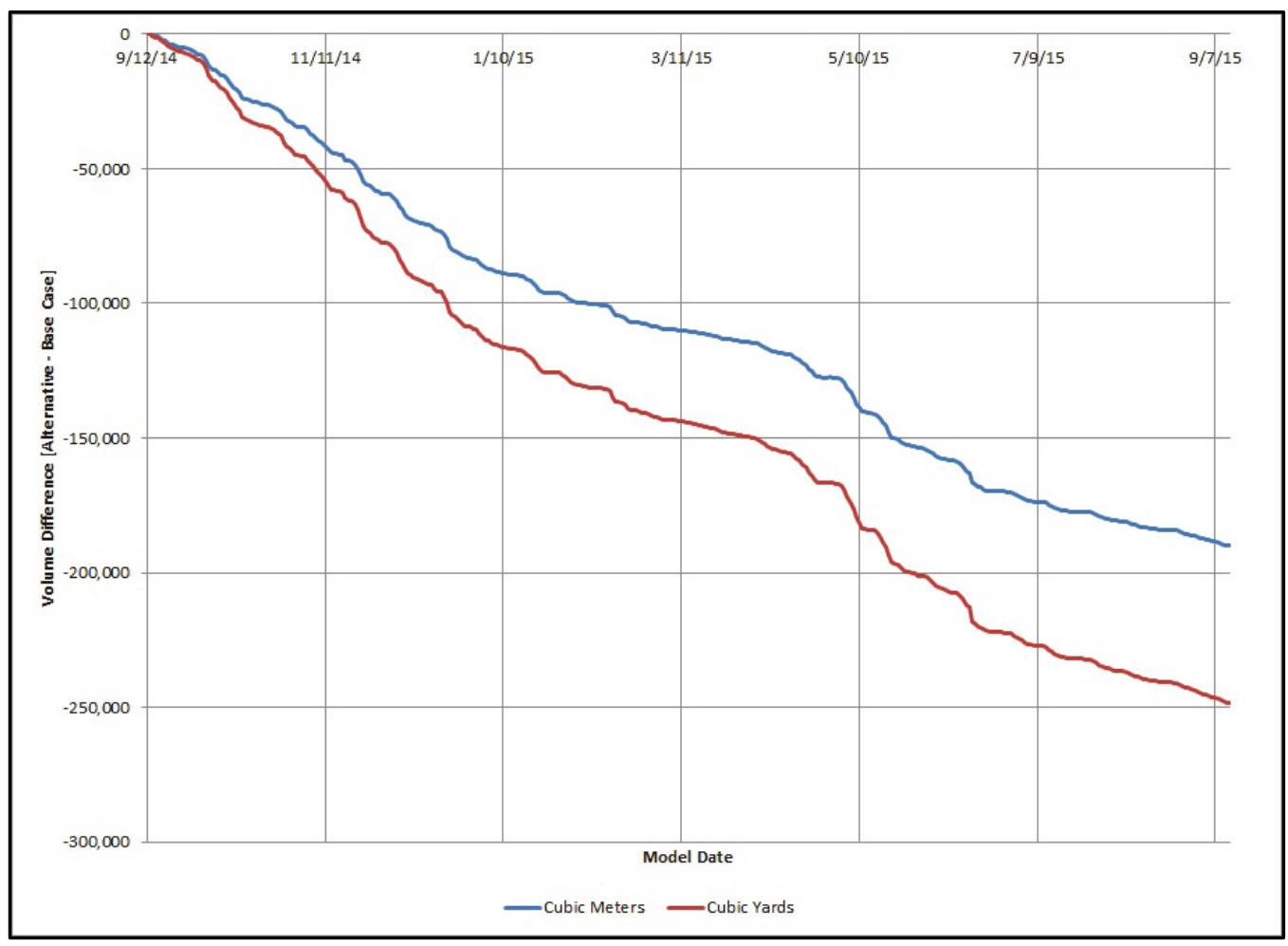




\section{Discussion}

This alternative clearly does an excellent job of solving the shoaling problem where it presently occurs in the vicinity of Channel Station-2200. However, it is reasonable to assume that this is merely shifting the shoaling problem to a different location farther westward along the Brownsville ship channel where it traverses the south end of Laguna Madre. Because the numerical model ran for only 1 year, the centroid of the new flood shoal location (if there were to be one) was not well defined. A potential downside of a new flood shoal that was farther westward than its present location would be that the costs to transport the dredged material to South Padre Island beaches would be higher.

\section{Heighten Jetties Alternative}

\section{Description of the alternative}

It is clear that an unknown, but possibly significant, amount of sediment transport into the BSI is aeolian (wind driven). At both the north and south jetties, the height of the sand at and seaward of the dune line is near or at the height of the jetties, as shown in Figure 8-14. Once this condition has been reached, additional wind-blown sediments are carried over the jetty crest and deposited into the inlet channel. This issue is a common concern at many inlets along the Texas coast, as discussed by Bales and Holley (1989) (Rollover Pass); Heilman and Edge (1996) (Mouth of the Colorado River); Kraus and Heilman (1997) (Packery Channel); Kraus (2007) (multiple inlets); Morang (2006), and Frey et al. (2016) (Galveston Entrance Channel).

Figure 8-14. Brazos Santiago Inlet south (left panel) and north (right panel) jetties at dune line showing sand level near the crests of the jetties.

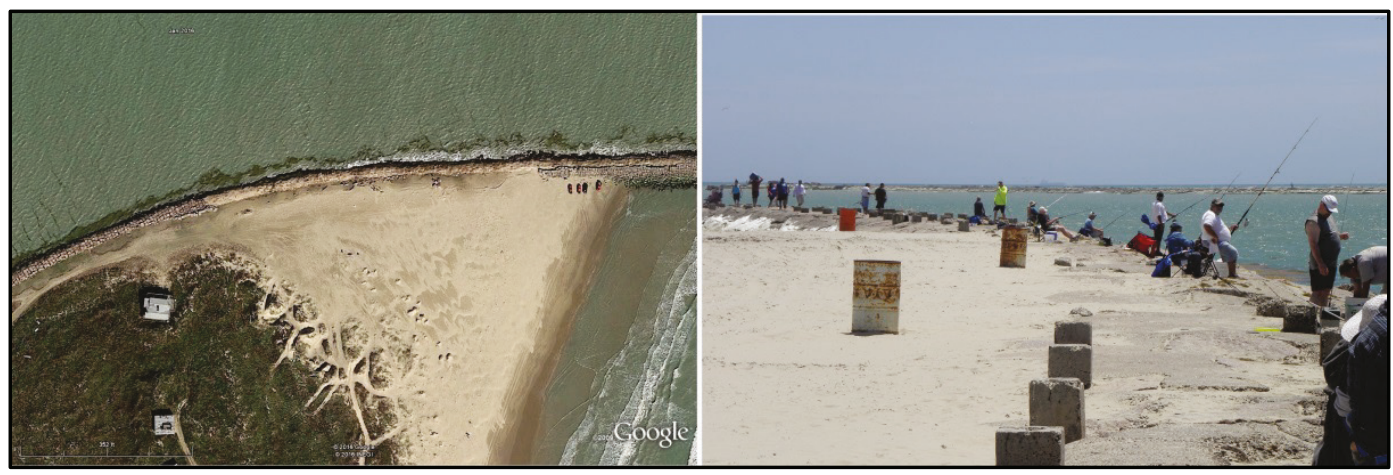


However, quantification of this transport rate through field measurements or analysis of winds is difficult. For that reason and also because the version of the numerical model used in this study is not presently capable of incorporating this type of additional sediment input, this alternative was not modeled in this study. Future model improvements are intended to address this issue. Even though this sediment pathway was not able to be addressed by this study, this alternative was included in the list, given the likelihood of a follow-up study to address it. If future studies quantify and conclude that aeolean transport of sediments into the inlet is an important pathway, one way to address the issue would be to raise the height of the jetties over a limited span, as shown in Figure 8-15. However, for long-term control of this issue, this would need to be combined with a method of passing the sediments onto downstream beaches.

Figure 8-15. Brazos Santiago Inlet showing likely locations (in red) to increase the jetty height for the Heighten Jetty Alternative (from Google Earth https://www.google.com/earth/).

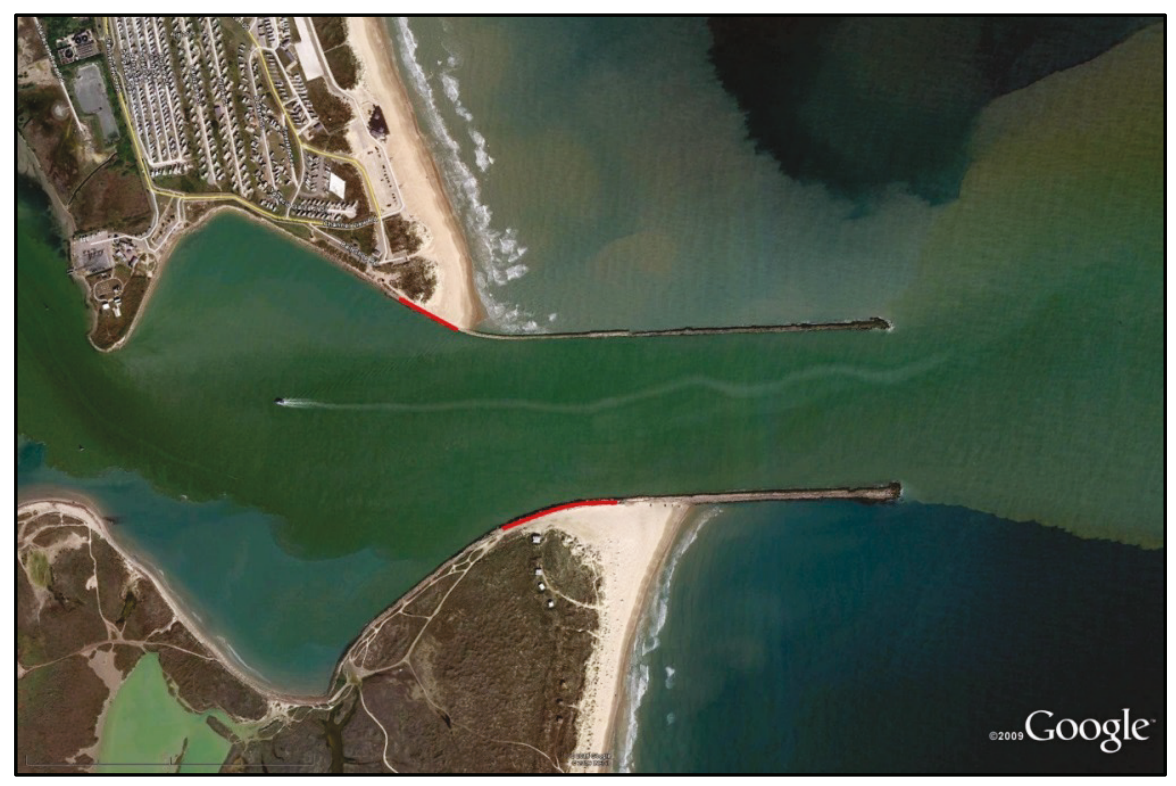

\section{Discussion}

To address this issue, first, fieldwork would need to be done to determine the amount of transport over the crest of the jetties. Then, modeling could be done to determine if the sediment is contributing to the sedimentation at the flood shoal. If it is determined that this pathway is a significant contributor to the shoaling problem, a long-term solution would need to be found. It is recognized that merely raising the jetty height is only a temporary solution until sand fills against the jetty to its new height. 


\section{In-Channel Sediment Trap Alternative}

\section{Description of the alternative}

Present dredging operations at the BSI involve contracting and bringing a seagoing dredge to the inlet on an as-needed basis. Presently, the asneeded basis is yearly, or nearly so. One method to increase the amount of time between inlet dredging events would be to deepen the channel at the location where the most extensive shoaling occurs. This would be expected to decrease the mobilization costs of bringing a dredge to the inlet. It would not, however, be expected to decrease the total volume of sediment dredged. The expectation is that larger volumes of sediment would be moved less frequently but with approximately the same total volume moved over time as is presently dredged.

This alternative looks at the impacts of having an in-channel sediment trap located at the flood shoal. The trap would be a deeper portion of the channel where the flood shoal occurs in the shape of a trench. The trap that was modeled was designed to hold a volume of $153,000 \mathrm{~m}^{3}$ (200,000 $\left.\mathrm{yd}^{3}\right)$, the average volume dredged in a year. The trap dimensions were $960.1 \mathrm{~m}(3,150 \mathrm{ft})$ in the along-channel direction by $94.5 \mathrm{~m} \mathrm{(310} \mathrm{ft)}$ cross-channel and $1.7 \mathrm{~m}$ (5.5 ft) deep. Figure 8-16 shows the approximate location of this trap. 
Figure 8-16. Location (in red) of the deepened portion of the channel for the In-Channel Sediment Trap Alternative (from Google Earth https://www.google.com/earth/).

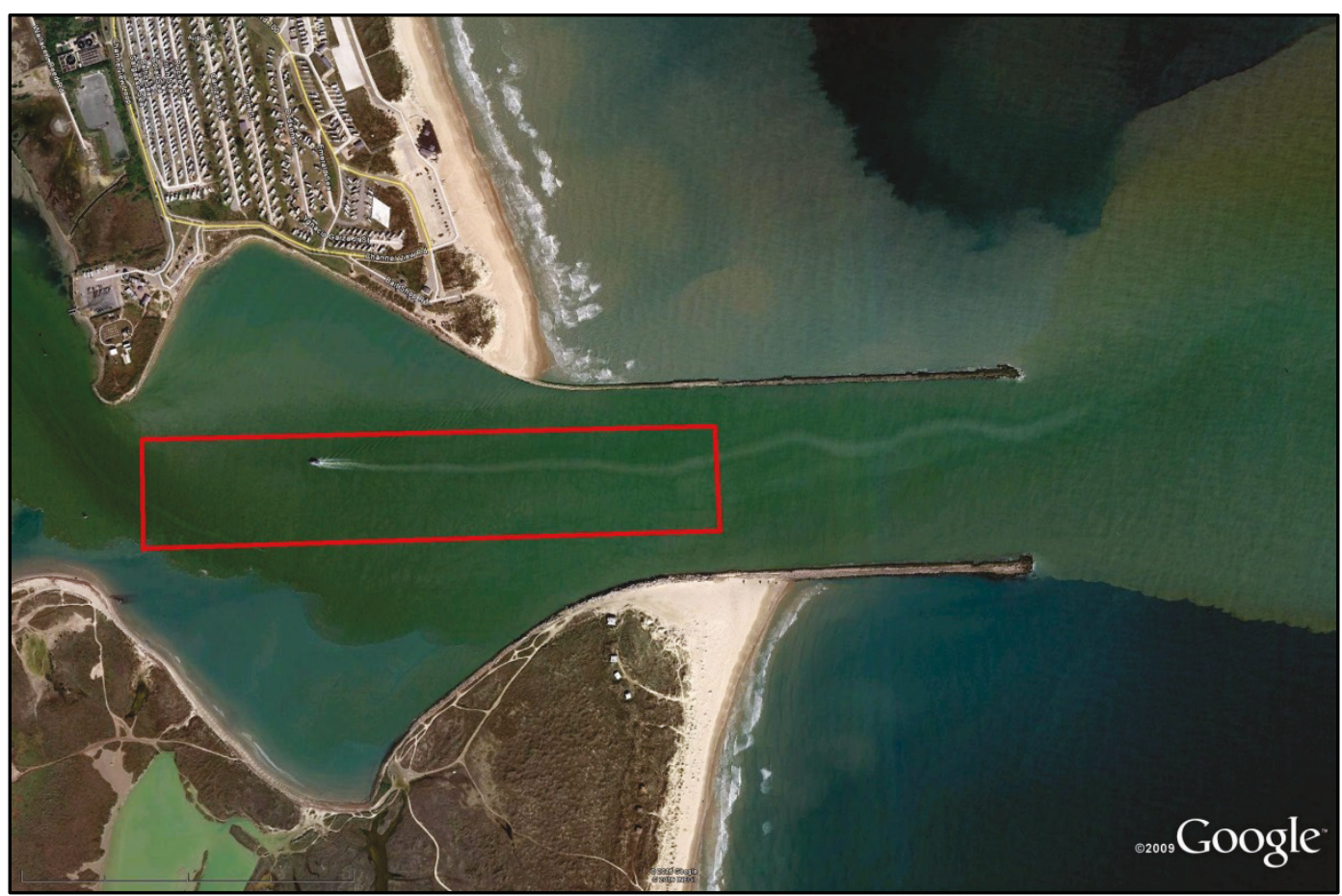

\section{Modeling results}

Figure 8-17 shows the growth of the flood shoal over time. It covers the same along-channel area as the similar figures for the other alternatives but has several modifications. One-year-long Base Case channel elevations are shown as dashed lines. Two-year-long sediment trap channel elevations are shown as solid lines. The two black lines show the initial channel elevations at the start of the model run for the Base Case (present condition, dashed line) and the deeper dredged initial depth for the Sediment Trap (solid line). The 6-month channel elevations are in yellow, and the 1 year elevations are in blue. For this alternative, the model was run for 2 years, and the 18- and 24-month elevations are shown in green and purple, respectively. Figure 8-17 shows that the channel minimum elevation after 2 years for the Sediment Trap is slightly less than for 1 year for the Base Case. 
Figure 8-17. Change in channel depth for the In-Channel Sediment Trap Alternative compared with the Base Case.

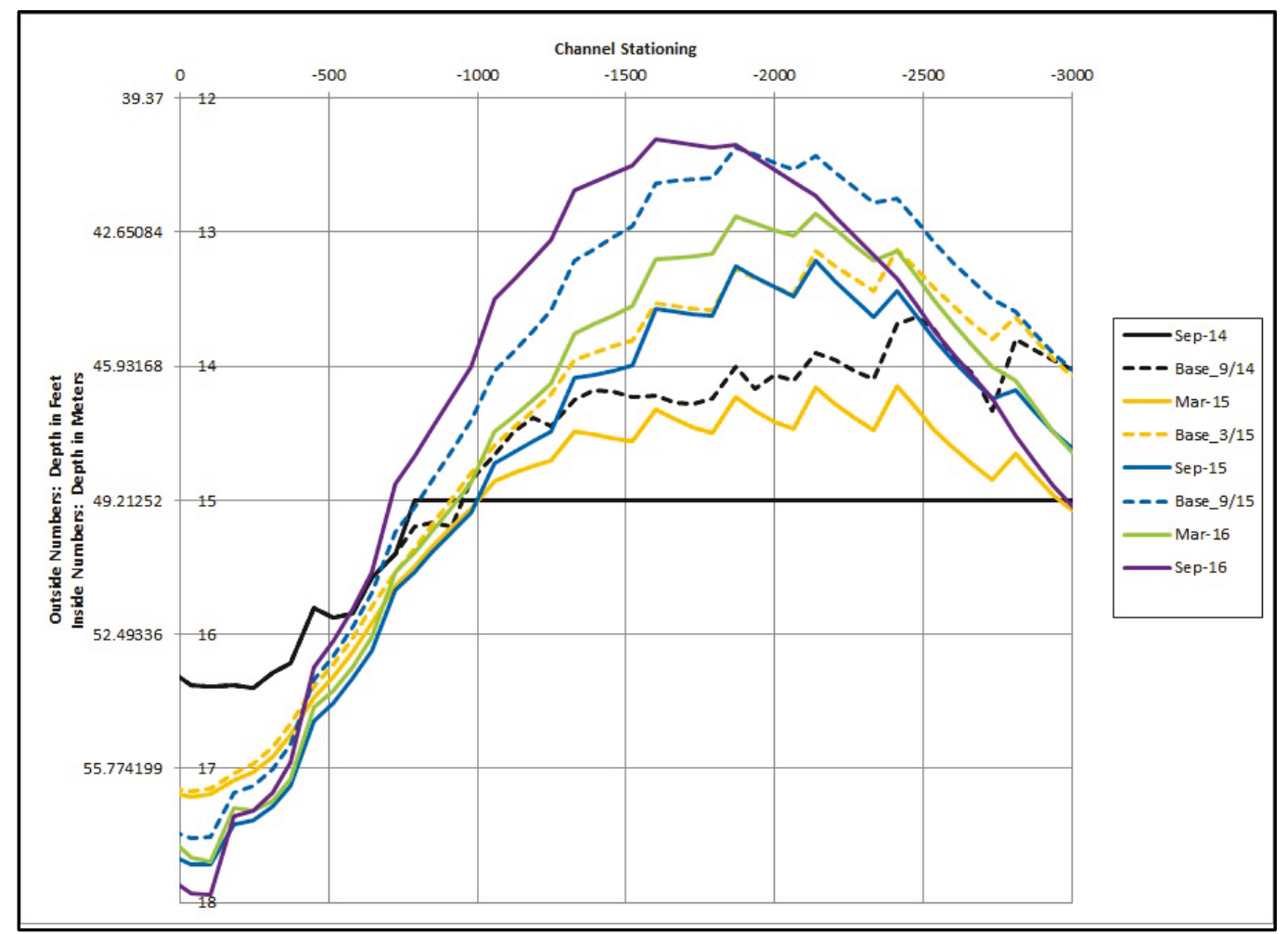

\section{Discussion}

Because the initial trench in the channel is deeper for this alternative, sediment would be expected to collect at a somewhat faster rate than for the Base Case. However, this alternative was modeled with a flat initial bottom. Additional model runs could be made to optimize the size and shape of the trap.

\section{Dedicated Dredging Plant Alternative}

\section{Description of the alternative}

An alternative to bringing an ocean-going dredge to the inlet each time it is needed could be to have a much smaller capacity dredge permanently located at the site. The pump plant could be either land based or floating. Both types of systems have been in operation at inlets around the country for many decades (Bray et al. 1997). One advantage to this type of system is that the sediment accumulates in the BSI at a location that is very close to where it is needed on the beaches of South Padre Island. Minimum distances from the channel shoal to closest deposition areas on SPI are of the order of a half mile. Once the sand is moved to South Padre Island, it 
could be truck-hauled to where it is needed, or as an alternative, a permanent distribution system of pipes buried beneath the dunes on SPI could be constructed. A similar sediment distribution system has been proposed for Galveston Island (Frey et al. 2016). A system such as this would have high up-front costs but could have much lower overall lifetime costs and could more precisely distribute sediment to where it is needed along South Padre Island.

This study did not model this alternative because the present version of the model does not allow for the bathymetry to be altered by the user during a model run. Proposed model upgrades will address this issue. The main benefit of modeling this alternative would be to determine if continuous dredging were confined to a limited area (where the shoaling is most rapid), how would the system respond. It could be that other areas in the inlet could continue to shoal, much as they do now. Also, it could be that sediment that would otherwise deposit elsewhere would be drawn to the site where shoaling is most favorable, particularly if there were a crater rather than a high spot at that location. It may be possible that bringing in a large dredge from elsewhere was seldom or never needed. The final design for this type of system could also combine elements of this alternative with the In-Channel Sediment Trap Alternative.

Figure $8-18$ shows this alternative schematically. The red oval is a suggested, confined, continuous dredging region, and the red straight line is a possible minimal path to a deposition location. 
Figure 8-18. Schematic location of the dredging location for a dedicated pump plant and associated discharge pipe (from Google Earth https://www.google.com/earth/).

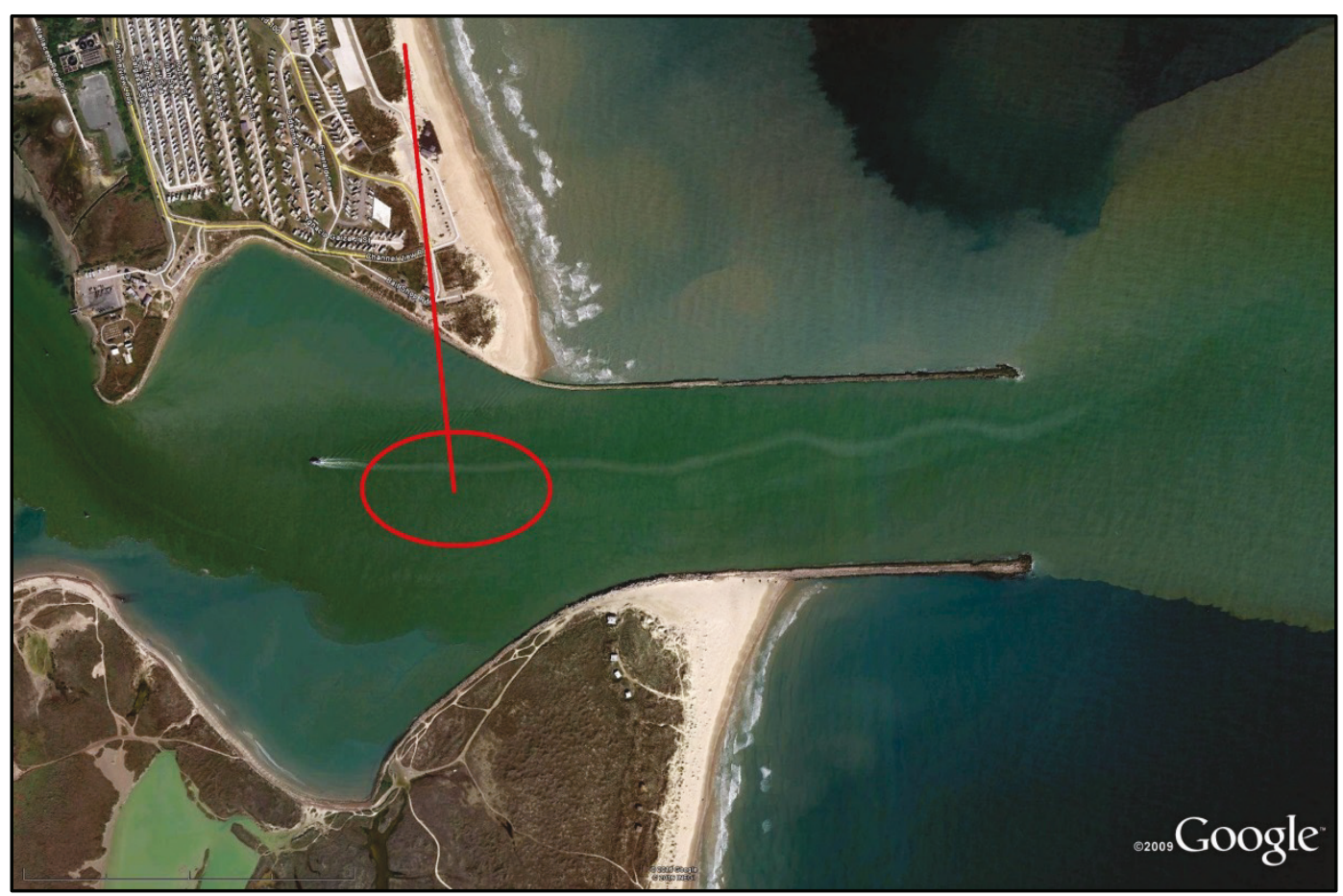

\section{Discussion}

Additional modeling is needed. However, initial economic studies could be undertaken to obtain a rough estimate of how overall costs would compare with present methodology.

\section{Proposed 15.8 m (52 ft) Channel Deepening Project}

CESWG has developed plans to increase the draft of the Brownsville Ship Channel to $15.8 \mathrm{~m}$ (52 ft) (USACE 2014a). Thus, the District requested that an additional model run be made to examine the infilling associated with this proposed channel. While this is not an alternative in the same sense as those discussed above, the model run and post-run analysis are similar and thus are discussed here.

\section{Modeling results}

Figure 8-19 compares the channel depth estimates for the Proposed $15.8 \mathrm{~m}$ (52 ft) Channel Deepening Project and the Base Case. Figure 8-20 shows the model-estimated increases in shoaling volume over the flood shoal. 
Figure 8-19. Change in channel depth for the Proposed $15.8 \mathrm{~m}$ (52 ft) Channel Deepening Project compared with the Base Case.

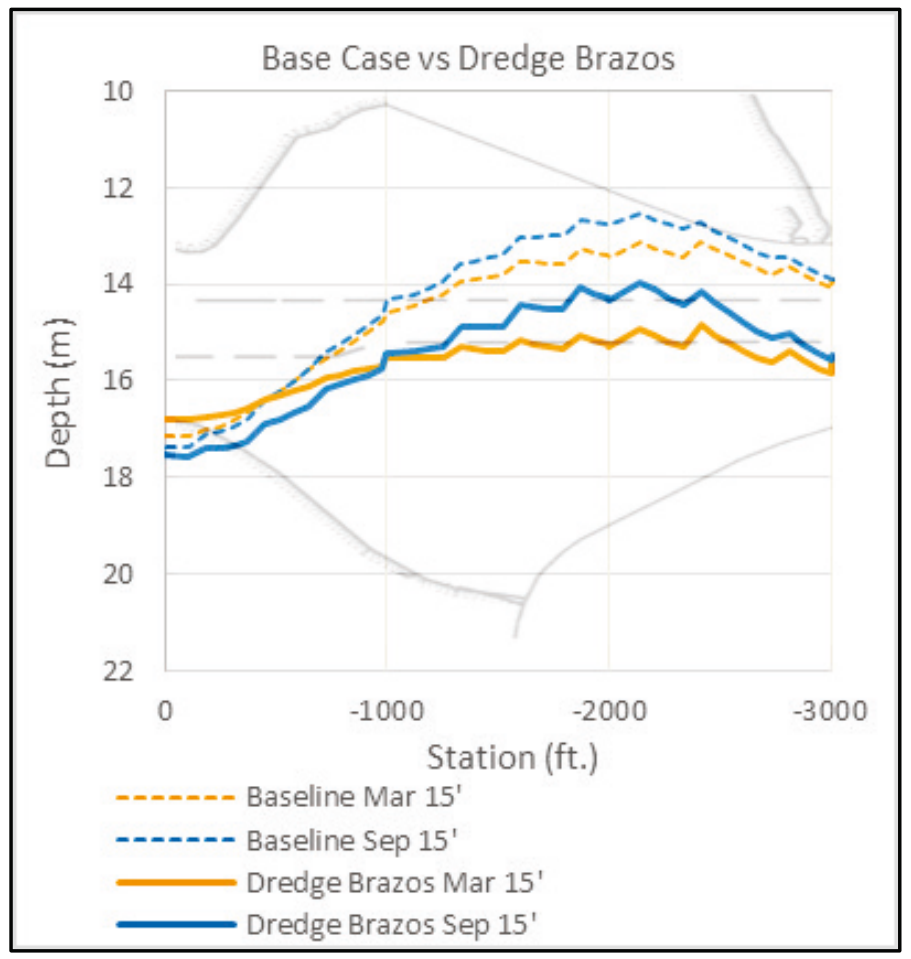

Figure 8-20. Differences in the model-predicted shoaling volume through time for the Proposed $15.8 \mathrm{~m}$ (52 ft) Channel Deepening Project compared to the Base Case.

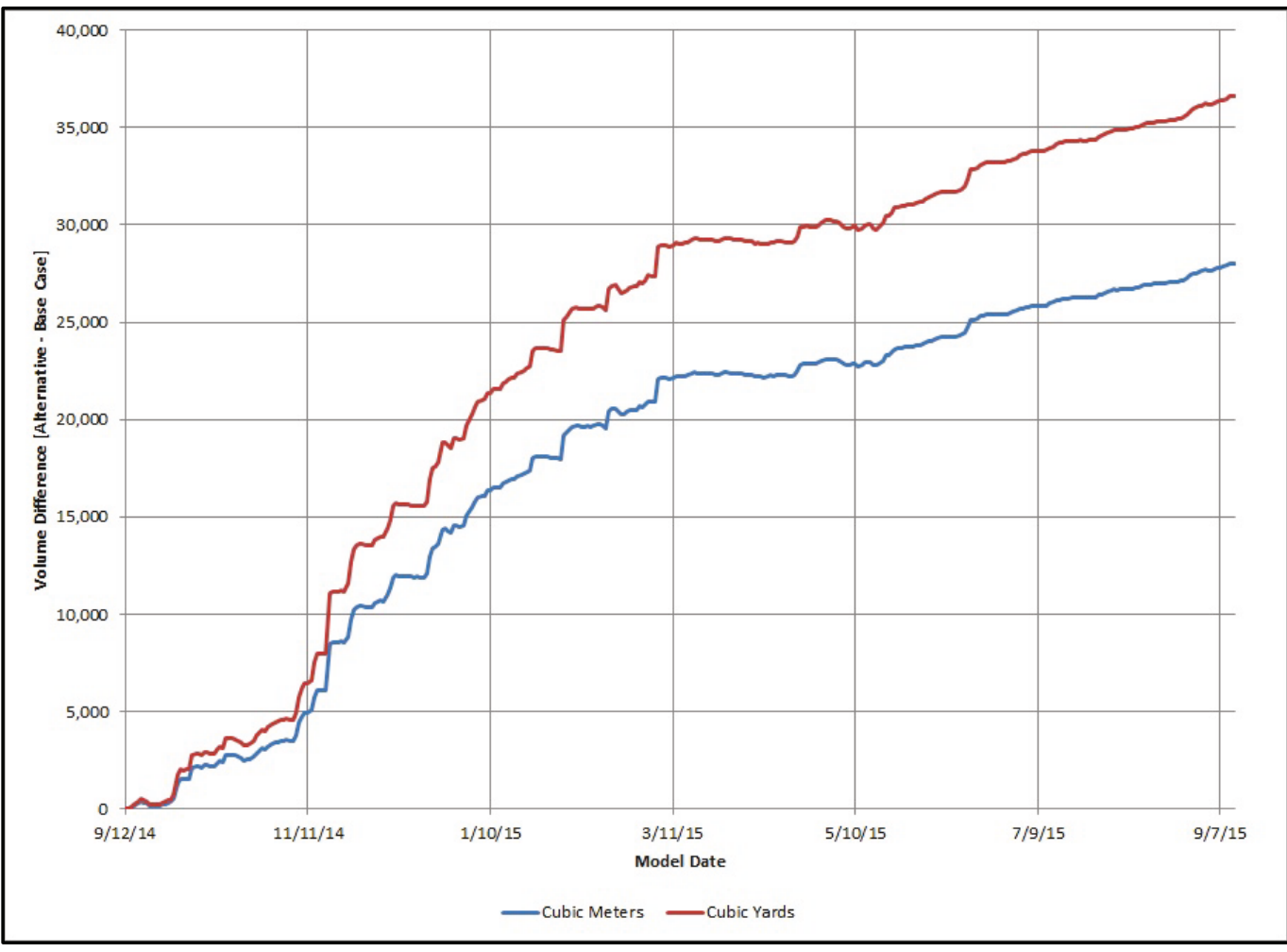




\section{Discussion}

The Final Engineering Appendix of the BSI, TX, Channel Improvement Project report (USACE 2014a; Table 2.6, page 14) indicates that for the Proposed $15.8 \mathrm{~m}$ ( $52 \mathrm{ft}$ ) Channel Deepening Project, there will be a maintenance dredging requirement of $540,090 \mathrm{~m}^{3}(706,000 \mathrm{yd} 3)$ of sediment every 1.5 years. This material will be removed from locations seaward of Station $0+000$ out to the seaward channel limit at $-17+000$. (The channel stationing is shown on Figure 8-1) This dredging estimate comes to approximately $360,100 \mathrm{~m} 3 /$ year $(470,700$ yd3/year).

The analysis from this study suggests that for shoaling on the flood shoal alone, the $15.8 \mathrm{~m}$ ( $52 \mathrm{ft}$ ) channel project will require an additional $28,300 \mathrm{~m}^{3}\left(37,000 \mathrm{yd}^{3}\right)$ of dredging (Figure 8-20) above the Base Case volume of $70,380 \mathrm{~m}^{3}(92,000 \mathrm{yd}$ ) (Figure 8-3) and that this volume is approximately half of the total amount needed to be dredged from the entire channel. Thus, the computed yearly dredge volume of $197,370 \mathrm{~m}^{3}$ $(258,000$ yd 3$)$ is a little over half of the District's estimate, indicating that the District's estimate is conservative. In addition, the modeling from this study indicates that the flood shoal can be expected to remain in the same location (Figure 8-19) and that the controlling depth over the flood shoal will decrease at a rate of approximately $1.8 \mathrm{~m}(6 \mathrm{ft})$ per year, rather than at the present rate of approximately $1.5 \mathrm{~m}(5 \mathrm{ft})$ per year.

\section{Summary}

Figure 8-21 compares the minimum controlling depths over the Brazos Santiago flood shoal for the six modeled alternatives. For the Jetty Straightening Alternative, the shoal eroded throughout the model year, and thus the controlling depth occurred at the beginning of the model run. For the other alternatives, it occurred at the end of the run. This plot is based upon 1-year model runs. However, for the In-Channel Sediment Trap Alternative, the controlling channel depth at the end of the second year is also shown as the red dot at $13.2 \mathrm{~m}(40.38 \mathrm{ft})$.

Figure 8-22 compares the accumulation volumes for each of the alternatives as the alternative volume divided by the Base Case volume. The red portion of the In-channel Sediment Trap bar shows the relative accumulation for the second year. Further summarization of each of the alternatives is provided in the executive summary at the beginning of this chapter. 
Figure 8-21. Minimum controlling depths over the Brazos Santiago Inlet flood shoal for the six modeled alternatives.

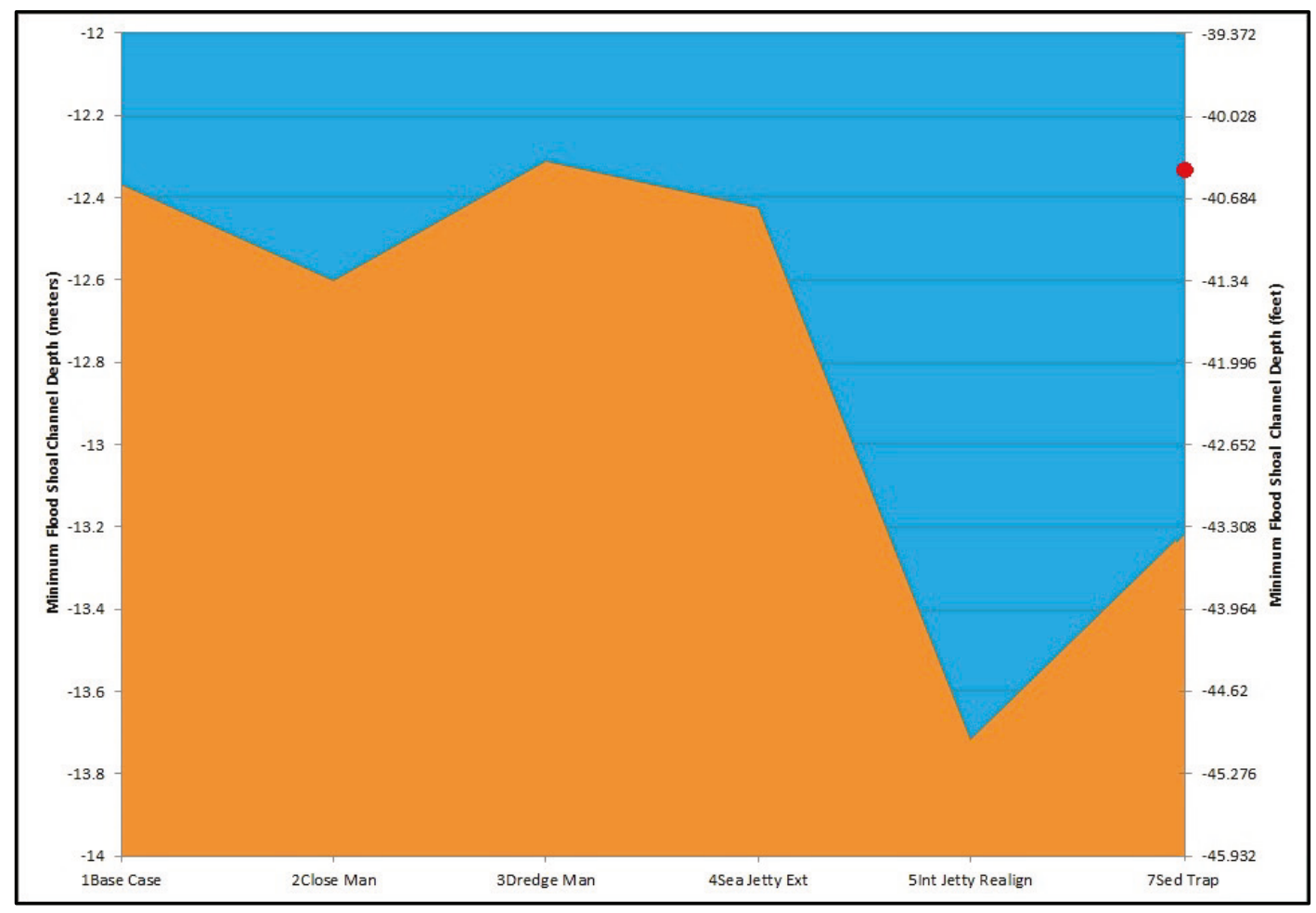

Figure 8-22. Relative accumulation volume for each of the alternatives.

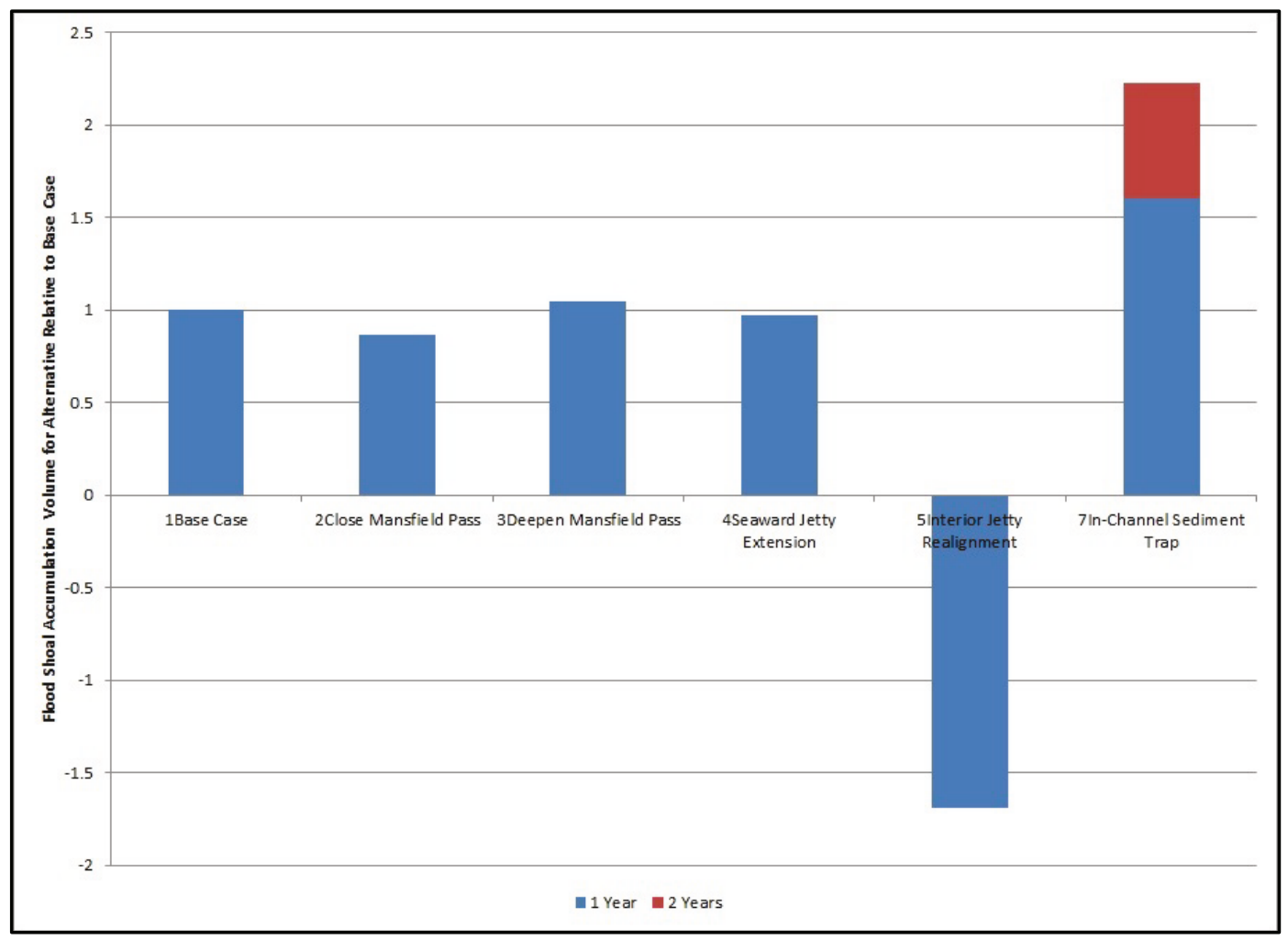




\section{Summary and Conclusions}

The Brazos Santiago Inlet (BSI) Project is a deep draft navigation channel in south Texas that has recently been experiencing localized channel shoaling. This localized channel shoaling, centered on -2+200, has reduced the navigable depth at these locations and has resulted in the implementation of draft restrictions. As part of the U.S. Army Corps of Engineers (USACE) Monitoring Completed Navigation Projects program, the study focus is to understand the shoaling processes in the BSI, and explored sand management alternatives to reduce inlet maintenance costs. To better understand the dynamics of the BSI, an extensive field collection effort was undertaken in 2014-2015. Deployed instruments included two Acoustic Wave and Current (AWAC) profilers, one inside the channel (inner) and another in the Gulf (outer), and four tide gages. Collected hydrodynamic data included tides, currents, and waves. Other collected data included multiple bed sediment grabs throughout Laguna Madre and intermittent bathymetry surveys within the immediate BSI study area.

The field data, as well as other agency gages within the area, supported a numerical modeling effort using the Coastal Modeling System (CMS-Flow and CMS-Wave). The purpose of the modeling is to gain insight into the complex circulation, wave action, and sediment deposition patterns of the area. The CMS model demonstrated high accuracy in predicting water levels at tide gages in the vicinity of the BSI and at those with strong tidal signals.

However, in northern and interior Laguna Madre, where wind is the dominant forcing, the model does not predict water levels as well. The depth-integrated velocities measured by the inner AWAC were modeled considerably better than those measured by the outer AWAC. CMS-Wave does an adequate job representing the wave climate at both the inner and outer AWAC. The bed change predicted by CMS was much more active than the measurements, with localized areas of extreme erosion. However, the model was able to effectively reproduce the localized shoaling within the navigation channel.

Eight alternatives, including the Base Case (present condition) as a do-nothing condition, were explored as possible actions for managing the localized shoaling. Of these eight alternatives, two were unable to be modeled by CMS but are discussed for completeness. 


\section{Alternatives for managing the BSI localized shoaling}

\section{Base Case (present condition)}

The Base Case is a do-nothing condition against which potential alternatives were compared.

\section{Close Mansfield Pass Alternative}

Numerical modeling indicates that closing Mansfield Pass could be expected to contribute to approximately a $15 \%$ shoaling decrease in the shoaling volume throughout the BSI. However, counter-intuitively, the modeling also suggests that where the shoaling rates are greatest, localized high spots in the channel might be slightly higher if Mansfield Pass were closed.

The wind-driven circulation patterns in the lagoon system (flow counterclockwise in winter and clockwise in summer) lead to a replacement of the hypersaline lagoon water with lower salinity water from the Gulf of Mexico. This current also flushes pollutants and low-oxygen water from the lagoon. Closing Mansfield Pass would cut off this circulation pattern. Additional consequences could include the disruption of fish migration patterns. It is expected that these types of environmental concerns would significantly exceed any benefits derived from decreasing the shoaling rate in the BSI.

\section{Deepen Mansfield Pass Alternative}

This alternative was modeled with Mansfield Pass deepened from its

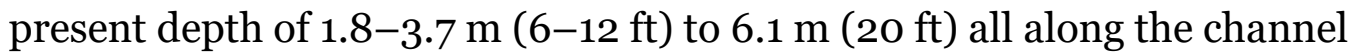
from the Gulf of Mexico to the channel's intersection with the GIWW adjacent to Port Mansfield.

This study has shown that deepening Mansfield Pass would increase the costs of channel maintenance at the BSI. This would occur because deepening Mansfield Pass would increase the circulation through the Brazos-Laguna Madre-Mansfield system (counterclockwise in winter and clockwise in summer). However, this increased circulation would also be expected to provide environmental benefits in the form of improved water quality. A deeper inlet is also favored by the residents of Port Mansfield as this would allow the inlet to be traversed by larger vessels. 


\section{Seaward Jetty Extension Alternative}

For this alternative, both the north and south jetty ends were extended $152 \mathrm{~m}$ (500 ft) seaward of their present positions.

The results of this alternative analysis did not demonstrate any result other than minor changes in the shoaling rate. In addition, the model was only run for 1 year, and it was not clear that nearshore bathymetry in the vicinity of the jetties had equilibrated to the new jetty length over that time period. Thus, a longer model run time would be required to definitively demonstrate what future shoaling rates could be expected. It was also assumed that any dredging reduction benefits from this alternative would be small compared to the jetty construction costs, which are expected to be significant, but this study did not perform an economic analysis.

\section{Interior Jetty Straightening Alternative}

This alternative models the conditions at the inlet if the interior portion of the jetties were straightened, removing the influence of the bulges in the north and south shorelines. The model results for this alternative with the straight and parallel jetties through the length of the inlet show that the current velocities remain essentially constant through the whole inlet.

This alternative clearly does an excellent job of solving the shoaling problem where it presently occurs in the vicinity of Channel Station -2200. However, it is reasonable to assume that this is merely shifting the shoaling problem to a different location farther westward along the Brownsville ship channel where it traverses the south end of Laguna Madre. Because the numerical model ran for only 1 year, the centroid of the new flood shoal location (if there were to be one) was not well defined. A potential downside of a new flood shoal that was farther westward than its present location would be that the costs to transport the dredged material to South Padre Island beaches would be higher.

\section{Heighten Jetties Alternative}

It is clear that an unknown, but possibly significant, amount of sediment transport into the BSI is aeolian (wind driven). However, quantification of this transport rate through field measurements or analysis of winds is difficult. For that reason and also because the version of the numerical model used in this study is not presently capable of incorporating this type 
of additional sediment input, this alternative was not modeled in this study. If future studies quantify and conclude that aeolean transport of sediments into the inlet is an important pathway, one way to address the issue would be to raise the height of the jetties over a limited span. It is recognized that merely raising the jetty height is only a temporary solution until sand fills against the jetty to its new height. For long-term control of this issue, this would need to be combined with a method of passing the sediments onto downstream beaches.

\section{In-Channel Sediment Trap Alternative}

Present dredging operations at the BSI involve bringing a seagoing dredge to the inlet on an approximately yearly basis. One method to increase the amount of time between the BSI dredging events would be to deepen the channel at the location where the most extensive shoaling occurs. This would be expected to decrease the mobilization costs of bring a dredge to the inlet every year. It would not, however, be expected to decrease the total volume of sediment dredged. A larger volume of sediment would be moved less frequently, but the total volume over time would remain the same. This alternative looks at the impacts of having an in-channel sediment trap located at the flood shoal within the BSI.

The trap that was designed for numerical modeling would hold $153,000 \mathrm{~m}^{3}(200,000 \mathrm{yd} 3)$, the average volume dredged in a year. The channel minimum elevation after 2 years for the In-Channel Sediment Trap is slightly less than for 1 year for the Base Case and would thus save dredge mobilization costs over a 2-year time increment by approximately $50 \%$. Because the initial trench in the channel is deeper for this alternative, sediment would be expected to collect at a somewhat faster rate than for the Base Case. Additional model runs could be made to optimize the size and shape of the trap.

\section{Dedicated Dredging Plant Alternative}

An alternative to bringing an ocean-going dredge to the inlet each time it is needed could be to have a much smaller capacity dredge permanently located at the site. One advantage to this type of system is that the sediment accumulates in the BSI at a location that is very close to where it is needed on the beaches of South Padre Island. A permanent distribution system of pipes buried beneath the dunes on SPI could be constructed. A system such as this would have high up-front costs but could have much 
lower overall lifetime costs and could more precisely distribute sediment to where it is needed along South Padre Island.

This study did not model this alternative because the present version of the model does not allow for the bathymetry to be altered by the user during a model run. Proposed model upgrades will address this issue. The final design for this type of system could also combine elements of this alternative with the In-Channel Sediment Trap Alternative. Additional modeling is needed. However, initial economic studies could be undertaken to obtain a rough estimate of how overall costs would compare with present methodology.

\section{Proposed $15.8 \mathrm{~m}$ (52 ft) Channel Deepening Project}

CESWG has developed plans to increase the draft of the Brownsville Ship Channel to $15.8 \mathrm{~m}$ ( $52 \mathrm{ft}$ ). Thus, CESWG requested that an additional model run be made to examine the infilling associated with this proposed channel. While this is not an alternative in the same sense as those discussed above, the model run and post-run analysis are similar.

The analysis from this study suggests that for shoaling on the flood shoal alone, the $15.8 \mathrm{~m}$ (52 ft) channel project will require an additional 28,300 $\mathrm{m}^{3}(37,000 \mathrm{yd} 3)$ of dredging above the Base Case volume of $70,380 \mathrm{~m}^{3}$ (92,000 $\left.\mathrm{yd}^{3}\right)$ and that this volume is approximately half of the total amount needed to be dredged from the entire channel. Thus, the computed yearly dredge volume of $197,370 \mathrm{~m}^{3}(258,000 \mathrm{yd} 3)$ is a little over half of the District's estimate, indicating that the District's estimate is conservative. In addition, the modeling from this study indicates that the flood shoal can be expected to remain in the same location and that the controlling depth over the flood shoal will decrease at a rate of approximately $1.8 \mathrm{~m}(6 \mathrm{ft})$ per year rather than at the present rate of approximately $1.5 \mathrm{~m}(5 \mathrm{ft})$ per year. 


\section{References}

Alperin, L. M. 1983. History of the Gulf Intracoastal Waterway. Washington DC: U.S. Army Corps of Engineers, Institute for Water Resources.

Aubrey, D. G., and P. E. Speer. 1985. "A Study of Non-Linear Tidal Propagation in Shallow Inlet/Estuarine Systems: Part I Observations.” Estuarine, Coastal, and Shelf Science 21(2): 185-205.

Bales, J. D., and E. R. Holley. 1989. "Sand Transport in Texas Tidal Inlet.” Journal of Waterway, Port, Coastal, and Ocean Engineering 115(4): 427-443.

Beven, John L., II. 2015. Tropical Storm Dolly; 1-3 September 2014. Tropical Storm Report AL052014. Miami, FL: National Hurricane Center. http://www.nhc.noaa.gov/data/tcr/AL052014_Dolly.pdf.

Boon, J. D., and R. J. Byrne. 1981. "On Basin Hyposmetry and the Morphodynamic Response of Coastal Inlet Systems.” Marine Geology 40(1-2): 27-48.

Bray, R. N., A. D. Bates, and J. M. Land. 1997. Dredging: A Handbook for Engineers. ISBN o 34054524 O. London: Arnold.

Breuer, J. P. 1962. "An Ecological Survey of the Lower Laguna Madre of Texas, 19531959." Publications of the Institute of Marine Science, University of Texas 8(15): $153-183$.

Dean, Robert G., and Robert A. Dalrymple. 1991. Water Wave Mechanics for Engineers and Scientists: Advanced Series on Ocean Engineering; Volume 2. Teaneck, NJ: World Scientific Publishers.

Diener, R. A. 1975. Cooperative Gulf of Mexico Estuarine Inventory and Study, Texas: Area Description. NMFS CIRC-393. Seattle, WA: U.S. Department of Commerce, National Oceanic and Atmospheric Administration, National Marine Fisheries Service

Frey, A., A. Morang, and D. B. King. 2016. Galveston Island Texas Sand Management Strategies. ERDC/CHL TR 16-13. Vicksburg, MS: U.S. Army Engineer Research and Development Center.

Gill, S. K., J. R. Hubbard, and G. Dingle. 1995. Tidal Characteristics and Datums of Laguna Madre, Texas. NOS OES 008. Silver Spring, MD: U.S. Department of Commerce, National Oceanic and Atmospheric Administration, National Ocean Service

Hansen, E. A. 1960. "Studies of a Channel through Padre Island Texas." In Proceedings of the American Society of Civil Engineering, Journal of the Waterways and Harbors Division 86(WW3): 63-82.

Hauck, L. M., and B. Brown, Jr. 1990. Numerical Modeling of Hydrodynamics: Brazos Island Harbor Project, Texas (Brownsville Ship Channel). TR HL-90-5. Vicksburg, MS: U.S. Army Engineer Waterways Experiment Station. 
Heilman, D. J., and B. L. Edge. 1996. "Interaction of the Colorado River Project, Texas, with Longshore Sediment Transport." In Coastal Engineering 1996, Proceedings of the Twenty-Fifth International Conference.

Henningson, Durham, and Richardson (HDR). 2009. Desktop Evaluation of Shoaling: Federal Feasibility Study to Deepen and Widen the Brownsville Ship Channel. Corpus Christi, TX. Report prepared for Port of Brownsville, TX. Corpus Christi, TX: HDR.

Hrametz, J. 2013. Increased Shoal Rate within the Brazos Santiago Inlet Project: Problem Statement for Monitoring Completed Navigation Projects (MCNP) Program. Galveston, TX: U.S. Army Corps of Engineers, Galveston District.

IBWC. 2010. International Boundary and Water Commission Press Releases. 8 July and 16 August 2010.http://www.ibwc.state.gov/News_Publications/10_Press_Releases.htm.

Keislich, J. M. 1977. A Case History of Port Mansfield Channel, Texas. Fort Belvoir, VA: U.S. Army Coastal Engineering Research Center and Vicksburg, MS: U.S. Army Engineer Waterways Experiment Station.

Kraus, N. C. 2007. “Coastal Inlets of Texas, USA.” In Coastal Sediments 'o7, Sixth International Symposium on Coastal Engineering and Science of Coastal Sediment Process, 1475-1488.

Kraus, N. C., and D. J. Heilman. 1997. Packery Channel Feasibility Study: Inlet Functional Design and Sand Management. Report 1 of a Two-Part Series. Final Report. Technical Report TAMU-CC-CBI-96-06. Corpus Christi, TX: Texas A\&M University.

Larking, T. J., and G. W. Bomar. 1983. Climatic Atlas of Texas. Austin, TX: Texas Department of Water Resources.

Lin, L., Z. Demirbilek. H. Mase, J. Zheng, and F. Yamada. 2008. CMS-Wave: A Nearshore Spectral Wave Processes Model for Coastal Inlets and Navigation Projects. ERDC/CHL TR-o8-13.Vicksburg, MS: U.S. Army Engineer Research and Development Center.

Longley, W. L., ed. 1994. Freshwater Inflows to Texas Bays and Estuaries: Ecological Relationships and Methods for Determination of Needs. Austin, TX: Texas Water Development Board, and Texas Parks and Wildlife Department.

Mase, H. 2001. "Multi-Directional Random Wave Transformation Model Based on Energy Balance Equation." Coastal Engineering Journal 43(04): 317-337.

McGowen, J. H., L. E. Garner, and B. H. Wilkinson. 1977. The Gulf Shoreline of Texas: Processes, Characteristics, and Factors in Use. Geological Circular 77-3. Austin, TX: University of Texas, Bureau of Economic Geology.

Miller, J. A. 1975. "Facies Characteristics of Laguna Madre Wind-Tidal Flats.” In Tidal Deposits, ed. R. N. Ginsburg, 67-73. New York, NY: Springer-Verlag.

Morang, A. 2006. North Texas Sediment Budget: Sabine Pass to San Luis Pass. ERDC/CHL-TR-06-17. Vicksburg, MS: U.S. Army Engineer Research and Development Center. 
Morton, R. A., and C. W. Holmes. 2009. "Geological Processes and Sedimentation Rates of Wind-Tidal Flats, Laguna Madre, Texas.” Gulf Coast Association of Geological Societies Transactions, No. 59: 519-538.

National Renewable Energy Laboratory (NREL). 2011. U.S. Average Annual Wind Speed at 80 Meters. Washington, DC: U.S. Department of Energy. https://windexchange.energy.gov/maps-data?height=80m.

Port Authority Advisory Committee (PAAC). Texas Ports 2015-2016 Capital Program: Executive Summary. Texas Ports Advisory Committee. https://ftp.dot.state.tx.us/pub/txdot-info/tpp/giww/port-capital-plan-2015-16.pdf.

Ranasinghe, R., and C. Pattiaratchi. 2000. "Tidal Inlet Velocity Asymmetry in Diurnal Regimes.” Continental Shelf Research 20(17): 2347-2366.

Sánchez, A., and W.Wu. 2011a. "A Non-Equilibrium Sediment Transport Model for Coastal Inlets and Navigation Channels." Journal of Coastal Research, Special Issue 59: 39-48.

Sánchez, A., W. Wu, T. Beck, H. Li, J. Rosati III, R. Thomas, J. Rosati, Z. Demirbilek, M. Brown, and C. Reed. 2011b. Verification and Validation of the Coastal Modeling System, Report 3, CMS-Flow: Hydrodynamics. ERDC/CHL TR-11-10. Vicksburg, MS: U.S. Army Engineer Research and Development Center.

Sánchez, A., W. Wu, H. Li, M. Brown, C. Reed, J. Rosati, and Z. Demirbilek. 2014. Coastal Modeling System: Mathematical Formulations and Numerical Methods. ERDC/CHL TR-14-2. Vicksburg, MS: U.S. Army Engineer Research and Development Center.

Sargent, F. E., and R. R. Bottin, Jr. 1989. Case Histories of Corps Breakwater and Jetty Structures. TR REMR-CO-3. Report 3: North Central Division. Vicksburg, MS: U.S. Army Engineer Waterways Experiment Station.

Schoenbaechler, C., and C. G. Guthrie. 2011. Coastal Hydrology for the Laguna Madre Estuary, with Emphasis on the Lower Laguna Madre. Austin, TX: Texas Water Development Board, Surface Water Resources Division, Bay and Estuaries Program.

http://www.twdb.texas.gov/surfacewater/bays/major_estuaries/laguna_madre/doc/TWDB_Hy drology_UpperLagunaM_20110921.pdf.

Tate, J., and C. G. Ross. 2012. Brownsville Ship Channel Hydrodynamic Modeling. ERDC/CHL TR-12-6. Vicksburg, MS: U.S. Army Engineer Research and Development Center.

Texas Department of Water Resources (TDWR). 1983. Laguna Madre Estuary: A Study of the Influence of Freshwater Inflows. LP-182. Austin, TX: Texas Department of Water Resources.

Tompkins, Shannon. 2010. "Lower Laguna Madre's Salinity Lowered by Storm Runoff." Houston, TX: Houston Chronicle, 12 September 2010. http://www.chron.com/sports/outdoors/article/Lower-Lauuna-Madre-s-salinity-lowered-bystorm-1699418.php. 
Tunnell, J. W., Jr., and F. W. Judd, eds. 2002. The Laguna Madre of Texas and Tamaulipas. College Station, TX: Texas A\&M University Press.

U.S. Army Corps of Engineers (USACE). 1977. Brazos Island Harbor, Texas: Brownsville Channel; Environmental Statement. Galveston, TX: U.S. Army Engineer District, Galveston.

1992. Inlets along the Texas Gulf Coast: Planning Assistance to States Program; Section 22 Report. Galveston, TX: U.S. Army Engineer District, Galveston.

. 1993a. Activities to Reduce Erosion Losses along the Texas Gulf Coast; Coast: Planning Assistance to States Program; Section 22 Report. Galveston, TX: U.S. Army Engineer District, Galveston.

.1993b. Requirements and Procedures for Referencing Coastal Navigation Projects to Mean Lower Low Water Datum. Engineer Technical Letter 1110-2349. Washington, DC: Headquarters, U.S. Army Corps of Engineers.

. 2002. Hydrographic surveying. Engineer Manual 1110-2-1003. Washington, D.C.: Headquarters, U.S. Army Corps of Engineers.

. 2014a. Brazos Island Harbor, Texas: Channel Improvement Project; Final Engineering Appendix. Galveston, TX: U.S. Army Engineer District, Galveston.

. 2014b. Brazos Island Harbor, Texas: Channel Improvement Project; Final Integrated Feasibility Report and Environmental Assessment. Galveston, TX: U.S. Army Engineer District, Galveston.

2014c. Channel to Port Mansfield, Texas; Fact Sheet. Galveston, TX: U.S. Army Engineer District, Galveston.

Watson, R. L. 1971. “Origin of Shell Beaches, Padre Island, Texas.” Journal of Sedimentary Petrology 41(4): 1105-1111.

Watson, R. L. 1979. Geological History of South Padre Island Wind-Tidal Flats, Port Aransas. http://www.texascoastgeology.com/papers/southpadre.pdf.

Willmott, C. J., S. M. Robeson, and K. Matsuura. 2012. "A Refined Index of Model Performance.” International Journal of Climatology 32(13): 2088-2094. 


\section{Appendix A: Datums}

\section{Horizontal datum}

The horizontal datum used for coordinate data input into the models and for presentation in final reports for this study was State Plane Texas South, 4205, NAD83 (which is unchanged from NAD27). Where necessary, horizontal coordinates in other datums were converted to this datum using the conversion program Corpscon, version 6.0.1, available at http://www.tec.army.mil/.

\section{Vertical datum}

The vertical datum used in in this study was mean sea level (MSL). Where necessary to convert data from other vertical datums, the relationships derived from tidal records collected at the Bob Hall Pier near Corpus Christi, TX, (NOAA Tide Station 8775870, located at $27^{\circ} 34.8^{\prime} \mathrm{N}, 97^{\circ}$ 13.0' W) were used (Table A-1).

Table A-1. Vertical datum relationships at the Bob Hall Pier, Corpus Christi, TX, NOAA Tide Station 8775870.

\begin{tabular}{|l|l|l|}
\hline Datum & $\begin{array}{l}\text { Value } \\
(\mathrm{ft})\end{array}$ & Description \\
\hline \hline MHHW & 22.47 & mean higher-high water \\
\hline MHW & 22.38 & mean high water \\
\hline MTL & 21.72 & mean tide level \\
\hline MSL & 21.77 & mean sea level \\
\hline DTL & 21.66 & mean diurnal tide level \\
\hline MLW & 21.07 & mean low water \\
\hline MLLW & 20.84 & mean lower-low water \\
\hline NAVD88 & 21.29 & North American Vertical Datum of 1988 \\
\hline STND & 0.00 & station datum \\
\hline GT & 1.63 & great diurnal range \\
\hline MN & 1.31 & mean range of tide \\
\hline DHQ & 0.10 & mean diurnal high water inequality \\
\hline DLQ & 0.22 & mean diurnal low water inequality \\
\hline
\end{tabular}

Both USACE Engineer Technical Letter 110-2-349, Engineering and Design; Requirements and Procedures for Referencing Coastal Navigation Projects to Mean Lower Low Water Datum (USACE 1993b), and USACE Engineer Manual 1110-2-1003, Engineering and 
Design; Hydrographic Surveying (USACE 2002), stress the necessity of converting local datum such as mean low tide (MLT) to MLLW. EM 1110-2-1003 further states that MLLW should be tied to the North American Vertical Datum (NAVD) 88. The predominant reason for conversion to MLLW is the need for consistency within the shipping and dredging industries with regard to channel depths.

Historically, the USACE Galveston District has used the MLT datum for its navigation channels. As noted in the regulations and guidance above, this datum was recently converted to MLLW for consistency with other USACE Districts. MLLW datum was used for all quantity calculations during plan formulation. For the BSI conversion, on average, the MLT/MLLW difference is $+0.31 \mathrm{ft}$. Because this difference was so small and it would have little to no effect on dredging quantities, the study addresses MLT as equal to MLLW for conversion from historic dredging records and drawings. Therefore, $-42 \mathrm{ft}$ MLT is considered equal to $-42 \mathrm{ft}$ MLLW. The elevations of dredged material placement areas are referenced to NAVD 88. 


\section{Appendix B: Sediment Sampling Data}

Bottom sediment grab sample locations.

Table B-1. Laguna Madre 2014: Brazos bed sample locations.

\begin{tabular}{|l|l|l|l|l|}
\hline SAMPLE NAME & $\begin{array}{l}\text { EASTING } \\
\text { (UTM14N_M) }\end{array}$ & $\begin{array}{l}\text { NORTHING } \\
\text { (UTM14N_M) }\end{array}$ & LATITUDE & LONGITUDE \\
\hline Brazos MPI-1 & 672808.54 & 2938617.37 & $263327.7018 \mathrm{~N}$ & $0971554.5105 \mathrm{~W}$ \\
\hline Brazos MPI-2 & 672659.98 & 2939359.18 & $263351.8685 \mathrm{~N}$ & $0971559.515 \mathrm{~W}$ \\
\hline Brazos MPI-3 & 672482.27 & 2940042.77 & $263414.1565 \mathrm{~N}$ & $097165.6017 \mathrm{~W}$ \\
\hline Brazos MPI-4 & 671665.8 & 2939282.39 & $263349.8095 \mathrm{~N}$ & $0971635.4721 \mathrm{~W}$ \\
\hline Brazos MPI-5 & 670165.36 & 2939213.96 & $263348.2393 \mathrm{~N}$ & $0971729.7161 \mathrm{~W}$ \\
\hline Brazos MPI-6 & 666849.56 & 2939024.3 & $263343.5 \mathrm{~N}$ & $0971929.6071 \mathrm{~W}$ \\
\hline Brazos MPI-7 & 663360.99 & 2938813.5 & $263338.1176 \mathrm{~N}$ & $0972135.7491 \mathrm{~W}$ \\
\hline Brazos S-1 & 680911.58 & 2887036.93 & $260528.2201 \mathrm{~N}$ & $0971127.8702 \mathrm{~W}$ \\
\hline Brazos S-10 & 669119.24 & 2912207.62 & $261911.2229 \mathrm{~N}$ & $0971820.3651 \mathrm{~W}$ \\
\hline Brazos S-11 & 668125.72 & 2915302.7 & $262052.21 \mathrm{~N}$ & $0971854.7299 \mathrm{~W}$ \\
\hline Brazos S-12 & 665434.93 & 2920864.65 & $262354.0619 \mathrm{~N}$ & $0972029.1895 \mathrm{~W}$ \\
\hline Brazos S-13 & 663404.3 & 2925753.45 & $262633.7542 \mathrm{~N}$ & $0972140.2085 \mathrm{~W}$ \\
\hline Brazos S-14 & 661239.59 & 2933125.82 & $263034.1899 \mathrm{~N}$ & $0972255 \mathrm{~W}$ \\
\hline Brazos S-15 & 659719.17 & 2941048.33 & $263452.23 \mathrm{~N}$ & $0972346.3199 \mathrm{~W}$ \\
\hline Brazos S-16 & 658206.11 & 2945054.42 & $26373 \mathrm{~N}$ & $0972439.2001 \mathrm{~W}$ \\
\hline Brazos S-17 & 656530.35 & 2949880.7 & $263940.5 \mathrm{~N}$ & $0972537.6298 \mathrm{~W}$ \\
\hline Brazos S-18 & 654061.25 & 2955667.25 & $264249.4999 \mathrm{~N}$ & $097274.3801 \mathrm{~W}$ \\
\hline Brazos S-19 & 652949.21 & 2960481.07 & $264526.3501 \mathrm{~N}$ & $0972742.5102 \mathrm{~W}$ \\
\hline Brazos S-2 & 680213.73 & 2888563.07 & $260618.1201 \mathrm{~N}$ & $0971152.2201 \mathrm{~W}$ \\
\hline Brazos S-20 & 676701.52 & 2887032.99 & $260529.97 \mathrm{~N}$ & $0971359.36 \mathrm{~W}$ \\
\hline Brazos S-21 & 674372.07 & 2889793.68 & $26070.6901 \mathrm{~N}$ & $0971521.8501 \mathrm{~W}$ \\
\hline Brazos S-22 & 672975.58 & 2893638.14 & $26096.2101 \mathrm{~N}$ & $0971610.27 \mathrm{~W}$ \\
\hline Brazos S-23 & 672113.32 & 2897163.56 & $26111.1302 \mathrm{~N}$ & $0971639.6301 \mathrm{~W}$ \\
\hline Brazos S-24 & 671366.02 & 2901073.71 & $26138.5001 \mathrm{~N}$ & $097174.6799 \mathrm{~W}$ \\
\hline Brazos S-25 & 681389.7 & 2885573.01 & $260440.4401 \mathrm{~N}$ & $0971111.3999 \mathrm{~W}$ \\
\hline Brazos S-26 & 682007.36 & 2884573.33 & $26047.68 \mathrm{~N}$ & $0971049.6801 \mathrm{~W}$ \\
\hline Brazos S-27 & 683363.21 & 2884323.63 & $260358.9499 \mathrm{~N}$ & $097101.0302 \mathrm{~W}$ \\
\hline Brazos S-28 & 684127.78 & 2884512.31 & $26044.7301 \mathrm{~N}$ & $0970933.4299 \mathrm{~W}$ \\
\hline
\end{tabular}




\begin{tabular}{|c|c|c|c|c|}
\hline SAMPLE NAME & \begin{tabular}{|l|} 
EASTING \\
(UTM14N_M)
\end{tabular} & \begin{tabular}{|l|} 
NORTHING \\
(UTM14N_M)
\end{tabular} & LATITUDE & LONGITUDE \\
\hline Brazos S-29 & 684190.96 & 2883935.8 & $260345.9701 \mathrm{~N}$ & $0970931.45 \mathrm{~W}$ \\
\hline Brazos S-3 & 679530.66 & 2890559.11 & $260723.28 \mathrm{~N}$ & $0971215.8101 \mathrm{~W}$ \\
\hline Brazos S-30 & 684411.6 & 2884216.84 & $260355 \mathrm{~N}$ & $0970923.37 \mathrm{~W}$ \\
\hline Brazos S-31 & 684636.35 & 2884246.19 & $260355.8501 \mathrm{~N}$ & $0970915.2701 \mathrm{~W}$ \\
\hline Brazos S-32 & 684835.22 & 2884277.94 & $260356.7901 \mathrm{~N}$ & 097098.0999 W \\
\hline Brazos S-33 & 685012.82 & 2884299.54 & $260357.4101 \mathrm{~N}$ & $097091.7 \mathrm{~W}$ \\
\hline Brazos S-34 & 685211.12 & 2884312.51 & $260357.74 \mathrm{~N}$ & $0970854.5599 \mathrm{~W}$ \\
\hline Brazos S-35 & 685305.93 & 2883998.38 & $260347.4901 \mathrm{~N}$ & 0970851.3098 W \\
\hline Brazos S-36 & 685579.75 & 2884017.66 & $260348 \mathrm{~N}$ & $0970841.45 \mathrm{~W}$ \\
\hline Brazos S-37 & 684891.18 & 2884565.89 & $26046.1199 \mathrm{~N}$ & 097095.9399 W \\
\hline Brazos S-38 & 685300.42 & 2884581.24 & $26046.4299 \mathrm{~N}$ & 0970851.2101 W \\
\hline Brazos S-39 & 685290.34 & 2883745.15 & $260339.2698 \mathrm{~N}$ & $0970852 \mathrm{~W}$ \\
\hline Brazos S-4 & 678611.31 & 2892802.46 & $260836.58 \mathrm{~N}$ & $0971247.79 \mathrm{~W}$ \\
\hline Brazos S-40 & 685274.55 & 2883427.91 & $260328.97 \mathrm{~N}$ & $0970852.7302 \mathrm{~W}$ \\
\hline Brazos S-41 & 685268.43 & 2883095.42 & $260318.1701 \mathrm{~N}$ & $0970853.1202 \mathrm{~W}$ \\
\hline Brazos S-42 & 685224.79 & 2882703.91 & $26035.47 \mathrm{~N}$ & $0970854.8898 \mathrm{~W}$ \\
\hline Brazos S-43 & 684834.75 & 2884859.64 & $260415.6899 \mathrm{~N}$ & 097097.8201 W \\
\hline Brazos S-44 & 684697.36 & 2885139.63 & $260424.8501 \mathrm{~N}$ & $0970912.62 \mathrm{~W}$ \\
\hline Brazos S-45 & 684570.22 & 2885402.83 & $260433.4601 \mathrm{~N}$ & $0970917.0599 \mathrm{~W}$ \\
\hline Brazos S-46 & 684482.53 & 2885667.51 & $260442.0999 \mathrm{~N}$ & $0970920.0799 \mathrm{~W}$ \\
\hline Brazos S-47 & 682699.16 & 2883784.93 & $260341.7501 \mathrm{~N}$ & $0971025.1901 \mathrm{~W}$ \\
\hline Brazos S-48 & 682011.79 & 2883300.11 & $260326.3102 \mathrm{~N}$ & $0971050.16 \mathrm{~W}$ \\
\hline Brazos S-49 & 680836.58 & 2882525.7 & $26031.6799 \mathrm{~N}$ & $0971132.8201 \mathrm{~W}$ \\
\hline Brazos S-5 & 677839.67 & 2895090.35 & $260951.2599 \mathrm{~N}$ & $0971314.44 \mathrm{~W}$ \\
\hline Brazos S-50 & 681736.59 & 2882221.2 & $260251.3801 \mathrm{~N}$ & 097110.5999 W \\
\hline Brazos S-51 & 679280.64 & 2882296.79 & $260254.9399 \mathrm{~N}$ & $0971228.8998 \mathrm{~W}$ \\
\hline Brazos S-6 & 676181.6 & 2898462.51 & $261141.56 \mathrm{~N}$ & $0971412.4899 \mathrm{~W}$ \\
\hline Brazos S-7 & 674622.01 & 2901445.9 & $261319.18 \mathrm{~N}$ & $097157.2101 \mathrm{~W}$ \\
\hline Brazos S-8 & 673711.58 & 2904458.76 & $261457.4699 \mathrm{~N}$ & $0971538.5499 \mathrm{~W}$ \\
\hline Brazos S-9 & 671931.33 & 2908725.63 & $261716.8799 \mathrm{~N}$ & $0971640.6501 \mathrm{~W}$ \\
\hline
\end{tabular}


Table B-2. Laguna Madre 2014: Brazos bed samples, including grain size distribution, sediment classification, and statistical deviations for all samples listed in Table B-1.

\begin{tabular}{|c|c|c|c|c|c|c|c|c|c|c|c|c|c|c|}
\hline $\begin{array}{l}\text { Sample } \\
\text { Name }\end{array}$ & Clay & Silt & Vf_sand & F_sand & Md_sand & C_sand & Vc_sand & Gravel & Pebble & d10 & d16 & d50 & d84 & d90 \\
\hline $\begin{array}{l}\text { Brazos MPI- } \\
118^{\prime}\end{array}$ & 0.00 & 0.03 & 29.61 & 64.29 & 5.53 & 0.00 & 0.21 & 0.33 & 0.00 & 98.11 & 107.22 & 149.84 & 210.31 & 230.62 \\
\hline $\begin{array}{l}\text { Brazos MPI- } \\
220^{\prime}\end{array}$ & 0.00 & 0.01 & 26.95 & 66.57 & 6.36 & 0.00 & 0.09 & 0.02 & 0.00 & 101.13 & 110.45 & 153.41 & 213.85 & 234.07 \\
\hline $\begin{array}{l}\text { Brazos MPI- } \\
325^{\prime}\end{array}$ & 0.95 & 7.10 & 37.94 & 47.67 & 4.45 & 0.00 & 0.17 & 1.71 & 0.00 & 68.21 & 81.35 & 130.78 & 201.00 & 226.32 \\
\hline $\begin{array}{l}\text { Brazos MPI- } \\
421^{\prime}\end{array}$ & 0.00 & 0.00 & 0.31 & 31.28 & 56.71 & 8.20 & 2.09 & 1.41 & 0.00 & 185.46 & 205.68 & 301.78 & 457.63 & 525.78 \\
\hline $\begin{array}{l}\text { Brazos MPI } \\
-515^{\prime}\end{array}$ & 0.00 & 0.00 & 2.58 & 66.77 & 30.52 & 0.00 & 0.13 & 0.00 & 0.00 & 147.77 & 160.76 & 215.23 & 288.50 & 312.33 \\
\hline $\begin{array}{l}\text { Brazos MPI } \\
-617^{\prime}\end{array}$ & 0.00 & 0.00 & 0.09 & 47.88 & 51.32 & 0.09 & 0.37 & 0.25 & 0.00 & 181.55 & 195.00 & 253.47 & 330.40 & 355.39 \\
\hline $\begin{array}{l}\text { Brazos MPI- } \\
716^{\prime}\end{array}$ & 0.20 & 1.41 & 0.80 & 45.96 & 49.13 & 1.16 & 0.82 & 0.53 & 0.00 & 163.74 & 181.09 & 253.52 & 353.56 & 390.44 \\
\hline $\begin{array}{l}\text { Brazos S-1 } \\
5^{\prime}\end{array}$ & 3.99 & 29.95 & 17.03 & 24.20 & 12.92 & 0.25 & 11.66 & 0.00 & 0.00 & 8.41 & 15.78 & 121.13 & 354.25 & 745.03 \\
\hline $\begin{array}{l}\text { Brazos S-2 } \\
5^{\prime}\end{array}$ & 4.63 & 24.15 & 13.17 & 26.58 & 16.31 & 2.42 & 12.73 & 0.00 & 0.00 & 7.66 & 14.87 & 157.11 & 466.28 & 1160.32 \\
\hline $\begin{array}{l}\text { Brazos S-3 } \\
5^{\prime}\end{array}$ & 2.93 & 21.44 & 9.50 & 26.53 & 17.04 & 2.72 & 19.84 & 0.00 & 0.00 & 10.70 & 20.20 & 194.71 & 1143.66 & 1410.34 \\
\hline $\begin{array}{l}\text { Brazos S-4 } \\
4^{\prime}\end{array}$ & 7.31 & 66.87 & 10.15 & 8.29 & 5.32 & 0.58 & 1.48 & 0.00 & 0.00 & 4.70 & 6.29 & 20.72 & 121.98 & 195.95 \\
\hline $\begin{array}{l}\text { Brazos S } 5 \\
4^{\prime}\end{array}$ & 4.19 & 48.63 & 14.11 & 19.67 & 12.44 & 0.97 & 0.00 & 0.00 & 0.00 & 6.94 & 10.24 & 53.01 & 228.05 & 285.14 \\
\hline $\begin{array}{l}\text { Brazos S-6 } \\
5^{\prime}\end{array}$ & 0.00 & 0.00 & 6.61 & 60.98 & 31.13 & 0.03 & 1.10 & 0.14 & 0.00 & 133.75 & 147.48 & 211.41 & 304.51 & 337.37 \\
\hline
\end{tabular}




\begin{tabular}{|c|c|c|c|c|c|c|c|c|c|c|c|c|c|c|}
\hline $\begin{array}{l}\text { Sample } \\
\text { Name }\end{array}$ & Clay & Silt & Vf_sand & F_sand & Md_sand & C_sand & Vc_sand & Gravel & Pebble & d10 & d16 & d50 & d84 & d90 \\
\hline $\begin{array}{l}\text { Brazos S-7 } \\
4^{\prime}\end{array}$ & 0.00 & 0.00 & 5.24 & 58.60 & 34.55 & 0.12 & 0.92 & 0.56 & 0.00 & 138.98 & 152.84 & 219.23 & 316.15 & 351.44 \\
\hline $\begin{array}{l}\text { Brazos S-8 } \\
4^{\prime}\end{array}$ & 3.47 & 15.67 & 11.52 & 38.77 & 26.34 & 0.20 & 4.02 & 0.00 & 0.00 & 16.91 & 38.94 & 184.27 & 326.02 & 380.37 \\
\hline $\begin{array}{l}\text { Brazos S-9 } \\
3^{\prime}\end{array}$ & 1.20 & 6.31 & 6.93 & 43.12 & 28.85 & 1.72 & 4.62 & 7.25 & 0.00 & 104.01 & 130.28 & 225.70 & 432.68 & 1323.28 \\
\hline $\begin{array}{l}\text { Brazos S- } \\
10(A) 2^{\prime}\end{array}$ & 1.36 & 14.38 & 22.52 & 27.57 & 13.33 & 6.62 & 4.55 & 9.67 & 0.00 & 36.99 & 62.95 & 164.15 & 817.24 & 1902.70 \\
\hline $\begin{array}{l}\text { Brazos S- } \\
11(A) 2^{\prime}\end{array}$ & 2.27 & 17.12 & 18.61 & 25.72 & 15.78 & 5.39 & 15.11 & 0.00 & 0.00 & 24.76 & 50.32 & 172.97 & 857.36 & 1264.24 \\
\hline $\begin{array}{l}\text { Brazos S-12 } \\
4^{\prime}\end{array}$ & 5.86 & 25.59 & 22.84 & 27.03 & 14.47 & 0.60 & 3.62 & 0.00 & 0.00 & 6.63 & 14.75 & 111.86 & 271.75 & 339.35 \\
\hline $\begin{array}{l}\text { Brazos S-13 } \\
2^{\prime}\end{array}$ & 4.59 & 28.83 & 27.79 & 27.68 & 8.53 & 0.00 & 2.59 & 0.00 & 0.00 & 8.70 & 20.42 & 97.52 & 214.00 & 261.22 \\
\hline $\begin{array}{l}\text { Brazos S-14 } \\
4^{\prime}\end{array}$ & 2.75 & 17.98 & 9.53 & 33.77 & 28.85 & 4.12 & 3.00 & 0.00 & 0.00 & 15.12 & 34.23 & 196.82 & 369.21 & 441.17 \\
\hline $\begin{array}{l}\text { Brazos S-15 } \\
\text { 9' }\end{array}$ & 9.13 & 58.95 & 13.41 & 10.66 & 7.26 & 0.58 & 0.00 & 0.00 & 0.00 & 4.23 & 5.98 & 31.12 & 147.14 & 216.91 \\
\hline $\begin{array}{l}\text { Brazos S-16 } \\
9^{\prime}\end{array}$ & 6.36 & 20.28 & 17.51 & 35.86 & 19.58 & 0.40 & 0.00 & 0.00 & 0.00 & 6.08 & 12.56 & 141.77 & 273.00 & 317.33 \\
\hline $\begin{array}{l}\text { Brazos S-17 } \\
8^{\prime}\end{array}$ & 2.67 & 7.68 & 14.39 & 47.96 & 21.95 & 0.06 & 5.28 & 0.00 & 0.00 & 28.13 & 100.81 & 182.56 & 308.57 & 365.73 \\
\hline $\begin{array}{l}\text { Brazos S-18 } \\
13^{\prime}\end{array}$ & 17.06 & 74.78 & 4.80 & 2.72 & 0.63 & 0.01 & 0.00 & 0.00 & 0.00 & 3.04 & 3.85 & 9.98 & 33.21 & 51.52 \\
\hline $\begin{array}{l}\text { Brazos S-19 } \\
6^{\prime}\end{array}$ & 2.23 & 10.31 & 9.48 & 33.16 & 27.05 & 9.73 & 8.03 & 0.00 & 0.00 & 25.41 & 96.90 & 227.26 & 545.06 & 824.01 \\
\hline $\begin{array}{l}\text { Brazos S-20 } \\
7^{\prime}\end{array}$ & 14.96 & 34.39 & 19.43 & 18.07 & 4.89 & 0.64 & 0.00 & 0.00 & 0.00 & 1.70 & 2.71 & 33.50 & 158.12 & 197.69 \\
\hline $\begin{array}{l}\text { Brazos S-21 } \\
6^{\prime}\end{array}$ & 6.35 & 24.25 & 21.57 & 33.68 & 14.03 & 0.11 & 0.00 & 0.00 & 0.00 & 6.22 & 12.52 & 119.13 & 239.18 & 280.30 \\
\hline
\end{tabular}




\begin{tabular}{|c|c|c|c|c|c|c|c|c|c|c|c|c|c|c|}
\hline $\begin{array}{l}\text { Sample } \\
\text { Name }\end{array}$ & Clay & Silt & Vf_sand & F_sand & Md_sand & C_sand & Vc_sand & Gravel & Pebble & d10 & d16 & d50 & d84 & d90 \\
\hline $\begin{array}{l}\text { Brazos S-22 } \\
6^{\prime}\end{array}$ & 1.00 & 5.86 & 19.43 & 33.34 & 17.99 & 10.32 & 7.76 & 4.30 & 0.00 & 75.94 & 95.73 & 202.06 & 748.03 & 1202.02 \\
\hline $\begin{array}{l}\text { Brazos S-23 } \\
5^{\prime}\end{array}$ & 0.68 & 2.82 & 14.34 & 44.32 & 24.58 & 6.50 & 3.46 & 3.29 & 0.00 & 102.11 & 119.84 & 208.09 & 425.49 & 708.55 \\
\hline $\begin{array}{l}\text { Brazos S-24 } \\
2^{\prime}\end{array}$ & 3.75 & 24.32 & 16.00 & 25.65 & 15.47 & 1.65 & 13.15 & 0.00 & 0.00 & 10.84 & 23.37 & 148.52 & 448.27 & 1083.51 \\
\hline $\begin{array}{l}\text { Brazos S-25 } \\
8^{\prime}\end{array}$ & 1.46 & 5.75 & 39.00 & 51.22 & 2.44 & 0.00 & 0.13 & 0.00 & 0.00 & 73.37 & 86.05 & 129.62 & 186.02 & 204.59 \\
\hline $\begin{array}{l}\text { Brazos S-26 } \\
12^{\prime}\end{array}$ & 0.00 & 0.23 & 32.68 & 60.62 & 6.42 & 0.00 & 0.02 & 0.03 & 0.00 & 92.62 & 102.36 & 147.31 & 211.77 & 233.13 \\
\hline $\begin{array}{l}\text { Brazos S-27 } \\
33^{\prime}\end{array}$ & 1.96 & 7.51 & 32.93 & 52.18 & 5.38 & 0.00 & 0.03 & 0.00 & 0.00 & 65.15 & 83.63 & 135.76 & 202.47 & 224.24 \\
\hline $\begin{array}{l}\text { Brazos S-28 } \\
7^{\prime}\end{array}$ & 0.00 & 0.19 & 35.20 & 60.78 & 3.80 & 0.00 & 0.03 & 0.00 & 0.00 & 92.46 & 101.60 & 142.12 & 198.43 & 217.84 \\
\hline $\begin{array}{l}\text { Brazos S-29 } \\
8^{\prime}\end{array}$ & 1.01 & 5.02 & 42.20 & 49.48 & 2.10 & 0.00 & 0.13 & 0.06 & 0.00 & 74.65 & 85.60 & 127.13 & 182.54 & 200.70 \\
\hline $\begin{array}{l}\text { Brazos S-30 } \\
30^{\prime}\end{array}$ & 0.60 & 0.52 & 5.26 & 56.33 & 36.15 & 0.31 & 0.51 & 0.33 & 0.00 & 136.09 & 151.31 & 221.00 & 320.82 & 354.86 \\
\hline $\begin{array}{l}\text { Brazos S-31 } \\
40^{\prime}\end{array}$ & 1.26 & 4.64 & 2.24 & 41.03 & 43.71 & 4.41 & 1.51 & 1.20 & 0.00 & 135.32 & 159.92 & 252.31 & 394.55 & 453.58 \\
\hline $\begin{array}{l}\text { Brazos S-32 } \\
40^{\prime}\end{array}$ & 0.00 & 0.00 & 9.23 & 64.23 & 26.44 & 0.00 & 0.09 & 0.00 & 0.00 & 126.92 & 139.58 & 199.34 & 283.99 & 312.50 \\
\hline $\begin{array}{l}\text { Brazos S-33 } \\
38^{\prime}\end{array}$ & 0.36 & 0.46 & 4.04 & 36.36 & 36.81 & 14.64 & 4.13 & 3.21 & 0.00 & 146.58 & 167.30 & 284.62 & 625.59 & 852.25 \\
\hline $\begin{array}{l}\text { Brazos S-34 } \\
44^{\prime}\end{array}$ & 0.68 & 2.45 & 8.38 & 46.14 & 29.71 & 3.33 & 3.06 & 6.26 & 0.00 & 119.49 & 138.21 & 226.10 & 420.89 & 757.37 \\
\hline $\begin{array}{l}\text { Brazos S-35 } \\
9^{\prime}\end{array}$ & 0.00 & 2.05 & 47.83 & 48.51 & 1.55 & 0.00 & 0.06 & 0.00 & 0.00 & 78.55 & 86.64 & 125.14 & 179.66 & 197.84 \\
\hline $\begin{array}{l}\text { Brazos S-36 } \\
16^{\prime}\end{array}$ & 0.00 & 0.86 & 40.47 & 54.81 & 3.79 & 0.00 & 0.07 & 0.00 & 0.00 & 84.91 & 93.83 & 135.73 & 195.78 & 216.26 \\
\hline
\end{tabular}




\begin{tabular}{|c|c|c|c|c|c|c|c|c|c|c|c|c|c|c|}
\hline $\begin{array}{l}\text { Sample } \\
\text { Name }\end{array}$ & Clay & Silt & Vf_sand & F_sand & Md_sand & C_sand & Vc_sand & Gravel & Pebble & d10 & d16 & d50 & d84 & d90 \\
\hline $\begin{array}{l}\text { Brazos S-37 } \\
10^{\prime}\end{array}$ & 0.00 & 0.01 & 20.76 & 64.27 & 14.71 & 0.00 & 0.22 & 0.04 & 0.00 & 105.60 & 116.89 & 169.82 & 246.54 & 272.92 \\
\hline $\begin{array}{l}\text { Brazos S-38 } \\
17^{\prime}\end{array}$ & 1.58 & 5.98 & 24.30 & 56.84 & 11.15 & 0.00 & 0.15 & 0.00 & 0.00 & 79.37 & 96.11 & 153.92 & 231.13 & 256.88 \\
\hline Brazos S-39 & 0.00 & 0.44 & 38.64 & 57.44 & 3.32 & 0.00 & 0.14 & 0.03 & 0.00 & 89.14 & 97.57 & 137.79 & 194.70 & 214.24 \\
\hline $\begin{array}{l}\text { Brazos S-40 } \\
12^{\prime}\end{array}$ & 0.00 & 0.23 & 33.72 & 60.10 & 5.95 & 0.00 & 0.00 & 0.00 & 0.00 & 91.93 & 101.52 & 145.66 & 209.15 & 229.95 \\
\hline $\begin{array}{l}\text { Brazos S-41 } \\
12^{\prime}\end{array}$ & 0.00 & 0.17 & 35.50 & 60.63 & 3.59 & 0.00 & 0.10 & 0.00 & 0.00 & 92.54 & 101.58 & 141.59 & 197.46 & 216.77 \\
\hline $\begin{array}{l}\text { Brazos S-42 } \\
12^{\prime}\end{array}$ & 0.00 & 0.28 & 35.26 & 59.78 & 4.60 & 0.00 & 0.08 & 0.00 & 0.00 & 91.49 & 100.81 & 142.62 & 201.90 & 221.88 \\
\hline $\begin{array}{l}\text { Brazos S-43 } \\
9^{\prime}\end{array}$ & 0.00 & 0.01 & 19.63 & 65.75 & 14.34 & 0.00 & 0.25 & 0.02 & 0.00 & 107.75 & 118.74 & 170.52 & 245.39 & 271.37 \\
\hline $\begin{array}{l}\text { Brazos S-44 } \\
10^{\prime}\end{array}$ & 0.00 & 0.01 & 19.79 & 65.16 & 14.63 & 0.00 & 0.36 & 0.05 & 0.00 & 107.20 & 118.39 & 171.02 & 246.82 & 272.92 \\
\hline $\begin{array}{l}\text { Brazos S-45 } \\
9^{\prime}\end{array}$ & 0.00 & 0.01 & 19.03 & 65.86 & 14.82 & 0.00 & 0.22 & 0.07 & 0.00 & 108.52 & 119.62 & 172.10 & 247.11 & 272.80 \\
\hline $\begin{array}{l}\text { Brazos S-46 } \\
9^{\prime}\end{array}$ & 0.00 & 0.01 & 19.54 & 65.96 & 14.15 & 0.00 & 0.31 & 0.03 & 0.00 & 107.83 & 118.86 & 170.75 & 245.07 & 270.43 \\
\hline $\begin{array}{l}\text { Brazos S-47 } \\
27^{\prime}\end{array}$ & 10.18 & 49.79 & 20.29 & 15.72 & 3.79 & 0.23 & 0.00 & 0.00 & 0.00 & 3.95 & 5.63 & 35.84 & 141.23 & 177.12 \\
\hline $\begin{array}{l}\text { Brazos S-48 } \\
30^{\prime}\end{array}$ & 4.16 & 20.17 & 8.80 & 5.52 & 1.02 & 0.03 & 5.21 & 55.10 & 0.00 & 9.13 & 20.62 & 2132.64 & 3270.80 & 3527.21 \\
\hline $\begin{array}{l}\text { Brazos S-49 } \\
40^{\prime}\end{array}$ & 11.34 & 65.98 & 14.89 & 6.30 & 1.47 & 0.02 & 0.00 & 0.00 & 0.00 & 3.68 & 5.22 & 23.13 & 81.28 & 109.19 \\
\hline $\begin{array}{l}\text { Brazos S-50 } \\
9^{\prime}\end{array}$ & 20.61 & 50.48 & 3.39 & 4.32 & 1.95 & 0.01 & 0.00 & 0.00 & 0.00 & 0.15 & 0.23 & 5.99 & 27.75 & 57.91 \\
\hline $\begin{array}{l}\text { Brazos S-51 } \\
30^{\prime}\end{array}$ & 14.69 & 68.87 & 11.68 & 4.03 & 0.73 & 0.00 & 0.00 & 0.00 & 0.00 & 3.13 & 4.26 & 17.00 & 63.21 & 85.67 \\
\hline
\end{tabular}




\section{Appendix C: CMS-Flow Model Control}

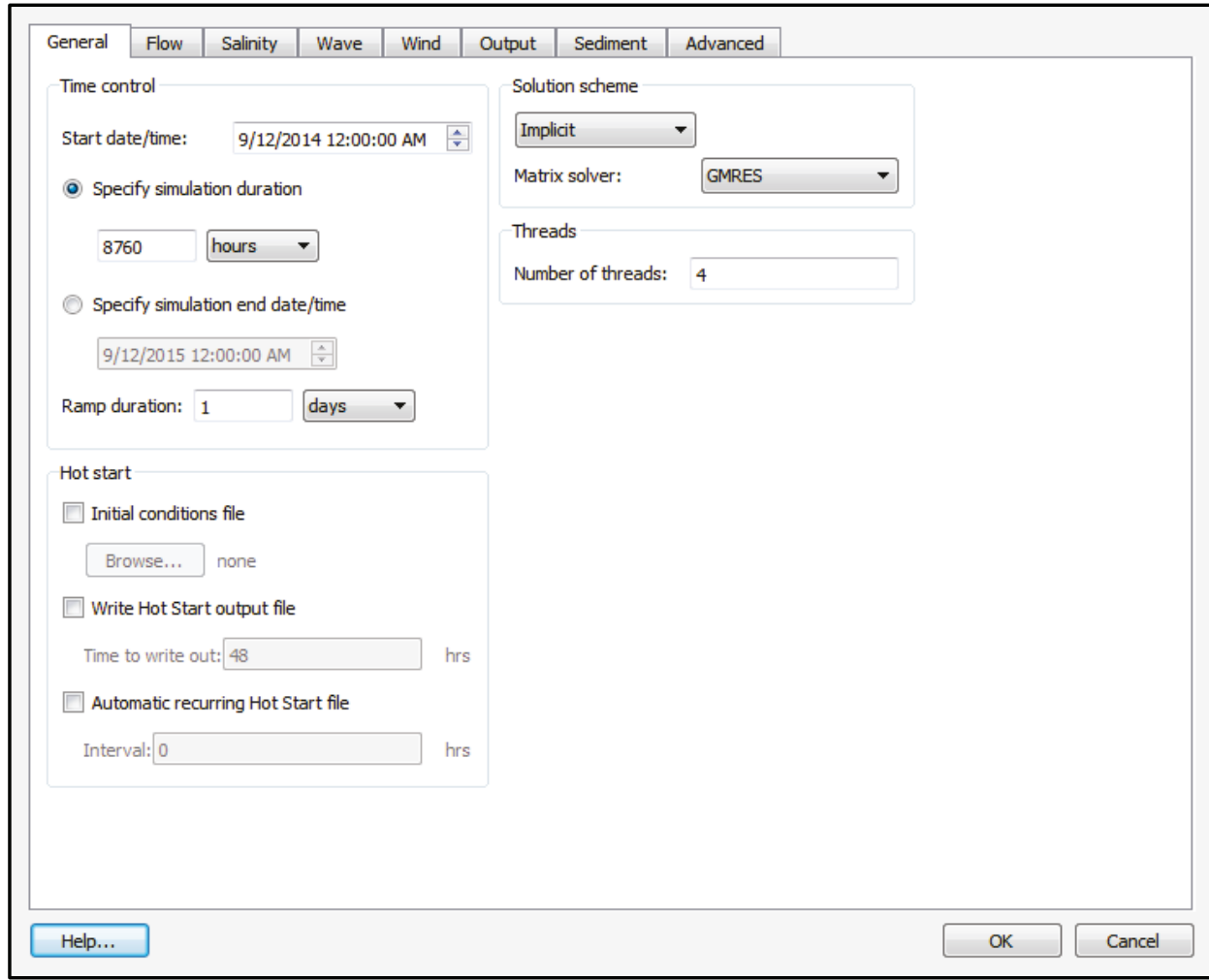




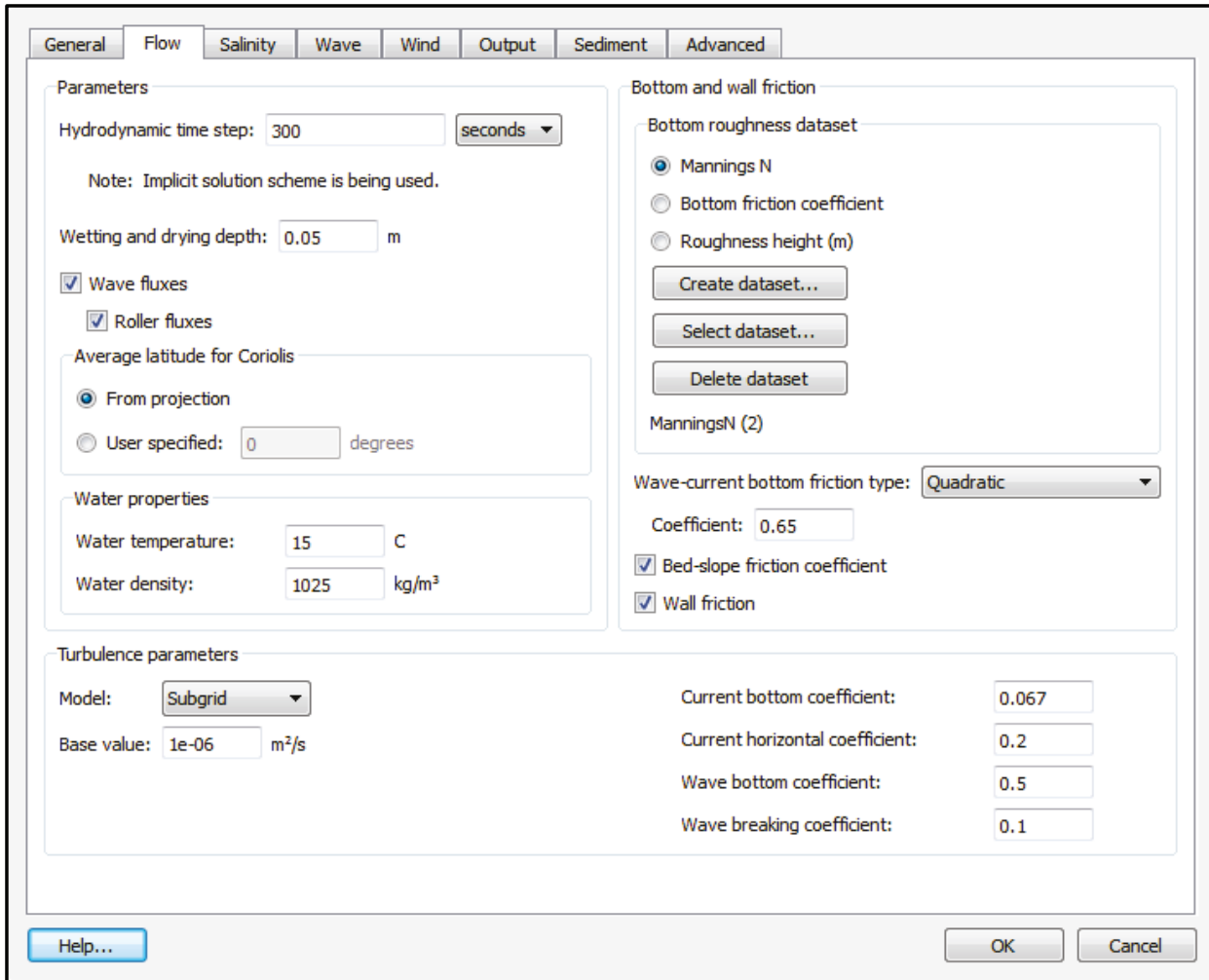

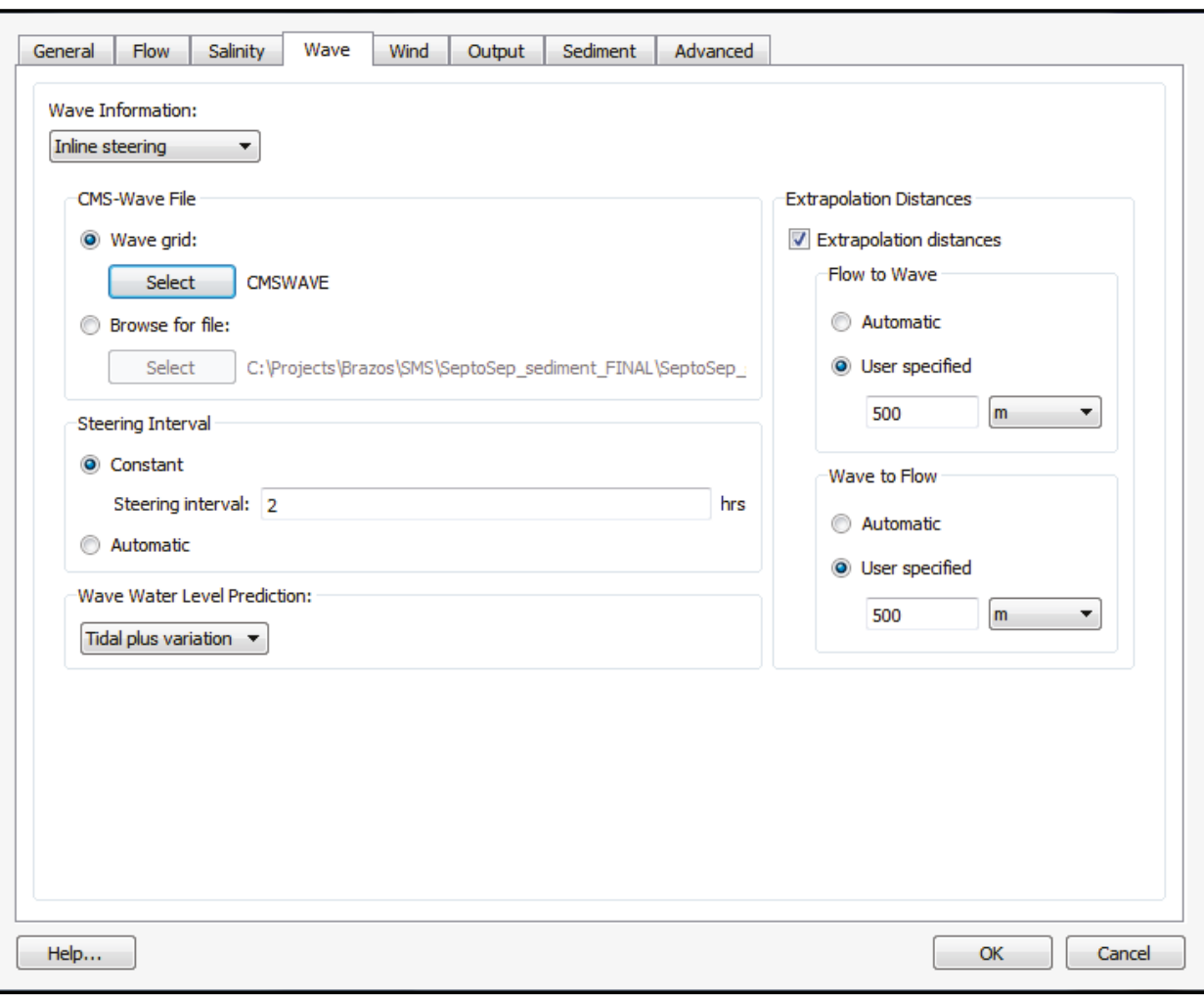



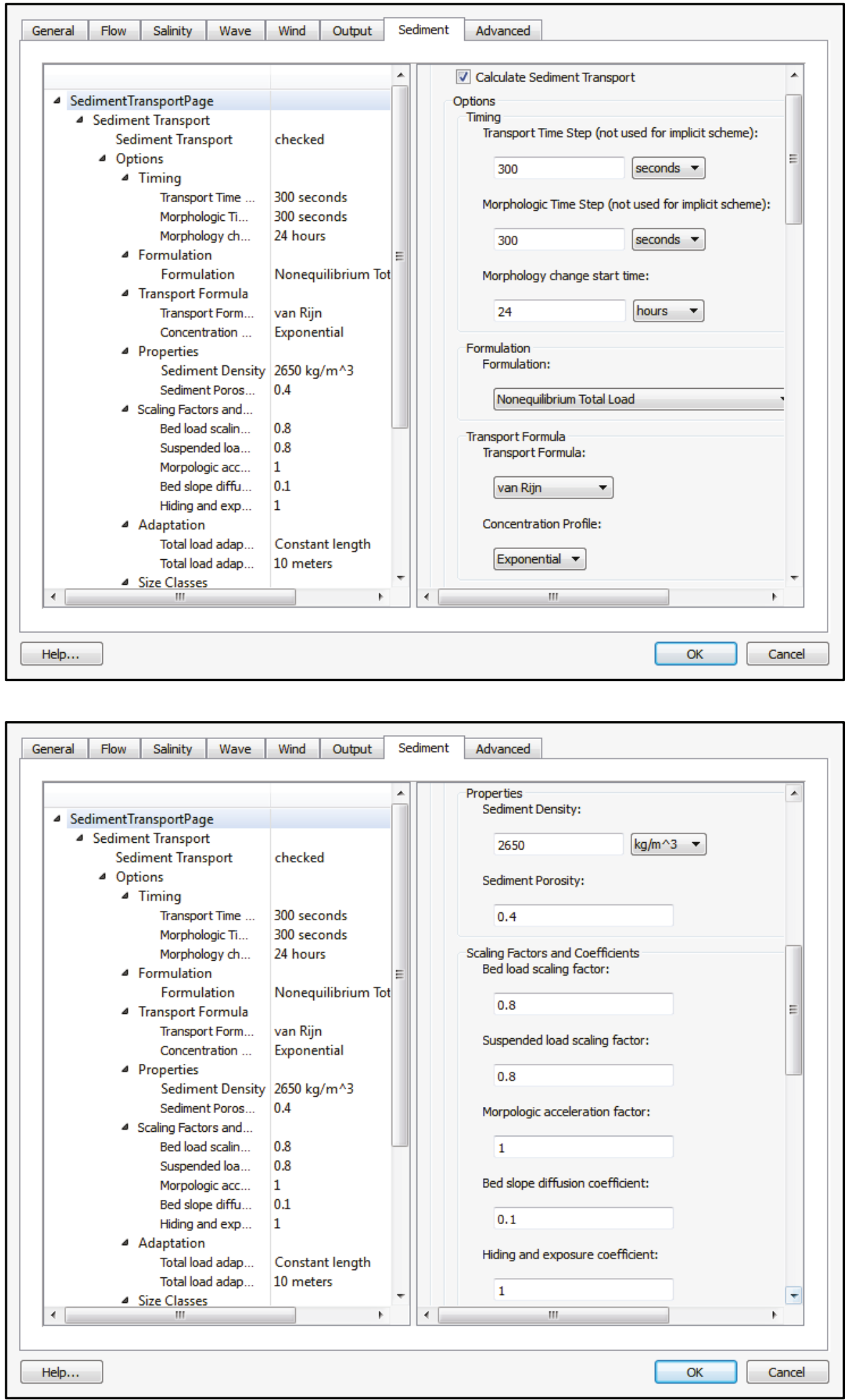

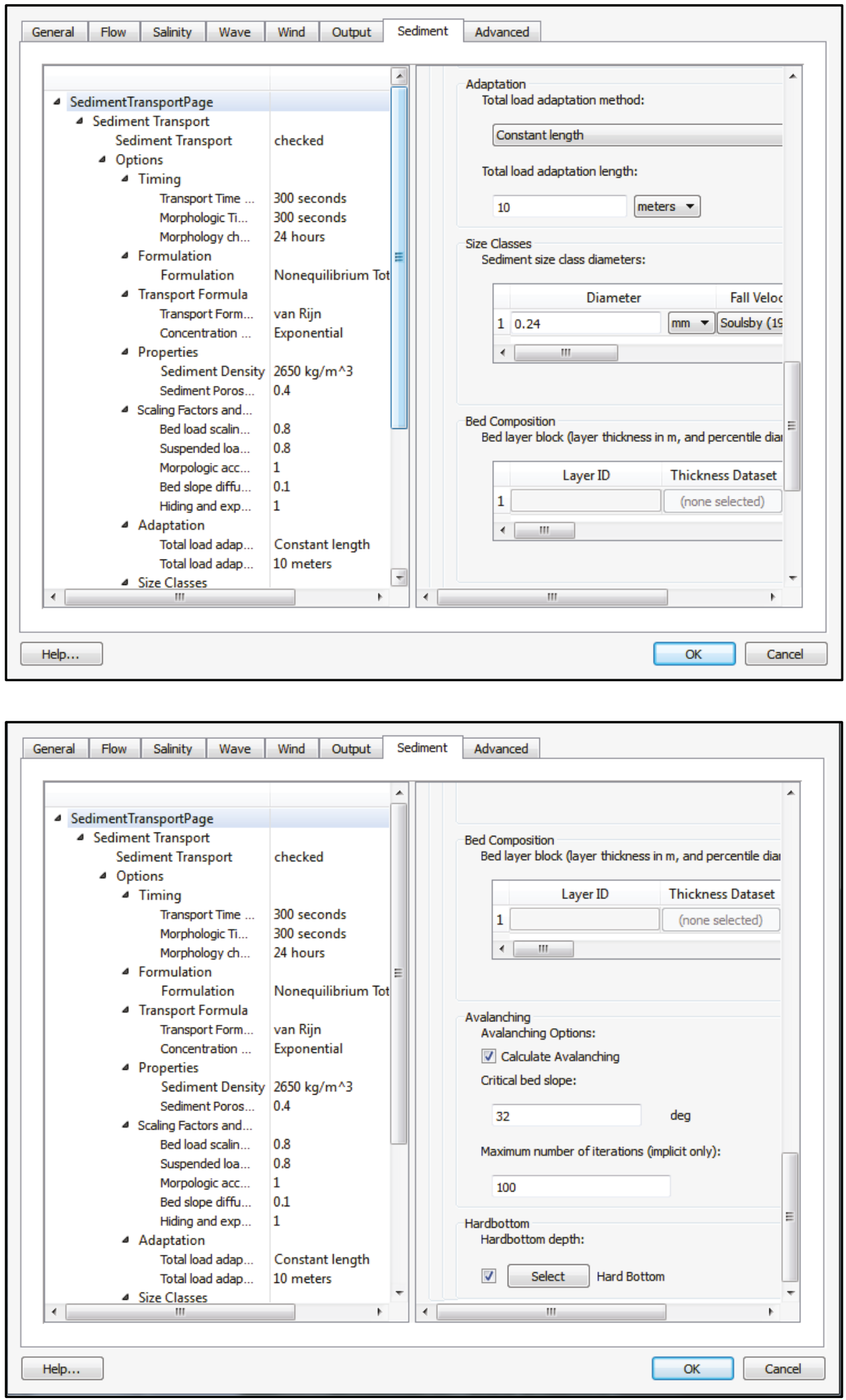


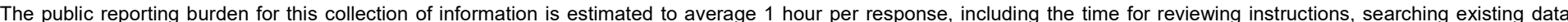

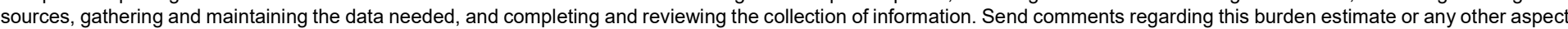

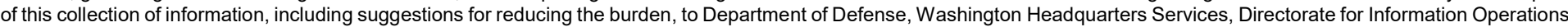

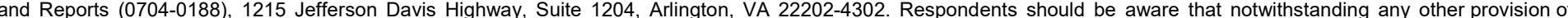
law, no person shall be subject to any penalty for failing to comply with a collection of information if it does not display a currently valid OMB control number.

PLEASE DO NOT RETURN YOUR FORM TO THE ABOVE ADDRESS.

\begin{tabular}{l|l|l}
\hline $\begin{array}{l}\text { 1. REPORT DATE } \\
\text { February } 2018\end{array}$ & $\begin{array}{l}\text { 2. REPORT TYPE } \\
\text { Final Report }\end{array}$ & 3. DATES COVERED (From - To) \\
\hline
\end{tabular}

\section{TITLE AND SUBTITLE}

Brazos Santiago Inlet, Texas, Shoaling Study 5a. CONTRACT NUMBER

5b. GRANT NUMBER

5c. PROGRAM ELEMENT NUMBER

5d. PROJECT NUMBER

454631

5e. TASK NUMBER

5f. WORK UNIT NUMBER

8. PERFORMING ORGANIZATION REPORT NUMBER

ERDC/CHL TR-18-2

10. SPONSOR/MONITOR'S ACRONYM(S) HQUSACE

11. SPONSOR/MONITOR'S REPORT NUMBER(S)

\section{DISTRIBUTION/AVAILABILITY STATEMENT}

Approved for public release; distribution is unlimited.

\section{SUPPLEMENTARY NOTES}

\section{ABSTRACT}

The Brazos Santiago Inlet (BSI), located at the southern end of Laguna Madre, is a key part of the federal deep-draft Brownsville Ship Channel extending from the Gulf of Mexico to the Port of Brownsville, TX. As part of the Monitoring Completed Navigation Projects program, the focus of this study was to understand the shoaling process in the BSI and to suggest sand management alternatives to reduce inlet maintenance dredging costs. Hydrodynamics and sediment transport were examined for the BSI region to understand the channel shoaling within the jetty entrance. Field data collection and numerical modeling using the Coastal Modeling System were performed to gain insight into the complex circulation, wave action, and sediment deposition patterns. Structural changes to the system as well as dredging modifications are presented as potential alternative solutions to reduce inlet shoaling. Results show the potential benefits of an in-channel sediment trap and alterations to the structure of the jetty. However, benefits to dredging costs are not considered and must be weighed against other issues such as environmental concerns.

\section{SUBJECT TERMS}

Brownsville (Tex.), Hydrodynamics-Mathematical models, Inland navigation, Inlets, Laguna Madre (Tex.), Sedimentation and deposition, Sediment transport

\begin{tabular}{|l|l|l|l|}
\hline \multicolumn{1}{|l|}{ 16. SECURITY CLASSIFICATION OF: } & 17. LIMITATION OF \\
aBSTRACT \\
a. REPORT & b. ABSTRACT & c. THIS PAGE & \\
Unclassified & Unclassified & Unclassified & SAR \\
\hline
\end{tabular}
18. NUMBER
OF PAGES

190 19a. NAME OF RESPONSIBLE PERSON Mary A. Bryant

19b. TELEPHONE NUMBER (Include area code) 601-634-2074 